

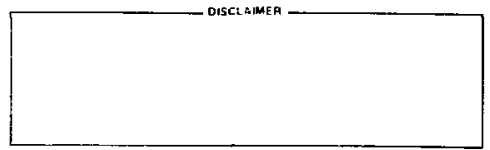

\title{
The effects of strain on the superconducting properties of niobium-tin conductors
}

\author{
Ronald Warren Hoard \\ (Ph.D. Thesis)
}

Manuscript date: November 1980

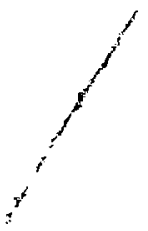

LAWRENCE LIVERMORE LABORATCRY University of California $\bullet$ Livermnre, California $\bullet \$ 4550$ 
The Effects of Strain on the Supercenducting Properties of Niobium-Tin Conductors

by

Ronald Warren Hoard

A dissertation submitted in partial fulfillment of the requirements for the degree of

Doctor of Philosophy

University of Hashington

1980

Approved

by

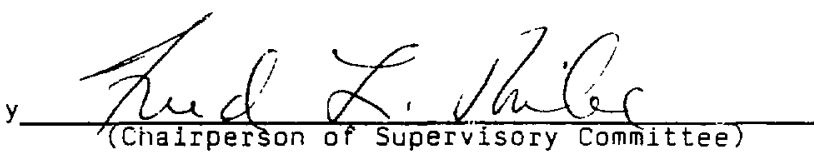

Program Authorized

to Offer Degree

Department of Nuclear Engineering

Date

October 16,1980 
Ir presenting this dissertation in partial fulfillment of the requirements for the Doctoral degree at the University of Washington, I agree that the Library shall make its copies freely available for inspection. I further agree that extensive copying of this dissertation is aliowable only for scholarly purposes, consistent with "fair use" as prescribed in the U.S. Copyright Law. Requests for copying or reproduction of this dissertation may be referred to University Microfilms, 300 North Zeab Road, Ann Arbor, Michigan 48106, to whom the author has granted "the right to reproduce and sell (a) copies of the manuscript in microform and/or (b) printed copies of the manuscript made from microform."

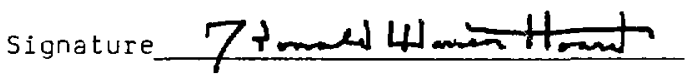

Date OCT. 16,1980 


\section{University of Washington}

Abstract

THE EFFECTS OF STRAIN ON THE SUPERCONDUCTING PROPERTIES OF NIOBIUM-TIN CONDUCTORS

By Ronald Warren Hoard

Chairperson of the Supervisory Committee:

Professor Fred L. Ribe

Department of Nuclear Engineering

Typical $\mathrm{Nb}_{3} \mathrm{Sn}$ multifilamentary superconducting composites produced by the branze diffusion process have lepetitive fiber elements of niobium embedded in a bronze matrix, with a $\mathrm{Nb}_{3} \mathrm{Sn}$ reaction zone serving as the interfacial layer between the two. Clusters of these units are surrounded by tin diffusion inhibitors, such as tantalum, and placed inside a second external copper matrix. The strain degradation of the critical current density has been both analytically and experimentally investigateo in an inversion of this configuration. The new geometry consists of bronze filament cores inside of ninbium tubes, with the usual $\mathrm{No}_{3} \mathrm{Sn}$ interface. Since the niobium acts as a diffusion barrier, copper can be directly utilized as the embedding matrix, eliminating the motivation for tantalum addition. Analytic results were obtained from a computer program (MAXIMSUPER) which evaluates the threedimensional strain fields on the $\mathrm{Nb}_{3} \mathrm{Sn}$ zones in a cylindrical repeating element of the composite due to both 
residual (thermal contraction) and applied axial loading. The cade then incorporates the calculated $\mathrm{Nb}_{3} \mathrm{Sn}_{\mathrm{n}}$ strain values into appropriate scaling laws to predict the critical current density and its degradation with increasing axial strain.

Investigations were performed to ascertain aditional information on the connection between the cubic to tetragonal martensitic phase transformation and the phenomenon of superconductivity in $\mathrm{Nb}_{3} \mathrm{Sn}$. Of particular interest is the degradation of the critical parameters, such as $T_{C}, H_{c 2}$, and $J_{C}$, with mechanical straining of the superconductor. These studies yielded information that assisted in the derivation of the critical current-strain scaling laws mentioned above. Since martensitic transitions are also known to be strain sensitive, pernaps the structural change is directly responsible for the anomalous reduction in the superconducting properties of the material. Low temperature $X$-ray diffraction experiments were performed on $\mathrm{Nb}_{3} \mathrm{Sn}$ ribbons (in which the bronze layers had been etched off) mounted to copper and indium sample stages. The cryostat has the unique feature that allows the superconductor to be placed under both compressive and tensile strains, while at low temperatures, by means of a vacuum mechanical insert. Results indicate that the martensitic phase transition temperature, $T_{m}$, 
increases with increasing compressive strains. Critical parameters, such as $\mathrm{H}_{\mathrm{C} 2}$ and $T_{C}$ are thought to vary according to a two-level state model which expresses the $\mathrm{Nb}_{3} \mathrm{Sn}$ cubic-to-tetragonal, marten'sitic-phase transformation as being strain sensitive.

Experimental investigations conducted with a 12 Tesla, low-temperature, tensile-test facility on both the niobium core and bronze core geometries confirm the importance of the tangential strains (in addition to the axial strain) on the critical current properties of the conductors. In particular, resulting higher radial and azimuthal strains yield lower critical current densities in the latter geometry. Under applied axial loading, the increasing tangential strains exhibit contradistinctive behavior from that of the axial z strain, which changes sign frum compressive to tensile. The magnitude of these tangential strains depends primarily on the composite geometry and configuration. Good agreement between the MAXIMSUPER predictions and experimental results indicates that the program may be suitable for superconducting composite design appljcations. 
TABLE OF CONTENTS

Page

List of figures. . . . . . . . . . . . . . . . iv

List of Tables . . . . . . . . . . . . . . . visi

Crapter 1: Intraduction and Purpose of the Study

A. Introduction to the Chapter . . . . . . . 1

B. Purpose of the Study . . . . . . . . . . 7

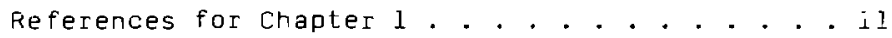

Cnapter 2: Code MAXIMSUPER

A. Introduction to the Chapter........ . 15

B. Mathematical Formulation: Strains

Produced from Thermal and Axial Loading . . . 22

C. Analytic Results and Predictions of PIOgiam MAXIMSUPER . . . . . . . . . . 38

References for Chapter $2 . .3 . .39$

Chapter 3: Critical Current-Strain Experiments

A. Introduction to the Chapter . . . . . . 53

В. Equipment . . . . . . . . . . . . 53

c. Instrumentation . . . . . . . . . 56

D. Experimcntal Procedures and Results . . . . 58

References for Chapter 3. . . . . . . . 64

Chapter 4: Low-Temperature, X-Ray Diffraction

Experiments

A. Introduction to the Chapter... . . . 66

B. Equipment

1. Low Temperature Cryostat. . . . . . . 69

2. X-Ray Generator and Diffractometer . . . 72

C. Instrumentation

1. Thermometry and Strain Gages... . . . 73 
Page

D. NbzSn Sample Preparation and Desciription . . 75

E. Experimental procedure ard Result;. . . . . 77

References for Chapter 4........ . 84

Chapter 5: Critical Current-Strain Scaling Law and Conclusions

A. Introduction to the Chapter . . . . . 87

B. The Influence of strain on the EubicTetragonal Transformation . . . . . . . 88

C. The Effect of Strain on $J_{\mathrm{C}}$ and $\mathrm{H}_{\mathrm{C} 2} \ldots . . .90$

D. Conclusions and Suggestions far Future Study .............. 100

References for Chapter 5.......... 104

figures................. 106

Tables . . . . . . . . . . . . . . 169

Bibliography .................... 171

Appendix 1: Cumputer Program Listing . . . . . . 180

Appendix 2: Sample Program Dutput listing . . . . 199 


\section{LIST OF F IGURES}

NumbeI

Page

1. Construction of the A.tF Magnet . . . . . . . 106

2. The MFTF Superconducting Nb-Ti Corductcr . . . 107

3. The Unit cell of the a-.15 Crystal Structure

for A3E Compounds................. $10 R$

4. Critical Current versus Strain Curve . . . . . jog

5. Rupp Normalized Critical Curzent-Strain Curves . 110

t. The Transition Temperature as a Function of Strain................... 111

7. The Upper Critical Field as a Function of Strain................... 112

3. Cross Section of a Multifilamentary Conductor. . 113

3. Cross Section of finother Multifilamentary Cnrouctcr Design . . . . . . . . . . . . . 114

10. Modelirg oi a Cylindrical cumposite Element. . Iij

11. Irternal Niobium-Core Filaments Shown Distorted From tile Manufacturjng Process . . . . 116

12. 1500X Photomicrograph of an Internal BronzeCore Conductor Design... . . . . . . . . 117

13. Several Clusters of Internal Niobium-Cora $\ddot{r i l a m e n t s}$ Surrounded by Tantalum Barriers... . 1 i8

14. Modeling of the Internal Bronze- and NiobiumCore Conductor Designs . . . . . . . . . . . 119

15. Measured versus Predicted ficmax Plot . . . . . 120

16. Critical Current Density as a Fur.ction of No $3 \mathrm{~S} n$ Reaction Time at Several Magnetic Fiela Strergths for various Internal Bronze-Core Conductors

i7. Plot of Effective Sirain Versus Intrinsic z Strain 
Numiver

Page

18. Plot of Measured Critical Current Densıty

of Several Conductors at $H=12 T$ as a

Functiin of the Code Fredirted Residual

Effective strain................ . . 123

19. The Low Temperature Tensile Tester chowing

the Sample Area Raised Above the Cryostat. . . . !24

20. Inside the Cryostat: A View 0 " the Upper

Terisile Grip, Conductor, and Copper Braid

Current Lead ................. . . 125

21. Sample conductor Fitted with iest Instrumen-

22. Tensile Tecter Schematic . . . . . . . . . . :27

23. Inside the Cryostat: Showing the complete

Assembly for the - vain-Critical Current

Experiments... . . . . . . . . . . . . . . .

24. Typical Voltage Versus Current Data Plots

notianed During the Tensile Test Experiments. . L."

25. Typical Extrapolation Plots Used to uetermin?

the Critiral Current at a Resistivity of

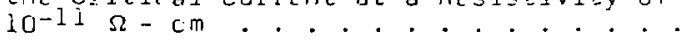

26. Cross Section of an Internal E: onze-core

Conductor

27. Cross Section of an Internal vionium-ture

Conductor

28. Internal B:anze-Core Corwuctor Ic Versus

Strain Curve No. $1 . . . . . . . . .83:$

29. Internal Bronze-care Conductor $I_{C}$ Vars ss

Strain Curve No.?...... . . . . . . . I:L

30. Rupp Normaizzed Critical Current Data fo:

Bronze-Core zonjuctors Plotted Against the

Intrinsic Strair. . . . . . . . . . . . . . . i3:

31. Stress-Strain Curve For an Internal Bronze-

Core Conductur No. l . . . . . . . . . . 136 
Huster

Page

32. Stress-Strain Curve For an Internai BronzeCore Conductor No. 2 . . . . . . . . . . 137

33. Martensitic Phase Transformation Diagram . . . . 138

34. Typical Heli-Tran Cryostat Setup . . . . . . . 139

35. Schematic of Flexible Transfer Line to Storage Dewar Connections.... . . . . . . 140

36. Schematic of Heli-Tran Cryostat Cold End and Connections................ 141

37. Inside the Heli-Tran LT-3-110A Cryostat . . . . 142

38. The Assemiled Cryostat Mounted in the Diffractometer............... . . 143

35. Tensile Test Sample Holder for $x$-ray Diffraction................. ... 144

40. Enlarged Drawing of CLTS Temperature Sencor . . 145

41. Caliuration Curve for the CLTS Temperature Sensor................. . . 146

42. Another View of the Cryostat and Diffractometer................... 147

43. Overall Setup for the $x$-ray Diffraction Experiments................ . . 148

44. Room Temperature Diffraction Profile of the

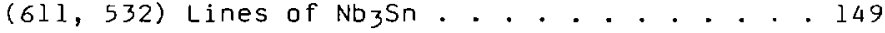

45. Diffraction Profile of the (611, 532) Lines of $\mathrm{Nb}_{3} \mathrm{Sn}$ at $8 \mathrm{~K}$............. . . 150

46. Diffraction Profile of the (61l, 532) Lines at $174 \mathrm{~K}$.................. . . 151

47. Diffraction Profile of the $(611,532)$ Lines at $152 \mathrm{k}$. . . . . . . . . . . . . 152

48. Diffraction Profile of the (611, 532) Lines at $138 \mathrm{~K}$................ . 153 
Number

Page

49. Diffraction Profile of the $(611,532)$ Lines at $124 \mathrm{~K}$. . . . . . . . . . . . . 154

50. Diffraction Profile of the (611, 532) Lines at $98 \mathrm{~K}$............... . . 155

5l. Diffraction Profile of the $(611,532)$ Lines at $80 \mathrm{~K} . .+. . .+. . . . . . .156$

52. Diffraction Profile of the (611, 532) Lines

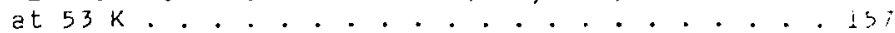

53. Uiffraction Profile of the (511, 532) Lines

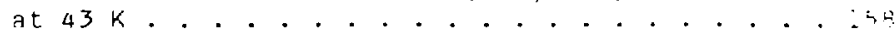

54. Diffraction Profile of the (EI.1, 532) Lines at $33 \mathrm{~K}$............... . . 156

55. Diffraction Profile of the (611, 532) Lines

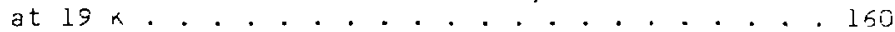

56. Plot of the Peak Height (Above Backoround) as a Function of Temperature.

57. Plot of the Peak Height (Above Backgiourid) as a Function of Tenperature and Strain . . . . . 1,2

58. The Temperature Dependence of Young's Modulus

for Three Different VzSi Samples...... . . 163

59. Plot of the Normalized Peak Height as a

Function of Temperature and Strain . . . . . . . is 4

60. Peak Height as a Function of Strain at $8 \mathrm{k}$. . . if,

61. Normalized Peak Height as a Function of Sirain

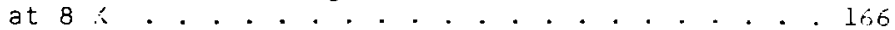

62. Triangular Lattice Structure of Supercurrents Near $\mathrm{H}_{\mathrm{C} 2}$. . . . . . . . . . . . . . . 167

63. The Electron-Phonon-Electron Interaction . . . . 16.8 


\section{LIST OF TABLES}

Number

Page

1. Internal Bronze-Core Conductor Fabrication

Parameters and Critical Current Properties . . 169

2. Critical Current Properties for Several

Internal Bronze Core Conductors at Various Heat Treatments and Filament Diameters . . . . . 170 


\section{DEDICATION}

Perhaps it would be interesting to assign a "label" or descriptive title to every generation of mankind, as if one were reading man's history fiom the chapters of some omniscient buok. As an example, the iirst ancestors of prehistoric man may have been duboed "The Tool Makers"; or the most recently passed modern generation could have been called "The Industrialists." Today man is growing more cognizant of his technology's interaction upon the environment. he is now developing a conscious concern in maintaining the earth's atmosphere, which is so vital to his existence; he may even learn to limit careless expioitation of her resources. For these reasons, the present generation may later be cited as "The Ecologists." Only the Lord God Almighty knows what will become of the next procreation. I would like to dedicate this humble work to Him and to all of them--past, present, and awaiting. 


\section{ACKNOWLEDGEMENTS}

The autior would like to express his sincerest appreciation to Doctor ?nnald M. Scanıan, whose encouragement, stimulating technical discussions, and friendship helped make the work fossible.

P. warm thank you goes to others for their helpful guiance and support. These include Doctors Donald $N$. Cornish, Jon P. Zbasnik, Gordon S. Smith, Roger W. Werne, Dennis K. Fisher, Charles L. Farrell, Jack C. Bullock, Donald G. Hirzel, Paul R. Carnahan, Jack E. Johnstor, Arthur R. Rosdahl, Michael R. Chaplin, and Phillip A. Waide.

Special thanks are extended co Vergie P. Zuppan, for her excellent typing and editing of this manuscriot; Professors Fred L. Ribe: Douglas H. Polonis; Raymund Taggart; J. Gregory Dash; Gene L. Woodruff; and the many others who cared. 
CHAPTER 1. INTRODUCTION AND PURPOSE OF THE STUDY

\section{A. Introduction to the Chapter}

The need for high-field magnets ( $B>10$ Tesla) to be utilized in the magnetic fusion energy program may well be satisfied with the development of superconducting composite current conductors. These composites are formed from the extrusion of a $r$. mal metal matrix with superconducting multifilaments ( $\mathrm{Nb}-\mathrm{li}$ ), or two metals are exiruded and reacted at some elevated temperature to form a supercanducting interface $\left(\mathrm{Nb}_{3} \mathrm{Sn}\right)$, between the filament core and matrix by means of the solid-state diffusion process. Throughout the 1970's, multifilamentary Nb-Ii has become the most commercially available superconductor, with planned additional applications that extend well into the 1980's, including the newly started construction of the Magnetic Fusion Test Facility (MFTF) at Lawrence Livermore National Laboratory (Fig. 1.). Currently Nb-Ti is deployed in fuston machines that produce magnetic fields up to 9 Tesla with the superconductor maintained at $4.2 \mathrm{~K}$ liquid helium temperature. We can anticipate that ruture reactor scale facilities may require larger fields of 12 Tesla and above; therefore, commercial 
efforts have to be expanded to include the fabrication of a newri high-field superconucting material. Niobium-tin $\left(\mathrm{Nb}_{3} \mathrm{Sn}\right.$ ) sepms to be a suitable next generation material having an upper citical field $H_{c 2}$ of 23 Tesla at $4.2 \mathrm{~K}$; however, the production of $\mathrm{Nb}_{3} \mathrm{Sn}$ conductors incroduces three additional problems that are not inherent with Nb-Ti superconductors. $\mathrm{Nb}_{3} S n$ is a orittie material, fracturing at elongation strains of approximately 0. \& percent, while $\mathrm{Nb}-\mathrm{Ti}$ is ductile up to about 10 percent slongation. Because of this ductile property of No-T:, it can be extruded along with the pure ofHr copper matix without producing filament breakage. Figure? shows the cross section of such a compositp conductor. However, $\mathrm{Nu}_{3} \mathrm{Sn}$ must be formed after the composite is mage by producing a reaction of the niobium filaments with the tin in a bronze region surgounding the filaments. Circunscribing the large clusters of superconducting fildments imbedded in bronze are tin diffusion inhibitors, such as tantaium, which prevent the migration of tin from the bronze to contaminate the high pusity of the copper outer zones. The copper acts to stabilize the conductor, allowing for a place in which the current can transfer during the accidental case of a quench (transition of the $\mathrm{Nb}-\mathrm{Ti}$ or $\mathrm{Nb}_{3} \mathrm{Sn}$ Trom the superconducting phase to the normal state). The thiru difficulty associated with 
Nb, $\mathrm{Sr}_{\mathrm{r}}$ is that its intrinsic superconducting properties are strasn sensitive. Therefore, it requires special handing and processing to prevent the degradation of its critical parameters, such as the upper critical fielo $\mathrm{H}_{\mathrm{C} 2}$, the transition temferature $\mathrm{T}_{\mathrm{C}}$, and the critical current density $J_{c}$, by the application of unwanted straining of the conductors.

The mecinanical interaction caused by the differing thermai expansior coefficients, Young's moduli, and Poisson's ratiog between the composite matrix ano the filament cores often induces residual stresses and strains upon the superconductor or superconducting tilament-matrix interface. This can Jccur wher the composite is either cooled from its initial fabrication temperature and'or placed under axial stress. In the case of $\mathrm{Nb}-\mathrm{Ti}$ filament cores, the superconductirg properties are only sìghtìy aífected by strains of less than l percent elongation. Higher field, less ductile conductors, such as the $\mathrm{Nb}_{3} \mathrm{Sn}$ filament-matrix interfaces which have larger critical current densities $J_{C}$ and greater critical temperatures, are much more sensitive to the effects of s'rain on their superconducting properties. Unfortunately, the degradation nf superconducting properties with increasing strain seems to plague all hard Type I superconducting compounds with crystal 
structures belonging to the class Als group (see Fig. 3). These include all of the $A_{3} b$ high-field compounds of both niobium and vanadium. Since these materials are the most promising for future high-field magnet development, adoitional research is needed to investigate the strain dapendence of their superconducting propelties.

The current method of experimentation in wolves cooling the composites down to liquid helium temperature and then applying axial strains while measuring the corresoonding critical currents. The strains are prototypic of those experted to arise from the coil winding tension of the magnct and those induced by the Lorentz furces during magnet operation. Figure 4 represents a conglomeration of such data taken for $\mathrm{Nb}_{3} \mathrm{Sin}$ composite conductors at various applied magnetic field strengths, compiled by Lawrence Li cermae National Laboratory and other snurces. There appeare to be wide scatter in the measurements, but several predominate trends seem to be consistent. The first observation is that nearly all of the data suggest that the critical current is at first enhanced with axial strain, reaches a maximum, and then decreases with further increasing strain. A second indication of the data trend is that there is a dependence on the applied magnetic field strength $H$. Previous investigators have concluded that. the $\mathrm{Nb}_{3} \mathrm{Sn}$ layers were under 
compression after the composite was cooled tu liquio helium temperature, aue to the differing thermal expansion coefficients of the $\mathrm{Nb}_{3} \mathrm{Sn}, \mathrm{niobium}$, and bronze regions in the composite. ${ }^{1-9}$ Subsequent applied axial strains wauld at first relieve the compressive strain causing the observed maximum in the criticai cirrent. Continued straining would place the $\mathrm{Nb}_{3} \mathrm{Sn} z$ ones under tensile stress and hence decrease the critical current. Consequently, authors have assumed that the peak in critical current occurs at near zero strain values of the Nb $3 \mathrm{Sn}$ layers.

The curves of Fig. 4 are further normalizeo with respect tu the strain which produces the maximum critical current. The intrinsic strain is assumed to be zero at the peak criticai zurrent ano is defined as "intr $=\varepsilon-$ "icmax" The results of Fig. A are replottea with the intrinsic strain in Fig. 5. Not only Joes Fig. 5 uisplay more detail of the dependence of the applied magnetio field on the critical curcent strain vegradation rate, but it also indicates lalong with Fig. 4) that cometrical factors, such as the Nb 3 Sn layer thickness and the ratio of the brorize crosssectional area to that of the $\mathrm{ND}_{3} \mathrm{Sn}$, may also contribute to the observed effects. 
In addition to the impact of strain-sensitive superconductors on future magnetic fusion magnet design, recent investigatıons have further prober the underlying physical cause of the phenomenon. Perhaps the first vital clue was illuminated by Testardi, who observed, using ultrasonic attenuation techniques, a temperature sensitive softening of the lattice elastjc constants in several of the Als compounds, such as vanadium silicon $\left(v_{3} \mathrm{Si}\right)$, riobium-tin $\left(\mathrm{Nb}_{3} \mathrm{Sn}\right)$, and niobium-germanium ( $\mathrm{Nb}_{3} \mathrm{Ge}$ ). 10-14 It was suggested that the unusual temperature dependence was indicative of a lowtemperature phase transition occuring for the suoerconductors of this group. The transformation was later observed by Batterman, who (using low-temperature $x-r a y$ diffraction reshniques) noted that the normally cubic Als lattices undergo a cubic-to-tetragonal phase transition. The temperature of the start of transition seems to occur several (approximately $50 \mathrm{k}$ ) degrees higher than the superconducting-to-normal transition temperature $\mathrm{T}_{\mathrm{c}}$ $\left(17.8 \mathrm{~K}\right.$ for $\left.\mathrm{Nb}_{3} \mathrm{Sn}\right) .15-16$ Previous authors have repeated the experiments on $\mathrm{Nb}_{3} \mathrm{Sn}$ and have found that in general the transformation temperature $T_{m}$ varied with the purity and stoichiometry of fabricated $\mathrm{Nb}_{3} \mathrm{Sn}$ samples. Indeed, some $\mathrm{Nb}_{3} \mathrm{Sn}$ samples have been reported not to undergo the phase transition at all, while others 
have either partially or completely transformed the entire crystal volume between the starting transformation temperature $T_{m}$ and a transition arrest temperature $T_{a}{ }^{17}$

These results bear a close resemblance to the martensitic phase transformations known to occur in various stainless steels; particularly since at sucn low temperatures, diffusion controlled transformations are ruled out as uniikeiy.18-19 currently, the exact linkage between the material superconducting properties and the martensitic phase transformation is uncertaln, although several efforts have been made to connect the two phenomena by theoretical models based on calcuiations of the materiai density of states and a form of Peierls instability. 20-35 Hopefully, continued research and investigations of these materials will yield sufficient information possibly to explain the even more fundamental question of why the Al5's crystal structure contains several of the hignest known transition temperature superconducting compounds.

\section{B. Purpose of the study}

The purpose of this study is to investigate further the phenomenon of strain sensitivity in superconducting $\mathrm{Nb}_{3} \mathrm{Sn}$, both from the practical viewpoint of its future application in magnetic fusion magnets and as an approach to extract additional information on the underlying physics of the connection between superconcuctivity and 
strain. In general, the techniques used for the two explaraticns will be different because applied engineering magnet design encompasses the macroscopic properties of che compound, such as infurmation on the critical parameters: the upper critical magnetic field $\mathrm{H}_{\mathrm{c} 2}$, the critical temperature $T_{c}$, tre maximum critical curcent density $J_{C}$, and the degradation of these values with applied and/or residual thermal strains on the conductor. On the other hand, investigation of the physics of the strain-superconducting interaction involves factors such as the superconducting Cooper electron pairs, the effect of the crystal lattice on the electrans, the cubicto-tetragonal martensitic phase transition, the electronphonon interaction between the lattice and the electrons, and other such considerations which are predominately microscopic in origin. Nevertheless, the success of such explanations is indicated by the amount of agreement and overlap bet.ween the results.

Using observations obtained from the experimental results, the author will attempt an analytical determination of the strain dependence of the critical current. This mathematical function ccuid later assist in the design of multifilamentary superconductors, in wich a predetermined strain could be induced to yield the 
desired critical current. The method of эttack for this problem can be divided into two stabes:

1. A program must be developed which predicts trie stresses and strains in compositer as a result of thermal and axial loading.

2. Tho functional dependenc? of the eritical current on strain inust be derived.

Charter 2 documents the development of the computer PIogram MAXIMSUPER, which has been applied with considerable success to predict the state of strain on the $\mathrm{Nb}_{3} \mathrm{Sn}$ layers in the composites. Chapter 3 discusses experimental methods which were useo to verify the analytical predictions of the program.

The second step requirad a further investigation into the nature of tue sensitivity of the critical parameters on strain. This was accomplished by studying the effects of strain on the martensitic phase transformation in superconducting $\mathrm{Nb}_{3} \mathrm{Sn}$. Chapter 4 describes this experiment using low temperature $x$-ray diffraction tecnniques. The diffractometer cryostu nas the unique feature that allows the $\mathrm{Nb}_{3} \mathrm{Sn}$ to be placed under both compressive and tensile strains, wile at low temperature, by means of a vacuum mechanical insert. A theoretical model to interpret the results of the investigation is developed in Chapter 5. From the theory emerges the critical- 
current scaling law, required for step 2, used in the MAXIMSUPER computer program.

The author anticipates that the program will not only be useful as an aid in accounting for the observed trends in the strain-I data, but should also find its greatest applicability in the theoretical design of future superconducting composites, since it allows the convenience of being able to model mathematically each proposed conductor design and to optimize (or adjust) parameters, such as the bronze-to-niobium ratio, $\mathrm{Nb}_{3} \mathrm{Sn}$ layer thickness, and then produce conductors with predetermined critical current characteristics. 


\section{REFERENCES}

\section{Chapter 1}

1. Rupp, G., "Enhancement of the Critical Curient of Muitifilamentary $\mathrm{Nb}_{3} \mathrm{Sn}$ Conductors by Tensile Stress," 3. Appl. Phys. 48, 3858 (Sept. 1977).

2. Rupp, G., "Stress Induced Normal to Superconducting Transition in Multifilamentary $\mathrm{Nb}_{3} \mathrm{Sn}$ Conductors," IEEE Trans. Magn. MAG.15:189-192 (Jan. 1979)

3. Koch, C. C. and Easton, D. S., "A Review of Mechanical Behavior and Stress Effects in Hard Superconductors," Cryogenics 17, pp. 391-413 (1977).

4. Van der klein, C. A. M. and Prij, J., "Stress Effects in $\mathrm{Nb} z \mathrm{Sn}$ - Nb - Bronze Composites," to be published in Adv. CIyog. Eng. 26 .

5. Clark, A. F., "Effects of Stress on Practical Superconductors," Proc. 6th International Conference on Magnet Technology, Alpha, Bratislava, pp. 612-618 (1977).

6. Specking, W., Easton, D. S., Kroeger, D. M., and Sanger, P. A., "Stress Effects in a NbzSn Conductor for Use in ihe Magnetic Fusion Energy Program," to be publisheo in Adv. Cryog. Eng. 26.

7. Suenaga, M., Luhman, T., Klamut, C., Fabrication and Properties of Conductors for Fusion Magnets, Annual Report Brookhaven National Laboratory, Upton, NY (Oct. 1, 1976 - Sept. 30, 1977).

8. Deis, D. W., Hirzel, D. G., Rosdahl, A. R., Roach, D. R., Freynik, H. S., and Zbasnik, J. P., "Evaluation of Large Multifilament Nb3Sn Conductors With a New 12-Tesia Tensile Test Apparatus," Adv. CIyog. Eng. 24, 317 (1977).

9. Luhmen, T. and Suenaga, M., "Effects of Stresses, Induced by Thermal Contraction of a Bronze Matrix, on the Superconducting Properties of Nbzsn Wires," Appl. Phys. Lett. 29, 61 (July 1976).

10. Testardi, L. R., Kunzler, J. E., Levinstein, H. J., and Wernick, J. H., "Unusual Strain Dependence of $T_{c}$ and Related Effects in A-15 Superconductors," Solid State Commun. 8, pp.. 907-911 (1970). 
11. Testardi, L. R., "Structural Instability, Anharmonicity, and High-Temperature Superconductivity in A-15 Structure Compounds," Phys. Rev. B: 5,4342 (June 1972).

12. Testardi, L. R. "Unusual Strain Dependence of ${ }^{T} C$ and Related Effects for High-Temperature ( $A-15$ Structure) Superconductors: Sound Velocity at the Superconducting Phase Transition," Phys. Rev. B:3, 95 (Jan., 1971 ).

13. Testardi, L. R., Kunzler, J. E., Levinstein, H. J., Maita, J.P. and Hernick J. H., "Unusual Strain Dependence of $T_{c}$ and Related Effects for HighTemperature (A-15 Structure) Superconductors: Elastic, Thermal, and Alloy Behavior," Phys. Rev. B: 3, 107 (Jan., 1971 ).

14. Testardi, L. R. and Bateman, T. B., "Lattice Instability of High-Transition-Temperature Superconduc:tors. II Single-Crystal V3Si Results," Phys. Rev. 154, pp. 402-10 (Feb., 1967).

15. Batterman, B. W. and Barrett, C. S., "Crystal Structure of Superconducting $v_{3} S i, "$ Phys. Rev. Lett. 13, 390 (Sept., 1964).

16. Mailfert, R., Batterman, B. N., and Hanak, J. J., "Observations Related to the Order of the Low Temperature Structural Transformation in $V_{3} S i$ and Nb3Sn," Phys. Status Solidi 32, K67 (1969).

17. Batterman, B. W. and Barrett, C. S., "Low Temperature Structural Transformation in V3Si," Phys. Rev. 145, 296 (May 1966).

18. Burke, J., The kinetics of Phase Transformations in Metals (Pergamon Press, Dxford, 1965), PP. 196-213.

19. Biliy, B. A. and Christian, J. W., The Mechanism of Phase Transformation in Matals and Alloys, Inst. of Metils, 1956 .

20. Gor'kov, L. P. and Dorokkov, O. N., "On the Theory of the Structural Properties of A-15 Type Materials," J. Low Temp. Phys. 22, pp. 1-26 (1976).

21. Knapp, G. S. and Bader, S. D., "Mode Softening and High Superconducting Transition Temperature in Some 
A-15 Compounds," Ferroelectrics 16, pp. 263-265 (1977).

22. Ting, C. S. and Birman, J. L., "Theory of the Arrest of Elastic Softening in Superconducting A-15 Compounds," Phys. Rev. B: 12, 1093 (Aug. 1975).

23. Lee, T. K. and Birman, J. L., "New Three-Dimensional K.P. Model for the Electronic Structure of A-l 5 Compourids and Application to Anomalous Properties of $V_{3} \mathrm{Si}$ and $\mathrm{Nb}_{3} \mathrm{Sn}$ in the Cubic Phase," Phys. Rev. B: 12, 4931 (June 1978).

24. Pickett, W. E., Ho, K. M., and Cohen, M. L., "Electronic Properties of $\mathrm{Nb} 3 \mathrm{Ge}$ and $\mathrm{Nb} 3 \mathrm{Al}$ From Self-Consistent Pseudopotentials. I. Bond Structure and Density of States," Phys. Rev. B: 19, 1734 (Feb. 1979).

25. Ho, K. M. Pickett, W. E., and Cohen, M. L., "Electronic Properties of $\mathrm{Nb} z \mathrm{Ge}$ and Nb $3 \mathrm{Al}$ From Self-Consistent Pseudopotentials. II. Bonding, Electronic Charge Distributions, and Structural Transformation," Phys. Rev. B: 19, 1751 (Feb. 1979).

26. Bilbro, G. and McMillan, W. L., "Theoretical Model of Superconductivity and the Martensitic Transformation in A-15 Compounds," Phys. Rev. B: 14,1887 (Sept. 1976).

27. Bhatt, R. N., "Structural Transition in A-15 Compounds: Possible Landau Theory Descriptions," Phys. Rev. B:17, 2947 (Apr., 1978).

28. Mukherjee, M. N. and Baixeras, J., "On the Relationship Between the Transition Temperature and the Density of States in A-15 Superconductors," Phys. Lett. 16. 375 (0ct. 1978).

29. Nakayama, [., "Structural Transformation and Superconductivity in A-15 Compounds," 3 . Phys. Soc. Jpn. 43, 1533 (Nov. 1977).

30. Entel, P., "On Structural Instabilities in Itinerant Magnets and Superconductors," $\underline{Z}$. Phys. B 28 , pp. 191200 (1977). 
31. Barisic, S. and Labbee, 3., "The Elastic Constants of $\mathrm{V}_{3} \mathrm{Si}$ Type Compounds in the Cubic Phase," $\mathrm{J}$. Phys. Chem. Solids 28, pp. 2477-2485 (1967).

32. Labbe, J., "Relationship Between Superconductivity and Lattice Instability in the A-15 Compounds," Phys. Rev. 172, 451 (Aug. 1968).

33. Horsch, P., "Electron-Phonon Interaction Due to Interchain coupling in $\mathrm{Nb}_{3} \mathrm{Sn}$, "Solid State Commun. 18, pp. 27-30 (1976).

34. Weger, M. and Goldberg, I. B., "Some Lattice and Electranic Properties of the A-15 Tungstens," Solid State Phys. 28, pp. 1-177 (1973).

35. Vieland, L. $\therefore$ and Cohen, R. W., Studies of Transition Temperatures in Superconductors, firal Report RCA Laboratories, Princeton, NJ (March 1968 - March 1970). 
CHAPTER 2. CODE MAXIMSUPER

\section{A. Introduction to the Chapter}

In essence, the general method of fabricating multifilamentary superconductors is to use trial and error approaches. Tne designs a conductor which has the required proportions of niobium and bronze to form an adequate amount of $\mathrm{Nb}_{3} \mathrm{Sn}$, as a result of the diffusion reaction. Inclujed in the considerations are the amounts of copper which must be added to the composite matrix to ensure stabilization against accidental superconducting to normal quenches, and the questicn of whether tantalum should be included to prevent contamination of the nighpurity, high-conductivity copper by diffusing tin during the reaction. A superconductor manufacturer takes these things into account, along with the mechanical constraints and limitations of his fabrication cechriques, to produce a prototypic sample, which is then tested for its superconducting properties. ${ }^{1-4}$ Typically, the average time between conductor design to fabrication and testing is approximately from six months to one year for each composite.

The conductors are tested for various superconducting and mechanical properties, such as the critical 
temperature $T_{C}$, the critical current dersity $J_{c}$, the upper critical field $H_{c 2}$, resistance to breakage under applied stress, resistivity of the copper stabilizer as a function of temperature, and the dependence of the critical parameters on mechanical strains. These strains are representative of those which would be induced in the conductor as the result of coil winding, mechanical strese from the magnet and support structure weight, and the Lorentz magnetic pressure induced once the coil is energized. Earlier investigators have shown that the multifilamentary conductor critical currents $I_{C}$, critical temperature $T_{C}$, and upper critical field $H_{c 2}$ appear to have a parabolic dependence on the axial tensile strain applied to short test lengths of superconductor isee Fius. 3,6 , and 7$) .5-8$. In addition, certain properties, such as the initial amount of compressive pre-strain, could be varied by changing some of the conductor's internal parameters like the volume ratio of bronze to niobium, diffusion reaction time and temperature, and the layer thickness of the $\mathrm{Nb}_{3} \mathrm{Sn}$ zones in the composite. $5,9-11$

Since the userved critical properties in $\mathrm{Nb}_{3} \mathrm{Sn}$ are indeed strain sensitive, one must develop a method of obtaining knowledge of the strain state of the $\mathrm{Nb}_{3} \mathrm{Sn}$ zones in the fioer composite, first as a result of the 
differing thermal expansion coefficients of the conductor components (copper, niobium, $\mathrm{Nb}_{3} \mathrm{Sn}$, tantalum, and bronze) and second as the result of the different mechanical properties of the materials under the influence of the axial strains placed on the conductor. Presently, the standard procedure is to affix to short sample lengths of the conductors resistive strain gages which yield the axial ' $z$ strain on the conductor while it is being loaded at liquid helium temperature by a low-temperature tensile tester. This method is inadequate for the following three reasons: first, the resistive strain gages are temperature sensitive and, therefore, cannot give any information on the initial strain state proouced by thermal contraction in the conductor as the result of cooldown from the $\mathrm{Nb}_{3} \mathrm{Sn}$ diffusion reaction temperature ( $1023 \mathrm{~K}$ ); secand, there are no existing strain gages that work from such elevated temperatures down to and including $4.2 \mathrm{~K}$; third, the strain gages are attached to the composite surface and, hence, orly give information on the applied : $z$ strain as the result of axial loading (the cooldown thermal expansion strain history is lost) while the $\mathrm{Nb}_{3} \mathrm{Sn}$ filaments are actually under a threedimension state of strain (axial, radial, and azimuthal). Commercially available composite conductors contain several thousand filaments of $\mathrm{Nb}_{3} \mathrm{Sn}$ (see Fig. 8). There 
is no available way to measure the strain configuration of each filament experimentally; therefore, analytical methods must be considered.

There are two ways to model mathematically multifilamentary conductors such as the ones shown in Figs. 8 and 9. It is possible to use finite element and grid techniques along with basic relations of elastic and plastic analysis to treat clusters of $\mathrm{Nb}_{3} \mathrm{Sn}$ filaments and, hence, calculate the strains present on the $\mathrm{Nb}_{3} \mathrm{Sn}$ zones. Alternatively, one can fastion each filament and its surrounding nearest neighbor environment of bronze and copper as a cylinder (infinitely long in the $z$ direction to exclude end effects) with concentric annular rings composed if the various composite materials. The author has chosen to use the latter approach, because of the availability of previously existing work done on stress strain relations in fiber composites and the ease of understanoing the physical and mathematical fouridations of the resulting theory.

One numerical solution to the problem of finding strains in filament composites was treated by $S$. Hecker, C. Hamilton, and L. Ebert, in which the elastic solutions were obtained and then iterated against plasticity data according to an elasto-plastic analysis developed by Hecker.12-14 Their results yielded a computer program 
capable of calculating the stress and strain states of a single composite fllament as the result of thermal contraction and applied loading. Experimental verification of the code predictions was performed first by using two component monofilaments of OFHC copper core with a 4340 steel and another sample with an 18 percent $N i$ maraging steel case (see Hecker Ref. No. 13). Hamilton later extended the experimental test of the code performance by investigating three material component composite filaments. He selected two such systems: a berylco 25 alloy core and case, with an OFHC copper central ring, and a maraging steel core and case with an OFHC copper ring. 15 All results yielded predicted versus experimental unaxiai stress-strain curves that were closer in agreement than curves predicted from the "rule of mixtures" calculations. 16

MAXIMSUPER is a Fortran modification of tro original ALGO general fiber composite program witten by Hecker. 13 First, the code calculates the residual strains (due to the different thermal expansion coefficients of the composite components) produced when the $\mathrm{No}_{3}$ Sn conductor is cooled from its initial fabrication temperature (the $\mathrm{Nb}_{3} \mathrm{Sn}$ diffusion reaction temperature is approximately $1023 \mathrm{k}$ ) to $4.2 \mathrm{~K}$. It is assume that the initial stressstrain state on the conductor is zero at the elevated 
reaction temperature because of the plastic mechanical properties of the bronze matrix ( $10 \%$ Sn - 90\% Cu bronze nas a solidus temperature of approximately $1118 \mathrm{~K}){ }^{17}$ Then axial strain loading is applied and the code calculates the three-dimensional states of stress and strain for each region of the repeating composite element. Finaily, an effective strain is calculated from the triaxial strain components on the $\mathrm{Nb}_{3} \mathrm{Sn} z$ ones and this is incorporated into appropriate scaling laws to predict the resulting critical current density $J_{c}$ of the conductor. The detajls of the functional dependence of the critical parameters $J_{C}, T_{C}$, and $H_{c 2}$ on strain are given in Chapter 5, which describes the critical current density subroutine used in the program.

MAXIMSUPER treats a single cylinoriral repeating element of the entire multifilament composite as shown in Figs, 8 and 9. This single superconducting filament. represents the average geometry and configuration (niobium-core radius, $\mathrm{Nb}_{3} \mathrm{Sn}$ layer thickness, bronze-toniobium ratio, and the prototypic amount of copper matrix separating each filament from the nearest neighbors) surrounding a typical filament. Since this average filament is in an approximately equivalent environment of perhaps thousands of its companions, its resulting strain fields from thermal expansion and axial loading snould be fairly 
representative of those on the average superconducting filament.

However, there are several protems which arise from this modeling which can provide erroneous strain results. MAXIMSUPER treats repeating cylindrical elements of the composite, mainly because the cylindrical symmetry yields strain solutions that are constant with respect to axial $z$ and azimuthat directions in the conductor. Fig. 10 snows such a repeating element; while Fig. 11 and 12 indicate that, although the cylindrical symmetry is approximately maintained for composites with large matrix to fiber voiume fractions, considerable distortions (due to fabrication techniques) can occur in the symmetry for conductors with closely packed filaments. Also, a monofllament sylinder has the boundary condition that its radial stresses vanish at its outer radius. Actual fabrication tends to deform the cylindrical elements intc. hexagonally close-packed structures. This destroys the axial symmetry, imposing an azimuthal dependence on the radial stresses. Ebert et al. have compared the resuits of their cylindrical code to those of a hexagonal repeating element program and have found that the reported states of strain show little difference for fiber to mat.rix volume ratios up to 0.5. 18 Therefore, the slightly hexagonally distorted filaments may be approximated as 
cylindrical repeating elements with an suter radius equal to one-half the average distance to its surrounding nearest neighbors, as shown in Fig. 10.

of course: this modeling is mure accurate "or conductors with uniform filament spacings and densities across the composite cross-sectional area. Composite superconductors with clusters of filaments, grouped into small isianus, separated by large areas of bronze or copper (see Fig. 13), present calculational protlems in that the strain states for the filaments near the "coasts" of the islands are drasticaily different from those in the island centers. Fortunately, the critical-current den: ity of the coastal filaments is lower than those in the body of the cluster (tecause of the higher strains imposed by the larger surrounding copper or bronze regions). Therefore, most of the current is transferred into the inrer filaments. making the moreling of an island central filament a reasonable approximation, provided the number of inns filaments is large.

B. Mathematical Formulation: Strains Produced From Thermal and Axial Loading

The problem of calculating the strains present on the representative cylindrical rapeating element is solved using the theory of elasticity with an iterative procedure to account for plastic effects developed by Hecker. 13 
The element is divided into a multi-N-ring composite cylinder, with a specifled material composition present in each zone (i.e., niobium, $\mathrm{Nb}_{3} \mathrm{Sn}$, bronze, and copper), as shown in Fig. 14. The zone radii are in the exact dimensions specified by the conductor design or the configuration revealed by microscopic examination of a fabricated conductor. The mathematical model makes the following assumptions about the composite cylinder.

1. The cylinder is infinitely long, ignoring end effects (typical filaments have a diameter of about $10 \mathrm{mi}$ crons, with continuous lengths of several meters).

2. The áxial strain ${ }^{{ }} z$ is constant across the filament cross-sectional area.

3. There is perfect bonding at the interfaces of all material zones (no slippane or separation of the N-rings).

4. No external body forces act on the composite. The gene:al approach to solving this problem is to express the equilibrium-of-forces equation in terms of the displacements and then to solve the resuluing differential equation subject to imposed boundary conditjors. The equilibrium of forces equation briefly states that for a polar element of unit thickness to be in a state of equilibiim, the sum of all the forces in the radial and azimuthal directions must be equal to zero. Fram 
elasticity theory, this summation in polar coordinates is known ta yield: 19

$$
\frac{\partial C_{r}}{\partial R}+\frac{1}{R} \frac{\dot{\partial} \tau G}{\partial \theta}+\frac{1}{R}\left(\sigma_{r r}-\sigma_{\theta \theta}\right)+F_{r}=0
$$

for the equation of equilibrium in the radial direction. In the absence of body forces, using the principle stresses, and accounting for the axial symmetry, equatjor 1 reduces to:

$$
\frac{d \cdot r}{d R}+\frac{1}{R}\left(i^{\prime} r-c_{\theta}\right)=0
$$

Thio differential equation for the stresses can be expressed in terms of the strains by using Hooke's law of eiasticity including the effects of thermal strain,

$$
\begin{aligned}
& \sigma_{r}=k\left|k_{r}(1-v)+v \varepsilon_{\theta}+v E_{Z}-(1+v) x \Delta T\right| \\
& o_{j}=k\left[v_{0}(1-v)+v_{r}+v_{z}-(1+v \Delta \Lambda T\right. \\
& \sigma_{z}=k\left|\varepsilon_{z}(1-\nu)+\nu \varepsilon_{r}+v \varepsilon_{G}-(1+v) i \Delta \Delta T\right|
\end{aligned}
$$

in which is the thermal expansion coeficient, $\triangle T$ is the temperature difference between the actual temperature and a reference temperature $T_{0}$, and $v$ is Poisson's ratio. For this problem $T_{0}$ is chosen as the $\mathrm{Nb}_{3} \mathrm{Sn}$ diffusian 
reaction temperature $(-1023 \mathrm{~K})$ because the "putty-like" yielding of the bronze matrix at these elevated temperatures initially places the composite in an approximately stress-free state. Cooling from this temperature supplies the thermal loading stresses and strains.

The triaxial strains can be expressed in terms of axial and radial displacements by:

$$
\begin{aligned}
& r_{r}=\frac{d u}{d R} \\
& \varepsilon_{t_{1}}=\frac{U}{R} \\
& \varepsilon_{z}=\text { Constant }
\end{aligned}
$$

These relations are inserted into equation 3 to yield Hooke's law, which expresses the principle stresses in terms of displacements.

$$
\begin{aligned}
& \sigma_{r}=k\left[(1-v) \frac{d U}{d R}+v \frac{u}{R}+v E_{z}-(1+) \quad \therefore T\right] \\
& \sigma_{\theta}=k\left[v \frac{d u}{d R}+(1-v) \frac{U}{R}+v E_{z}-(1+\because) \therefore T\right] \\
& \sigma_{z}=k\left[v \frac{d u}{d R}+v \frac{U}{R}+(1-v) \varepsilon_{z}-\therefore I+v\right) \therefore \Delta T \mid
\end{aligned}
$$

Equations 5 are directly substituted into the force equilibrium equation (equation 2), which gives the controlling 
differential equation for the radial displacements in the cylind ical composite element.

$$
R^{2} \frac{d^{2} u}{d R^{2}}+R \frac{d u}{d R}-u=0
$$

Equation 6 is an Equidimensianal linear differential equation having the solution

$$
u=c_{1} R+c_{2} / R
$$

This equation is salved for each of the $\mathbf{N}$ radial zones of the composite element shown in Fig. 14; therefore, it is re-expressed as

$$
u_{i}=c_{1 i} R+C_{2 i} / R \text { where } i=0,1,2,3, \ldots . N(2-8)
$$

The solution of the probjem is obtained winen the constants $c_{1}$ and $c_{2}$ are found for each of the material zones and radial rings of the composite; in the case of thermal loading, i $z$, which is uniform across the cross-sectional area, is also an unknown. These constants are determined subject to the following boundary conditions:

A. For axial loading, $\varepsilon_{z}$ is known bevause it is the strain praduced by the tensile test. It is mathematically modeled in the code by inserting predetermined values into the program. 
B. All displacements at the zone interfaces must be continuous, or:

$$
\begin{aligned}
u_{i}=u_{i+1} \text { at } R & =R_{i}\left(R_{i} \text { goes from } R_{1} \text { to } R_{n}\right) \\
c_{1 i} R_{i}+c_{2 i} / R_{i} & =C_{1 i+1} R_{i}+c_{2 i+1} / R_{i} \\
i & =0,1,2,3, \ldots . N-1
\end{aligned}
$$

C. Radial stresses across the interfaces must be continuous (equilibrium of forces), or:

$$
r_{i}=r_{i+1} \text { at } R=R_{i}
$$

Inserting equation 8 into the " relationship of equation 5 im 3 lies that boundary condition 10 gives the followirg result:

$$
\begin{aligned}
k_{i} c_{1 i} & -k_{i+1} c_{1 i+1}-\left(1 / R_{i}^{2}\right)\left[k_{i}\left(1-2 c_{i}\right) c_{2 i}\right. \\
& \left.-k_{i+1}\left(1+2 v_{i+1}\right) c_{2 i+1}\right] \\
& -k_{z}\left[k_{i+1} v_{i+1}-k_{i} v_{i}\right]=r\left[k_{i}{ }^{\prime}\left(1+v_{i}\right)\right. \\
& \left.-k_{i+1}{ }^{a} i+1\left(1+v_{i+1}\right)\right]
\end{aligned}
$$

for $\mathbf{i}=0,1,2,3, \ldots . . N$; these constitute $N+1$ linear equations. 
0. To exclude nonphysical results, all displacements must be finite, implying that:

$C_{2 i}=0$ for $i=0$ (at the composite central core) (2-12)

E. The radial stress vanishes at the cylincer outer surface. This is satisfied by assuming the material external to the cylinder is vacuum, setting all the material constants $\left(K_{n+1}, j_{n+1}\right.$, and $(n+1)$ ang hence the radial stress equal to zero.

F. For thesmal logaing, ${ }_{z} z$ is unknown, out may be derived lrom the condition of keeping an equilibrium ol forces in the axial direction:

$$
\sum_{i=0}^{N} \int_{R_{i-1}}^{R_{i}} i_{z}^{i} R d R=0 \quad \text { with } R_{-1}=0 \quad(2-i 3)
$$

Equations 13,5 , and 8 give:

$$
\begin{aligned}
& \sum_{i=0}^{N}\left[\left(R_{i}^{2}-R_{i-1}^{2}\right) / R_{n}^{2}\right] k_{i}\left[2 \cdot c_{1 i}\right. \\
& \left.+\left(1-v_{i}\right) E_{z}-\left(1+v_{i}\right) k_{i}^{T}\right]=0
\end{aligned}
$$

Therefore, the bcundary conditions have been used to transform equation 8 into $2 N+3$ simultaneous linear equations witn $2 \mathrm{~N}+1$ unkrown constants $\left(\mathrm{C}_{1 \mathrm{i}}, \mathrm{C}_{2 \mathrm{i}}\right.$, and. $\mathrm{z}_{\mathrm{for}}$ 
$i=0,1,2,3, \ldots$. . N). These are solved by a Gaussian elimination routine enabling the three dimensional elastic stress state for each zone to be calculated by substituting equat:on 7 into equation 5 .

$$
\begin{aligned}
& \therefore=k \mid C_{1}-\left(C_{2} / R^{2}\right)(1-2 \because)+\because z-(1-\therefore 2 T] \\
& \because=k\left[C_{1}+\left(C_{2}, R^{2}\right)(1-2 v)+z_{z}-(1+.), T\right](2-i 5) \\
& z_{z}=k\left[2 \cdot c_{j}+(1-v) \varepsilon_{z}-(1+\cdot) \cdot T\right]
\end{aligned}
$$

The corresponding elastic strains for each zone are found by inserting equation 7 into equation 4 .

$$
\begin{aligned}
& r=c_{1}-c_{2} / R^{2} \\
& s_{G}=c_{1}+c_{2} / R^{2}
\end{aligned}
$$

To account for the effects of plasticity in composite cylinders, Hecker, et al., developed a method of elastic-plastic analysis. 14,20 The underlying premise for this technique is to develop stress and strain relationships that include both the effects of elastic and plastic deformation; preferably the relationships are also compatible with treatment by Hooke's law. Currently the main source of plasticity data for a given material 
30

is compiled in its axiai-loading stress-strain curve.

Hector has shown that quantities sled the effective stress and effective strain, which include both tree pffacts of elastic and plastic deformation, can be directly Linked to the axial stress-strain curve. The effective stresses and strains are proportional to the second invariant of the stress deviator tensor and are a measure of the amount of deformation produced in an elastic arid plastic material. They can also be derived from the strain energy of distortion theory, which relates the van-Mises-Hencky-Huber yield criterion for ductile materials to the effective stresses and strains. $27-2$

$$
\begin{aligned}
& \left.-=\sqrt{2}\left[(r-\therefore)^{2}+(0-z)\right)^{2}+(z-z)\right]^{1 / 2}(2-17 \\
& a^{-}=\frac{\sqrt{2}}{2(1+M)}\left[(d: z-d \cdot)^{2}+(d \cdot \ldots-d \cdot z)^{2}\right. \\
& \left.+(d \cdot z-d \cdot I)^{2}\right] d / 2
\end{aligned}
$$

The constant multipliers are chosen so that the effective stress and strain become equal to the applied stress and the largest principal strain during axial tension. For any three-dimensional stress field, the relationship between the effective stress and strain becomes equal to the unaxial stress-strain curve with Mating as 
31

the Poisson's ratio which changes with the effects of plasticity. Likewise, Young's modulus $E$, which is also modified to include plastic phenomenor, becomes equal to the instantaneous slope of the stress-strain curve $P$. For a given material, the modified poisson's ratio $M$ ano roung's moduses $E$ are determined from its stress-strain curve by

$$
\begin{aligned}
& P=\frac{d j}{d r_{z}} \\
& M=\frac{1}{2}-\left(\frac{j}{\partial}-\cdot\right) \frac{1}{E} \frac{d z}{d z_{z}}
\end{aligned}
$$

The : nput stress-strdin curves are poiynomials fitteu by least square alguritnms to availaule data for each composite material. With the new parameters $M$ and $P$ replacing the elastic constants. and $E$, the stress-strain relationships (including both elastic and plastic effects) become

$$
\begin{aligned}
& d r_{r}=\frac{1}{P}\left[d v_{r}-M\left(d \sigma_{r}+d \sigma_{z}\right)\right] \\
& d \varepsilon_{\theta}=\frac{1}{P}\left[d \sigma_{\theta}-M\left(d \sigma_{z}+d \sigma_{r}\right)\right] \\
& d \varepsilon_{z}=\frac{1}{P}\left[d \sigma_{z}-M\left(d \sigma_{r}+d \sigma_{\theta}\right)\right]
\end{aligned}
$$


Notice that the general form of equations 20 is equivalent to Hooke's law of equation 3, hence the transition from elastic to plastic behavior requires no separate analysis except the modification of $E$ and; to become $P$ and $M$, since the structure of the stress-strain relations are iuentical for both regions.

The paraneters $P$ arod $M$, which include both elastic and piastic effects, are dependent on the effective strair. However, the effective strain cannot be determineo without the initial values of $P$ and $M$. Therefore, an iterative techniase is used to determine the effective strain and, consequently, the camplete elastic and plastic solution to the cylindrical element composite. The methodology is tabulated below:

1.a. The initial guess for $P$ and $M$ is that they are elastic and, therefore, are equal to $E$ and.

2.a. For thermal loading the initial stress-free high temperature $T_{0}\left(T_{0} \approx 1023 \mathrm{~K}\right)$ is decremented by a small amount, $\Delta T=1 \mathrm{k}$. The first effective strain increment $d \bar{\varepsilon}_{n}$ (equation 18) is calculated using the elasticity solutions from equations 16 in each radial zone of the composite. The total accumulative effective strain is given by

$$
\bar{T}_{n} x=\bar{i}-1+d \bar{r}
$$




\section{3}

where $\&$ is the number corresponding to the loading step and $n$ is the iteration number. By definition and compatibility with physical assumptions $\bar{\varepsilon}_{-1}=0$ at the stress-free temperature of $\tau_{0}$.

3.a. The resulting total effective strain is used to calculate new values for $P$ and $M$ by equations 19 from the stress-strain curves of each material radial zone at each temperature. Due to the limited arailability of stress-strain data, in general, roomtemperature curves are used with elastic properties (E, , and i), expressed as functions of temperature. The current data used in this study are tabulated in the first appendix.

4.a. Using the new values of $P$ and $M$, the elastic solutions of equations 15 and 16 are found again and a new value of $d^{-}{ }_{n+1}$ is computed by means of equation 18 .

5.a. Now if ' $n$ ? corresponds to the correct location on the material stress-strain curves, then the correct values for $P$ and $M$ have been determined and hence $d \bar{\varepsilon}_{n}$ represents the proper incremental strain. This is tested by comparing the error between $d \Sigma_{n+1}$ and $d \bar{\varepsilon}_{n}$ against a preset convergence criterion : (good results were obtained with \& equal to 0.001 ). 
i. If $\left(d \bar{\varepsilon}_{n+1}-d \bar{r}_{n}\right) / d \bar{\varepsilon}_{n} \%$ for all composite regions, convergence has been obtained ano d' represents the correct strain increment. The program is returned to decrement the temperature for the next thermal loading in step $z$.

ii. It $\left(d \cdot_{n+1}^{-}-\sigma_{n}^{-}\right) / \sigma_{n}^{+}>$for any radiai zone, then d: $n+1$ replaces d. ${ }_{n}^{-}$for all rings and the code returns to step 3 to recalculate new values for $P$ and $M$ ano a new $d n+1$. This procedure is continued until condition 5.a.i is satisfied.

6.a. The thermal loading continues in temperature decrements until a liquid helium temperature of $4.2 \mathrm{~K}$ is achieved, with the code reporting the final threedimensional stresses and strains and effective stress-strain results for all material zones within the cylinarical repeating elemert.

These eftorts give the complete state of stress and strain on the composite components as the result of stresses induced by differential thermal contraction. The next stage of the program mathematically simulates the conditions inherent in a superconducting composite tensile test in which an applied axial load is placed on the conductor producing a corresponding axial z strain. The axial strain can be measured experimentally via 
strain gages attacheo to the sample, what is unknown are Lhe resultiny cranges in the radial and azimuthal strains in the Nis ${ }_{3} \mathrm{Sn}$ zones. The code has the capacity to determine these by repeating steps one through six above, wit.. sijght modifications.

i.t. The initial guesses for $P$ and $M$ now assume the values remaining from the thermal loading solution (because the last reported total effective strain represents the residual strain states of the composite before axial loacingl.

2.b. With the temperature maintained at $4.2 \mathrm{~K}$, the axial 2 strain is incramented in steps tto simulate a lowtemperature tensile test) or: $=0.0002$ percent. The elastic solutions of the cangential stress and strdin components for equatiurs: and is are found subject to the boundary conditions. However, now $z$ is known in equations 15, ana the thermal expansion terms are set equal to zero. The totdi tective strain is stiil determined by equation 21 witn d. increment.

3.b. - 5.b. Steps 3.b thru 5.b are the same as in the thermal-loading problem defined by steps 3.a. thru 5. a. 
6.b. Axial loading continues until the thermally contracted composite has been stretched to an axial z strain of 1.0 percent.

The program requires the following input data:

1. The radial hositions and thicknesses of each composite material (niobium, $\mathrm{Nb}_{3} \mathrm{Sn}$, bronze, and copper) that makes up the cylindical repeating Eiement, determined by photomicrographs or the intenced lesign of the composite cruss section. In general, the tantalum anti-diffusion barriers are ignored, since they surround clusters of thousands of filaments; only the environment if an averaje filament is modaled.

2. Temperature dependent data on the Young's moaulus, Poisson's ratio, thermal expansion coefficient, a'ud stress-strain curves for each composite materia!. Poissun's atio and stress-strain curves as al funcIion of temperature are rar" for must raterials; therefore, room or liquid nelium temperature axial stress-strain curves were used in conjunction with temperature dependent Young's modulus. This coarse approximation still yieldeo good qualitative and quantitative results. The input data, their source references, and the program listing are tabulated in Appenaix 1 . 
The program first prints the residual stresses and strains resulting from the therma? cooldown from $1023 \mathrm{~K}$ to $4.2 k$ on each material zone of the composite. Thus the signs (ccrpressive or tensile) and the magnitudes of the three-dimensional stress-strain state of the repeating comoosite cylindrical element are rt horteo. These values are converted to effective stresses and stains by use of equations $i 7$ and 18 . Natice that the square root functions of the effective stress and strain equations lase information on signs of the defcrmation field; they simply report the magritude of the materjal yie?ding or charge of shape. Previous investigations have shorn that critica? superconducting Froperties suct as $J_{C}, T_{C}$, and $H_{c}$ are dependent on the axial strain presant on the concucto:. For a conductor with a triaxial state of strain or the No 3 Sn zones, these critical properties snouid vary as the magnitude of the elastic and plastic Jeformation, which is the effective strain.

Next, axial loading is apolied to the composice: the code reports the resulting stress-strain fieids for each zone at selected values of the axial z strain. The Eflective strains on the $\mathrm{Nb}_{3} \mathrm{Sn}$ regions $\exists$ re inserted into appropriate scaling laws which relate the critical current density to the amount of strain on the $\mathrm{Na}_{3} \mathrm{Sn}$. The details of these scaling laws are the subject of 
Chapter 5, which develops a possible physical explanation to account for the reduction of the critical current with strain.

c. Analytic Results and Predictions of Program MAXIMSUPER Lurrentiy two types of multifilamentary conductors have been modeled into the program; the incernal niobiumand brorize-core filament composites. Conductors with niobium cores produced by the bronze-diffusion process have repeating fiber elements of niobium rods immersed in a bronze matrix with a reacted $\mathrm{Nb}_{3} \mathrm{Sn}$ interface between the bronze and niobium. As shown in Fig. 13, clusters consisting of perhaps several thousind of these elements are surrmuded by walls of tantalum metal, which act as difiusion barriers prohibiting the migration of tin from the bronze into the high purity second copper matrix. The code models oniy the immediate environment surrouricing a typical filament, as described by Section $A$ of this chapter. A second type of multifilamentiry conductor consists of bronze-core filaments inside of niobium tubes with $\mathrm{Nb}_{3} \mathrm{Sn}$ acting as the interface. In this case, the unreacted niobium acts as the diffusion barrier ano eliminates the need for tantalum barriers. This new goometry also has the desirable property of placing the copper stabilizer closer to the $\mathrm{Nb}_{3} \mathrm{Sn}$ superconductor, minimizing the 
current transfer distance in the event of a superconducting to normal transition in the $\mathrm{Nb}_{3} \mathrm{Sn}$.

Several conductors of the two geometry types with various bronze-to-niobium volume ratios, $\mathrm{Nb}_{3} \mathrm{Sn}$ layer thicknesses, anu amounts of copper surrounding each filament have been modeled into the computer program. The first predaminant observation was that the residual, thermally-induced ' $z$ strain, achieved by the cooldown from reaction temperature to 1 iquid nelium, resulted in $z$ values of approximately - -1.0 to -1.5 percent strain for all the conductors analyzed (see Appendix 2). The amourt of residual axial z strain increases with the volume fraction of the bronze and/or copper present in the repeating composite element. Most ố the residual strains occur between the reaction temperature approximately $1023 \mathrm{k}$ ) and room temperature, which is expected, since the thermal contraction is propartional to the reference and ambient temperature difference. When axial tension is applied to the sample at $4.2 \mathrm{~K}$, the effective strain on the $\mathrm{Nb}_{3} \mathrm{Sn}$ zone (reported at the center of the layer thickness), calculated by equation 18 , aecreases to a minimum value and then increases with cantinued axial straining, as shown by the sample output listing of Appendix 2. The effective strain is a square root function that only reports the magnitude of the $\mathrm{Nb}_{3} \mathrm{Sn}$ 
change of shape. However, the program also gives the principle stresses and strains on the $\mathrm{Nb}_{3} \mathrm{Sn}$ layers as a function of applied axial loading. These results show that the $\mathrm{Nb}_{3} \mathrm{Sn}$ is always under compression (n gative strains) from the radial and azimuthal strain components. In fact, the tangential strains on the $\mathrm{Nb}_{3} \mathrm{Sn}$ become more compressive with increasing tensile strain.

Previous investigators have rearranged the existing strain-critical current data using the Rupp normalization method (see Figs. 4 and 5). 29-30 The jntrinsic strain is assumed to be zero at the peak critical current and is defined as intr $={ }^{f} z-{ }^{\prime}$ icmax. The findl output page of the code also expresses the results using Rupp normalization by subtracting the axial ${ }_{2}$ strain, which yields the smallest effective strain, from the rest of the : $z$ values. Also, notice that minus signs are appended to the effective $\mathrm{Nb}_{3} \mathrm{Sn}$ strain magnitudes for axial. $z$ values, in which the $\mathrm{Nt}_{3} 5 n$ is thought to ve under compression (before decreasing to the minimum value), while those thought to arise from tension have positive signs. The sign addition just visually indicates when the $\mathrm{Nb}_{3} \mathrm{Sn}$ is under compression and tension to make the results commensurate with the experimental data, since the sign of the distortion is lost by the square root function used in calculating the effective 
strain. Consequently, it is expected that higher effective strains on the $\mathrm{Nb}_{3} \mathrm{Sn}$ result in lower critical currents $I_{C}$.

One of the most important attributes of the computer program is its ability to predict the axial strain component ' $z$ ', which corresponds to the maximum $I_{c}$ for a wide variety of conductor designs tested by different investigators. Fig. 15 shows a plot of the measured strain percentages of several conductor designs at peak $I_{c}$ value (see also Fig. 4) versus the calculated strain percentage predicted by MAXIMSUPER. The code results are in agreement with the Luhman and Suenaga data (using composite monofilaments) which show that higher precompressive, $z$ strains are obtained with increasing bronze-toniobium ratios. ${ }^{5}$ In general, the progran results show that the residual thermal strains on the $\mathrm{Nb}_{3} \mathrm{Sn} z$ ones are not only sensitive to the bronze-to-niobium ratio, but also to the layer thicknesses of the $\mathrm{Nb}_{3} \mathrm{Sn}_{n} z$ ones arriving from the diffusion reaction. This may also influence the necessary heat treatment ireaction time and temperature) which yields the highest value of critical current density $J_{c}$ for a conductor (see Fig. 16). The higher elastic modulus for $\mathrm{Nb}_{3} \mathrm{Sn}$ (as compared to niobium) results in less thermal strain in the $\mathrm{Nb}_{3} \mathrm{Sn}$ for thicker reaction layers. Also included in Fig. 16 is data 
from internal niobium-core filament conductors pror. : : by some investigators from Fig. 4 and some recently measurcd samples of the internal bronze-core configuration. The good agreement shown in Fig. 15 indicates that the program is suitably adapted to encompass both conductor types.

One unique distinction is demonstrated by the MAXIMSUPER strain field predictions for the bronze-core filament geometry as compared to the niobium-core configuration. Whila the two conductor designs yield approximately the same $z$ component strains ' $z$, the radial : $r$ and azimuthal $f_{f}$ are much higher for the bronze-core filament design. To illustrate this effect, the code used the geometrical averaging of the threedimensional strain fields to calculate the effective strain in equations 18 and 21 and plotted tnis value against the intrinsic' $z$ strain component for a prototypic bronze- and niobium-core filament conductor in Fig. 17. Notice that the effective strains are much higher for the bronze-core sample because of the contributions to the effective strain (equation 18) from the larger tangential (to, ${ }^{r}$ ) strain components. Fig. 17 illuminates an interesting anomaly: while earlier investigators have concluded that the peak citical currents of Figs. 4 and 5 occurred at approximately zero strain on 
43

the conductor, it can be seen that the zero intrinsic : $z$ strain values, which give the peak critical current, actually coincide with non-negligible radial and azimuthal strain components on the $\mathrm{Nb}_{3} \mathrm{Sn}$ zones. Hence, the maximum current displayed at zero intrinsic z strain is the result of a minimum in the effective strain of the threedimensional strain field, and the minimum value is not necessarily zero. This is particularly true for the internal bronze-core geometry, as shown in Fig. 17, in which the minimum effective strain on the $\mathrm{Nb}_{3} \mathrm{Sn}$ zones is $\sim 1$ percent. In the case of axa loading, it is known that the tangential stresses arising on multicomponent, cylindrical composites result from the differences in the value of the Poisson ratios. Experimental and analytical studies performed on two- and three-component material composites have revealed trat the intensity of the transverse stresses developed between two mechanically interacting materials is nearly in direct proportion to the differences in the value of their respective Poisson ratios. $13,15,27$ As an illustration, one can treat the elasticity equations 15 and 16 for the case of an axially loaded, two-component, cylindrical composite and produce two simultaneous linear equations which are solved to yield: 20 


$$
\begin{aligned}
& r=k\left\{\frac{a^{2} z(1-2)\left(1-b^{2} / R^{2}\right)}{\vdots}\right\} \\
& . .=k\left\{\frac{a^{2} \cdot(1-2 \cdots)\left(1-b^{2} / R^{2}\right)}{s}\right\} \\
& r_{z}=E r_{z}+2 a^{2} \cdot z\left[\frac{k(1-2 i)}{\vdots}\right] \\
& \ddot{r}=\cdot \dot{ }=k^{\prime} \cdot z\left\{\frac{a^{2}(1-2 \because)+b^{2}}{!}-(1-\because 1)\right\}(2-25) \\
& z^{\prime}=E^{\prime} z+2 \cdot z^{\prime} k^{\prime}\left\{\frac{a^{2}\left(a-2 u+b^{2}\right.}{1}-(-,)\right\}(2-2 \epsilon) \\
& r=\frac{a^{2} z}{r}\left[(1-2 v)-\frac{b^{2}}{R^{2}}\right]-\therefore z \quad(2-27) \\
& . .=\frac{a^{2}}{i}\left[(1-2 i)+\frac{b^{2}}{R^{2}}\right]-z \\
& \dot{I}=: \dot{1}=\quad:(R=a) \\
& \therefore=\frac{1}{\left(-u^{\prime}\right)}\left\{a^{2}(1-2 \because)\left(1-\frac{k}{K^{\prime}}\right)\right. \\
& \left.+b^{2}\left[1+(1-2 v) \frac{K}{K^{\prime}}\right]\right\}
\end{aligned}
$$

This is the elastic solution for a composite with a core material of radius "a" surrounded by an annular ring of material with radius "b." The primes denote solutions and physical properties pertinent to the core region of 
the double concentric cylinder. There are several conclusions that are apparent from these results:

1. All radial and azimuthal stresses vanish in both zones if the poisson ratios of the two materials are equal.

2. The tangential stresses and strains scale nearly proportional to the differences of the value of the Puisson ratios.

3. The solutions are obviously not symmetrical with respect to the interchange of tne two material locations (Ieplacing the care material with the case material and vice versa yields different states of stress ano strain).

MAXIMSUPER models a superconducting composite filament with about four material components, each further segmented into several radial zones, in order to report the stress-strain conditions at various radial positions across the cylinder cross section. For the investigation reported in this dissertation, the superconducting filament was divided into typically ten to twelve annular zones. Although the Gaussian elimination method solves a much larger set of simultaneous linear equations for these composites, the resulting stress-strain state of each radial zone is congruent with the above conclusions concerning the simple two-zone cylindrical composite. 
Therefore, it appears that the development of higher tangential (radial and azimuthal) strains, resulting from thermal contraction and axial loading, ìn the bronze-core composite geometry is simply due to the interchange of the locations of the bronze and niobium. The functional dependence of the resulting strains on the differences between the Poissons ratios of the bronze, niobium, and $\mathrm{Nb}_{3} \mathrm{Sn}$ is rot symmetrical with respect to changing the lucitions of composite materials.

The prediction of higher residual effective strains in the bronze-core geometry is experimentally verified in Fig. 18, which is a plot of the measured critical current density of several conductors at an applied magnetic field of $H=12$ Tesla (and resistivity $=10^{-1} \ldots$ - cm) as a function of the MAXIMSUPER predicted residual effective strain (before axial tensie loadiny). The critical current density datd was obtained from the experimerital results of various monofilament niobium-core and bronzecore geometry conductors (Chapter 3 contains the experiinental methods). Photomicrographs of the conductor cross sections were examined to model each campasite into the code. In general, Fig. 18 shows that one should expect the bronze-core configuration to be iriferior to the niotsium-curt Ja.jigr, with a decreasp in critical cuirent density of fiutors from three to ten times. 
One possible way to obviate the higher residual tangential strains inherent in the bronze-core geometry is to attempt to match the Poisson ratios of the bronze, niooium, and $\mathrm{Nb}_{3} \mathrm{Sn}$. Of the three components, the bronze is the first to undergo plastic geformation; consequently, its Poisson's ratio climbs from about 0.34 to about 0.50 , ine value obtained for a metal which yields under plastic flaw. Beryllium has a Poissan's ratio of about 0.05 and is aften used to both stiffen and increase the Poisson's ratio of companion metals in alloys. The addition of various amounts of beryllium to the gronzecore illament would produce a closer match of the Poisson's ratios, thus lowering the transverse stresses and strains on the $\mathrm{Nb}_{3} \mathrm{Sn}$ layer. Recent work performed by Lunman ano suenaga has revealed that the eftect of beryllium addition to the bronze matrix of niubium-core composites is to increase the amount of initial thermal prestrain in the axial z direction on the conduztor. 31,32 Some initial compressive axial z prestrain is a desirable factor in the design of conductors, because the composite is often subject to some tensile strain during fabrication and with coil energization (due to Lorenz forces). However, high residual transverse strains ( ${ }_{r}$, and, ) are undesirable since they cannot be completely removed by axial straining, which only causes them to increase, as 
shown by the code predictions in Fig. 17. Therefore, the continued study of the effects of metal alloying with bronze in the internal bronze-core configuration may provide a way to resolve the strain, and nence critical current density problems associated with this design. 


\title{
REFERENCES
}

\author{
Chapter 2
}

i. Deis, D. W. Cornish, D. N., Zbasnik, J. P., Nelson, R. L., Sackett, S. J., and Taylur, C. E., Superconducting Magnet Development PIogram Anrilal Report, July 1975 Through September 1976, Lawrence Livermore Laboratory, Livermore, CA, UCRL-50031-76 (1976).

2. Roberge, F., "Status of the Development of HighField Als Superconductors," J. Magnetism and Magnet $C$ Materials 11, Pp. 182-185 (Apr. 1979).

3. Murase, S., Koike, Y., and Shiraki, H., "Studies on Superconducting Nb3Sn formed from High-TinConcentration Cu-Sn Alloy," J. Appl. Phys. 49, 6020 (1978).

4. Luhman, T. and Dew-Hughes, D. Eds., Metallurgy of Superconducting Materials, Academic Press, New York (1979).

5. Suenaga, M., Luhman, T., Klamut, C., Fabrication and Properties of Conductors for Fusion Magnets, Annual Report Broakhaven National Ladoratory, Upton, NY (uct. 1, i976 - Sept. 30, 1977).

E. Deis, D. W., Hirzel, D. G., Rosdahl, A. R., Ruach, D. R., Freynik, H. S., and Zoasnik, J. P., "Evasution of Large Multifilament NojSn Conductors with a New 12-Tesla Tensile Tes. Apparatus," Aav. Cryog. Eng. 24, 317 (1977).

7. Luhman, T. and Suenaga, M., "Ef jects of S2resses, induced by Thermal Cantraction of a Bronze Matrix, on the Supercanducting Properties of Nb $3 \mathrm{Sn}$ Wires," App 1. Phys. Lett. 29, 61 (July 1976).

8. Deis, D. W., Cornish, D. N., Rosdahl, A. R. and Hirzel, D. G., "Mechanical Strain of Large, Multifilament Nb3Sn Conductors far Fusion Machines," Proc. 6th International Conference on Magnet Technology, Bratislava, Czechoslovakia, Aug. $29-$ Sept. 2, 1977 .

9. Scanlan, R. M., Cornish, D. N., Zbasnik, J. P., Hoard, R. W., Wong, J., and Randall, R., "Properties of Multifilamentary $\mathrm{Nb}_{3} 5 \mathrm{n}$ Superconductors 
Fabricated by the Internal Bronze Approach," to be published in Adv. Cryog. Eng. 26.

10. Hoird, R. W., Scanlan, R. M., and Hirzel, D. G., "MAXIMSUPER: A Computer Program to Assist in the Design of Multitilament- Superconducting Composites," to be publishe - Hdv. Cryog. Eng. 26.

11. Scanlan, Q. M., Hoard, R. W., Cornish, D. N., and Zbasnik, J. P., "Mechanical Properties of HighCurrent Multifilamentary NbzSn Canductors," presented at the InLernational Cryogenic Materials Conference, Brookhaven National Laboratory, Upton, NY, May 28-29, 1980 .

12. Hecker, S. S., Hamilton, C. H., and Ebert, L. J., Elastoplastic Analysis of Residual Stresses and Axial Loading in Composite Cylinders," J. Mater.: JMLSAM S, pp. 868-900 (Dec. 1970).

13. Hecker, S. S., Elasto-Plastic A alysis of Composite Cy! inders in Axial Tension, Ph.u. Thesis, Case Hestern Reser:e University, Cle:elanú, ondo (seut. 1968).

14. Herker, S.S., Hamilton, ‥ H., ano Ebert, L. ?. "Elastic-Plastic Analyses: A Simplitied Approart," Scr. Metall. 3, pp.793-798 (1969).

1: Hanitun, C. H., Hecker, S. S. aro Euert, i. ... "Mechanical Behavior of Uneaidly Losdeo Multidsyerpd Cy:indrical Composites," J. Basic Er.C.,

pp. $651-670$ ( Dec. 1971).

L. Kelly, A, ano Davies, G. J., "Princiules of Fibri Reinforcement of Metals," Metall. Rev. 10, po $1-77$ (1)65).

17. Lyman, 1., Eo., Metals Handbook gtn Edition, vo?. I, Properties and selection of Metals, ASM, Motals Park. ohio, p. 1028 (1361).

8. Euprt, L. J., Feoor, R. 3., Hamilton, C. H. Hocker, S. S., and Wright, P. K., Analytical Approach to Eomposite Behavior, AFML-TR-6 $9-129, A D-357,059$ ? June $1969)$. 
19. Hearn, E. J., Mechanics of Materials Vol. 2, Pergamon Press, oxford, p. 610 (1977).

20. Ebert, L. J., Hecker, S. S., and Hamilton, C. H., "The Stress Strain Behavior of Concentric Composite Cylinders," J. Compos. Mater. 2, pp. 458-476 (1968).

21. Hentenyi, M., Ed. Handbook of Experimental Stress Analyses, John Hiley, NY, pp. 440-444 (1950).

22. Muvdi, B. B. and McNabt, J. W., Er.gineering Mechanics of Materials, MacMillan, NY (1980).

23. Hearn, E. J., Mechanics of Materials vol l, Pergamon Press, 0xford (1977).

24. Patl, B., "Macroscopic Criteria for Plastic Flow ano Brittle Fracture," Fracture: An Advanced Treatise, EJ. H. Liebowitz, Academic Press, NY, pD. 385-489 $(1968)$.

25. Mendelson, A., Plasticity Theory and Application, Macmillen Book, NY (1968).

2b. Bobroy, E. 5., Massachusetts Institute of Technology, Cambridye, MA, private communicacion i.iune 1980).

27. Hamilton, L. H., Micromecnanics of Axially Loaded Filamentary and Cylindrical Composites, Ph.D. Cissertation, Case "estern Reserve university, iseveland, $\mathrm{OH}$ (Sept. 1968).

23. Hecker, S. S., "Experimental Studies of Yield Phenomona in Biaxially Loaded Metals," in Constitutive Equations in Viscoplasticity: cumputational and Engineering ispects, Stricklin, J. A. and Sáczalski, K. J., EdS. (ASME AMD-Vol. 20, NY, Dec. 1976) pp. $1-34$.

29. Rupp, G., "Enhancement of the Critical Current of Multifi 'amentary $\mathrm{Nb}_{3} \mathrm{Sn}$ Conductors by Tensile Stress," 3. Appl. Phys. 48, 3858 (Sept. 1977).

30. Rupp, 3., "Stress Induced Normal to Superconciuctina Transition in Multifilamentary Nb3Sn Conductors," 1tEE Trans. Magn. MAG-15:189-192 (Jan. 1979)

31. Lunman, T., Kaiho, K., and Su'=naga, M., "Efrects of Aldoying on the Strain Response of Critical Currents 
in Nb3Sn Conductors," to be published in Adv. Cryog. Eng. 26.

32. Luhman, T., "Effects of Be Alloy Additions to the Bronze Matrix of Nb35n Monofilament Wires," J. Appl. Phys. 50, 3766 (May 1979). 
CHAPTER 3. CRITICAL CURRENT-STRAIN EXPERIMENTS

\section{A. Introduction to the Chapter}

Critical current versus strain measurements were performed on several conductors of the new internal bronzecore configuration. The purpose of these experiments was first to ascertain information on the effects of mechanical straining on the $J_{c}$ performance of these multifilamentary superconaucting composites and to compare these results with the theoretical predictions of the MAXIMSUPER code as described in Chapter 2. This chapter documents the equipment, instrumentation, procedure, results, and conclusions of these experiments.

\section{B. Equipment}

DI. D. Deis of Lawrence Livermore National Laboratory has designed and constructed a cryogenic tensile testing facility for evaluating the mechanical and superconducting properties of short-sample lengths (approximately $60 \mathrm{~cm}$ ) of $\mathrm{Nb}_{3} \mathrm{Sn}$ conductors. These conductors are prototypical of those which will be used for the fabrication of advanced, new generation, high-field $(B>10 T)$ magnets for the world magnetic fusion effort. 
Photographs of the tensile-test apparatus are shown in Figs. 19 and 20. Basically, the device is a hydraulically controlled tensile machine capable of delivering a maximum loar of $223 \mathrm{kN}$ to the short-sample conductor, while applying a magnetic field perpendicular to the sample length. The canductor, tensile-pull grips, and superconducting magnet are immersed in a pool of liquid helium (at 4.2 K) within a "ruperinsulated" low-temperature cryostat. The crosshead (shown in Fig. 19) is raised and lowered by two hydraulic pistons, thus allowing the sample, magnet, and entire load structure to be placed into the cryostat after the sample is mounted or removed following a test. Force is applied to the sample by the main hydraulic load piston located at the top center of the crosshead, while the cryogenic structure takes the conductor tensile load into compression on its three stainless-stefl cylinders. Support structures of the load frame and cryostat are constructed from nonmagnetic stainless steel to minimize distortion and interaction with the magnetic field.

Current is supplied to the sample by two copper contacts which are indium soldereo at the conductor ends. Flexible braided copper leads connect the copper blocks to the main cryostat current leads to minimize external forces on the sample. The pawer supply generates a 
maximum of $10 \mathrm{kA}$ in the conductor, which produces ${ }^{2}{ }^{2}$ heating in the current contacts and leads of approximately $5 \mathrm{w}$ each. During operation, the entire cryostat, magnet, and sample have a liquid helium boil-off rate of about $60 \mathrm{l} / \mathrm{hr}$.

Generally, the Lorentz force, resulting from a transverse field of 12 Tesla in the presence of a conductor carrying several thousand amps, would exert a force on the sample causing it to bow between the upper and lower tensile grips, which rigidly hold it in place. Side pole plates of epoxy G-io prevent the sample from deforming under this force.

Electronic control of the tensile tester is maintained by a null detector servo-meter, which compares a programmed command input to a measured value and equalizes the two by sending an output response to the mechanical hydraulic system. The output response activates a servovalve which regulates the amount and flow rate of hydraulic fluid to the pistons, which raise and lower the upper tensile grip. The null detector continuously checks the two signals and readjusts the system status until the measured response signal equals the programmed signal. The device can operate in two modes, under load control and under position control. During the load control mode, the task of the servo-detector is to have the system follow a 
preprogrammed load. Therefare, the tensile grips are instructed to maintain a sequence of constant forces on tine sample, regardless of the conductor elongation. The force exerted on the sample is reported to the servodeteztor by a load cell located at the top of the test facility crosshead. Generaldy, for stress-strain measurements (and also for the strain-critical curzent experiments), the tensile tester is operated in the position control mode. The location of the moving upper tensile grij is reparted co the servo-detector by a linear voltage transducer detector, LVDT, within an accuracy ui sevaial thousandtis of an inch.

\section{Instrumentatior:}

H1though the LVOT gives the position of the upper grip, the actual strain produced on the conductor is monitorea by resistive strain gages affixed along the sample length. The strain gages and their associated instrumentation yield a resolution of strains as low as \pm 0.001 percent, which for a typical $60-c m$ long sample corresponds to a length change sensitivity of $10 \mathrm{l}: \mathrm{m}$. Figure 21 shows a typical conductar affixed with the resistive strain gages. The gages used were MicroMeasurements type wK-15-250BG-350 strain gages, which were sonded to the sample conducturs with M-Bond 600 
adhesive, according to the manufacturer's suggested technique. These instruments report longitudinal strain changes in the conductor by monitoring the change produced in the qage's resistivity, which depends on the thickness of the wire grid that forms the strain gage. The resistance of the nominally $350 \%$ strain gages was measured using a four-arm wheatstone bridge. The excitation current to the bridge was $10 \mathrm{~mA}$ constant current, which was found to produce minimal heating of the strain gage. Previous studies involving the effect of magnetic fields (magnetostriction), temperature compensation, apparent strain, and bridge excitation have been performed and reportea elsewhere. 1

The voltage developed across the superconductor was measured using the four-point method: two leads supply current to the sample, and two additional leads between the current leads measure the voltage which occurs when the conductor undergoes the superconducting-to-normal transition. The resistance is simply the ratio of the voltage to sample current. 2 There are often problems associated with this measurement because a finite distance is required for the current, introduced at the conductor ends, to transfer from the copper and bronze matrix to the inner superconducting microfilaments. Therefore, the voltage taps have to be spaced sufficiently 
away from the current connectors. A magnetic field gradient also tends to distort the uniform current distribution within the sample. This can be avoideo by placing the voltage taps within a region of uniform field strength. 3,4 Since the 12 Tesla magnet at the facility has a two-inch innes bore in which the field is constant, the voltage taps were spaced one inch apart in the ceriteof each conductor. The strain gages, afrixed in the certer of each conductor were also within the high-field region of the magnet, making it necessary to correct the reported st-ain values with available maneto-resistance dค

the i, testa magnet is a split-pole superconducting

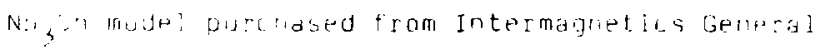
gropuration. It spist allows the sample conductor tu rep inse-ted into it with the magnetic tield perpendiruas to the sample ifrogth. Magnetoresistance wobes mounteu in the magnet tore mediste the certal fieidyalue. The magnet and conducto: $s^{4}$.up is illustrated in the rchematic diagran jt 1 l $2 ?$, whil tre actual experimental arrangement is shown ir Fiug. 23.

\section{Experimental Procedures and Results} The procedure was to charge up the magnet ta a fielu of 8 Tesla, measure the critical current, increment the 
fielo to 10 and 1. Tesla, recording the criticai current for each field value, then to place a tensile strain on che conductor ard Froeat the measurements. At each strain and field valuf, voltage versus current plots are produced by ramping a current into the sample from a oower supply and tneasuriry the voltage induced in the condector as it transfurms tu the nommal state. An axample of sucm a $V-I$

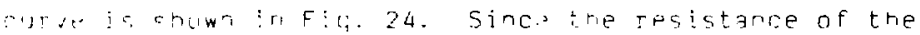

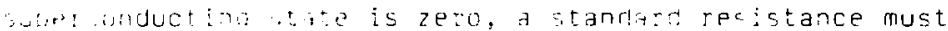

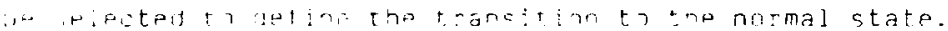

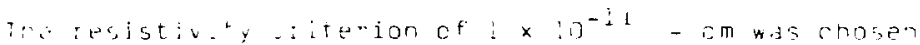
tu: :epresent tre point of tansition to morinal conductiv-

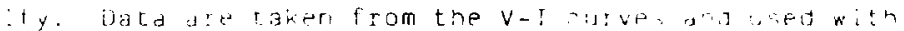

$$
\frac{M}{I L} \quad: \quad \times 10^{-11}-i m
$$

tu produce plots of resistivity versus current, which are thon extrapolated to yield the value of the conductor current and voltage, which equailed this value of resistivity \{fi(j. $; 5)$. In equation 1 , A is the cross-sectional area ot the niobium, niobium-tin, tantalum, ano bronze (every component except the copper), while L is the eistance betweer the attached voltage taps. For each strain increment, the critical current was measured at 8,10 , and 12 TEsia. 
Four conductors of the internal bronze-core design were analyzed on the tensile testing facility. The details of the conductor fabrication are given in another report, but summary oata displaying the major geometry, composition, fatrisation, and resulting critical currents twit.h ro appiled strain on the conductors) ar tabulated in Taje :.$^{5-7}$ iraind photomicrographs gf the conductar

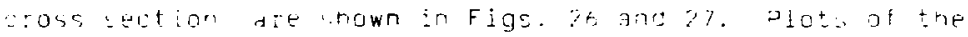

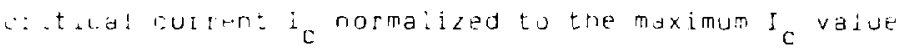
as y furction of applieo axial strain are shown in figs.

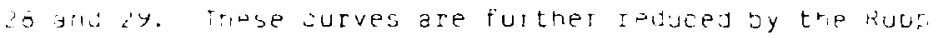

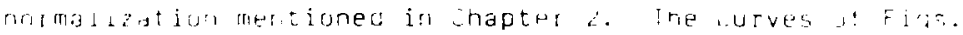

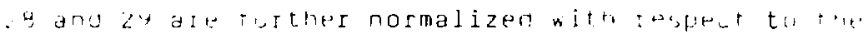
stai: that oroduces the maximum erjticsl rispert. Thr

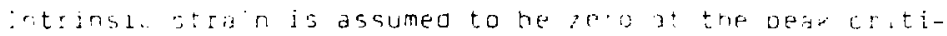

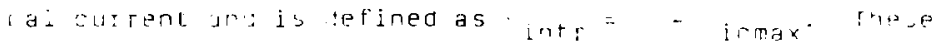
cusves are snow in fig. 30 with rupp nozmalizaijori. For purposas of comparjson, the envelope curves ot the irtrrna! nishidju-lura multifilamenlary sundur: ore are supe: imposed yver the internal oronze-curedata ir to is figure. In yoreral, there is no difterence between thase Lurves and trosf atalned from the niobium-bue tilament conductors ut tiq. 2 . This inuicates that the rale of

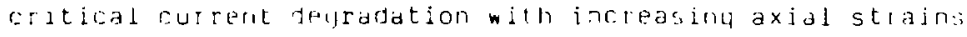
is equivaler: : ol noth conuuctor geometi im.. However, 
the initial critical current densities, J measured at $4.2 \mathrm{k}$, for the internal bronze-core geometry conouctors are facturs of three to ten times smalier than niobiumware desigris with rquivalent bronze-to-niobium ratios as shown in fig. 13 . These lower critical current densitie= tre a viret ver:ication of the analytic results of the

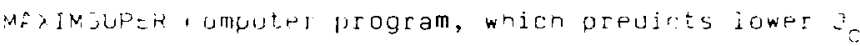

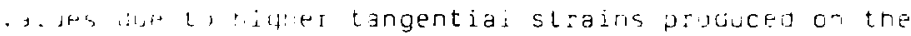
No zor rones, as ine result of differential thermai onicactiun of i'ie composite materiad cumponents, irus ta:, nu valiation of the heat treatment times and cono:ijoris has hepn shown to alleviate this effect. Several $\therefore$ values wete reasured by J. Zbasnik tor cunouctors of tis peumetry with differing heat treatments. ${ }^{8}$ Thest perutes art tauulated in Table 2 ; in ald Eampies, the $J_{c}$ values are less than those obtained fus trie niobiumcure contiguration. For several conductors, the reportea $J_{c}$ values are lower by factors as large as 30 times. Some corroborating data on tnis effect was independentiy obtained on these and other internal oronze samples by $K$. Aihara and $M$. Suenaga, wno noticed a niughe: suppression of the transition temperatures $T_{C}$ in these canductors. ${ }^{7,9-10}$ For a comparable bronze-to-niobium rario, the $T_{c}$ reduction in the internal bronze-core onductor is about $1.8 \mathrm{~K}$, compared with avout $0.2 \mathrm{~K}$ for 
an internal niobium-core conductor. Similarly, the transition temperature deyradation for the internal bronze samples, on a master plot of $T_{c}$ reduction versus strain, woulo indicate a scrain of greater tnan 1.0 percent in the Nu, Sn layers (Fig. 6). This is in ayreement with the coce results of $\mathrm{Fig}$. 18, which invicate preaicteo

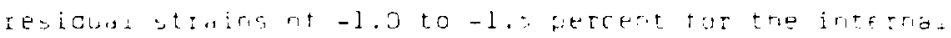

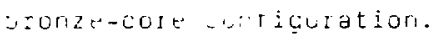

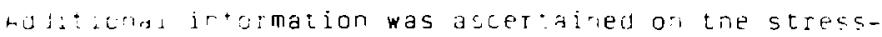

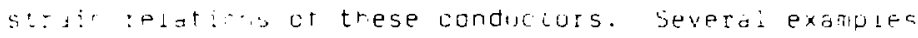

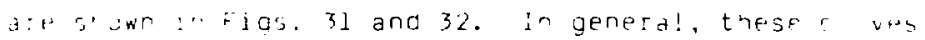
asem to agrep with those taken of the miobium-core

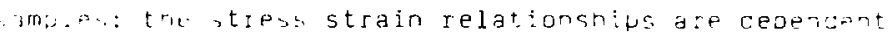

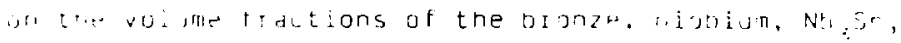
tne utrer impositp material components. Heymo a ser-

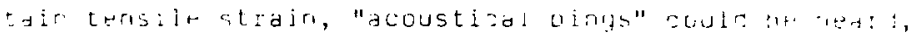

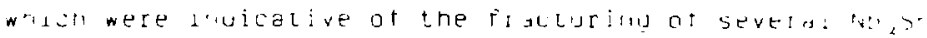

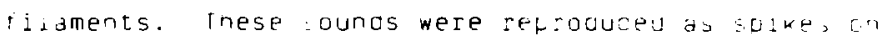
tlie stress-strain curves. A comparisor ol te st:ar-

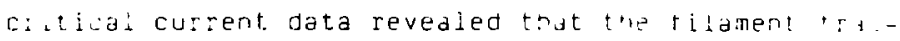
turing starteo at approximately 0.a pereett stralo dust thr strain cocrespanding to the naximum in the cillicid current. Tnis was verified by relifving tre strain in a conductur (Fig. $\angle G$ ) and repeatiny the $I_{e}$ measurmment. which reveyled thas the strain deqradation of the c: itical 


\section{r. 3}

current as reversible for strains less than 0.2 percent beyond tie peak I max value. It is thought that a jtrough Ne; Sn can withstand iarge precompressive stiáins $2 r$ - i percent, it fractures in tension tor strains yreater rndi 0.2 percent. These results may serve as a expianat:o. tor the dsymetry snown on the paraboilc auves af

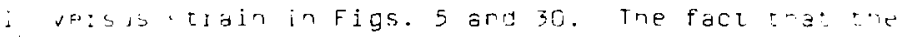

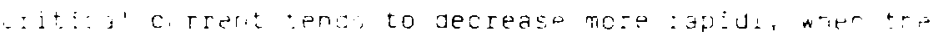

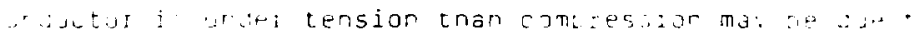

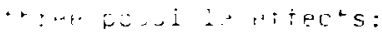

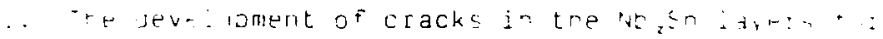

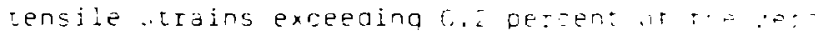
intrinsi. strain value.

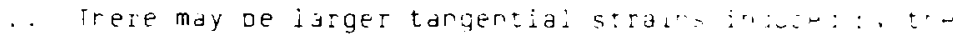

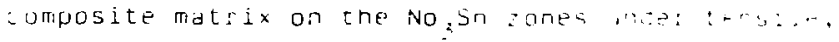
ratner than compressive, strains.

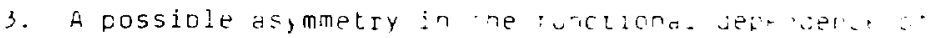
the lo versus strain reiatlonsmins to: iviz : " . : may be a function of votr o dis dicer powes.: 


\section{REFERENCES}

Chapter 3

1. Freynik, "?. S., Roach, D. R., Veis, D. W., ant: Hirzel, D, G., "Evaluation of Metal Foil Straln Cidges or iryogenic Appicalion in Hign Majpetis Fielos," Auv. Cryog. Eng. 24, pp. 463-479 1:97?.

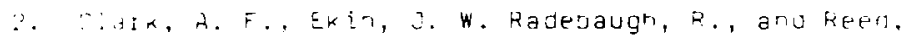
U. '., "The Uevelopment of Standarcs for Practial:

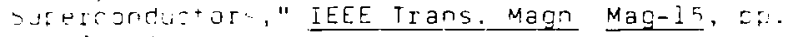
.... . its.

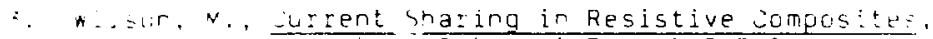
ri.t. eit.: : ar.ratory Interna: Report SMRII.

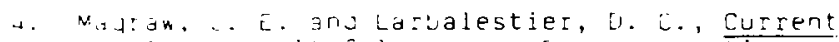

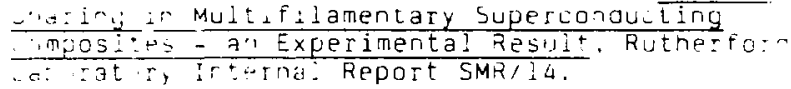

o rean, h. M., Corrish, U. iv., Lbasnik, $\therefore$. . .

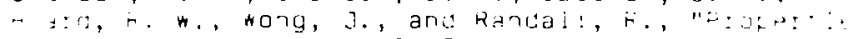

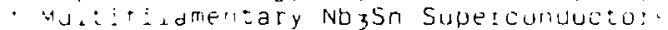

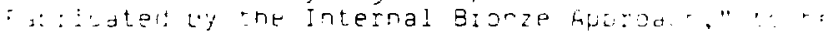
i. $\therefore$. ed ir da. Cryog. Eng. ar.

$\because$, gart. K. W., scan!an, R. M., anc tizz:1, L.,.,

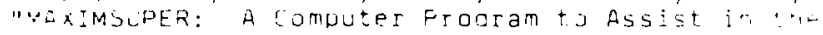

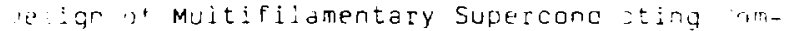
L. ites." to be oubisher ir Adv.

$\therefore$.anda, F. M., Hoard, R. H., us risp. i. M., : :

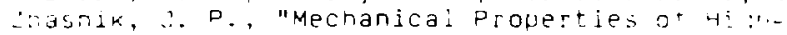
1: :en" Mul! ifilamentary Nhzsn Condumtnt", " iteser.ed at the International Cryogenic Ma:e!is.:

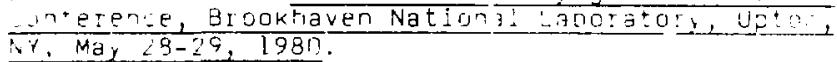

o. ?adshik, J. P., Lawrence Live: more ial bunal

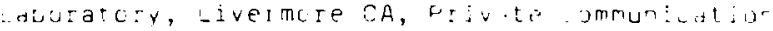
+.;. . . . 79.

4. Suenaga, M., Brooknaven National Laboratory, Unton, NY, Private Communication (Arr.? 1979 : 


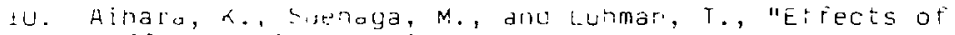
Differetiul arrinal Cortraccion Between the Matrix

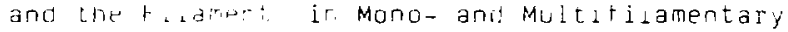

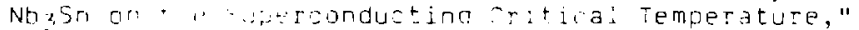

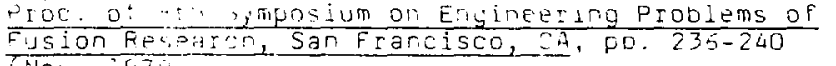


CHAPTER 4. LOW TEMPERATURE X-RAY OIFFRACTION EXPERIMENTS

\section{A. Introduction to the Chapter}

A possible clue to the anomalous degradation of the $\mathrm{Nb}_{3}{ }^{\mathrm{n}}$ supercondicting critical parameters $\mathrm{J}_{\mathrm{c}}$, $\mathrm{H}_{\mathrm{c} 2}$, and $\mathrm{T}_{\mathrm{C}}$ with incriar,ing strain may be provided by the existerce of the low-temperature phase transition reported for tre material. Using ultrasonic attenuation and reutron scattering techniques, Testardi and others have observec that the elastic corstants, and hence the velocity of souri,

Jecrease in Nb. Sn at low temperatures. $1-8$ As noted by kittal, the softening of an clastic constant is usually indicative of lattice instability and, therefore, cam result in a phase transition.

Generally, a lattice structure which is stable at higher temperatures becomes metastable as the temperature is reduced and finally transforms to a structure with less symmetry at the transformation temperature $T_{m}$. In the case of $\mathrm{Nb}_{3} \mathrm{Sn}, \mathrm{T}_{\mathrm{m}}$ has been found to be approximately $50 \mathrm{~K}\left(\mathrm{~T}_{\mathrm{m}}\right.$ is used 50 as not to confuse the crystalline phase change with the superconducting transition temperature $T_{C}=17.8 \mathrm{~K}$ for $\left.\mathrm{Nb}_{3} \mathrm{Sn}\right) \cdot 14$ 
Investigatils trave measured the lat ticp constants during the transformation and have concluded that the phase change involves a cubic to tetragonai transiinon, 5,10-1? apparently, the tetragonal distortion retujusts oot wly tre lattice c length, but also the a dxis 50 as to maintain nearly constant if not equal) sjteire ceil volume under the transition.

inere $j$ : sume quastion concerning the nature and iassification of the prase change. Phase transitions in mothic systems can be divided into two main classes, musieatior-and-gruwth transformations and martensitic

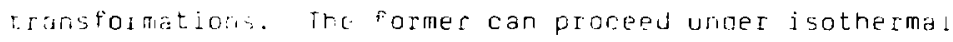
aracitions ir: that, given sufficient time, the amount of material trantormed increases even if the temperature is neld fixed: with thermal activation and uiffusion acting as the driving toice for the transformation. On the other hand, martensitic phase changes usually only occur while the temperature is changing and are dependent only slightly, if at al1, on thermal agitation. Diffusion is not required: there is a change of the shape of each region that transforms, which can lead to the productica uf surface tilcing andor strain in the vicinity of the tronsformed volume in the material.

What appears to be confusing is the fact that some investigators have reported $\mathrm{Nb}_{3} \mathrm{Sn}$ samples in which they 
noted no observable transformation or single crystaj; which were only partially transformed. 10-12

King has shown that this anomalous behavior can be attributed to the djfferences between the stoichiometry of the prepared specimens; variations in the ratio of niobium to tin lead to changes in the cubic lattice rell pirameler. 33 Ihus, it appears as if only $\mathrm{Nb}_{3} \mathrm{Sn}$ compounde whowe urit. rifoll sizes fall within a linited rarge ut lot.. tice paramelers car actualiy underga a prase transition. His results are shown in Fig. 33. This figure implies that if the cubic-to-tetragonal. phase transformation is dependent on the lattice parameter, it may well also be a function of the strain on the material.

Strain induced transitions have already been reporter: un stainless sleels and many other alloys, in which transformations have oew excited at tomperatures well above the martensitio slart temperature $T_{m} \cdot 14-18$ Indeed, these results may be interpreted as if $T_{m}$ itself is a function of the applied strain. This may be obtained analylically by writing the Gibbs free energy of the two phases as a sum of terms dependent on the temperature and strain. Minimizing this expression with respect to the temperature should yield the transformation temperature $T_{m}$. Since every martensitic transformation involves a distortion of a local region of the material which produces stresses on 
the surrounding untransformed volume, it would be expected tnat all could be aided by the application of externally applied stresses.

In order to determine if the phase transition in $N_{3} S n$ is strain sensitive, it is necessary to study the transformation as a function of temperature under varying increments of strain. Phase transitions are normally observable by $x-r a y$ diffraction techniques; unfortunately Battermar, and others have noted that $\mathrm{T}_{m}$ (for $\mathrm{Nb}_{3} \mathrm{Sn}$ ) occurs at approximately $50 \mathrm{k}$ which necessitates the utilization of a low-temperature cryostat suitable for $x$-Iay diffraction measurements. This chapter cocuments the equipment, instrumentation, experimental metmod, resilts and conclusiors of the phase transition studies performed on Nozön.

\section{B. Equipment.}

1. Low Temperature Cryostat--The cryostat used for the mounting, cooling, and $x-$ ray analysis of the $\mathrm{Nb}_{3} \mathrm{Sn}$ samples was a continuous flow Heli-tran LT-3-llo cryostat manufactured by Air Products, Inc. The continuous flaw operation utilizes a flexible transfer line which transports liquid helium from a 501 storage dewar to the cryostat. The continuous liquid helium stream cools a copper sample holder in the cryostat, which in turn cools 
the attached sample by conduction. For a liquid helium flow rate of 0.7 1/hr., the net refrigeration capacity of the oryostat. is sul mw at $4.2 \mathrm{~K}, 3 \mathrm{w}$ at $20 \mathrm{~K}$, and $7 \mathrm{~W}$ at $50 \mathrm{~K}$. The system uses a micrometer needle valve to permit. control of the flow rate. The approximate cooldown time is 45 mirutes from a warm start and about 15 minutes far subsequent cooldowns. Figures 34, 35, and 36 show the schematic views of the cryostat conmections and rysten setup.

Radiation shiplds and vacuum shroud covers are interchangeable on the Heli-tran unit, with designs appros:jate for a wide variety of low temperature apolicatiors, such as INMR, optical spectroscopy, x-ray diffractior, Mössuaver effect; etc. The vacuun shroud WMX-2A was selected matese of its ease of mountinn and campatisle gonioneter shatt to the Phillips $x-r a y$ : iffractometer. The WMX-2A shroud has a one-half inch wite, 180 degaes cutout window over which a sheet rylliun ト-っ been attached to allow minimum absarptio he $x$-ray beam before it interacts with the sample. 1. .ljndrical radiation shield also has a one-half inch by 180 degree cutout window (see Figs. 37 and 38 ).

The cryostat comes equipped with a 20 woninductjve heater, mounted in the tip of the base plate, which houses the sample holder. The temperature of the cfyotip 
is inaicated by a chromel versus gold with 0.07 atom: percent iron doping thermocouple.

Ali materials used in the construction of the cryostat are non-magnetic, these include 304 stainless steei, UFHC copper, orass, and hard solder.

Several modifications were made in the as-manfacturea equipment. These are tabulated below:

1. The tiquio neljum pickup tube of the flexis:e zarisfer line was found to be too short. A typical wy j: storage dewar contains approximately ls incnes o: liquid helium; the as-purchased transter line could only pick up about 8 inches. This probicin was eiiminated by adding a lo-inch stainless-steel extender tube to the end of the transfer line.

2. The one-half inch by 180-degree cutout vacuum shroud oeryllium window, which was originally affixed with "Fuller Resi-Weld Epoxy," was found to leak in vacuims of $1 \times 10^{-5}$ Torr. The leak was sealed by coating the rim of the window with Torr-Seal epoxy.

3. A sample holiar was constructed which would allow the material to be placed under both compressive and tensile strains, while at low temperatures, by means of a vacuum mechanical insert. The holder consisted of 
an OFHC iscemtjly which used an ad:ancing A sen scrow to ceparat. t.wo copper, wedge poles. The samples wele tapped and mounted to the top of the werge ubles (set Fig. 3y).

4. The Allerr irow was advanced by a vacuum incert. A? ipr. diver which passes thru an o-ring seal in the shrour cuver, directly opposite the beryllium window (sae tig. $\quad ; n$

2. X-Ray Generator and Diffractometer--x-rays were wroducrd b; a Norelco generator operated at a power ifve. ol sj $\mathrm{kV}$ at $30 \mathrm{~m} / \mathrm{A}$. A wide angle diffractometer manufactured by Phillips Eloctronics, Inc., was used with copper K. radiation. Radiation incident on the crystal cintilation letector was diffracted by a graphite cryetal monochromator to improve the signal-to-noise ratio.

The entire $x$-ray generator and diffractometer apparatus was operated under automated control by 3 computer data acquisition system assembled by Lawence Livermore National Laboratory. The computer directs the angular scanning of the sample through a stepping motor and stores the digital count rate versus scan angle data un a magnetic disk. All computer hardware (dual floppy disk system, teletype, etc.) and software were received from the Uiqital Equipment Corporation. The software included 
f disto ndysi, iouline (RT-11) wiluh is used lr conjunctor ath inte: ut ive grapnics naroware iNu. 4012 itxtorix telifiris and No. 4631 hardcopy unil; to further Wores, "nus idisidy the stored data.

1nstrumentatior.

J. Thermometry and Strain Gages--As mentioned in SHit:or B-1, the Heli-tran cryostat comes with a caliilistar chromel versus gold-iron thermocouple which is

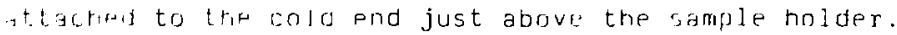
iffortuately, a separate temperature sencur affixed to the sample ofter: revealed temperature djfferences of $10 \mathrm{~K}$ whwer the two locations. Therefore, the thermocouple wis not used, since it could not re located closer to the sample. The the:mometry userd was Micro Measurement, Inc., Gryogenic linear temperature sensors (CLTS). Tre CLTS is a sma 1 , surface-mounted thermometer gage formed from two thin, foil, sensory grids laminated into a glass-fiberepoxy-resin matrix. The foils are anutactured from alloys of nickel and manganin which are processed for equal and opposite nonlinearities in their resistance versus temperature characteristics. The resulting composite gage displays a nearly linear change of resistance with temperature. A diagram depicting the CLTS construction and a typical calibration curve are shown in Figs. 40 
and 41. Belween room temperature and $4.2 \mathrm{~K}$, the resistance changes approximately $70 s$, yielding a linear sensiLivity of $4.197 \mathrm{k} / 2$. Generally, a four-point resistance measurement enables the temperature to be determired within $\$ 0.44 \mathrm{~K}$.

Two CLTS gages were used; one mounted to the sample nolder reported its temperature to a Cryogenics systems temperature controller. The temperature controller is a null detector that compares the measured tempera-ure to a pres-iected value ario directs output curpent to the hieitran cryostat vase-tip 'רeatar until the two temperatures are equalized. The other $L$ : 'S sensor was affixed under tme sample (which was the closest approach without being urectly exposed to the incident $x$-ray beam) and reported the sample temperature via a four-point resistance mersur-ment and the calibration curve of Fig. 41. Figure 39 Is a photograph showing the sample, tensile sample nulder, and temperature sensor locaiions for the experiment.

The strain gages used were the smaller MicroMadsurements type wK-09-'25BT-350 resistive gages wired to form the active element of a four-arm wheatstone bridge with three lead temperature and resistance compensation. These were mounted next to the Nb 3 Sn ribbons (see next section) to avoid interception of the $x$-raj 
veam. The strain gage is shown next to the $\mathrm{Nb}_{3}$ Sn sample in Fig. 39.

D. Nb3Sn Sample Preparation and Descriptjon

The niobium-tin samples used in this study were bronze-diffusion-processed $\mathrm{Nb}_{3} \mathrm{Sn}$ tape, prepared by $\mathrm{M}$. Suenaga and T. Luhman of Brookhaven National Laboratory. No direct analysis has been done to assay the stoichiometry of the formed $\mathrm{Nb}_{3} \mathrm{Sn}$ layer, but transition temperaturc measurements of the tape revealed c srall composite T. i $7.5 \mathrm{~K}$. Removal of the precompressive bronze layers would iricrement this value even closer to that of unstressed $\mathrm{N}_{3} \mathrm{Sn}\left(\mathrm{T}_{2}=17.8 \mathrm{~K}\right)$.

The major advantage of using $\mathrm{Nb}_{3} \mathrm{Sn}$ bronze-proce,st tape instead of multifilanientary conductors in tnj.s experiment is that the bronze can be completely acio-etched away exposing a t'lat continuous surface of $\mathrm{Nb}_{3} \mathrm{Sn}$ to the incident $x$-ray beam. The flat thin I ibbons also facilitace in the mounting and application of strains an the samples. Since both conductors are fabricated from the tin diffusion reaction and have comparable transition temperatures, their chemical stoichiometry and metallurgy should be equivalent. Extrapolation of these results to those which would have been obtained by using mallifilamentary conductors is only complicated by the difference 
in geometry between the two (rlat ciovone versus cys:ndrical filaments: .

To view the diffraction patteir ot Nt 3 sn, it was first neressary to remove the outer bronze layers. inis

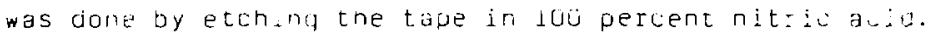
The resultiny niobium plus sity 3 fn foil, with a trickns of approximately $13 ; \mathrm{m}$, was attached to an indium wa: with the same strain gage auhesive menioned earlier. F resistive strair gage was also bonded to tre inaium, if A:

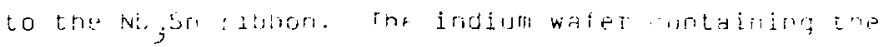
No 3 Sn loil and strain gage was bolted unte the two conper wedge poles of the tensile tester sample holcer, a shown in Fig. 39.

The atcractive properties ut indium, used in this experlment, ale its relatively good thermal coriductivity and its Large thermal contraction at low tempeadurra. the indium sheet places a residual compresaive stridn af -0.7 percent on the strain gage and $\mathrm{No}_{3} \mathrm{Sn}$ Foil w' an it is cooleu from room temperature to $4.2 \mathrm{~K}$. Tro purpose of the tensile cesting sample holder is merely to relieve the precompression by expanding the wedge poles and the attached indium wafer. Generally, this would yield an effective straining range of -0.7 to 0.0 percent, or until the $\mathrm{Nb}_{3} \mathrm{Sn}$ fractured at about +0.2 percent. However, the low lemperature creep of the indium water 
compounder the dil:i, uity of obtainimg mpasurements over this entire range. Instead, measuremen:s were recorded at 5 trains of $-0.7,-0.5$, ard n.4 percent, using the Endium sapie sta jw. An OFHC copper ptate whicen nas a

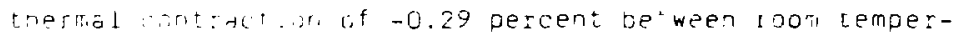
utje arj... $x$ na useo to take doaitiunal cata at -u. 3 i, t: : : r., t.

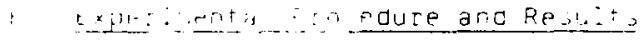

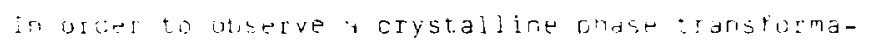
tiur, one jenesaliy studies the $x$-ray riffraction patterns jefore and after the transition. The change of rrysta? symmetry introauces more diffraction ines it the rew , tructure has iers symmetry. For a tancition from cubic to tetragonal, the interplanar spacing a, ohanges trorn

$$
\begin{array}{ll}
\frac{1}{a^{2}}=\frac{n^{2}+k^{2}+1^{2}}{a^{2}} & \text { to } \\
\frac{i}{d^{2}}=\frac{h^{2}+k^{2}}{a^{2}}+\frac{1^{2}}{c^{2}} & (4-1)
\end{array}
$$

where $c$ and t subscripts refer to the cubic and tetragonal symmetry; $a, b$, and $c$ are lattice parameters of the unit cell; and $h, k$, and $l$ are integer valup indices of planes in the set (hkl). When equation 2 is comoined with the 
Bragg law, the aryular locations for the diffedeted lines are given hr

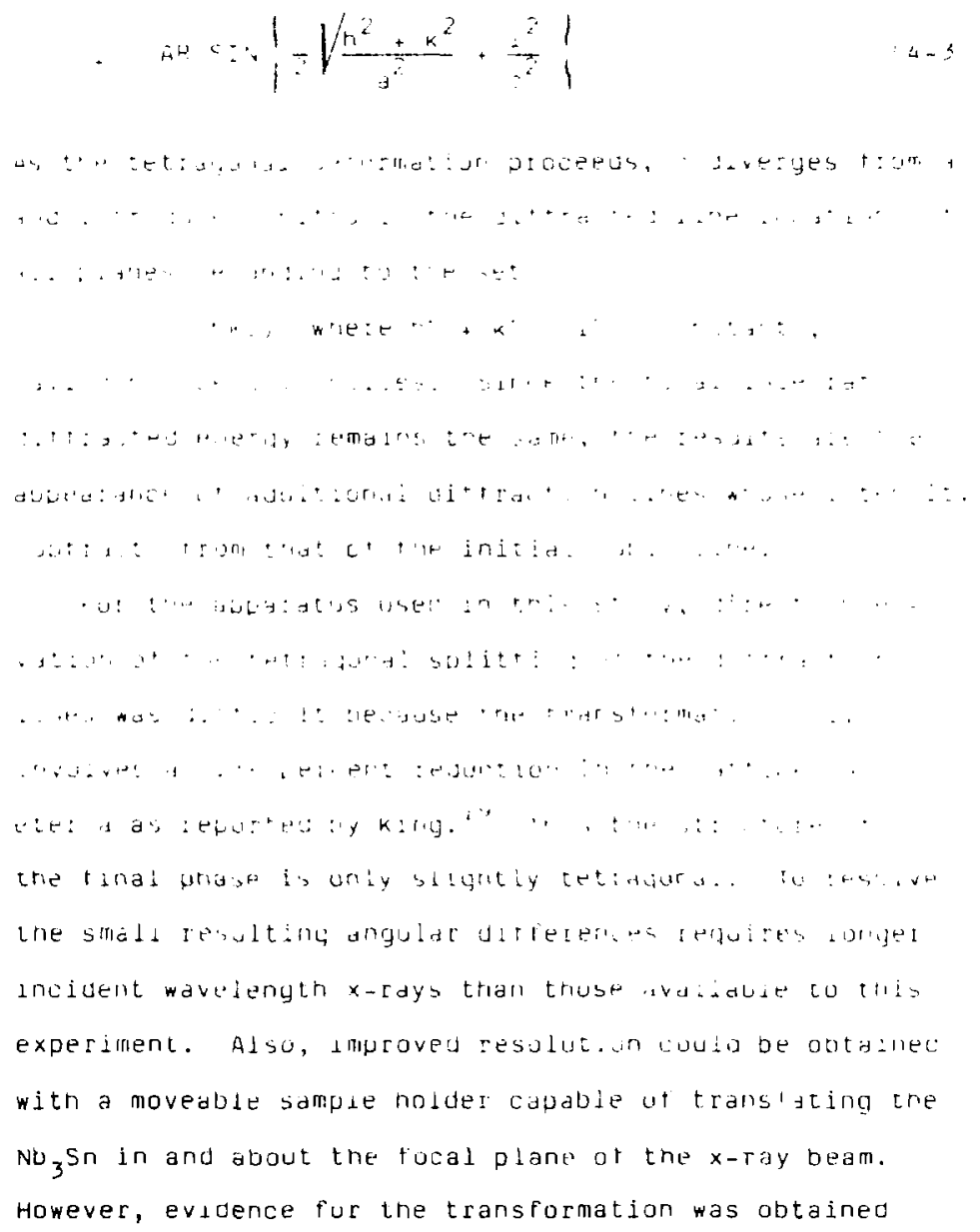


using uk, Iadiation by oosarving the bil, 532) diffraction line.
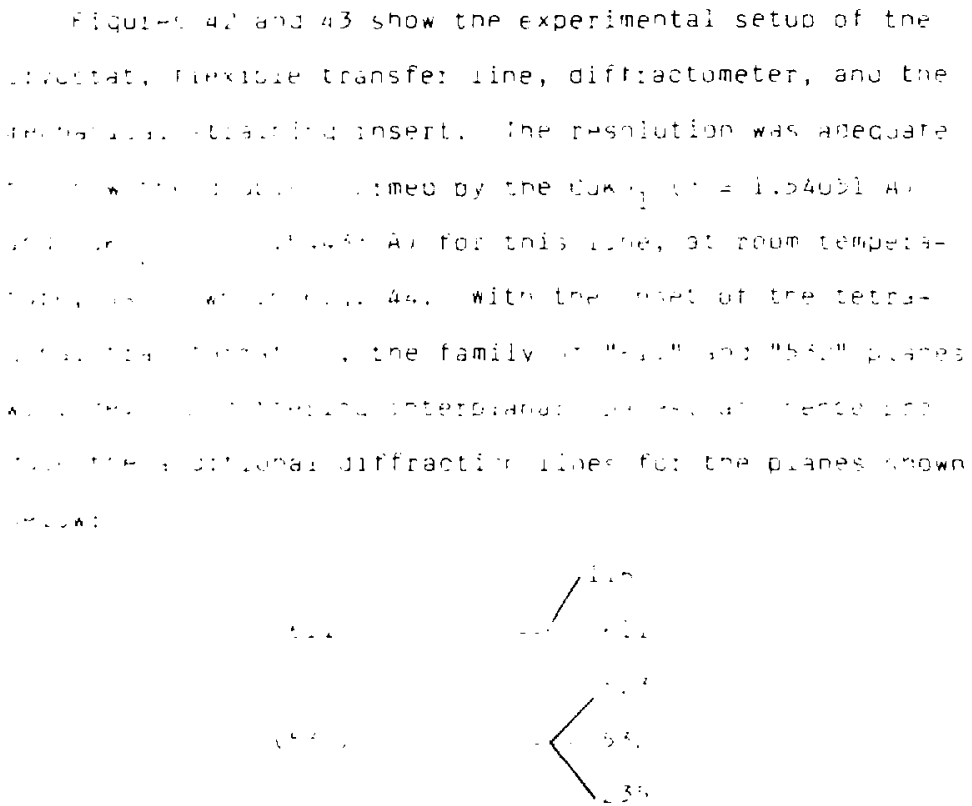

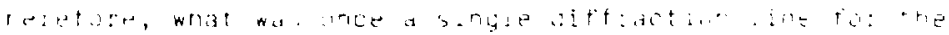

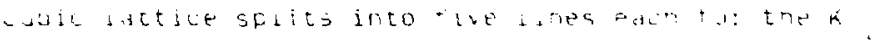
dru k., radiation. Jince tre total interrited irtensit,

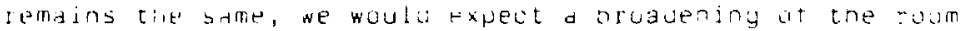
temperatute fidterr with a corresponuing decrease in the pattern peak intensity.

Figure 45 shows the $\mathrm{Nb}_{3} \mathrm{Sn}$ diffraction protile after the sample was cooled to $8 \mathrm{~K}$. Notice that the kil and 
$\mathrm{K} \alpha_{2}$ doublet is no longer resolvable, the peak intensity has lowered, and the angular width of the pattern has spread. The diffusing of the lines is in opposition to the effect of temperature on diffraction patterns, which tends to produce sharper images as the lattice thermal excitation decreases. 20

An attempt was made to determine the martensitic transformation temperature $T_{m}$ by exciting the cryostat tip heater via the temperature controller, regulating tr. liquid helium flow valve, and repeating the diffraction scan at approximately $10 \mathrm{~K}$ increments. Figures 46 thru 55 indicate that the phase transitior, is active over a broad temperature range when the indium compressive strain on the $\mathrm{Nb}_{3} \mathrm{Sn}$ is -0.65 percent. The predoininant feature of these patterns is that the peak height decreases, while the peak FWHM increases as the temperature is lowered, until a certain minimum low temperature is achieved below which the transition is arrested. This can be seen in the plot of Fig. 56, which shows peak height (above background) as a function of temperature for an initial $\mathrm{Nb}_{3} \mathrm{Sn}$ compressive strain of -0.65 percent at $8 \mathrm{~K}$.

In general, the effects of inhomogeneous strains in a material is to broaden the lines of its diffraction pattern. 21 In order to ascertain that the observed broadening of the $(611,532)$ lines at low temperatures was not 
coupled with this effect, roum temperature scans were performed at various strains. The peak height of the diffraction line was found to be constant for the small strain interval of 0 to 0.5 percent, indicating that the observed line broadening was more likely due to line splitting initiated by the phase transformation.

At this point the residual compressive strain exerted on the $\mathrm{Nb}_{3} \mathrm{Sn}$ by the infium sample stage was relieved at $8 K$ by using the mechanical insert to spread the copper wedge poles. The $x$-ray scans over the $(611,532)$ lines weI repeated at different values of the compressive strain and the peak maxima are displayed in Fig. 57. The last curve, at an initial strain of -0.29 percent was achieved by mounting the $\mathrm{Nb}_{3} \mathrm{Sn}$ sample on an OFHC copper plate. The first observation obtained is that the higher strains tend to broacen the temperature range over which the transition occurs. At a strain of -0.641 percent, the transformation starts at approximately $100 \mathrm{k}$ and finishes at $20 \mathrm{~K}$; while at -0.29 percent, the range occurs between 40 and $50 \mathrm{k}$. The intermediate strain values also support this trend. A second result is that the change in peak height between $8 \mathrm{~K}$ and room temperature increases for larger strains. This may be indicative of the number volume of lattice cells in the material which actually undergo the cubic-to-tetragonal transformation. Fig. 58 
shows a similar effect, reported by Vance, in which the elastic constants, as a function of temperature, were measured for different samples of $\mathrm{Al}_{5} \mathrm{~V}_{3} \mathrm{Si}^{22}$ Although diffractior patterns do not measure elastic moduli, possibly the common feature of the two different observations is that they both relate to volume-averaged quantities of the bulk material. The fraction of unit cells wich have transformed acquire new lattice parameters and elastic constants corresponding to those of the tetragonal structure.

Assuming that the data support the occurrence of fractional transformations in the $1 . \omega_{3}$ Sn tape, it should be possible to normalize the plots of Fig. 57 by dividing each curve by its room-temperature peak height (since $\mathrm{Nb}_{3} \mathrm{Sn}$ is known to be completely cubic at ambient temperatures). The resulting cuives should be proportional to the volume fraction of cubic unit cells remaining in the material as a function of temperature. Figure 59 shows the normalized curves with the cubic volume fraction saturating to one at higher temperatures. Strain not only increases the temperature range over which the transformation takes place, but it is also interesting to notice that even below the cubic-to-tetragonal arresting temperatur at which ine phase transition stops, strain acts to 
83

enhance the production of tetragonal unit cells in the material.

In order to investigate further the strain dependence of the phase transition at low temperatures, the cryostat was held at $8 \mathrm{k}$ and diffraction profiles were taken of the $(611,532)$ line at different compressive strains. Figure 60 shows a plot of the peak height versus strain on the $\mathrm{Nb}_{3} \mathrm{Sn}$ ribban, while Fig. 61 repeats this plot with the peak heights normalized by the extrapolated zero strain intensity to display the cubic volume fraction as a function of strain at $8 \mathrm{~K}$. Several observations concerning the strain dependence of the $\mathrm{Nb}_{3} \mathrm{Sn}$ transformation can be made from the last three figures. Extrapolation to higher strains indicates that tro $\mathrm{Nb}_{3} \mathrm{Sn}$ transformation should be complete at a strain of approximately -1.8 percent at $8 \mathrm{~K}$. 5xtrapolation to low strains indicates that $\mathrm{Nb}_{3} \mathrm{Sn}$ may not undergo a phase transformation at zero strain. However, No $3 \mathrm{Sn}$ has a thermal contraction of -0.13 percent betneen 298 and $4.2 \mathrm{~K}$, which may also augment the transfarmation. 


\section{REFERENCES}

Chapter 4

1. Testardi, L. R., Kunzler, 3. E., Levinstein, H. J., and Wernick, J. H., "Unusual Strain Dependence of Ic and Related Effects in A-15 Superconductors," Solid State Commun. 8, pp.. 907-911 (1970).

2. Testardi, L. R., "Structural Instability, Anharmonicity, and High-Temperature Superconouctivity in A-15 Structure Compounds," Phys. Rev. B: 5,4342 (June 1972).

3. Testardi, L. R. "Unusual Strain Dependence of Tc and Related Effects for High-Temperature (A-15 Structure) Superconductors: Sound velacity at the Superconducting Phase Transition," Phys. Rev. B: $\underline{3}$, 95 (Jan., 1971).

4. Testardi, L. R., Kunzler, J. E., Levinstein, H. J., Maita, J. P. and Wernick J. H., "Unusual Strain Dependence of $T_{C}$ and Related Effects for HighTemper; ture (A-15 Structure) Superconductors:

Elastic, Thermal, and Alloy Behavior," Phys. Rev. B: $: 3,107$ (Jan., 1971).

5. Testardi, L. R. and Bateman, T. E., "Lattice Instability of High-Transition-Temperature Superconductors. II Single-Crystal V3Si Results," Phys. Rev. B:154, pp. 402-10 (Feb., 1967).

6. Mailfert, R., Bat.terman, B. N., and Hanak, J. 3., "Observations Related to the Order of the Low Temperature Structural Transformation in $V_{3} \mathrm{Si}$ ana NbzSn," Phys. Status Solidi 32, K67 (1969).

7. Vieland, L. J. and Cohen, R. W., "Evidence for a First-Orcer Structural Transformation in NbzSn," Phys. Rev. Lett. 7, $373-376$ (Feb. 1971).

8. Snirane, G. and Axe, J. D., "Phonon Softening of NbzSn in T Modes," Phys. Rev. B:18, 3742 (Oct. 1978).

9. Kittel, C. Introduction to Solid State Physics, 5th Ed., John wiley, NY, p. 117 (1976). 
10. Battarman, B. W. and Barrett, C. S., "Crystal Structure of Superconducting $v_{3} S i, "$ Phys. Rev. Lett. 13, 390 (Sept., 1964).

11. Mailfert, R., Batterman, B. N., and Hanak, J. J., "Observations Related to the Order of the Low Temperature Structural Transformation in $V_{3} S i$ and Nb3Sn," Phys. Status Solidi 32, K67 (1969).

12. Batterman, B. W. and Barrett, C. S., "Low Temperature Structural Transformation in $\mathrm{V}_{3} \mathrm{Si}, "$ Phys. Rev. 145, 296 (May 1906).

13. King, H. W., "The Mechanism of Phase Transformation in Crystalline Sclids," Proc. of Int. Symposium, Manchester, July 1968, (Institute of Metals 1969), p. 196.

14. Durlu, T. N., "High Voltage Transmission Electron Microscopy Studies of Strain Induced Martensitic in Fe-Ni-C Alloys," Acta. Metall. 26, 1855 (Dec. 1978).

15. Povolotskii, V. D., Zhuravlev, L. G., ano Shteinberg, M. M., "Martensitic Transformation During Deformation of Fe-ivi-Alloys," Met. Sci. and Heat Treat. 19, pp. 434-8 (May 1977).

16. Shimizu, K., Sakhmoto, H., and Otsuka, K., "Phase Diagram As sociater: with Stress Induced Martensitic Transformations ir a Cu-Al-Ni Alloy," jicr. Metall. 12, pp. 771-6 (Sept. 1978).

17. Tadaki, T., Nagaura, T., and Shimizu, K., "Two Different Morphologies ano Crystal Structures of Stress-Induced Martensites in a Ag-45 at. $*$ Cd Alloy," Scr. Metall. 12, pp. 453-6, (May 1978).

18. Kato, M., Monzen, R., End Mori, T., "A Stess-Induced Martensitic Transformation of Spherical Iron Particles in a Cu-fe Alloy, Acta. Metall. 26, pp. 605-l3 (Apr. 1978).

19. King, H. W., Cocks, F. H., and Pollock, J. T. A., "Further Evidence of the Low Temperature Phase Transformation in $\mathrm{Nb}_{3} \mathrm{Sn}_{n}$ and $\mathrm{V}_{3} \mathrm{Si}$," Phys. Lett. 26A, 77 (Dec. 1967). 
20. Cullity, B. D., Elements of $x$-ray Diffraction, Addison-Wesley, Reading, MA, pp. 130-131 (1956).

21. Barrett, C. S. and Massalski, T. B., Structure of Metals Crystallographic Methods, PI inciples, and Data, 3rd Ed., McGraw Hill, NY, pp. 453-464 (1956).

22. Vance, E. R. and Finlayson, T. R., "The Lattice Softening in $V_{3} S i, " 3$. Appl. Phys. 39, 1980

(Mar. 1968). 


\section{CHAPTER 5. CRITICAL CURRENT-STRAIN SCALING LAW ANIS}

CONCLUSIONS

\section{A. Introduction to the Chapter}

The purpos? of this chapter is to formulate conclusions concerning the experimental and analytical results obtained in the previous sections of the current investigation. Thus far, the repart has defined the strain sensitivity of the critical parameters of $\mathrm{Nb}_{3} \mathrm{Sn}$, discussed the development of an improved method of calculatirg the triaxial state of strain on the $\mathrm{Nb}_{3} \mathrm{Sn}$ regions within a multifilamentary composite, and probed the underlying mechanism of the strain sensitivity, via low temperature $x$-ray diffraction, to find a linkage between the martensitic phase transformation and strain. The output strain values, as determined by the MAXIMSUPER program, are inserted into appropriate scaling laws that relate the functional dependence of the critical current density $J_{c}$ to strains present on the superconductor. This chapter utilizes the experimental results of chapters 3 and 4 to formulate the $J_{S}$ (E) scaling laws. The first step is to attempt to find an analytical expression which relates the volume fraction of niobium-tin transformed, 
at low temperatures, to the amount of applied strain; then the effect of the two different lattice cell properties on $\mathrm{H}_{\mathrm{C} 2}$ and $\mathrm{J}_{\mathrm{C}}$ are explored.

B. The influence of Strain on the Cubic-Tetragonal

\section{Transformation}

The observation that the martensitic phase transition is continuous indicates that it may be amenable to treatment as a second order transformation. Following a derivation by Landau, one can write the Gibbs free energy of the double phase $\mathrm{Nb}_{3} \mathrm{Sn}$ as a power series expansion of the tetragonal volume fraction ${ }^{1}$

$$
G(\cdot, T, n)=G_{0}(\cdot, T)+A(\varepsilon, T) n^{2}+C(\cdot, T) n^{4}+\cdots \cdot(5-1)
$$

in which the coefficients $G_{0}, A$, and $C$ are functions of both strain and temperature. Cubic and first order terms were shown to vanish for second order transformations that resulter in changes in the parent phase crystal symmetry. The tetragonal volume fraction that minimizes this expression is determined by equating the derivative $\partial G / \partial n$ to zero, which yields

$$
n_{\mathrm{t}}^{2}=-\frac{A(\varepsilon, T)}{2 C(?, T)}
$$


89

Since $\mathrm{Nb}_{3} \mathrm{Sn}$ is operated at $10 w$ temperatures and small strains $A$ can be expanded in a two variable Taylor series, about $T$ and $c$ equal zero.

$-A(E, T)=A_{0}(0,0)+\alpha \varepsilon+\frac{1}{2} B \varepsilon^{2}+\gamma T+\frac{1}{2} \delta T^{2}+v E T+\ldots(5-3)$

At temperatures below $20 \mathrm{~K}$, the tetragonal volume fraction appears to be relatively constant with temperature and nearly linear with strain, as shown in Figs. 59 and 61. Therefore, the series in equation 3 is truncated after the first four terms, and the denominator of equation 2 is approximated as a constant (set equal to unity). The tetragonal volume fracture now becomes

$$
r_{t}=\sqrt{A_{D}+\alpha E+\frac{1}{2} B E^{2}+r_{T}}
$$

Notice that if $\mathrm{Nb}_{3} \mathrm{Sn}$ does not transform in the total absence of strains, then $A_{0}$ should be zero. However. even without external stresses, the material should undergo thermal sontraction, making it possible to interpret the first and fourth terms as the thermal residual strain. Equation 4 can be written as

$$
n_{t}=\sqrt{\alpha \varepsilon+\frac{1}{2} \beta \varepsilon^{2}+\alpha \Delta T}
$$


where $\alpha \Delta T$ is the $\mathrm{Nb}_{3} \mathrm{Sn}$ thermal contraction between reaction temperature and $4.2 \mathrm{~K}$. The corresponding cubic volume fraction is given by

$$
\eta=1-\sqrt{x i+\frac{1}{2} \varepsilon \varepsilon \varepsilon^{2}}+a t \mathrm{~T}
$$

C. The Effe, $C$ of Strain on $J_{C}$ and $H_{c 2}$

In inis soction, an attempt will be made to derive the functional relaionship between strain and the critical current for type II superconductors. The first step is to obtain an expression for $J_{c}$ (b); this is done with the ait of a Gerivation given by Kramer, which yielded that the pinning forse on if flux line is:

$$
F(h)=\frac{0.56}{\left(1-a_{0} \sqrt{6}\right)^{2}}\left(\frac{H_{c / 2}^{5 / 2}}{k^{2}}\right) n^{1 / 2}(1-n)^{2}
$$

for type I I hard supecunductors in which $h$ is the redurec magnetic field strength, the ratio of the applied magnetic ficld to that of the ipper critical field $\mathrm{H}_{1}=\mathrm{H}_{\mathrm{a}} / \mathrm{H}_{\mathrm{CZ}} \mathrm{2}^{2}$ The variables $k, a_{0}$, and $f$ are the Ginzburg-tandas parameter, the flux line lattice spacing, and the pinningsite density. Luhman later modified this expressior by noting that the flux line spacing is rolated to the quantum flux unit $\phi_{0}$ by: ${ }^{3}$ 


$$
\begin{aligned}
& a_{0}=\left(\hat{o}_{0} / H_{d}\right)^{1 / 2} \text { in which } \\
& \dot{*}_{0}=\frac{n c}{2 e}=2.07 \times 10^{-7} \text { gauss }-c^{2}{ }^{2}
\end{aligned}
$$

Equation 7 now becomes

$$
F(h)=\frac{0.56 H_{a}^{1 / 2}\left(H_{c 2}-H_{a}\right)^{2}}{\left[1-\left(\frac{\phi_{o}}{H_{a}}\right)^{1 / 2}\right]^{2}{ }^{2}}
$$

when the current in the superconductor reaches the critical current. the pi.nning force is equal to the Loreniz force:

$$
F_{L}=J_{C} \times H_{0} C
$$

Equations 9 and 10 yield the critjcal current density

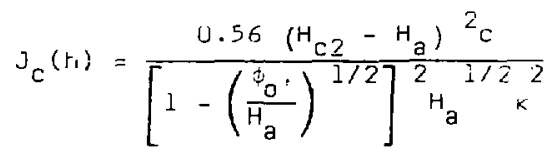

The major contributors to the pinning sites are the No ${ }_{3}$ Sr. grain boundaries; since these are relatively insensitive to small strains 2 , the pinning-site density, is a constant. Therefore, $H_{c_{2}}$ and $k$ are the only strain dependent paraneters that determine the critical current density. Further insight conceining the physical roles of 
$\mathrm{H}_{\mathrm{C} 2}$ and r can be obtained from the Ginzburg-Landau differential equation:

$$
\therefore+\cdots+\left.\right|^{2}+\frac{1}{2 m^{*}}\left(\frac{n}{\bar{i}} \overline{\bar{\gamma}}-\frac{e^{*}}{\mathrm{c}} \bar{A}\right)^{2}=0
$$

in which the coefficients i' and $k^{\prime}$ are functions of temperature, $A$ is the magnetic vector potential. $|\Delta|^{2}$ is the density of supercorducting electruns, and both $m^{*}$ and $e^{*}$ correspond to the mass and charge of the superconducting Cooper electron pairs. ${ }^{4}$ Near the critical current, the density of the superconducting electrons is small and equation 12 can be linearized to become

$$
\left(\frac{\bar{T}}{\bar{i}}-\frac{2 n \bar{A}}{0}\right)^{2} \cdot=-\frac{2 m * u}{h^{2}}=\frac{1}{\bar{\zeta}^{2}}
$$

in which : is the coherence length. For a bulk sample in the presence of a uniform field $\mathrm{H}$ in the $e_{z}$ direction, a possible gage choice is

$$
\vec{A}=A_{y} \dot{e}_{y}=H x \dot{e}_{y}
$$

Inserting equation 14 into 13 yields

$$
\left[-v^{2}+\frac{4 \pi i}{\phi_{0}} H x \frac{\partial}{\partial y}+\frac{2 \pi H}{\phi_{0}} x^{2}\right] \psi=\frac{1}{y^{2}} \psi
$$

which has as eigenfunction solutions the Hermite polynomials as functions of $x$ and is periodic in $y$ and $z$. 
$\cdot \cdot e^{i k} y^{y} e^{i k z z} f(x)$

Surstituting equation 16 into 15 produces

$$
-F "(x)+\left(\frac{2 y H}{\sigma_{0}}\right)^{2}\left(x-\frac{K y+0}{2 \pi H}\right)^{2} f=\left(\frac{1}{i^{2}}-K_{z}^{2}\right) i
$$

The eigenvalues are those of a harmonic oscillator with cyciotron frequency

$$
E_{n}-(n+1 i j) n \cdot c=(n+1 / 2) n \frac{2 e H}{m^{*} c}
$$

which are equal to the energy cafactor of equation 17

$$
(n+1 / 2) \hbar \frac{2 e H}{m^{*} c}=\frac{\pi^{2}}{2 m^{*}}\left(\frac{1}{r^{2}}-k_{z}^{2}\right)
$$

Equation 19 derines the magnetic field able to nucleate inside the bul!' superconductor. The nighest field value, Hic2, occurs when $K_{z}=0$ and at the $y$ round state energy $(n=0)$.

$$
H_{c 2}=\frac{\kappa_{c}}{2 \mathrm{e} \xi^{2}}=\frac{\phi o}{2 \pi \xi^{2}}
$$

The corresponding solution at $\mathrm{H}_{\mathrm{c} 2}$ is

$$
\forall(x, y)=\sum_{n} C_{n} \exp \left(i K_{n} Y\right) \exp \left[-\frac{\left(x-x_{n}\right)^{2}}{2 \varepsilon^{2}}\right] \text { with }(5-2.1)
$$




$$
x_{n}=\frac{k_{n}: 0}{2 r}
$$

The soluciun tiven uy equatiun 21, as noted oy Abrikusav represents a two virensional lattice structure at juper-

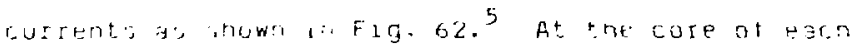
current ripa is tre penetrateo magnet.1c tiux ine quantum. Far minirum ereagy densit:, tree constants co have been duterman' is yifis a lotticp that is hexagonelly

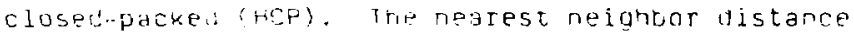

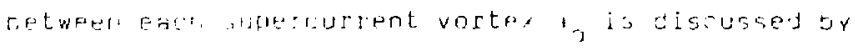
tinktiall ard onown to be:

$$
a_{0}=\left(\frac{4}{z}\right)^{1 / 4}\left(\frac{0}{11}\right)^{1 ! 2} \geq
$$

Now the cohwence length $i$ is a materiz? yroperty: i the applied tield strength sends so many flux Iines into the superconductor trat it is impossiale to arranye them! in a HCP structure, the supercurrents overlap, supercunductivity is destroyed, and the material becomes normai. we can see i $10 m$ equation 23 that this occurs when $H$ increases such as tu make a approach $\xi_{0}$

Thus far the upper critical field has been shown to be a function af the coherence Iength in equation 20 , and; in turn dirterinines the spacial width of the 
cupperconducting electron pair wave packet, as shown in equation 21. The goal of these efforts is tu show that $\mathrm{H}_{\mathrm{C} 2}$ odtains its strain dependence through the coherence Jength, which is related to the elastic properties of the superconducting material. This relationship stems from the fact that : is a function of the fermi velocity

$$
\xi=\frac{\hbar_{L} v_{f}}{k T_{C}}
$$

The superconoucting electrons are bound into cooper pairs via the electron-phonon-electron coupling. Essentiailly one electron, transversing through the crystal, leaves a distortion of the lattice in its wake, another electron is attracted to the surplus positive charge of the oeformation and hence behaves as if it is coupleo to the first electron (Fig. 63). Obviously, the lattice distortion cannot propagate faster than the material sonic velocity, hence if the electrans are accelerated to higher speeds, the pair bonding is destroyed. The maximum kinetic energy allowable to the cooper electron pair is simply equal to the condensation energy gap at $\mathrm{o} k$

$$
1 / 2 M V_{S}^{2}=\Delta(0)=1.764 \mathrm{kI}_{\mathrm{C}}
$$


Only electrons close to the Fermi surface participate ir. - he supercurrent, so equations 24 and 25 can be combined to yield

$$
=\frac{h}{M V_{S}}
$$

wich relates the coherence lergth to the maximum electron velocity, i.e., the material sonic velocity. The longitudinal and transverse velocities are usually equal to particular summations of the elastic constants, with the sum dependent on the crystallographic direction of the traveling wave. An isotropic average velocity can de expressed as

$$
\cdot v_{s}=\left(\frac{\sum_{i j} a_{i j} c_{i j}}{a}\right)^{1 / 2}
$$

where the values of $C_{i j}$ are material elastic modulj and $\therefore$ is the density. Notice that a stiffer material with migh moduli is more favorable to producing a smaller conerence length. Hence the upper critical fies $\mathrm{u}_{\mathrm{C}} \mathrm{H}_{\mathrm{s}}$ is also related to the elastic constants via equations 20 , 26, and 27 .

$$
H_{c 2}=\frac{o^{M} v_{s}^{2}}{h^{2}}=\frac{m_{0} M^{2}}{2 h^{2}}\left(\sum_{i j} \frac{a_{i j} c_{i j}}{i}\right)
$$


Tr.e upper critical field is, therefore, a linear function of the elastic constants. Combining equations 24,26 , and 27 yields an expression for the critical temperature $T_{C}$.

$$
T_{C}=\frac{M V_{s}^{2}}{2 K}=\frac{M}{2 K}\left(\sum_{i j} \frac{a_{i j} c_{i j}}{i}\right)
$$

which is also linear with the material stiffness.

The phase transition in $\mathrm{Nb}_{3} \mathrm{Sn}$ involves a softening of the lattice at low temperatures, which leads to structural instability; this $n$ turn causes the cubic-tocetragonal transformation. The results of the last chapter indicate chat the transformation is partial with only a certain volume fraction $\eta_{t}$ of the lattice cells undergoing the transition. Furthermore, the fraction changed can be incremented by the auplication of external strains. If the elastic moduli measurements obtained by vieland are indicative of those arising from samples of varying lattice parameters and hence internal strains, then the elastic constants may be volume averages of the two crystal structures present (see Fig. 58). The values of $C_{i j}$ of expressions 28 and 29 are related to strain by equations 5 and 6 .

$$
\left\langle C_{i j}\right\rangle=c_{i j t} r_{1}(t)+c_{i j c} \eta_{c}(E)
$$

in which the average moduli are determined by a "rule of 
mixtures" calculation of the volume fraction of cubic and tetragonal cells and their corresponding moduli.

Guided by these considerations $H_{c 2}$ for the transforminj $\mathrm{ND}_{3} \mathrm{Sr}$ may also be written as a strain dependent volume average

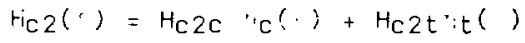

There is additional experimentas evidence trat support; the modei of two coexisting phases in $\mathrm{Nb}_{3} \mathrm{Sn}$ each riaving a contribution to its superconducting properties. Mathias and Dayan have observed double trarsition temperatures in some samples of $\mathrm{Nb}_{3} \mathrm{Sn}$, and Forer has showr. that the tetragonal structure has a lower upper critical field $\mathrm{H}_{\mathrm{C} 2^{-6-8}}$ This proposed thecry predicts lcwer critical parameters for the tetragonal structure due to its softer tattice.

A return to the critical current density scaling law of equation li shows that the Ginzburg-Landeau order parameter $k$ must also be strain dependent because of the relationship

$$
\therefore=\lambda / s(\therefore)=\frac{{ }^{\lambda} \mathrm{mV}_{5}}{r_{1}}=\frac{\pi \lambda m}{h} \sqrt{\frac{\sum^{a} i_{j}^{c} j_{j}}{f}},
$$

in which $\lambda$ is the penetration depth. The critical current versus strain scaling law used in the MAXIMSUPER 
program combines equation ll with tine str $\exists$ in sensitive functions of $\mathrm{K}$ and $\mathrm{H}_{\mathrm{C} 2}$

$$
\begin{aligned}
& { }_{c}\left(\text { f.) } \frac{0.55\left(\mathrm{H}_{\mathrm{C} 2}(\varepsilon)-\mathrm{H}_{\mathrm{a}}\right){ }^{2} \mathrm{c}}{\left[1-\left(\frac{\phi_{0}}{\mathrm{H}_{\mathrm{a}}}\right)^{1 / 2}\right]^{2} \mathrm{H}_{\mathrm{a}}^{1 / 2} \mathrm{k}^{2}(\varepsilon)} \text { with } \quad\right. \text { (5-33) } \\
& H_{c 2}(\varepsilon)=H_{c 2 t} \sqrt{\alpha \varepsilon+\frac{1}{2} E r^{2}+x A T} \\
& +H_{c 2 c}\left(1-\sqrt{a t+\frac{1}{2} \delta r^{2}+\cdot 2 \cdot T}\right) \\
& r(b)=t \sqrt[4]{x t+\frac{1}{2} B \varepsilon^{2}+a t T} \\
& +r_{c}\left(1-\sqrt[4]{a s+\frac{1}{2} j c^{2}+u \Delta T}\right)
\end{aligned}
$$

The normalized critical current of a conductor in a tensile test is then equation 33 , divided by $J_{c}\left(\varepsilon_{m}\right)$, the current density occurring with the smallest strain on the $\mathrm{Nb}_{3} \mathrm{Sn}$ during the test;

$$
\frac{I_{c}(\varepsilon)}{I_{c}\left(E_{m}\right)}=\frac{\kappa^{2}\left(\varepsilon_{m}\right)}{k^{2}(\varepsilon)}\left(\frac{H_{c 2}(\varepsilon)-H_{a}}{H_{c 2}\left(\varepsilon_{m}\right)-H_{a}}\right)^{2}
$$

with tne unknown constants in equations 34,35 , and 36 determined by fitting the formulas to the universal 
degradation curves of Fig. 5 by means of a least squares data fitting program (See Appendix 2).9

\section{Conclusions and Suggestions for Future Study}

The primary objective of this study was to develoo an improveu method of calculating the stresses and strains in the $\mathrm{Nu}_{3} \mathrm{Sn}$ zones in a multifilamentary composite during the course of a tensile test. It is possibie to simulate cumpletely the test results with a mathematical model, if the analysis also includes a mechanism that couples the strain state of the $\mathrm{Nb}_{3} \mathrm{Sn}$ with the degradation of its critical parameters, the most important being tne critical current density $J_{C}$. The relationship of $J_{c}$ to strain required additional experimentation into the nature of the low temperature marlensitic phase cransformation; this was accomplished by $x$-ray diffraction techniques. The major conclusions and summary of findings revealed by this work are tabulated helow:

1. The author has completed the development of a computer program MAXIMSUPER that calculates the threedimensional strain field presert in the $\mathrm{Nt}_{3} \mathrm{Sn}$ regions in a multifilamentary superconducting composite arising from both the residual thermal contraction of the composite materials from reaction temperature down to 
$4.2 \mathrm{~K}$ and those additional strains resulting from the axial loading of the conductor during an unaxial tensile test.

2. A preliminary application of the program revealed a major difference in the triaxial strain states of two conductor designs: concentric material filaments, in which the bronze acts as the core, and niobium-cnre filaments. The code predicted higher tangential strains (radial and azimuthal) for the bronze-core geometry.

3. Experimental measurements of the critical parameters $J_{c}$ and $T_{c}$ for the $t w$, conductor designs indicated a more pronounced suppression of $J_{c}$ and $T_{c}$ for the bronze-core multifilamentary conductors, thereby verifying the anaiytic predictions of the conputer program.

4. In order to relate the influence of strain on the critical parameters, additjonal experiments were performed to ascertain the dependence of the martensitic phase transformation on strain. The results were consistent with a partial transformation in which $\mathrm{Nb}_{3} 5 \mathrm{n}$ was composed of both the cubic and tetragonal phases at low temperatures. The application of strains to the compound enhanced the vo'ume fraction of tetragonal lattice cells. 
5. A thearetical model was developed to show that critical parameters $J_{C}, H_{c 2}$, and $T_{C}$ are related to the superconducting material sonic velocities and nence are dependent on the elastic moduli of the cubic and tetragonal phases present in $\mathrm{Nb}_{3} \mathrm{Sn}$.

6. It was postulated that the tetragonal phase has lower values of its citical parameters than the cubic because of its softer moduli. Therefore, the strain sensitivity of $J_{C}, H_{C 2}$, and $T_{C}$ is due to the strain-assisted production of tetragonal lattice cells at low temperatures.

7. Expressions were oerived that relate the criticad parameters to the strain incremented volume fraction of tetragonal phase. These functions comprise the $J_{c}$-strain scaling laws utilized in the computer progrem.

Improved focusing techniques, langer wavelength $x-T$ ay radiation, and diffraction pattern srans of higher (roo) planes should yield enhanced resolution and more dramatic splitting of the diffraction lines Juring the transformation. The ipparent strain enhancement of the transition in $\mathrm{Nb}_{3} \mathrm{Sn}$ should also be investigated in the other Als superconductors. This includes the germanium campounds, such as $\mathrm{V}_{3} \mathrm{Ge}$ and $\mathrm{Nb}_{3} \mathrm{Ge}$, which, according to the results 
of Testardi and others, experience a hardening of the elastic constants at low temperature. ${ }^{10-14}$ The theory presented in this report predicts that the critical parameters of these compounds should increase with strain.

Calculations of the strain state in the $\mathrm{Nb}_{3} \mathrm{Sn}$ layer, using codes such as MAXIMSUPER, require more somplete data on the mecnanical properties of the composite components for additional accuracy. This incluces temperature dependent properties, such as stress-stiain curves, Poisson ralios, elastic moduli, and thermal expansion coefficients at both high and low temperatures. Thus far, good agreement between the MAXIMSUPER predictions and experiminta! results indicate that the code may be suitable for superconducting composite design applications. 
REFERENCES

Chapter 5

1. Landau, L. D. and Lifshitz, E. M., Statistical

Physics, Pergamor Press, London (1958).

2. Kramer, E., "Scaling Laws for Flux Pinning in Hard Superconductors," J.Appl. Phys 44, pp. 1360-1370 (Mar. 1973).

3. Luhman, $T$. and Pande, C.: "Flux Pinning in Bronze Processed Nb3Sn," J. Appl. Fhys. 47, pp. 1459-1463 (Apr. 1976 ).

4. Tinkham, M., Introduction to Superconductivity, MCGraw-Hill, $\overline{N Y}(1975)$.

5. Abrikosov, A. A., "Or, the Magnetic Properties of Superconductors of the Second Group," Sov. Phys.-

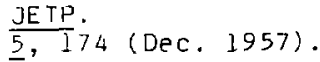

6. Matihias, B. T., Corenzwit, E., Cooper, A. S., and Longinotti, L. [u., "Instatilities of High Temperature Superconductors, ir reprinted from Proc. of the National Academy of Sciences 68, pp. s6-57 (Jan. $1971)$.

7. Dayar, M., Goldman, A. M., and Huang, C. r.: "rouble Superconducting Transitions in Single rrystals of v3Si," Phys. Rev. Lett. 42, 335 (Jan. 1979).

d. Foner, S. and MCNiff, E. J., "Anisotrophy of $\mathrm{H}_{C}$ 2 in Single Crystal $\mathrm{Nb}_{3} \mathrm{Sn}$ and $\mathrm{V}_{3} \mathrm{Si}$ at Hiyh Magnetic Fields: Limitations of Linear Chain Model," Phys. Lett. 58A, pp. 318-320 (Sept. 1975).

9. Olsson, D. M.: "A Sequential Simplex Program for Solving Minimization Problems," J. Quai. Technol. ó. 53 (Jan. 1974).

10. Testardi, L. R., Kunzler, J. E., Levinstein, H. J., and Hernick, J. H., "Unusual Strain Dependence of TC and Related Effects in A-15 Superconductars," Solid state Commun. 8, pp.. 907-911 (1970). 
11. Testardi, L. R., "Stru tural Instab.lity, Anharmonicity, and High-Tempersture Supercondsctivity in A-15 Structure Ccmpounds," Phys. Rev. B: 5,4342 (June 1972).

12. Testardi, L. R. "Unusual Strain Dependence of $T_{C}$ and Related Eifects for High-Temperature ( $A-15$ Structure) Superconductors: Sound velocity at the Superconducting Phase Transition." Phys. Rev. B: $\underline{3}$, 95 (Jan., 1971).

13. Testa:di, L. R., Kunzler, J. E., Levinstein, ti. J., Maita, J. P. and Wernick J. H., "Unusuai Strain Depenoence of $\mathrm{T}_{C}$ and Related Effects for Highirmperature (A-15 Structure) Superconductors: Elastic, Thermal, and Alloy Behavior," Phys. Rev. B: 3., 107 (Jan., 1971).

14. Testardi, L. R. and Bateman, T. B., "Lattice Instability of High-Transition-Temperature Supercorid'ctors. II Single-Crystal $V_{3} S i$ Results," Phys. Hev. 154, pp. 402-10 (Feb., 1967). 


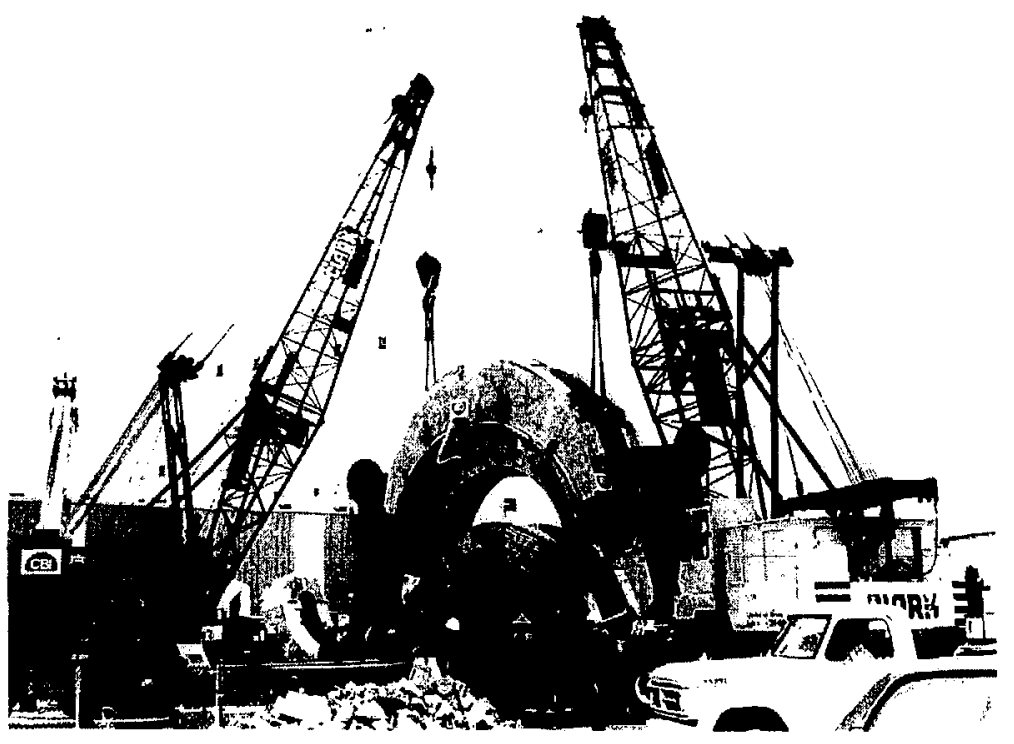

Fig. 1. Construction of the MFTF magnet. It is currently the world's largest superconducting magnet; capable of storing $409 \mathrm{MJ}$ at $7.68 \mathrm{~T}$ maximum field. 


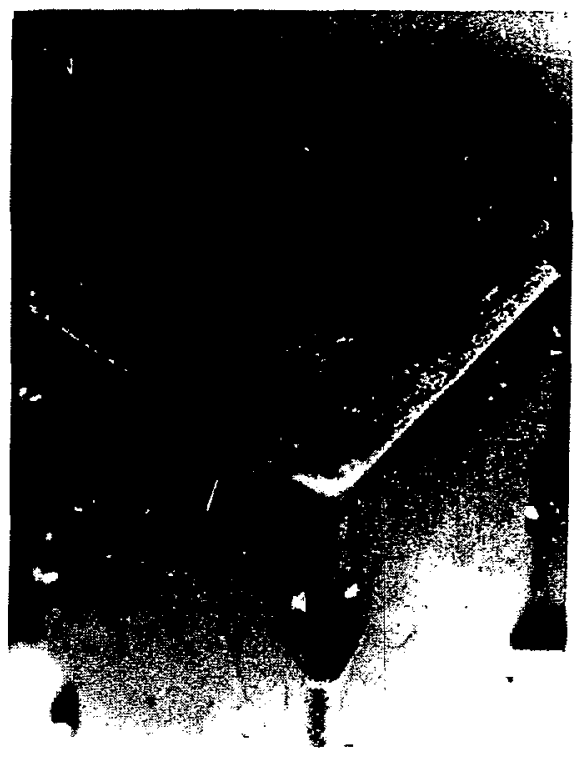

Fig. 2. The MFTF superconducting $\mathrm{Nb}-\mathrm{Ti}$ conductor. The composite consists of Nb-Ti filaments in a copper matrix surrounded by an external copper stabilizer. 


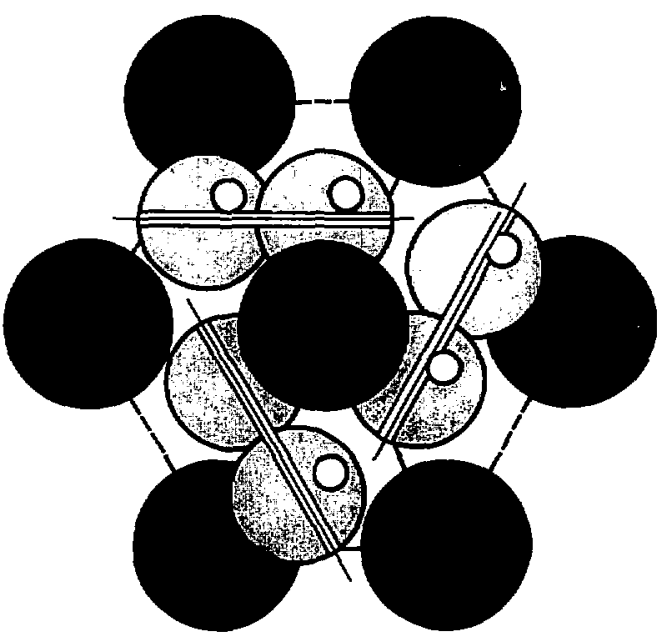

Fig. 3. The unit cell of the A-15 crystal structure for $A_{3} B$ compounds. Currently, the highest known $T_{C}$ superconducting compounds are in this group. The smaller A atoms form orthoganal chains. 


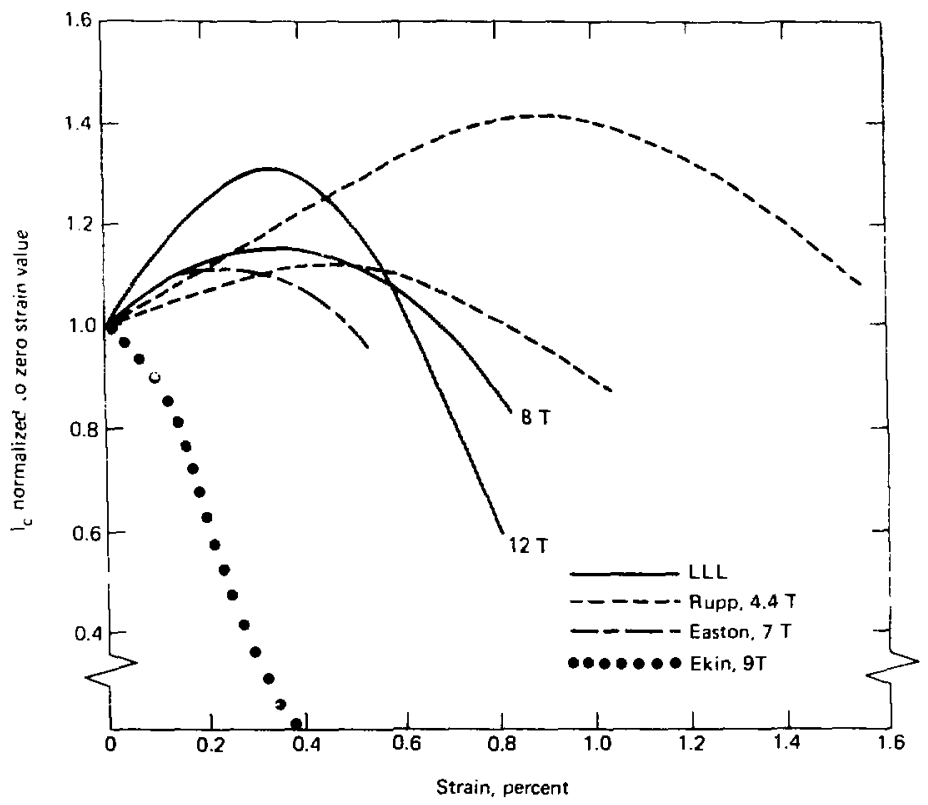

Fig. 4. Critical current versus strain curves. A comparison of the results of critical current-strain measurements on monolithic conductors by different investigators shows that widely varying data has been reported (D. Deis, Aug. 1977). 


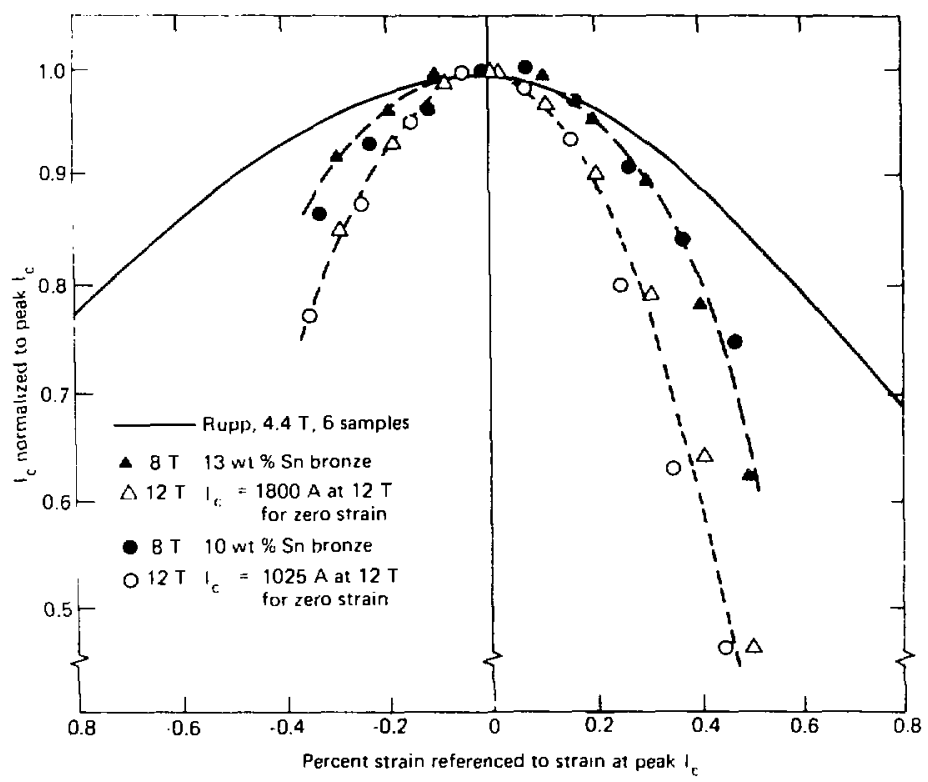

Fig. 5. izpp noritai i jit critical current-strain curves. The crilical current obtained at fixed magnetic field for various strains can be normalized to the peak current and intrinsic stivin. Thio results are from Fig. 4 (D. Deis, Aug. 1977). 


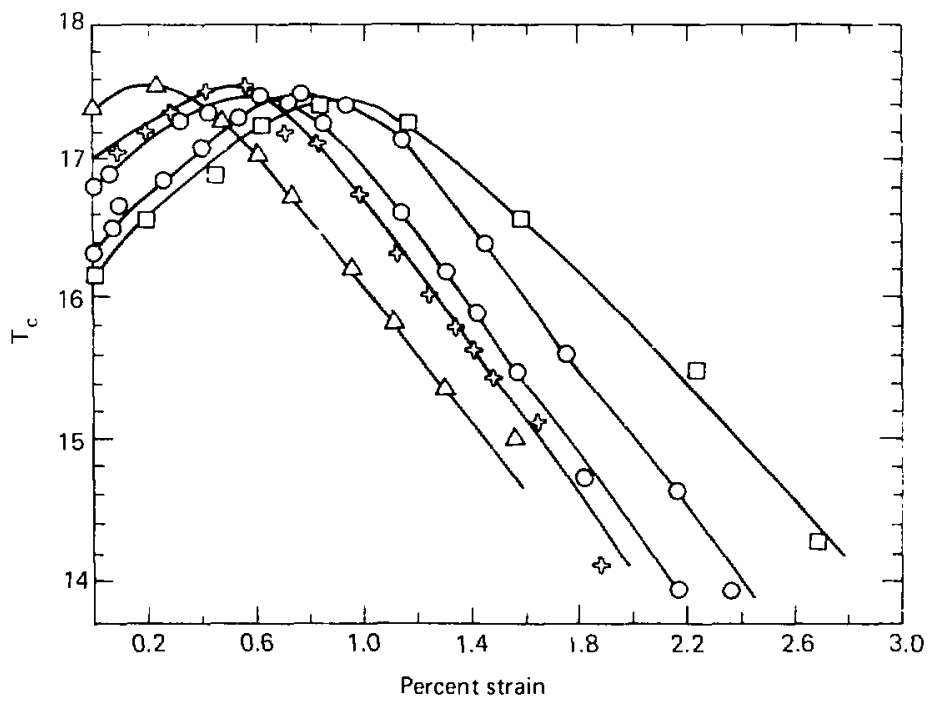

Fig. 6. The transition temperature as a function of strain. The effect of strain on the $T_{C}$ of various monofilament conductors with differing bronze-to-niobium ratios, Bz:Nb $=1.1$ to 44 (T. Luhman, Dct. 1978). 


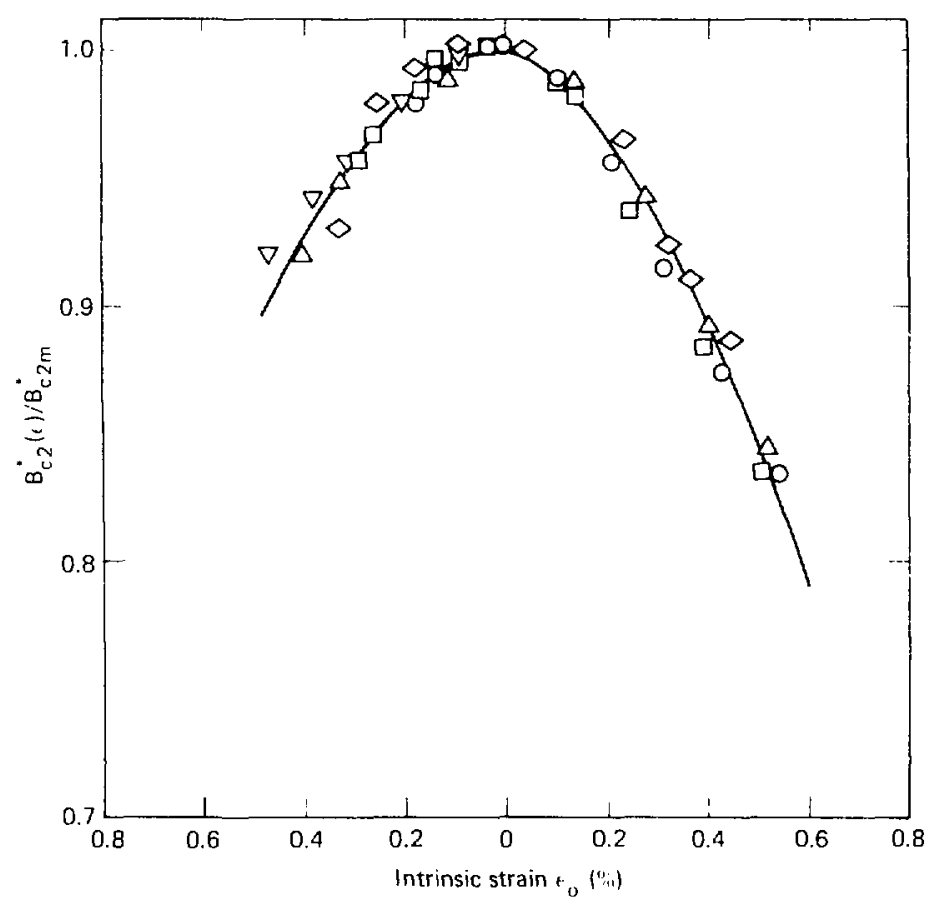

Fig. 7. The upper critical field as a tunc .ion of strain. The effect of ritain on the upper critical i ield of various conductors +,otted using Rupp normalizatio (\%. Ekin, 1980). 


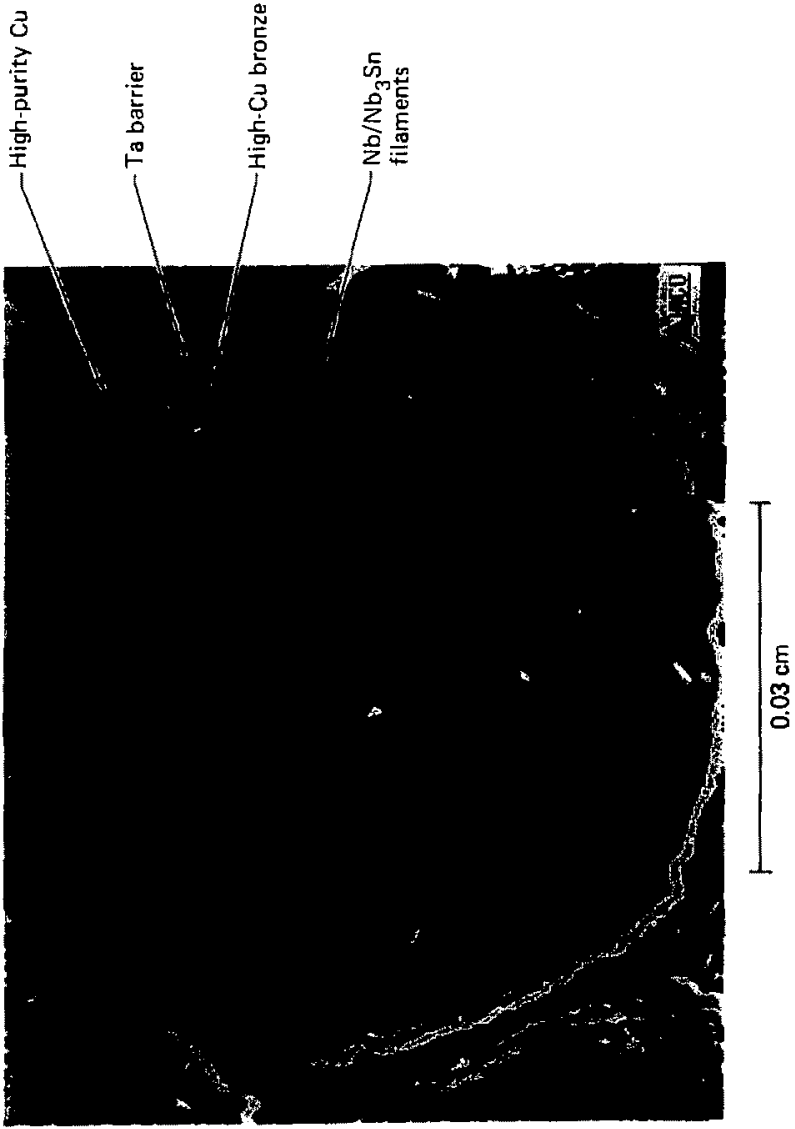

Fig. 8. Cross section of a multifilamentary conductor. A cluster of $\mathrm{Nb} / \mathrm{Nb}_{3} \mathrm{Sn}$ multifilaments in a bronze matrix surrounded by tantalum diffusion barriers to prevent tin from contaminating the OFHC copper stabilizer. The five micron diameter fllaments consist of niobium cores with an $\mathrm{Nb}_{3} \mathrm{Sn}$ outer ring. 

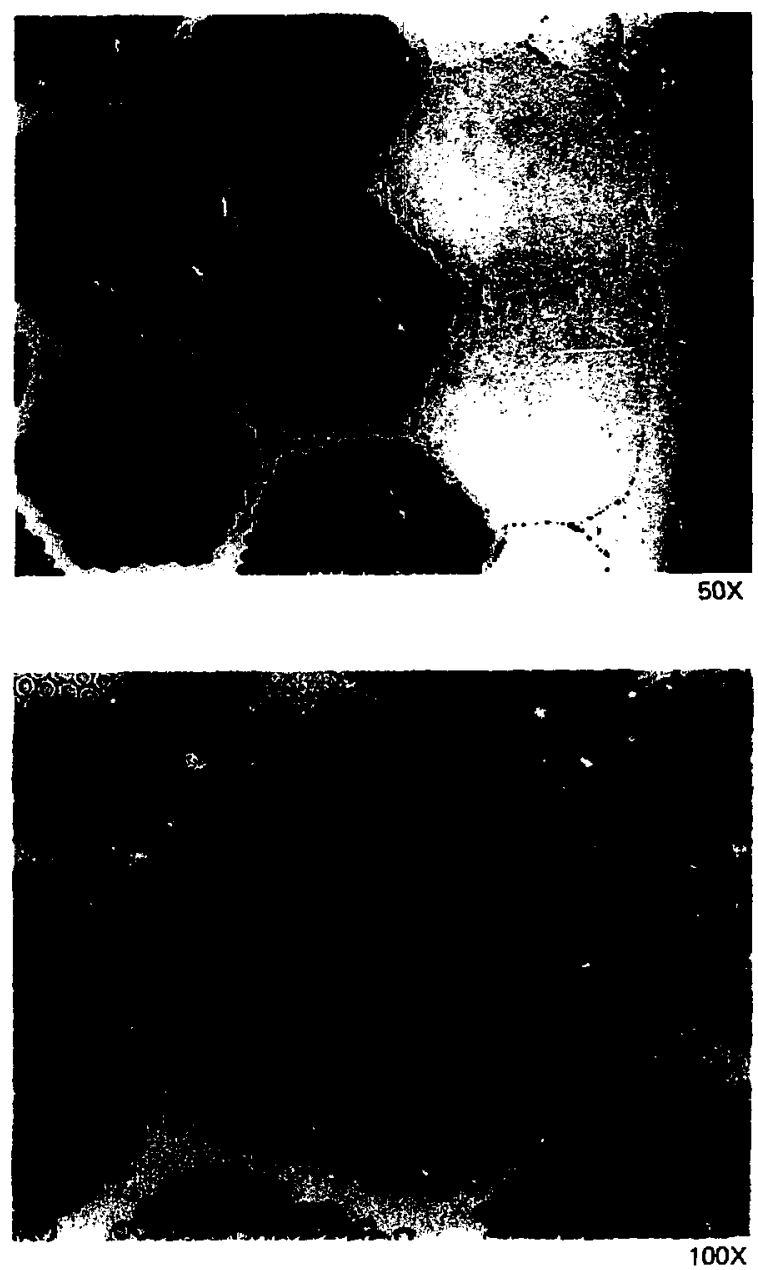

Fig. 9. Cross section of another multifilamentary conductor design. These clusters show niobium tubes in a ccpper matrix with bronze cores (internal bronze geometry). 


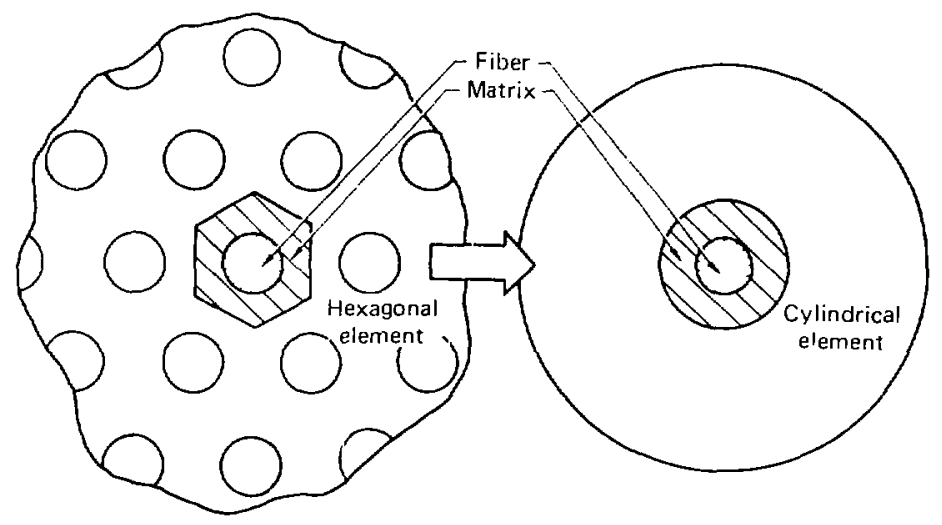

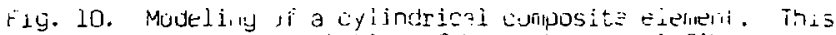
rigure shows a represertition of how a hexagonal fiber yumposite filament and its lucal environnent is mathemiticilly nodelea as a cylindrical elenent (L. Eoert, June 1969). 
116

Fig. 11. Internal niobium-core filaments shown distorted from the manufacturing process. The dark cavities are voids formed during the diffusion reaction in which the tin is depleted from the bronze matrix. 


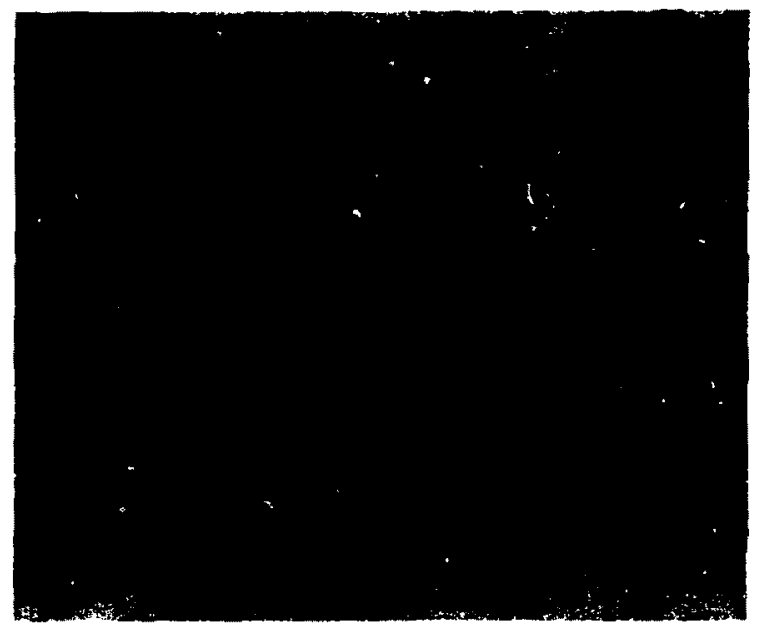

Etched 500X

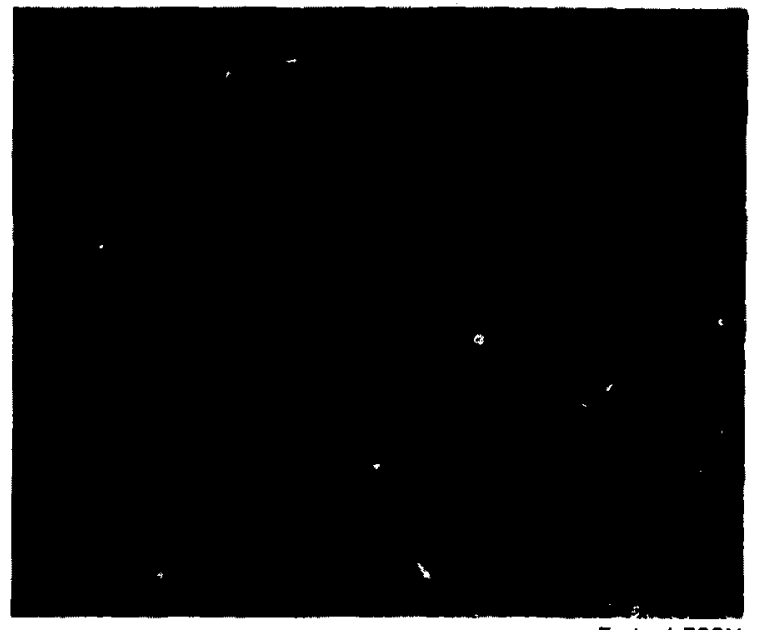


117

Fig. 12. 1500x photomicrograph of an internal bronze-core conductor design. Several filaments are shown here. The inner dark rings are $\mathrm{Nb}$ Sn layers (approximately 1 micron thick). The outer rings are unreasted niobium surrounded by high purity copper. 


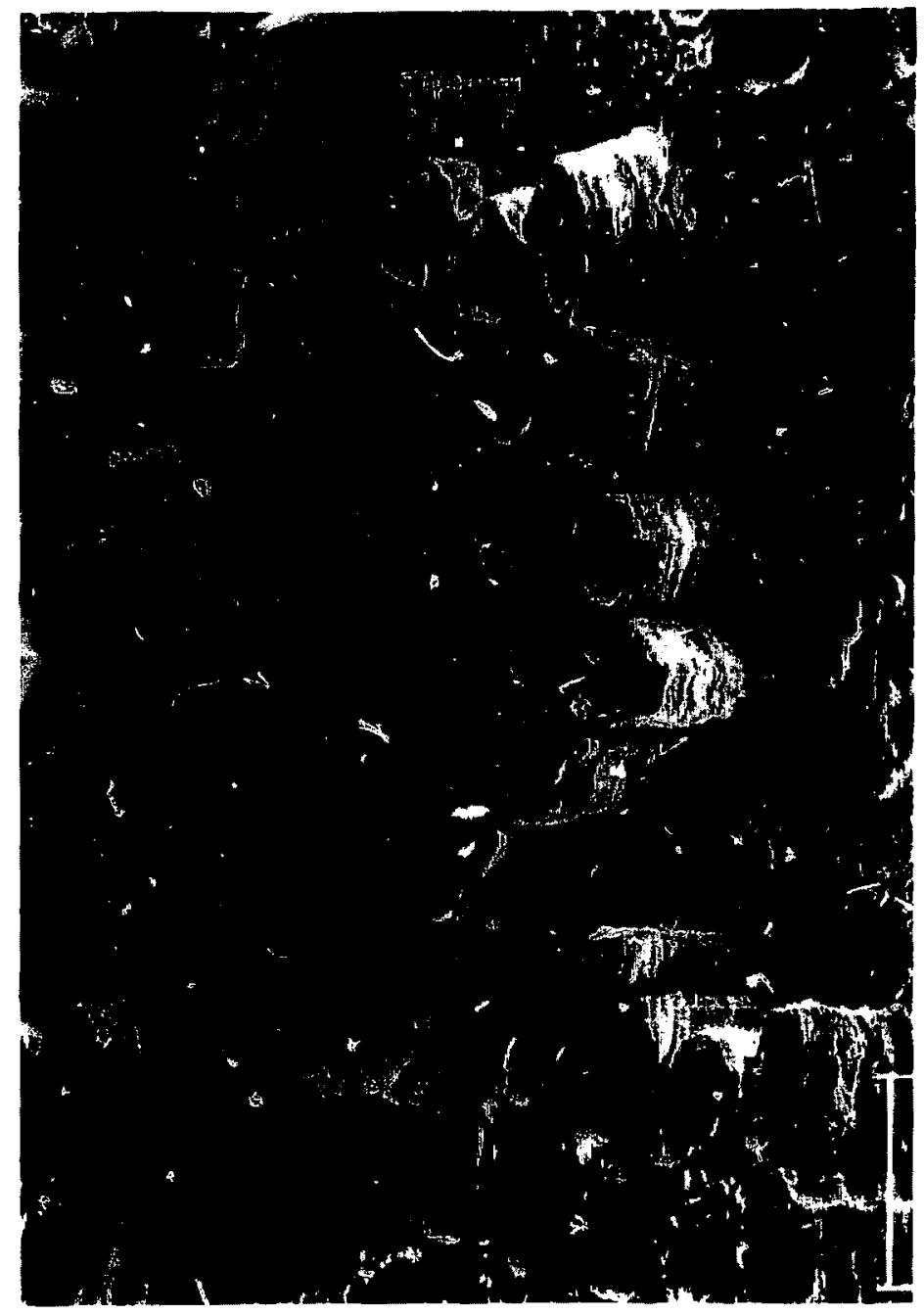


118

Fig. 13 Several clusters of internal nicbium-core filaments surrounded by tantalum barriers. 

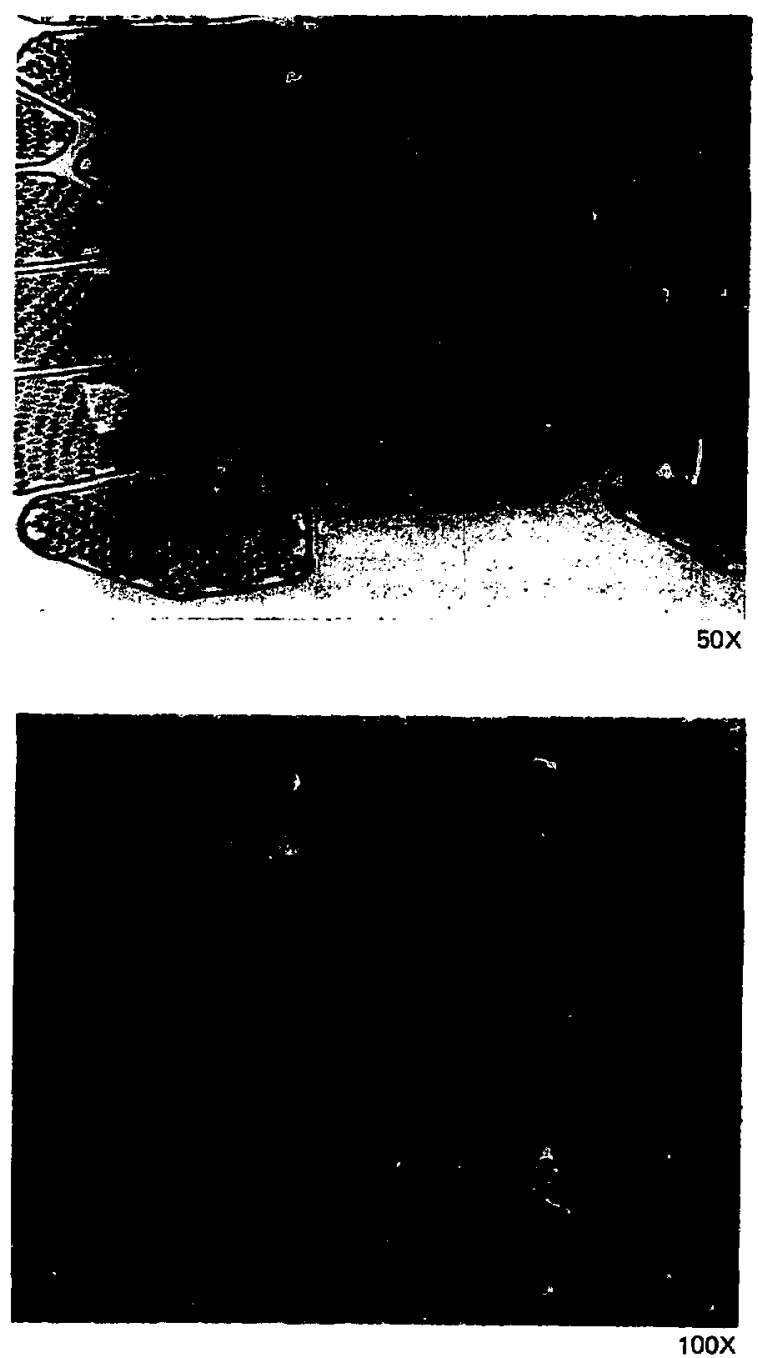


\section{9}

Fig. I4. Modeling of the interna! bronze- and niobium-core conductor designs. The schematic shows the internal niobiumand bronze-core filament geometries and the tangential strain components present on the Nb3Sn zones. These conductor designs are mathematicaliy modeled into the MAXIMSUPER computer program. 


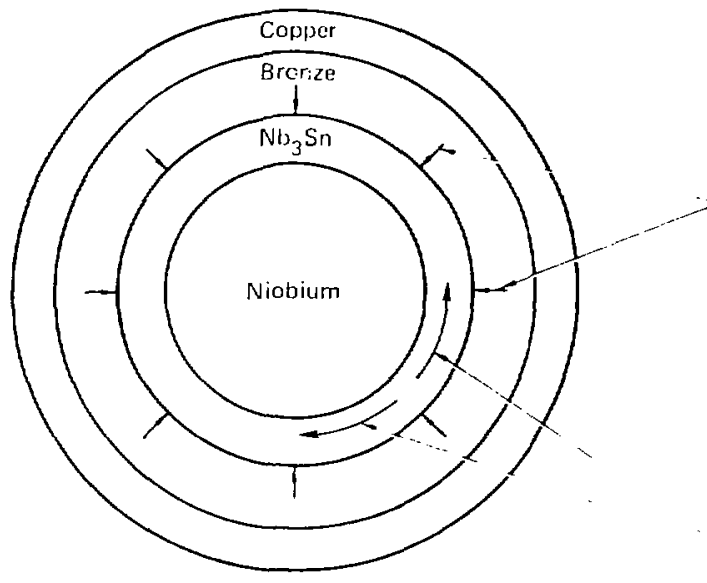

Niobium core filament
Radial strain component ',

- Azımuthal strain component ',

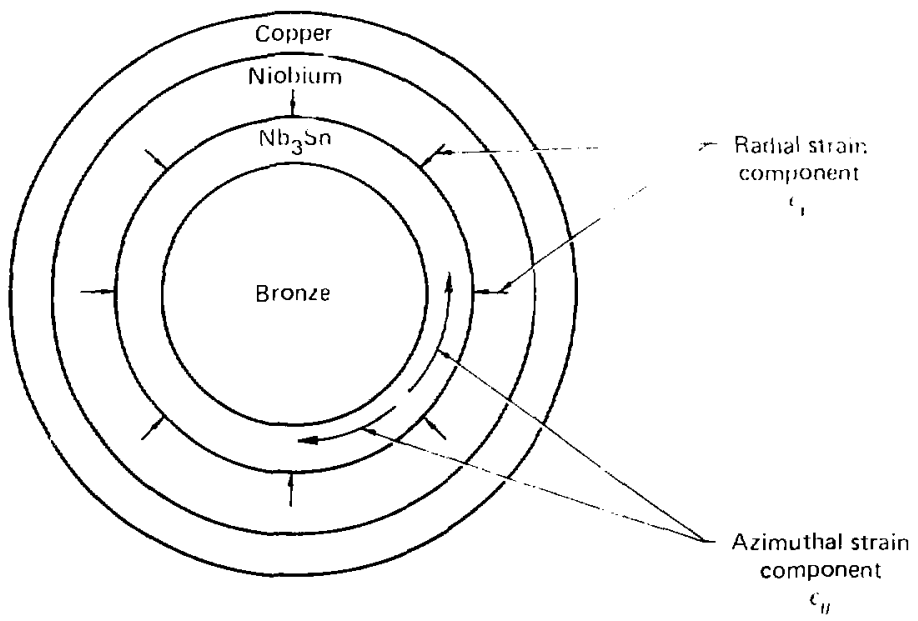

Internal bronze filament 


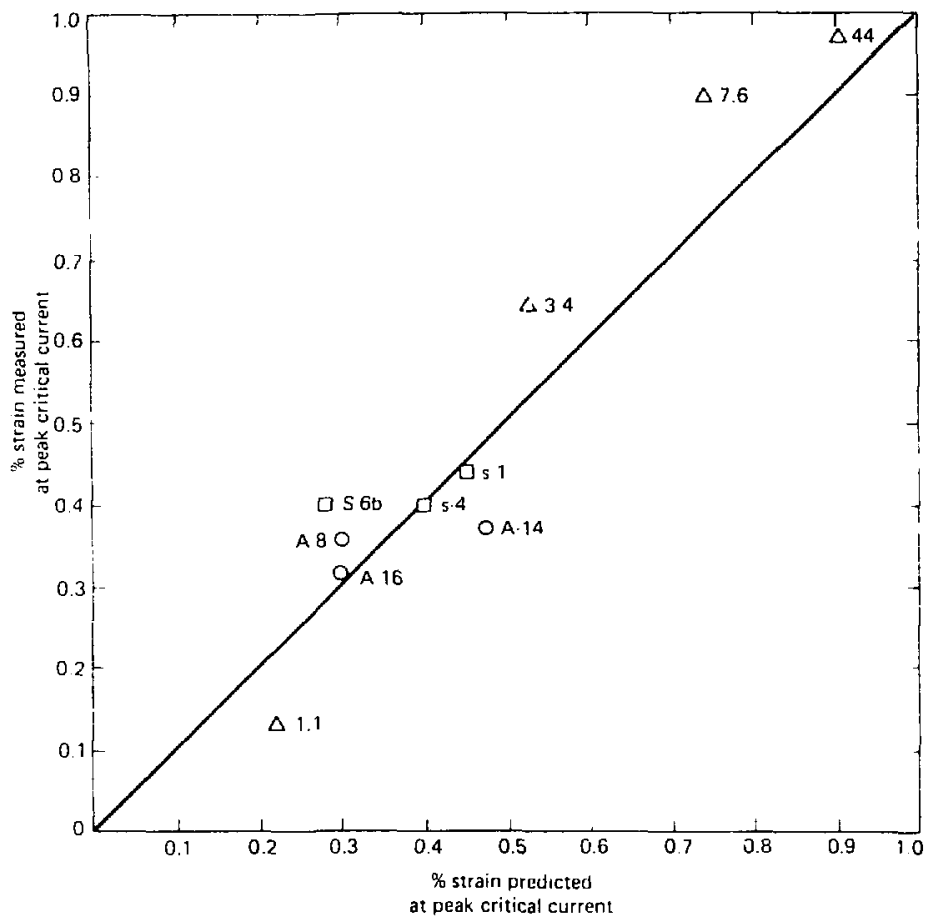

Fig. 1b. Mirasured versus predicted Eicmax plot. A plot of the measured strain values that yielded peak critical currents (F icmax) versum, (!) "AXXIMSUPER prediciluns fo" a variety of niobium- aru: brunze-cose composites. Ihe triarigles are monufilaments with the bronze-to-niobiun rolios witen next to each point. The jircles and squares are internis] n! bium- and bronze-

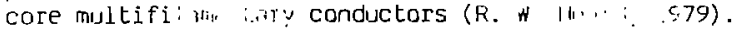




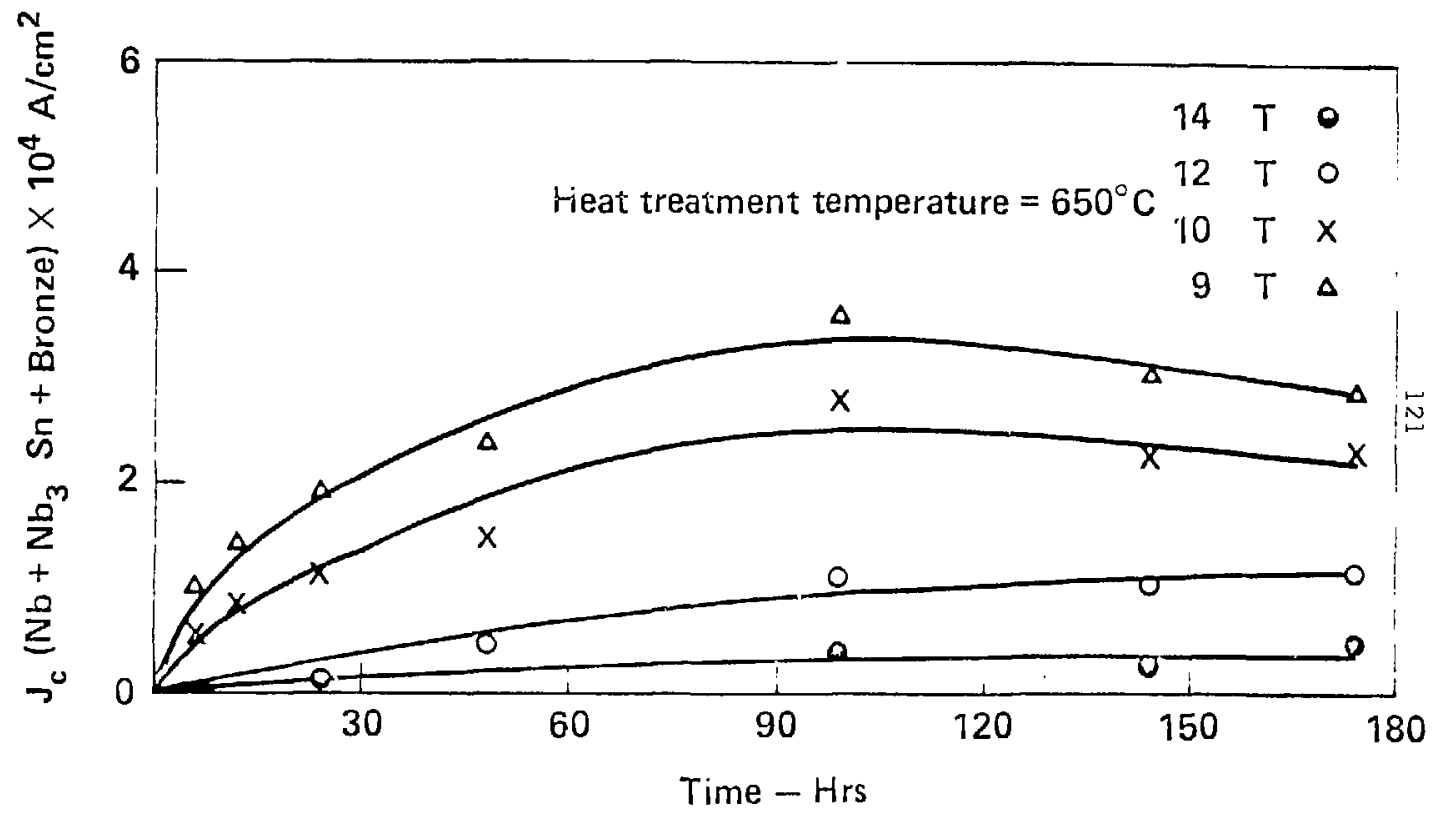

Fig. 16. Critical current density as a function of NbzSn reaction time at several magnetic field strengths for various internal bronze-core conductors (R. M. Scanlan, 1979). 


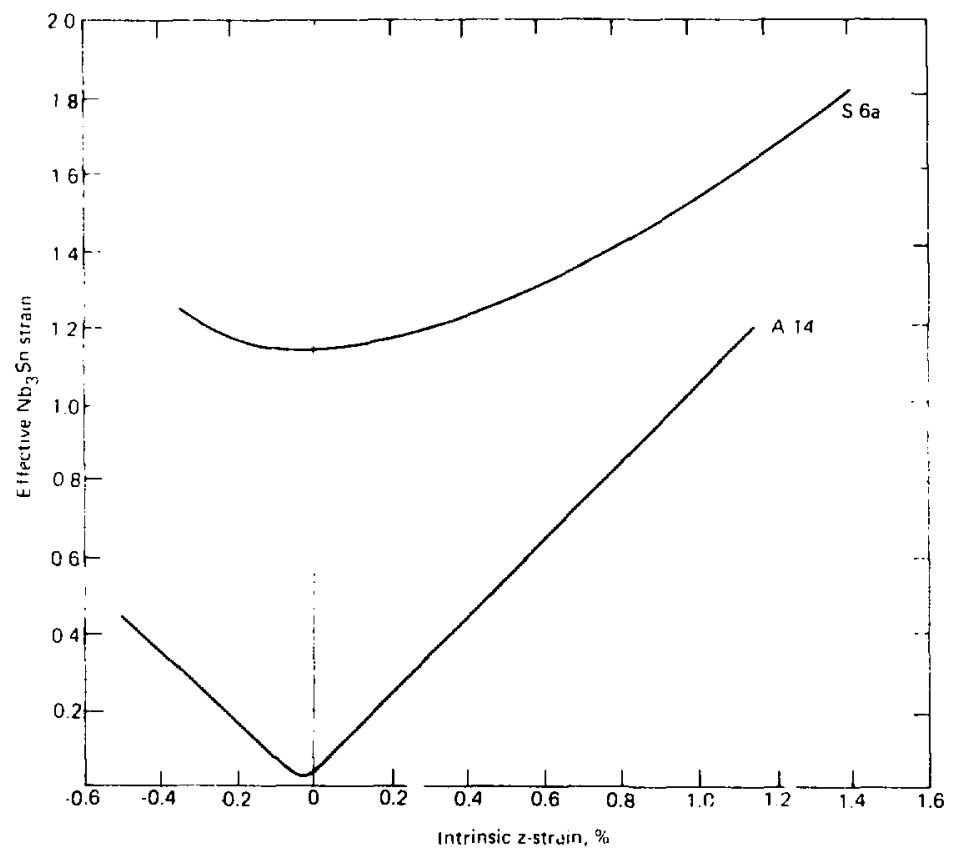

Fig. 17. Piot uf effective strain versus intrinsic z strain. line plot shows the effective strain on tine IbzSn layers versus the intrinsic 2 strain from the MAXIMSUPER code. The $S-6 i$ and $A-14$ are typical bronze- and niobium-core conduc: 4. usiurl: (k. w Husrit, 1979). 


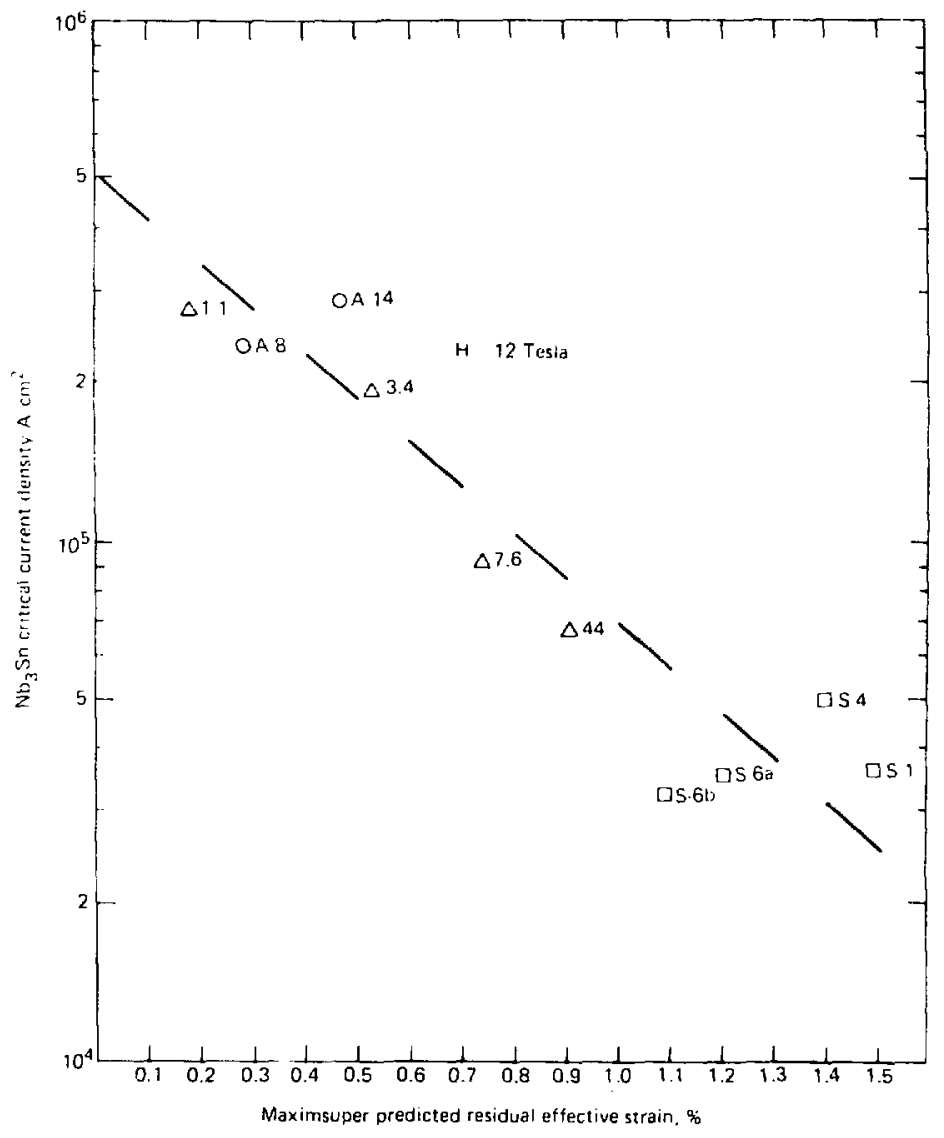

Fig. 18. Plot of measured critical current density of several conductors at $H=12 T$ as a function of the code predicted residual effective strain. The sample designations are the same as those in Fig. 17. 
124

Fig. 19. Ine low temperature tensile tester showing the sample area raised above the cryostat. 


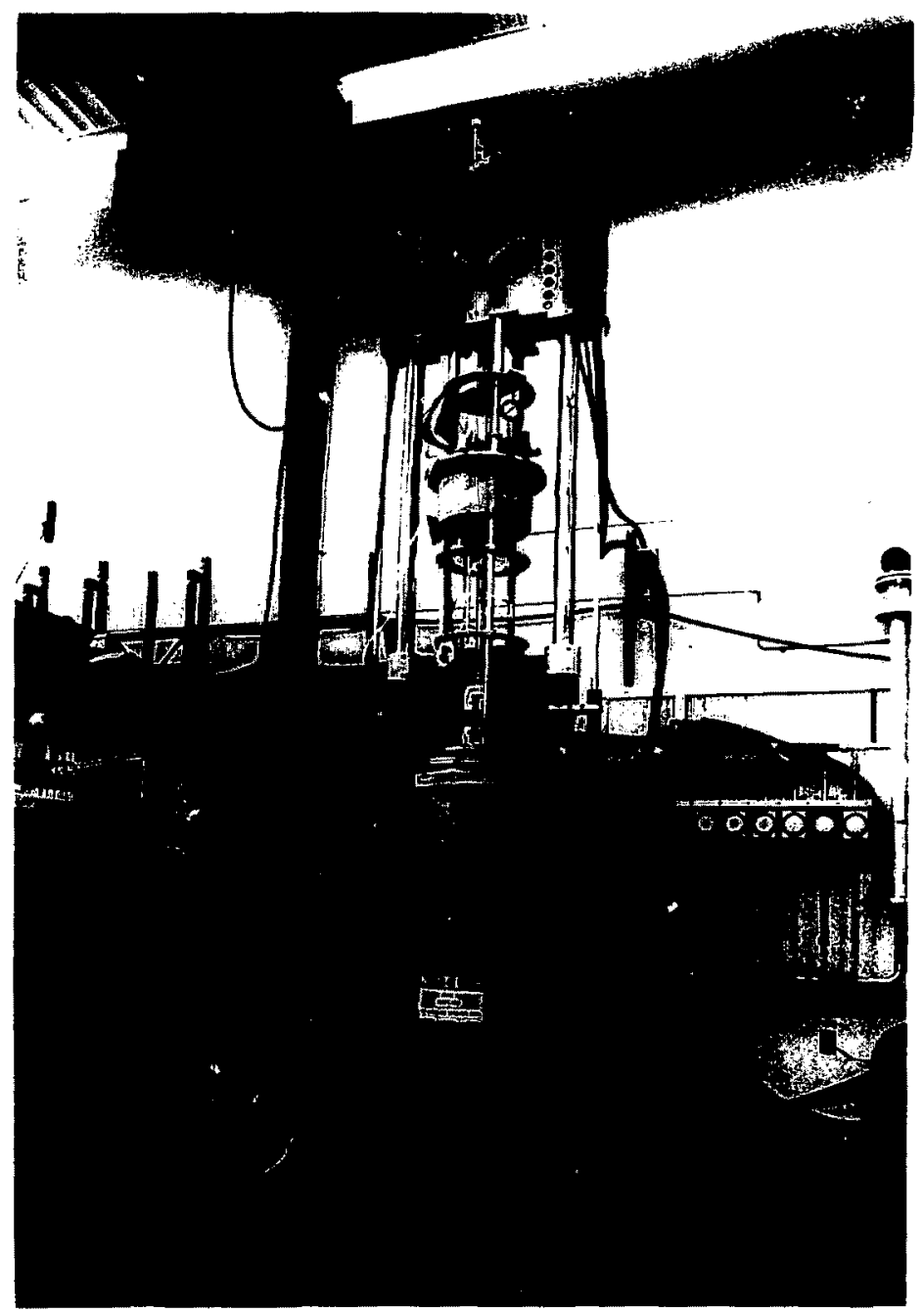


123

Fig. 20. Inside the cryostat: A view of the upper tensile grip, conductar, and copper braid current lead. 


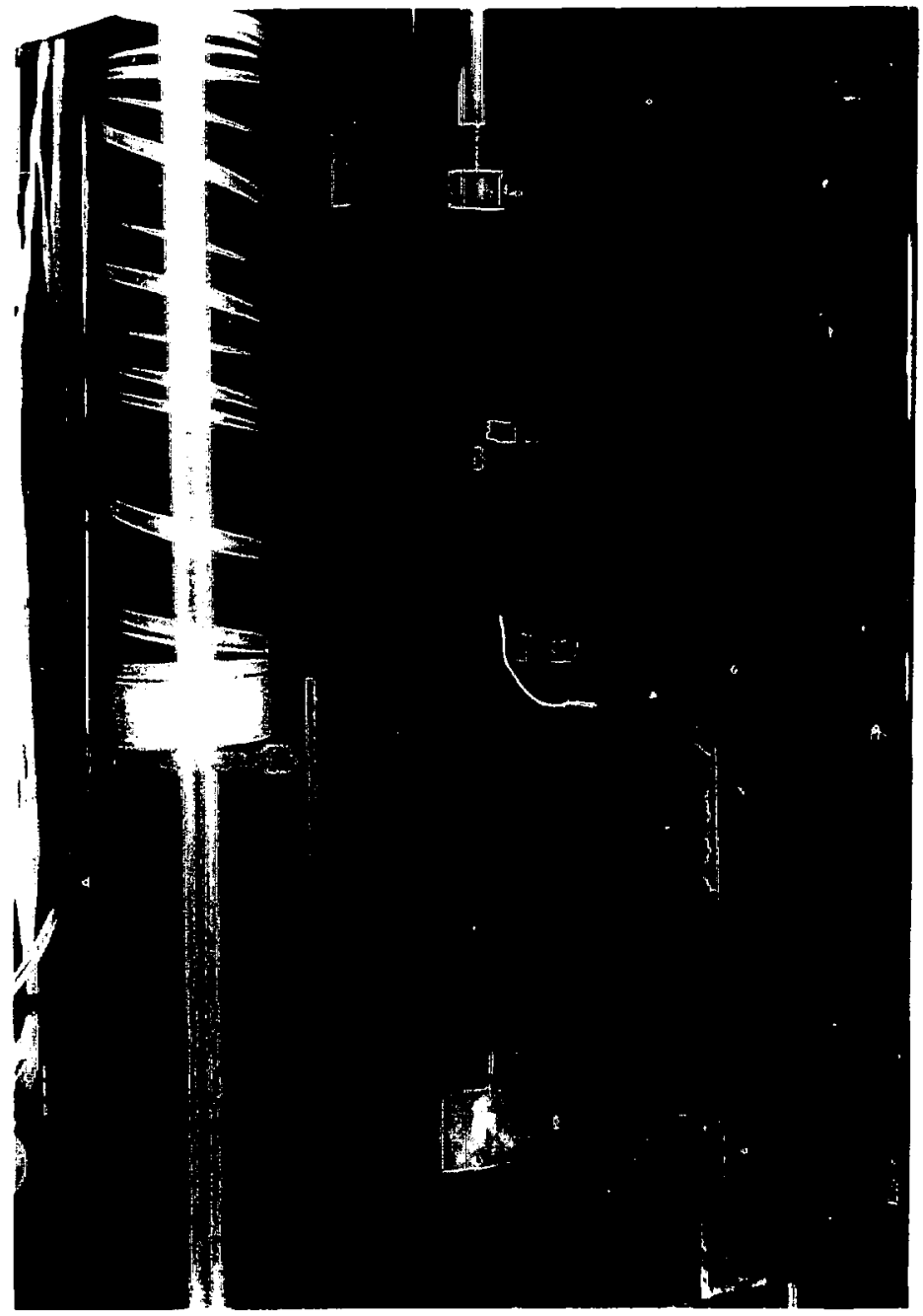


126

Fig. 21. Sample conductor fitted with test instrumentation.

Attached to the shert sample conductor are strain gages and voltage taps. The side pieces are epoxy G-10 structural pules to prevent the sample from bending under the action of Lorentz incres. 



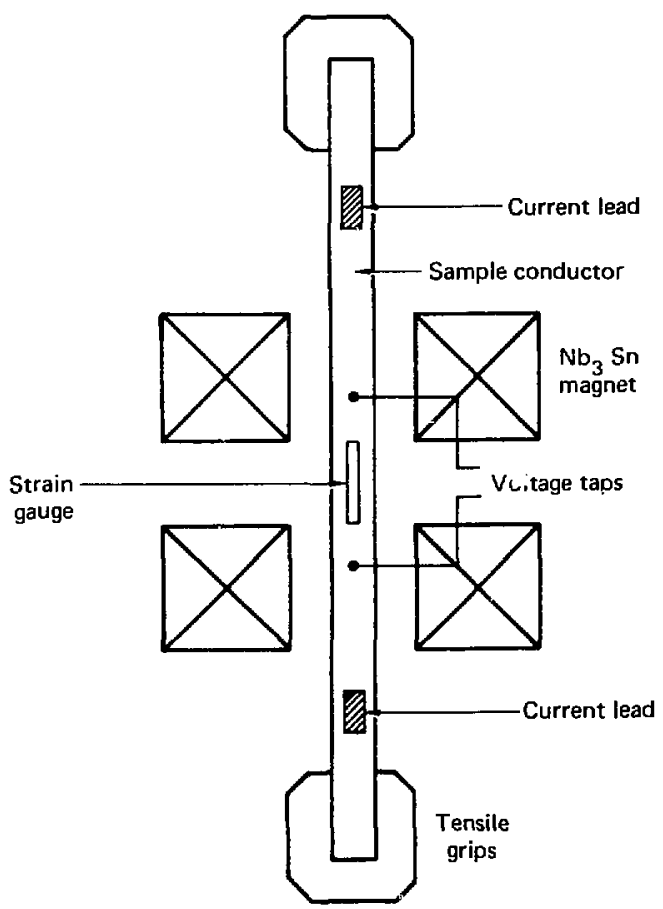

Fig. 22. Tensile tester schematic. This schematic shows the active components of the tensile tester sample area. The figure shows the split pole $12 \mathrm{~T}$ magnet, sample, current leads, voltage taps, and the location of the tensile grips. 
Cryogenic apparatus for $4.2 \mathrm{k}$ mechanical testing of $\mathrm{Nb}_{3} \mathrm{Sn}$ conductors

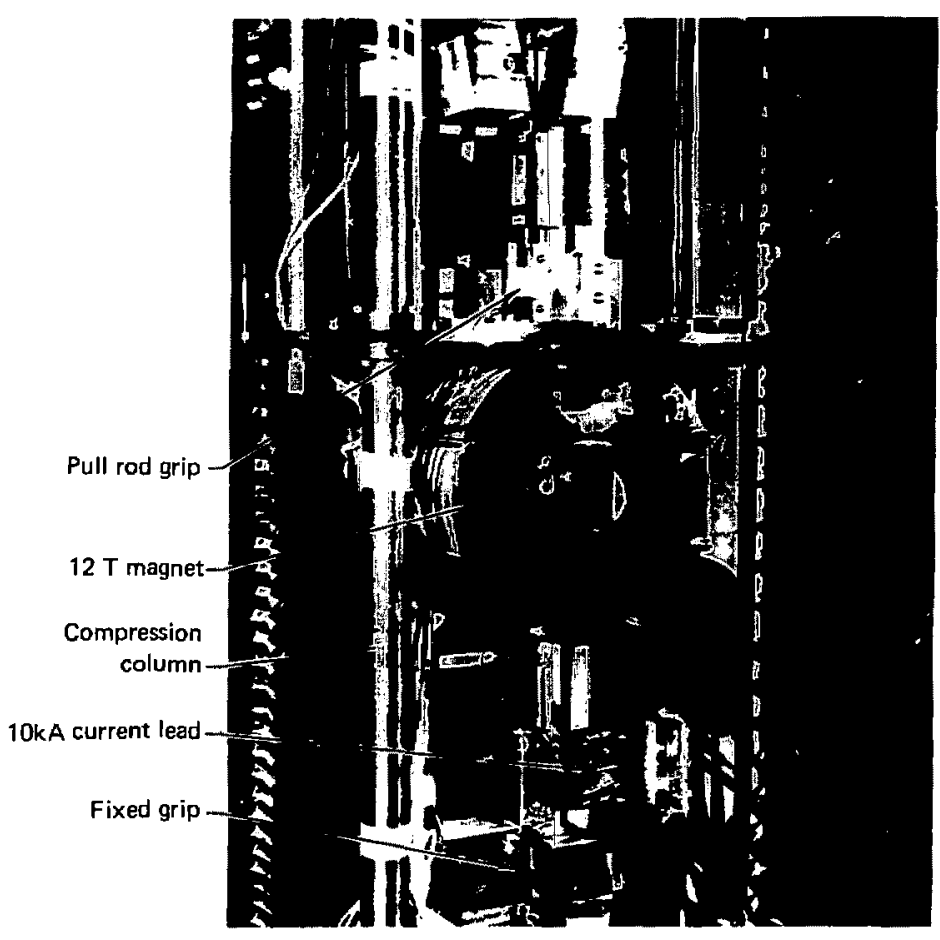

Fig. 23. Inside the cryostat: Showing the complete assembly for the strain-critical current experiments. 


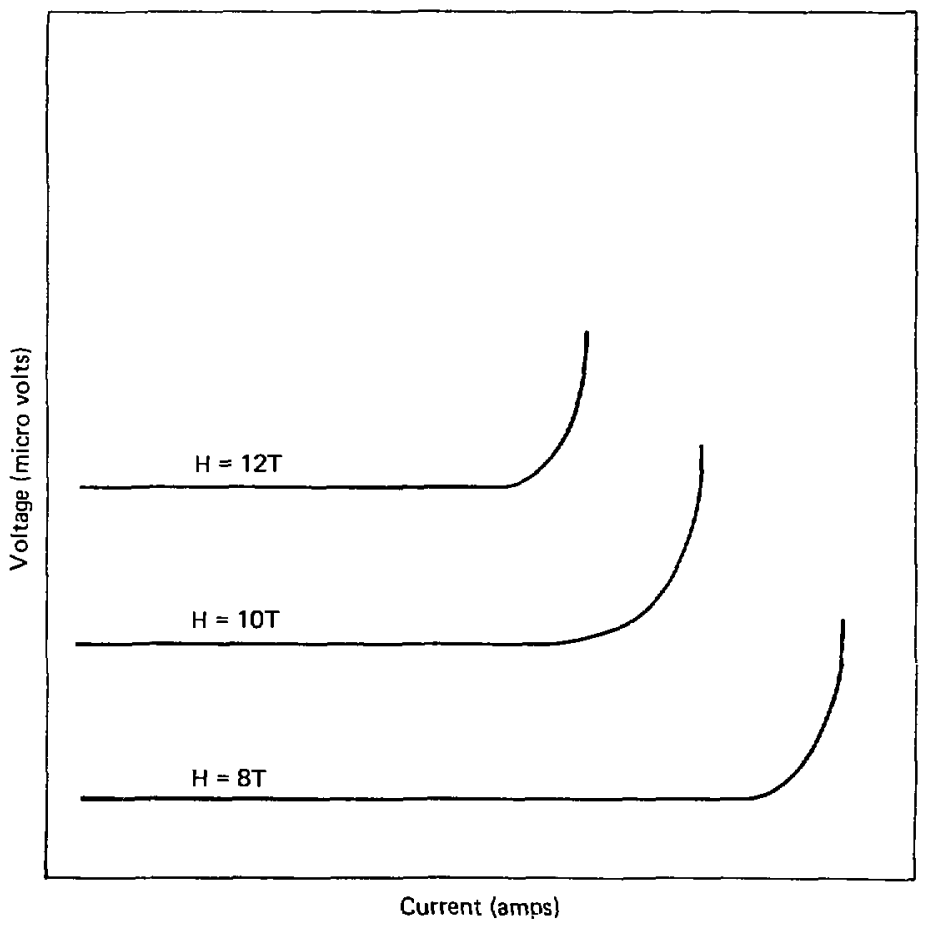

Fig. 24. Typical vultage versus current data plats obtained curing the tensile test experiments. 


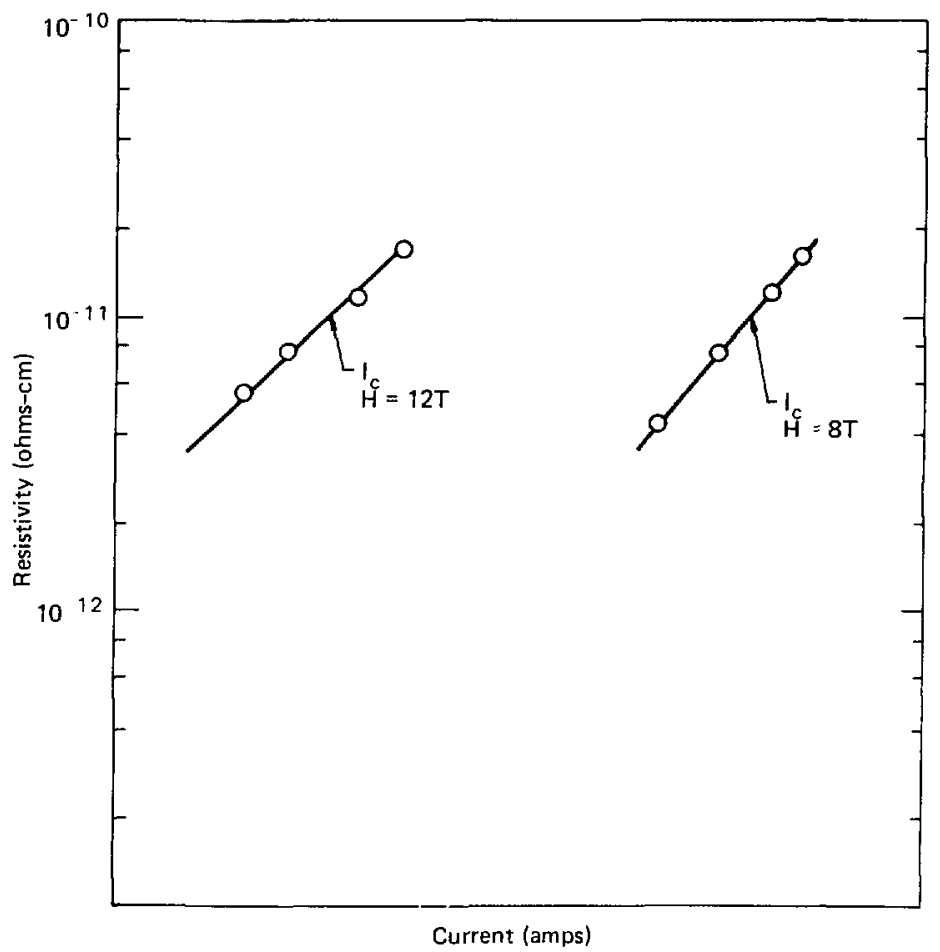

Fig. 25. Typical extrapolation plots used to determine the critical current at a resistivity of $10^{-11} \Omega-\mathrm{cm}$. 


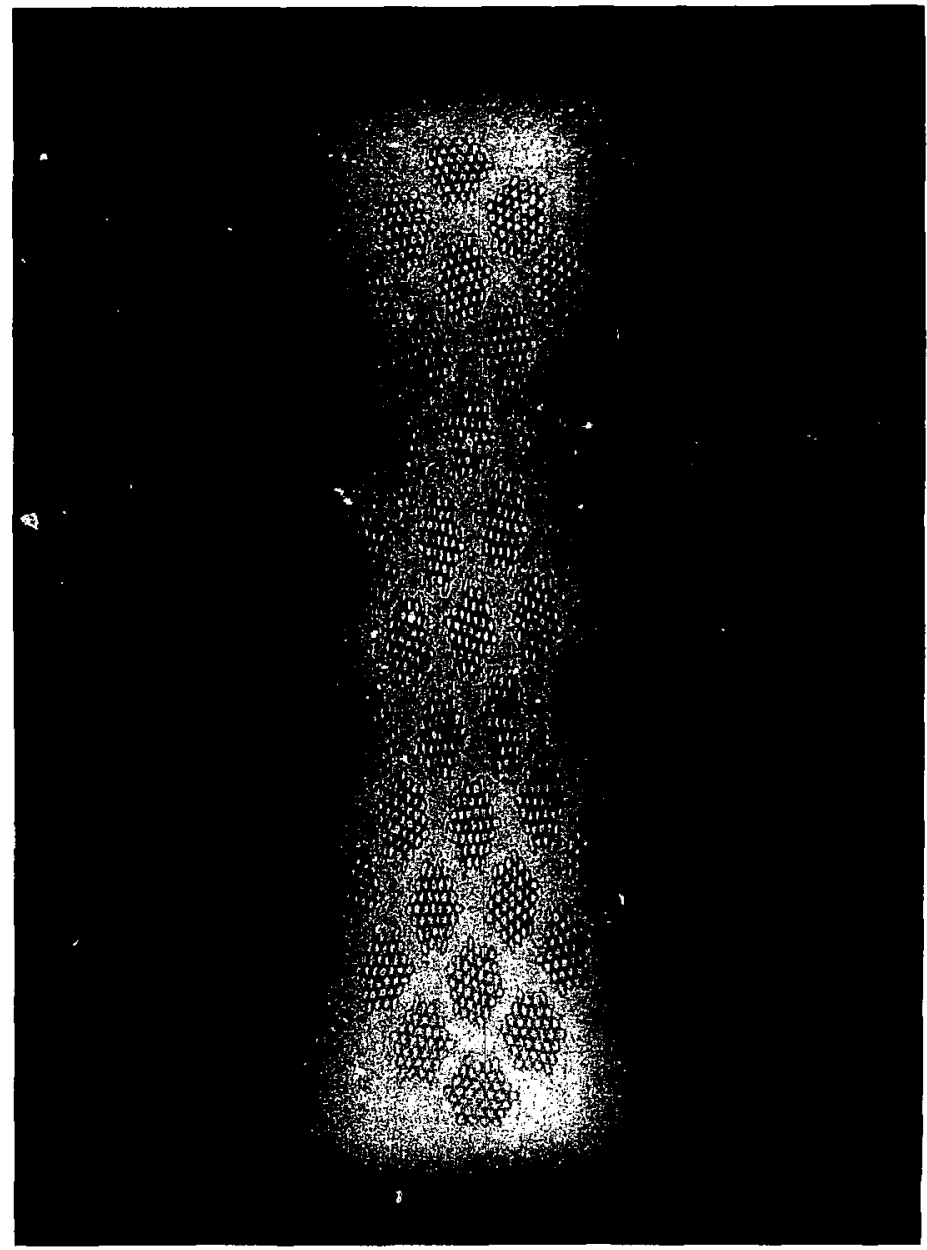

Fig. 26. Cross section of an internal bronze-core conductor. 

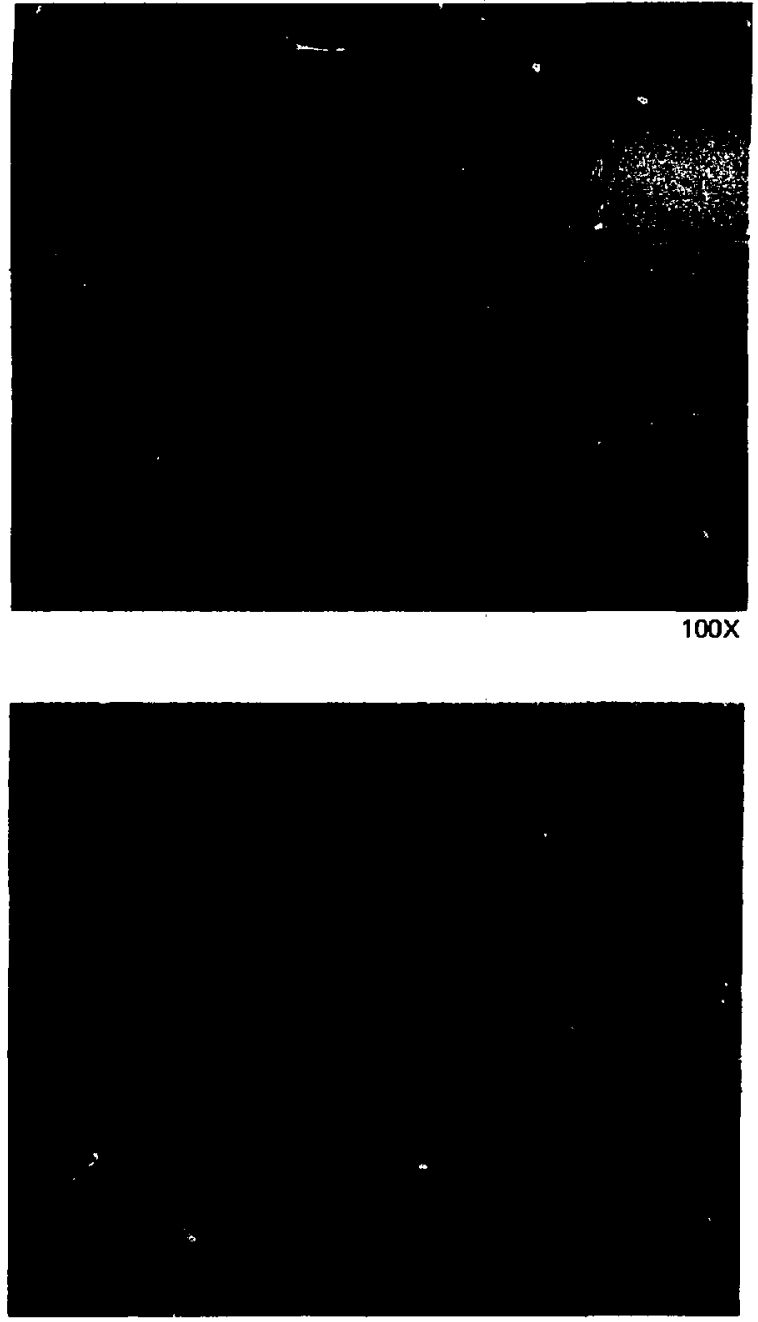

Fig. 27. Cross section of an internal niobium-core conductor. 


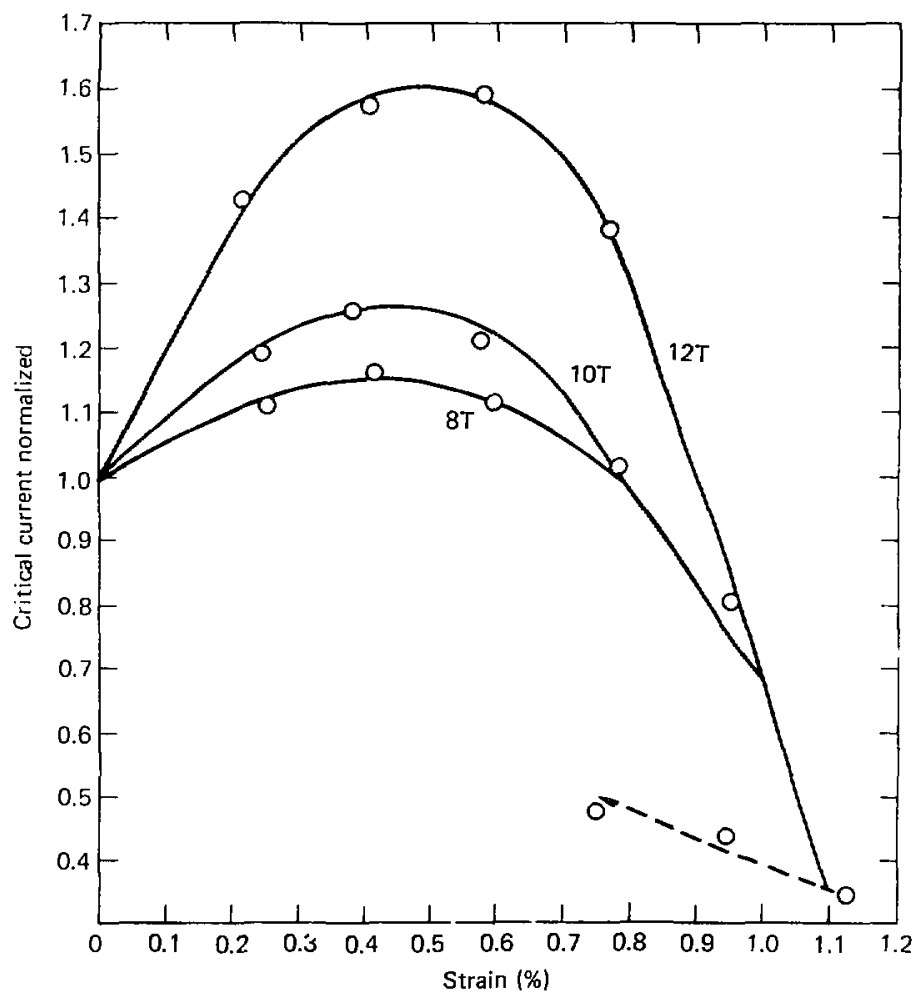

Fig. 28. Internal urunze-core conductor $I_{C}$ versus strain curve No. 1 . In this figure, the normalized critical current is plotted as a function of the applied axial strain for a conductor at 8,10 , and $12 \mathrm{~T}$. The dashed line represents the reduction of $I_{C}$ after the strain is lowered from 1.1 percent at $12 \mathrm{~T}$. 


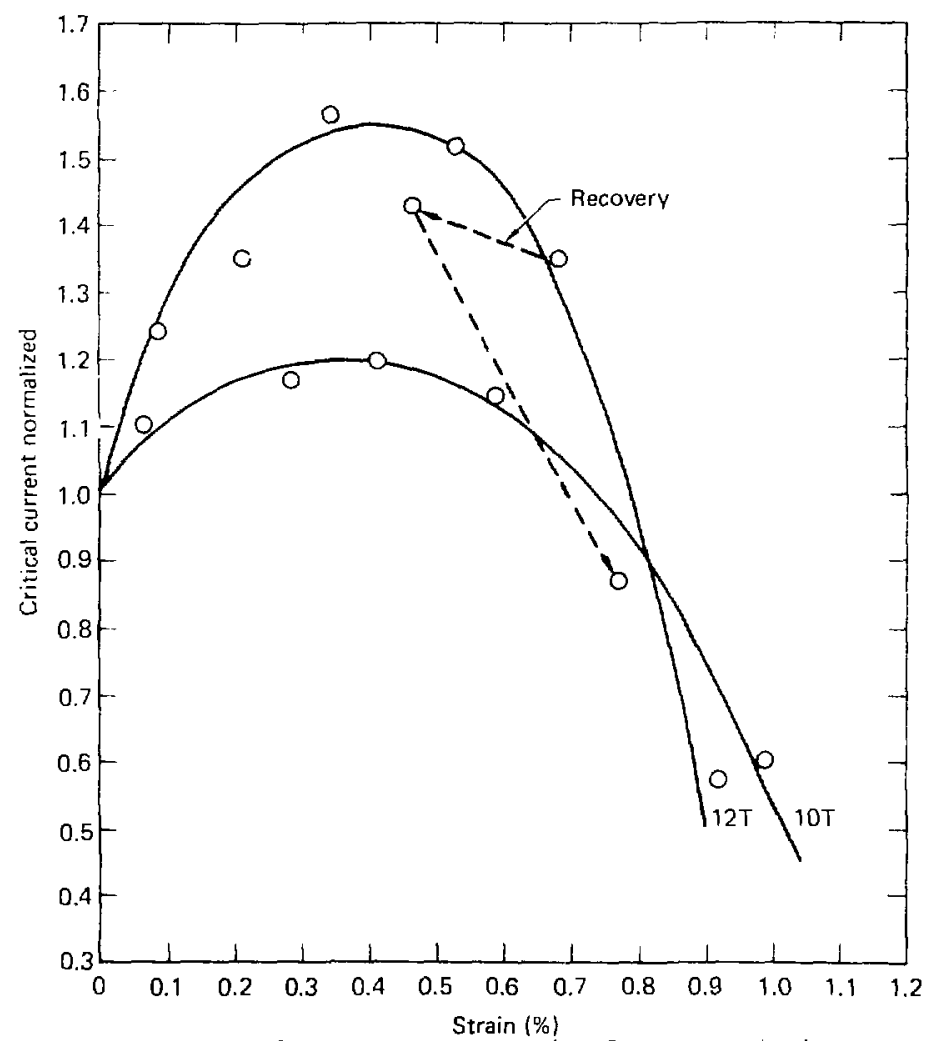

Fig. 29. Internal bronze-core conductor $I_{r}$ versus strain curve No. 2. In this figure, the $I_{C}-$ strai, characteristics are plotted for a second conductor at $H=10$ and $12 \mathrm{~T}$. Once again, the dashea lines show that the conductors current-carrying characteristics are irreversibly degraded at strains higher than 0.2 percent of the strain that yiel.ds the maximum critical current, $\varepsilon_{\text {icmax }}$. 


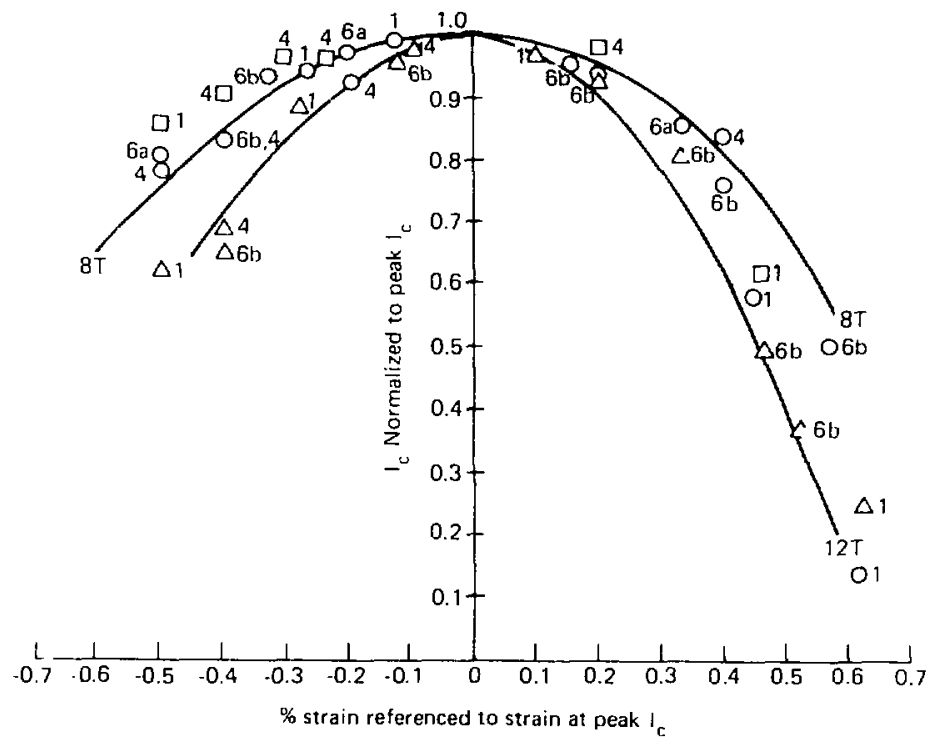

Fig. 30. Rupp normalized critical current data for bronze core conductors plotted against the intrinsic strain. The square, circular, and triangular symbols represent data points taken at $H=8,10$, and $12 \mathrm{~T}$, respectively. The numbers are cunductor identification name:; from Table 1. The solid envelope curves are the 8 and 1? T lines from Fig. $b$. 


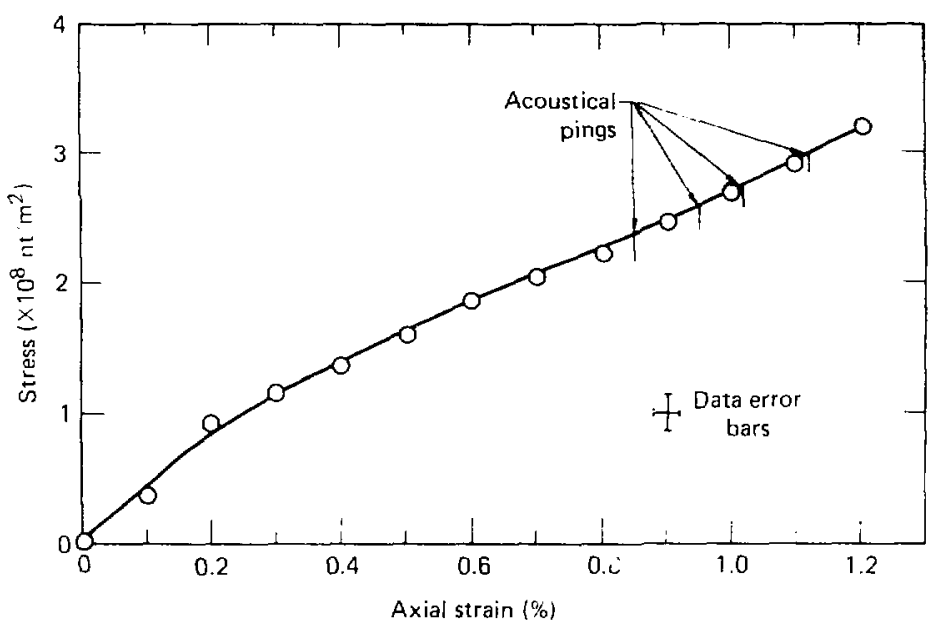

Fig. 31. Strus-itrain curve from internal bruize-tore conductur No. i. The vertical ticks ucinteu slouitaneously witn the emission of "acoustioal pings," thought to be indicative of Nosr: filament breakage. 


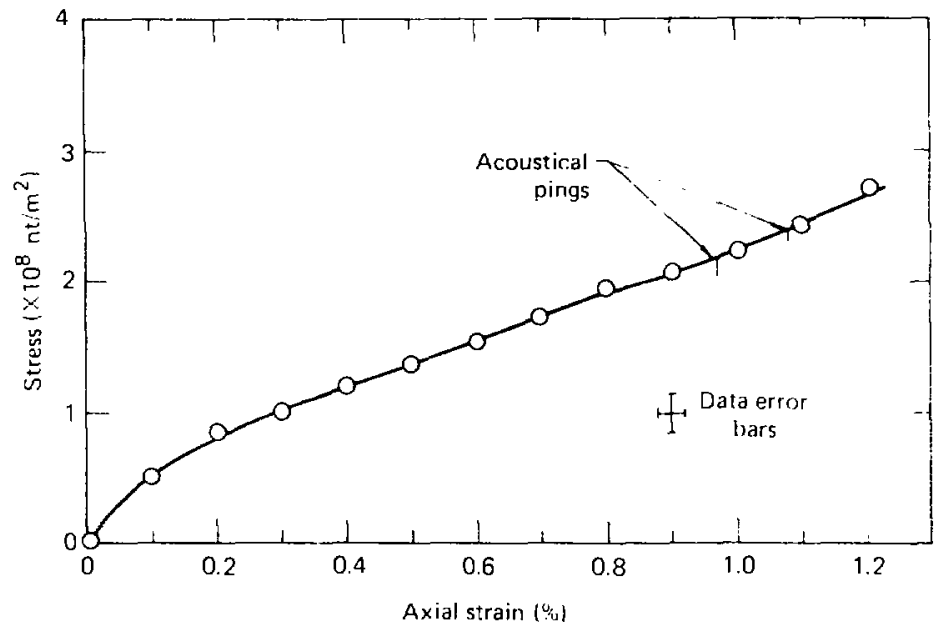

Fig. 32. Stress-strain curve for ar inttrna! bronze-core Lisciductur No.?. 


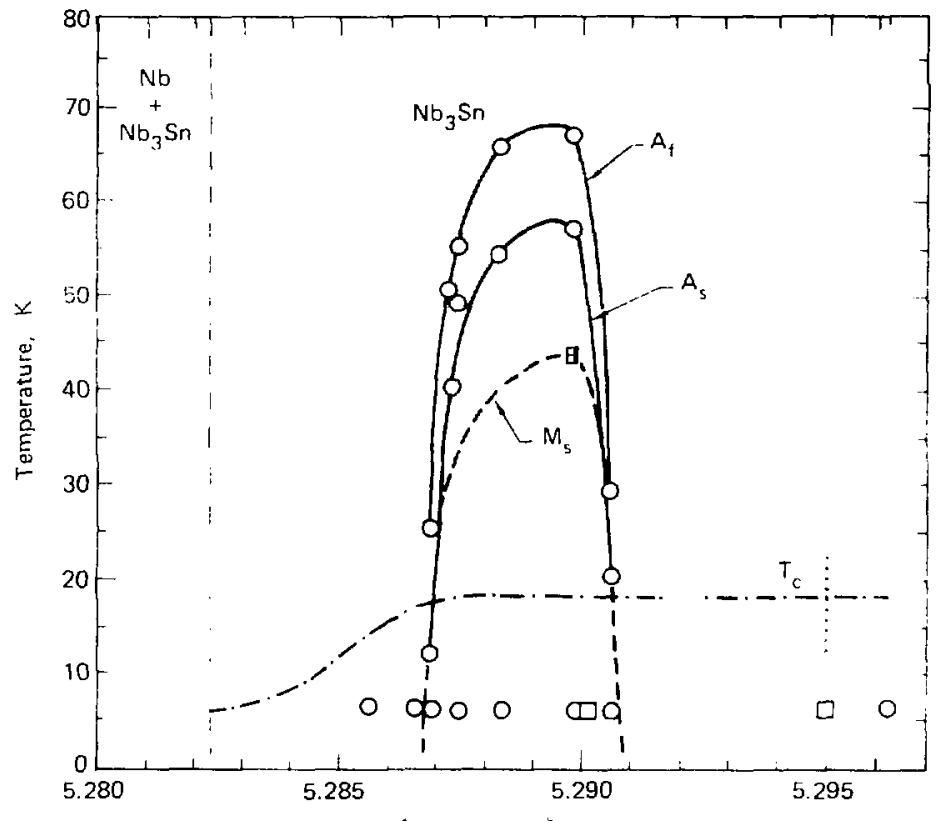

A parameter, $\lambda$

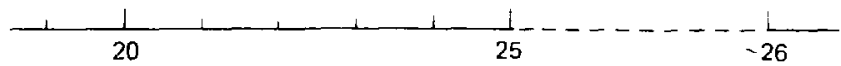

Atomic \% $\mathrm{Sn}$

Fig. 33. Martensitic-phase-transformation diagram. This figure shows the relationship betweer the lattice parameter (or stoichiometry) and the superconducting and martensitic transformation temperatures $T_{j}, A_{S}, A_{t}$, and $A_{f}$. The dita was obtained from noserving the reverse (tertragonal-to-cubic) transformation in samplea

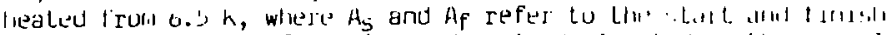
of the reverse transformation and $M_{S}$ is designated as the normal cutic-to-tetragonal start temperature (H. W. King, 1969). 


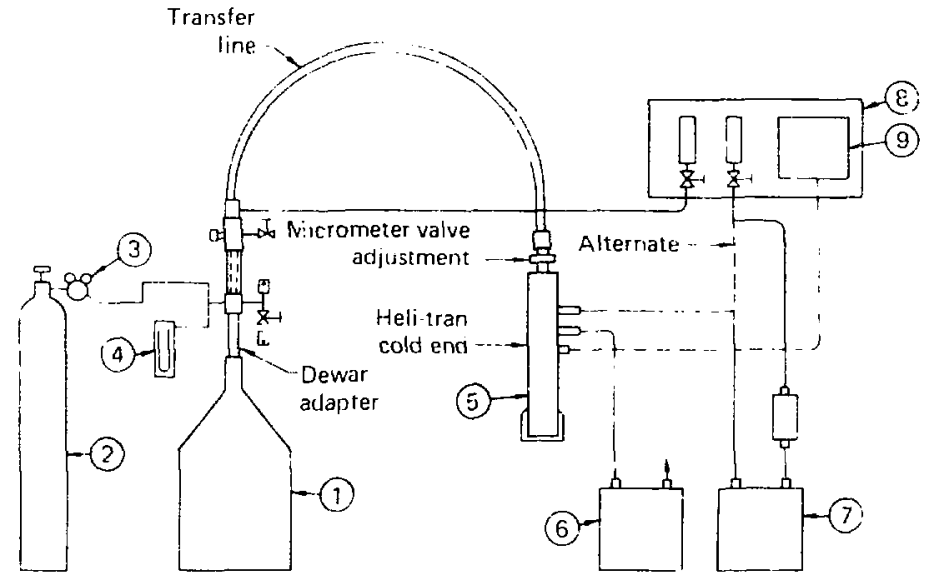

1. Helium dewar

2. Helium cylinder

3. Pressure regulator

4. Mercury mananeter, 0 to $20^{\circ}$ Hig or pressure gauge on helium , war

5. Vacuum shroud

6. Vacuum shroud pump

7. Vacuum pump for operation below $4.2^{\circ} \mathrm{K}$

8. Accessory flow control panel

9. Accessary temperature controller. manual or automatic

Fiq. 34. Typical heli-tran cryostat set-up. 


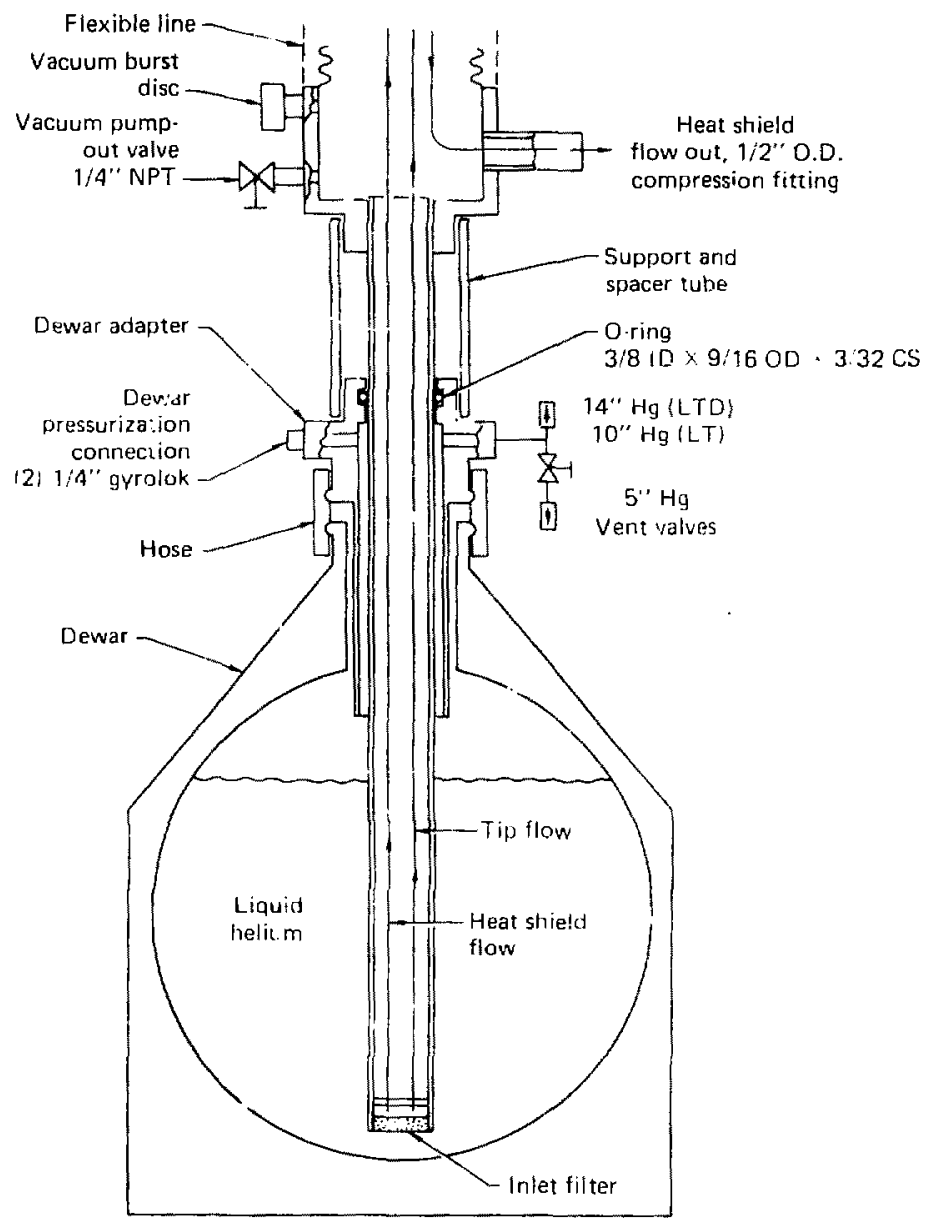

Fig. 35. Schematic of flexible transfer line to storage Dewar connections. 


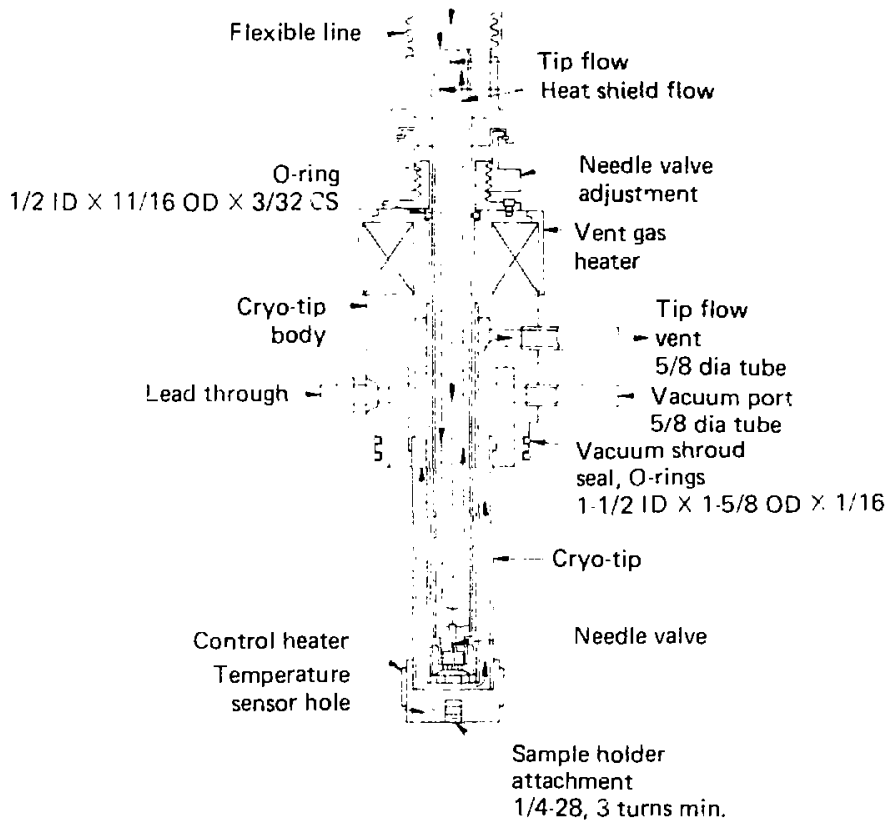

Fig. 36. Schemotic of heli-tran cryostat cold enc and connections. 
142

Fig. 37. Inside the heli-tran LT-3-110A cryostat, the vacuum shroud cover has been removed to show the cut-out radiaticn shield and sample. 


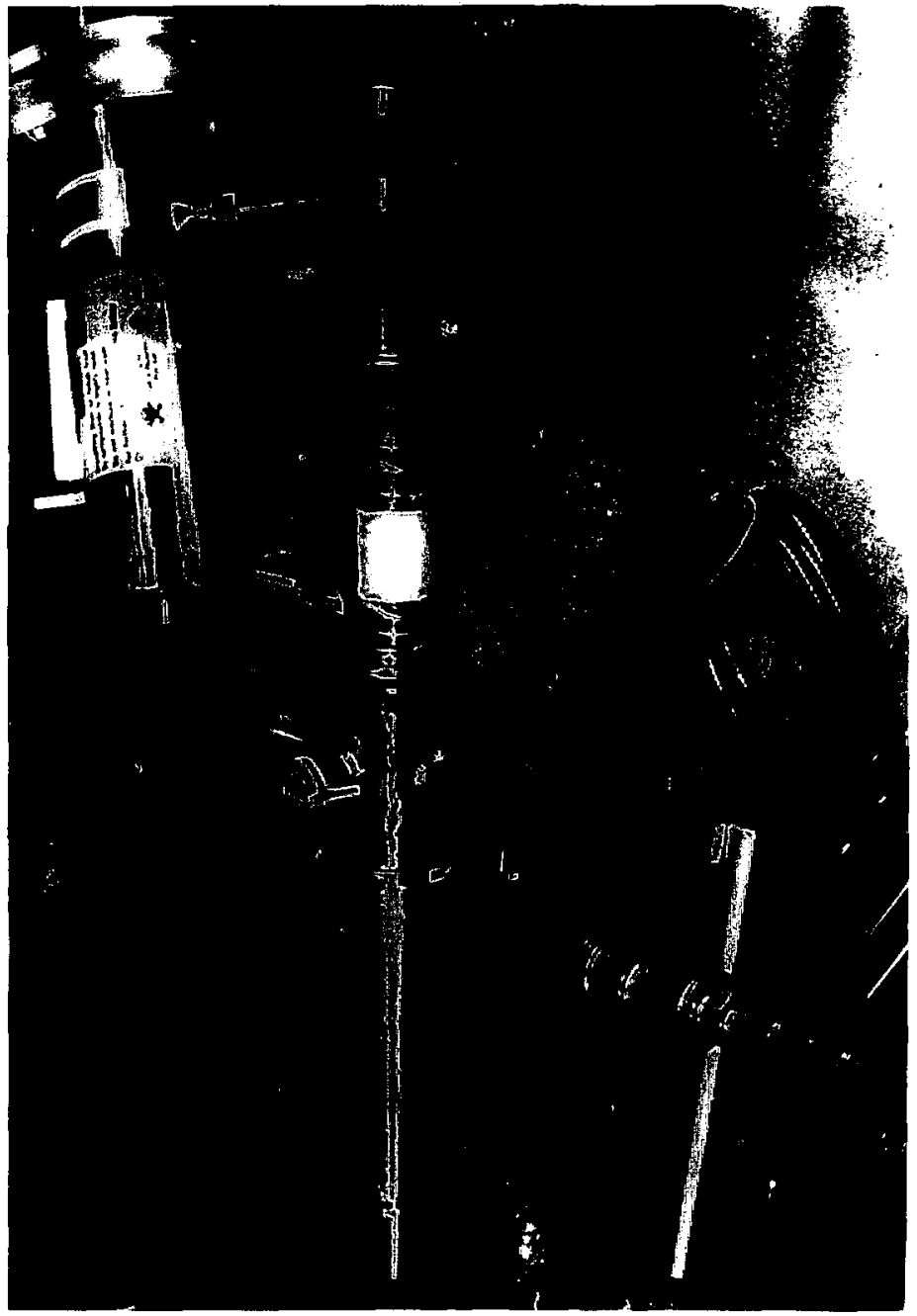




\section{3}

Fig. 38. The assembled cryostat mounted in the diffractometer. The $1 / 2$ inch by 180 degree beryllium window can be seer, on the vacuum shroud cover. The mechanical vacuum insert for straining the sample is also shown below the beryllium window. 


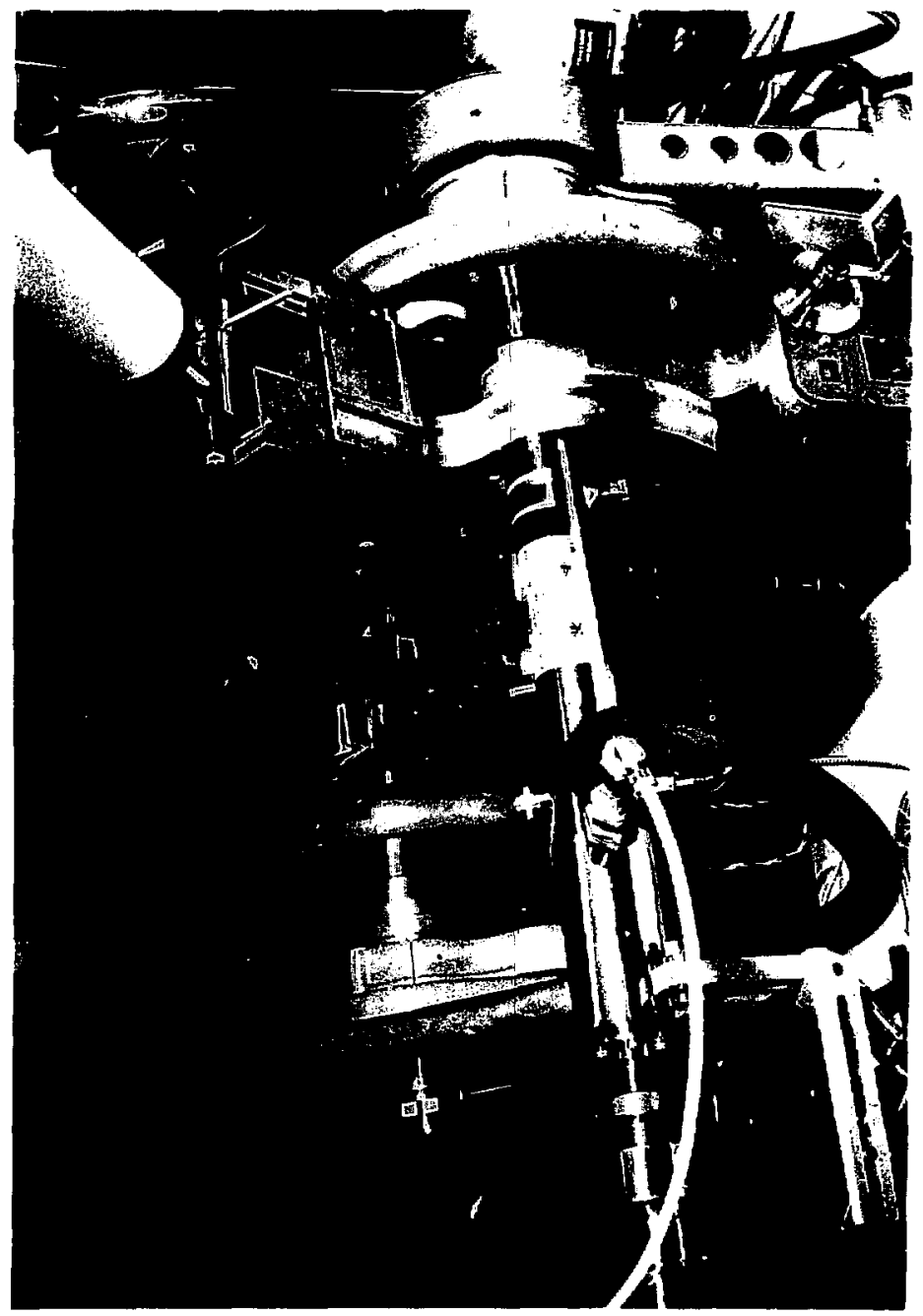


Fig. 39. Tensile test sample holder for x-ray diffraction. This figure shows the sample holder attached to the tip of the cryostat cold end. The strain gage and $\mathrm{N}_{3} \mathrm{Sn}$ ribbon are bonded to the top of an indium wafer. The wafer is secured (by the four screws shown) to two movable copper wedge poles. These poles spread apart when a set screw (in the outer side of the holder) is advanced by the mechanical vacuum insert shown in Fig. 38. Two CLTS thermometers are also shown; one is under the indium stage, the other is mounted on the end of the sample holder. 


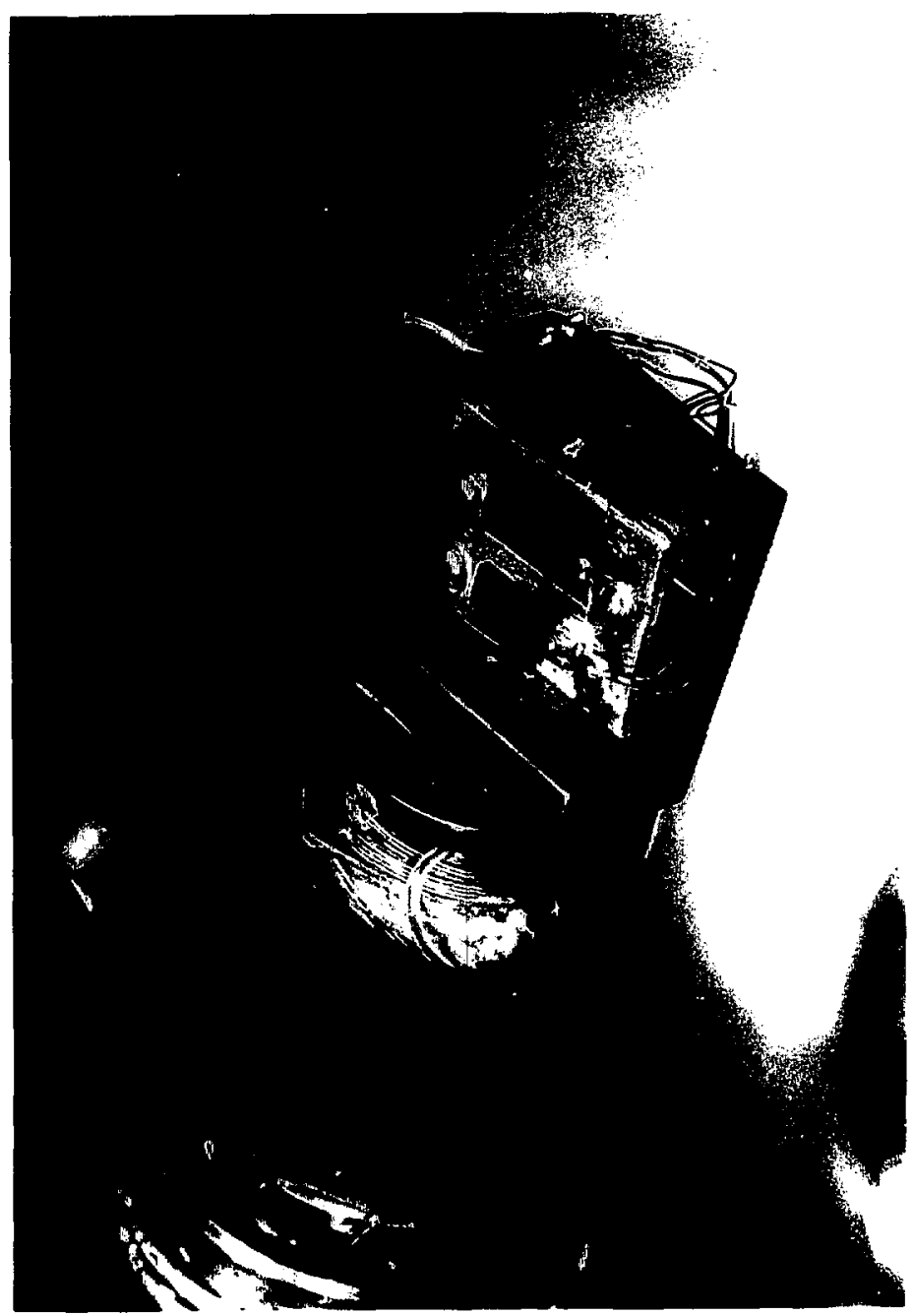




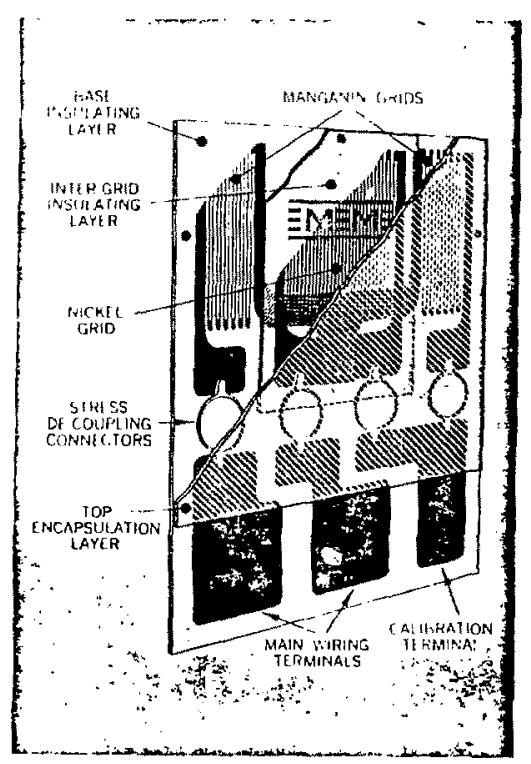

Fig. 40. Enlarged orawing of CLTS temperature serisor. 


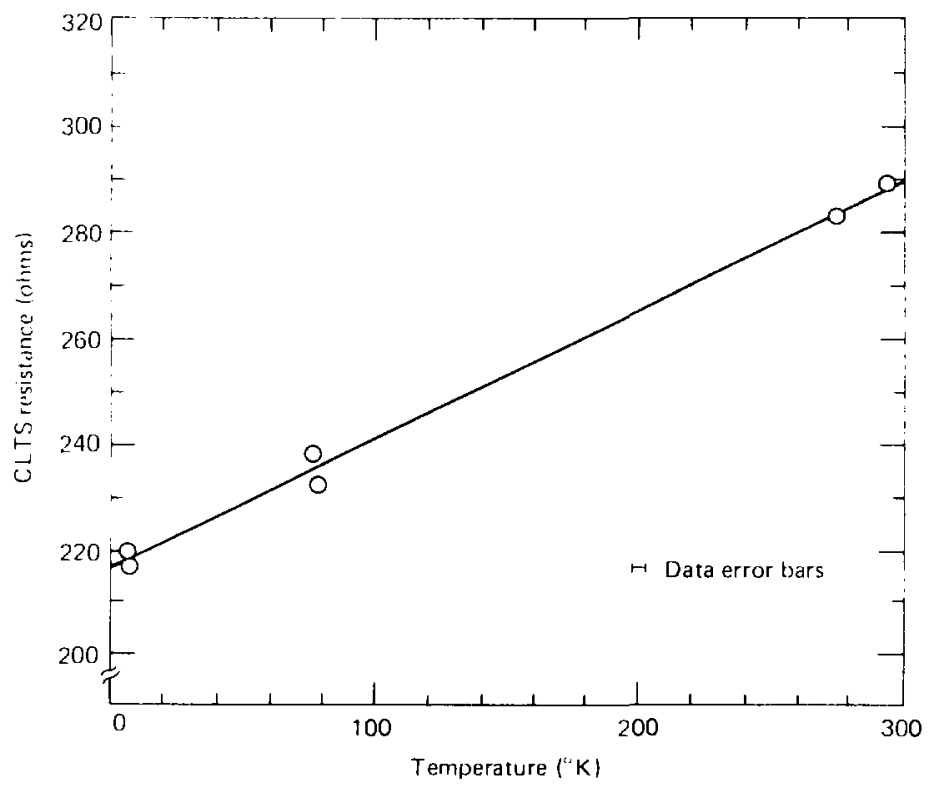

Fig. 4l. Calibration curve for the CLTS temperature sensor. Two CLTS sensors were immersed in baths of liquid helium, nitrogen, and ice to produce this curve. 
147

Fig. 42. Another view of the cryostat and diffractometer. 


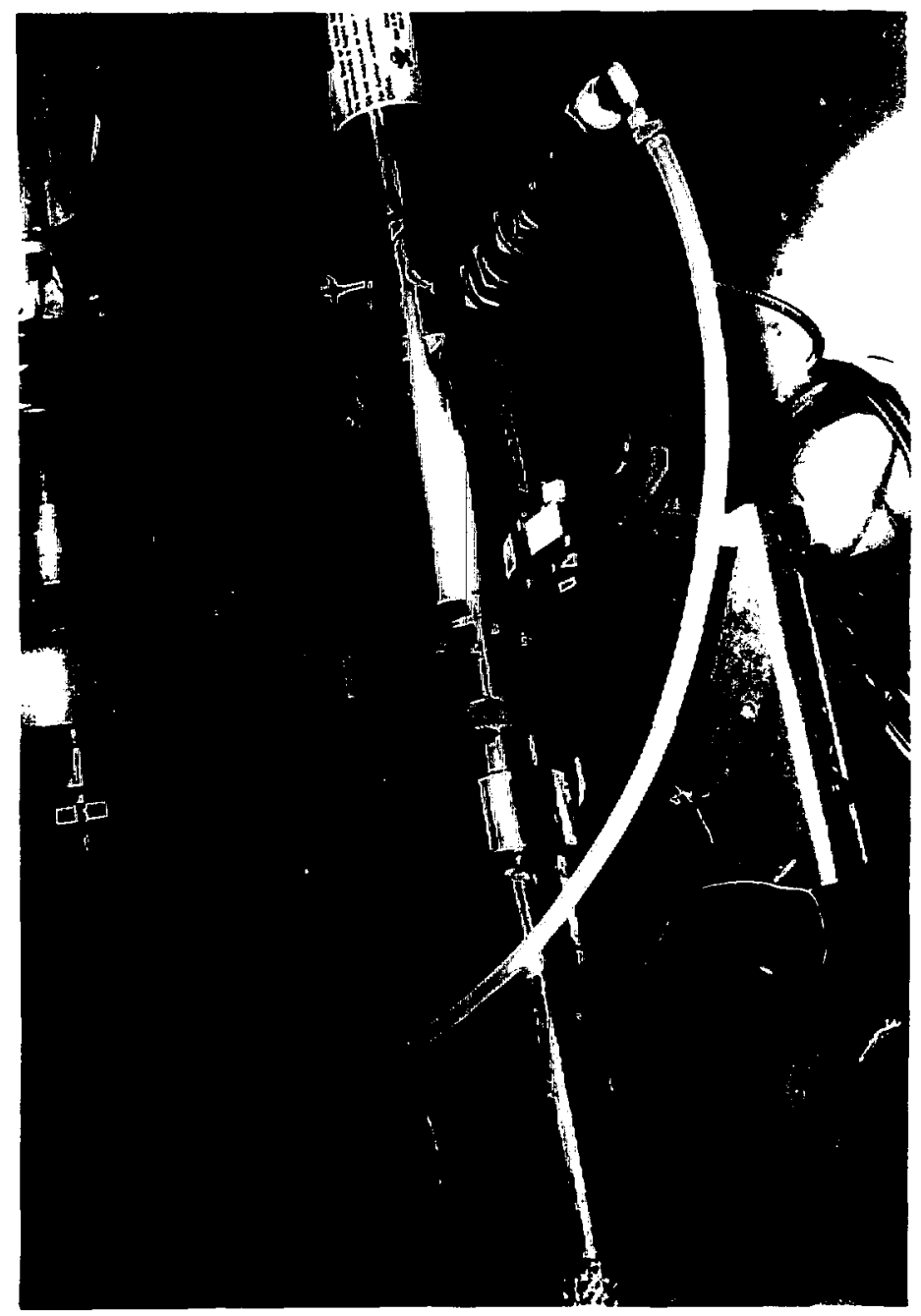


Fig. 43. Overal: setup for the x-ray diffraction experiment. This figure shows the low temperature $x$-ray diffraction cryostat, diffractometer, automated data acquisj.tion system, temperature control, and strain gage instrumentation. 


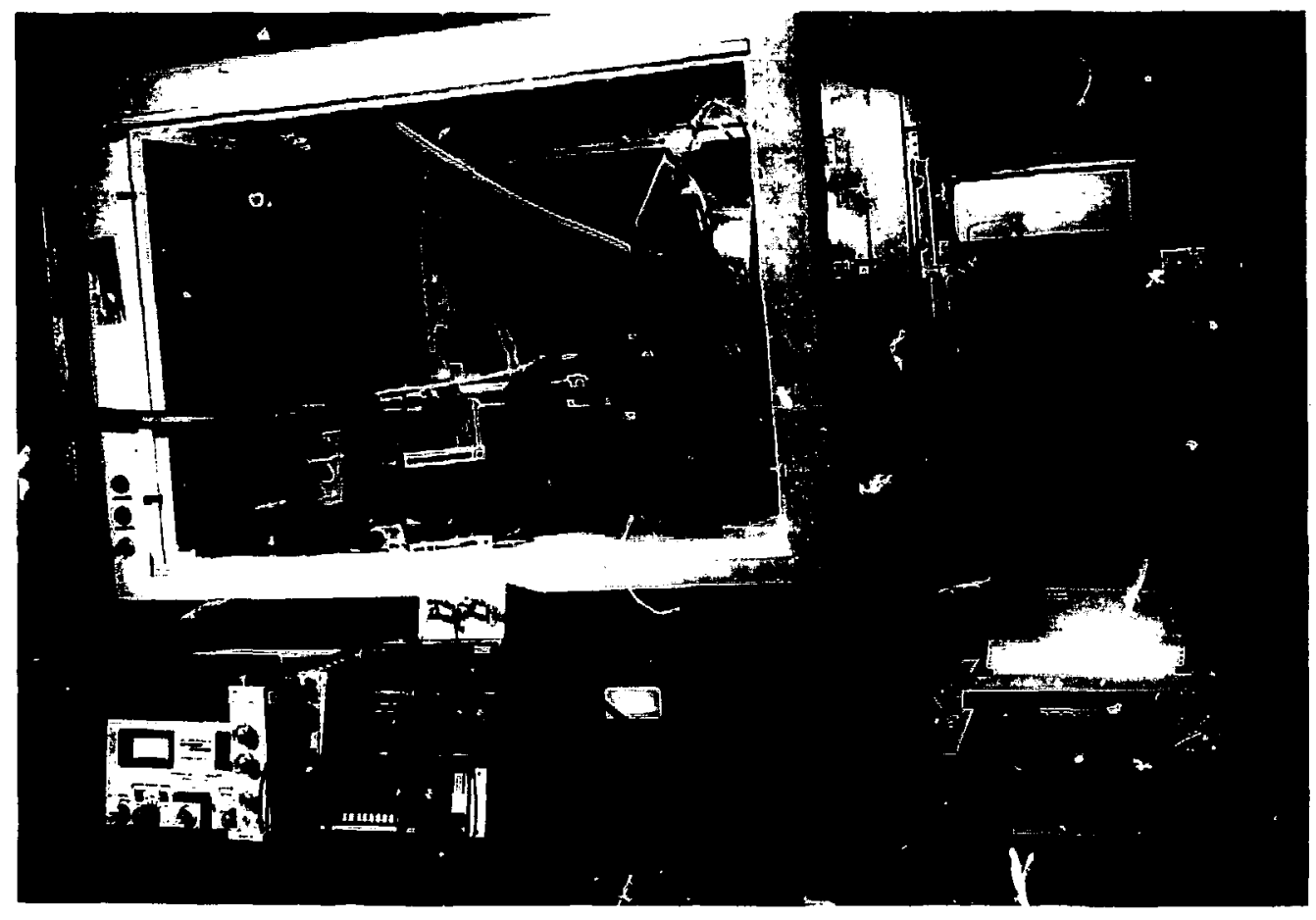




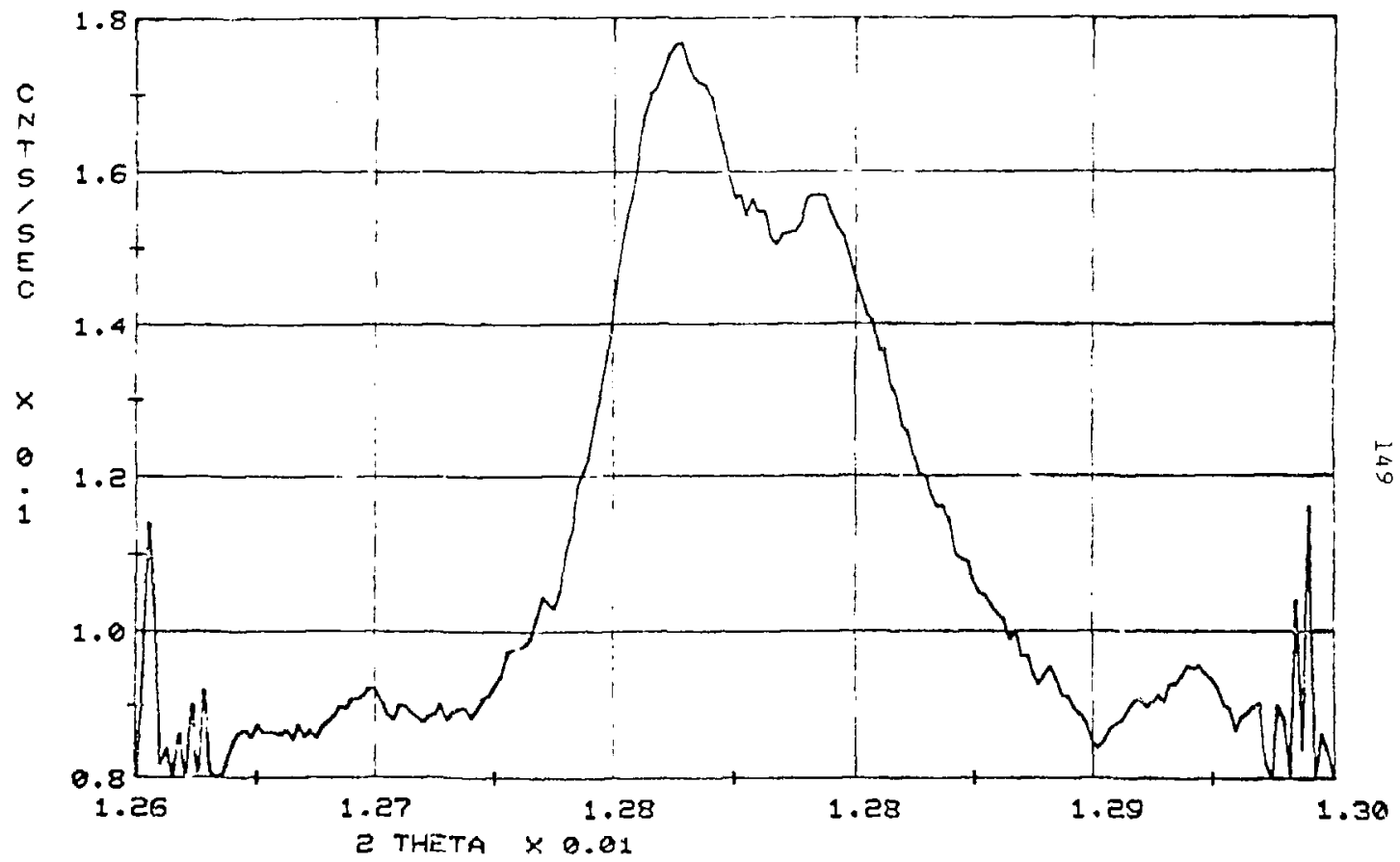

Fig. 44. Room temperature diffraction profile of the $(611,532)$ liries of NbzSn. The two preaks are due to the $k, l$ and $k$ 's wavelengths. 


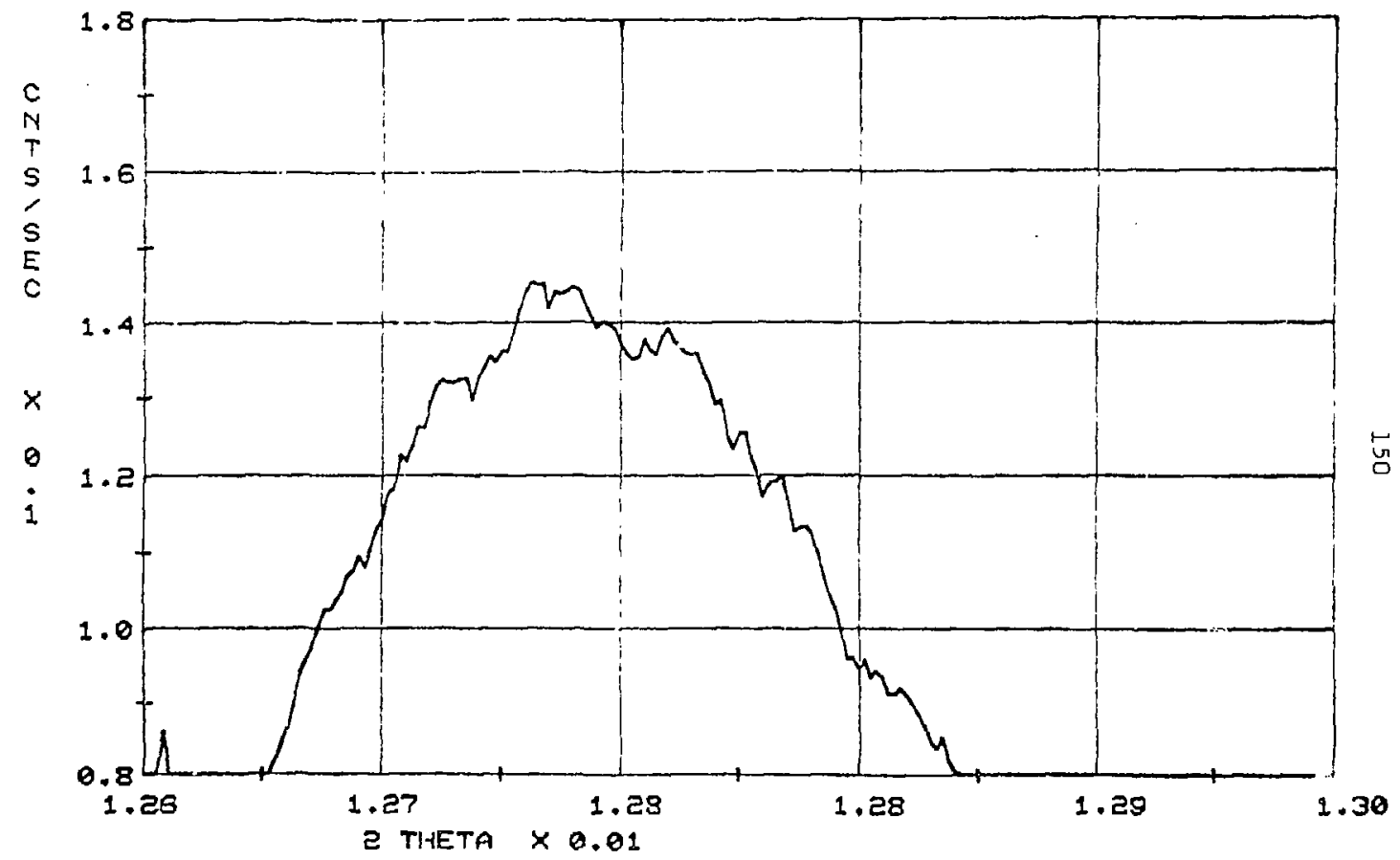

Fig. 45. viffraction profile of the $(611,532)$ lines of $\mathrm{N}_{3} \mathrm{Sn}$ at $8 \mathrm{k}$. Notice that the $K_{1}$ and $K_{2}$ peak separation is no longer resolvable. 


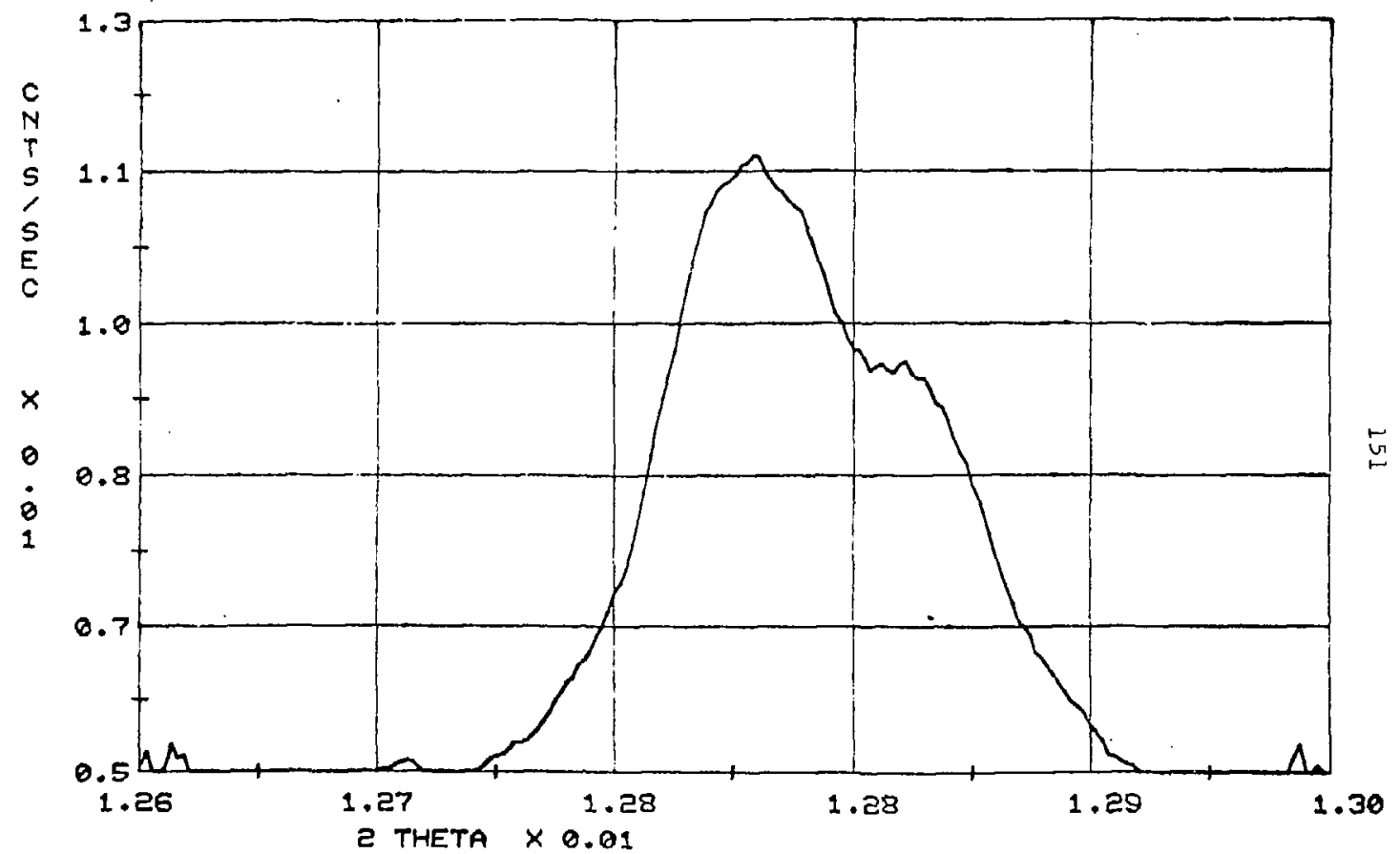

Fig. 46. Diffraction profile of the $(611,532)$ ines at $174 \mathrm{~K}$. Figs. 46 through 55 sh.w diffractometer traces of the $(611,532)$ line for Nb3Sn at various temperatures. 


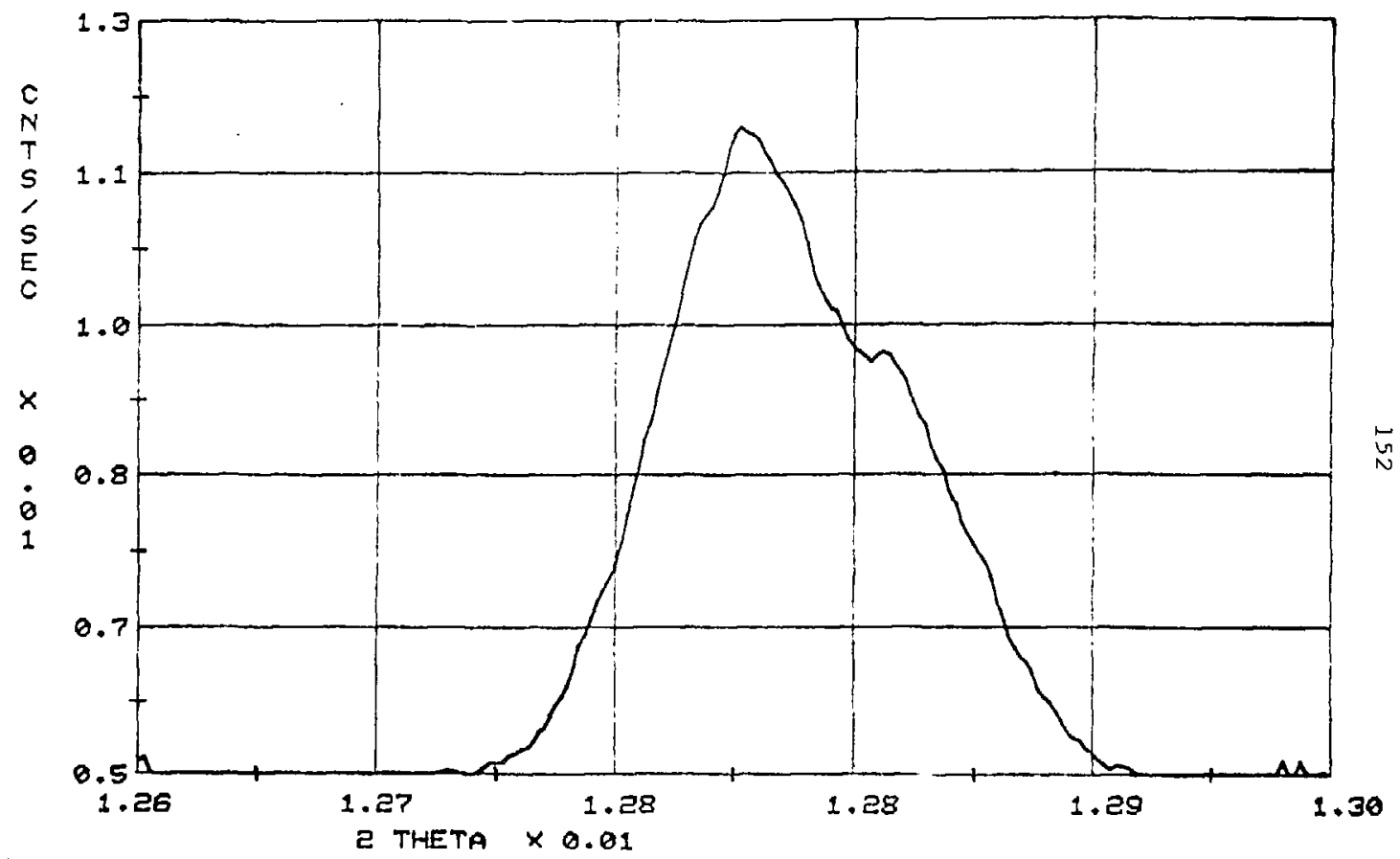

Fig. 47. Diffraction profile of the $(611,532)$ lines at $152 \mathrm{~K}$. 


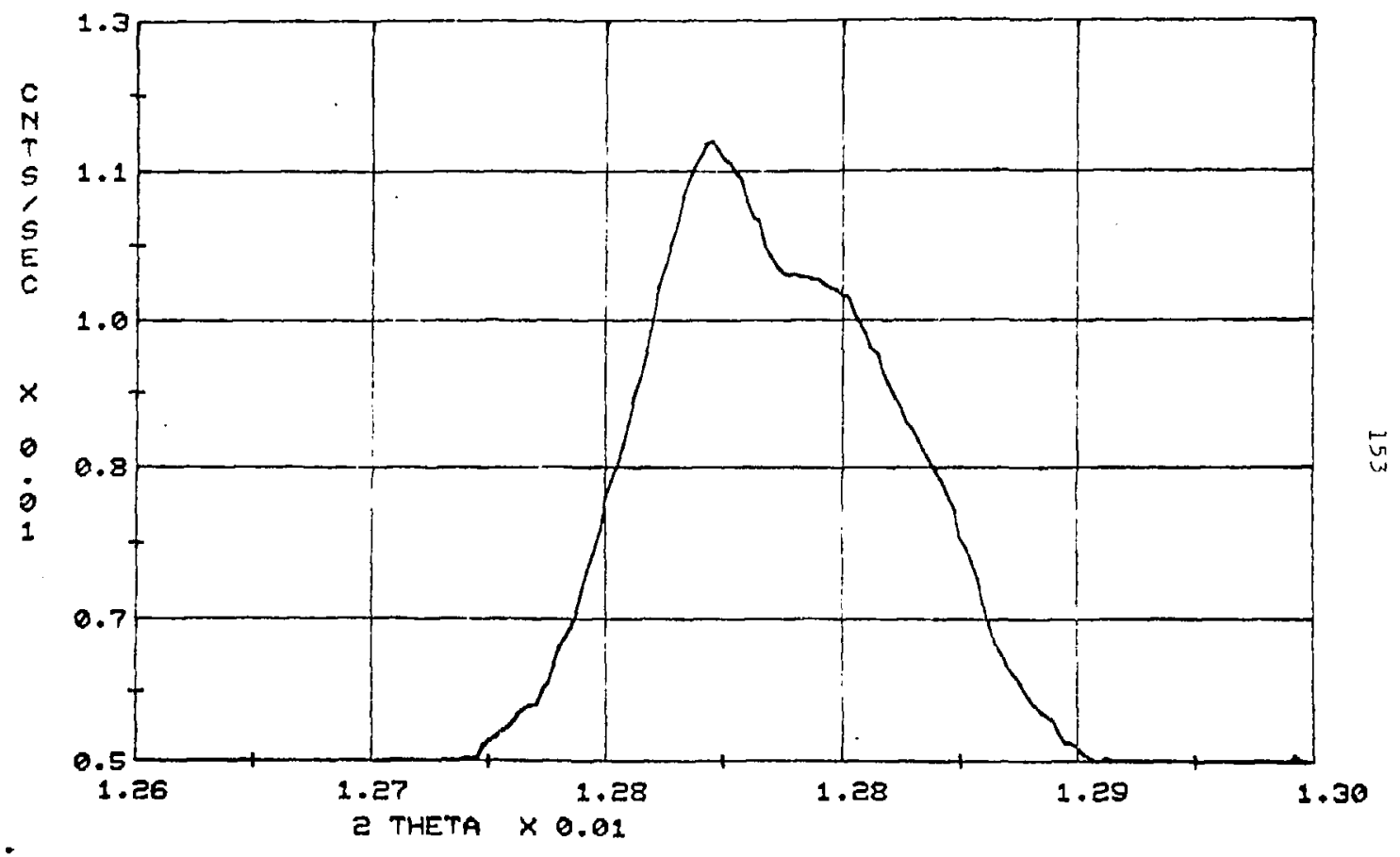

Fig. 48. Diffraction profile of the $(611,532)$ lines at $138 \mathrm{~K}$. 


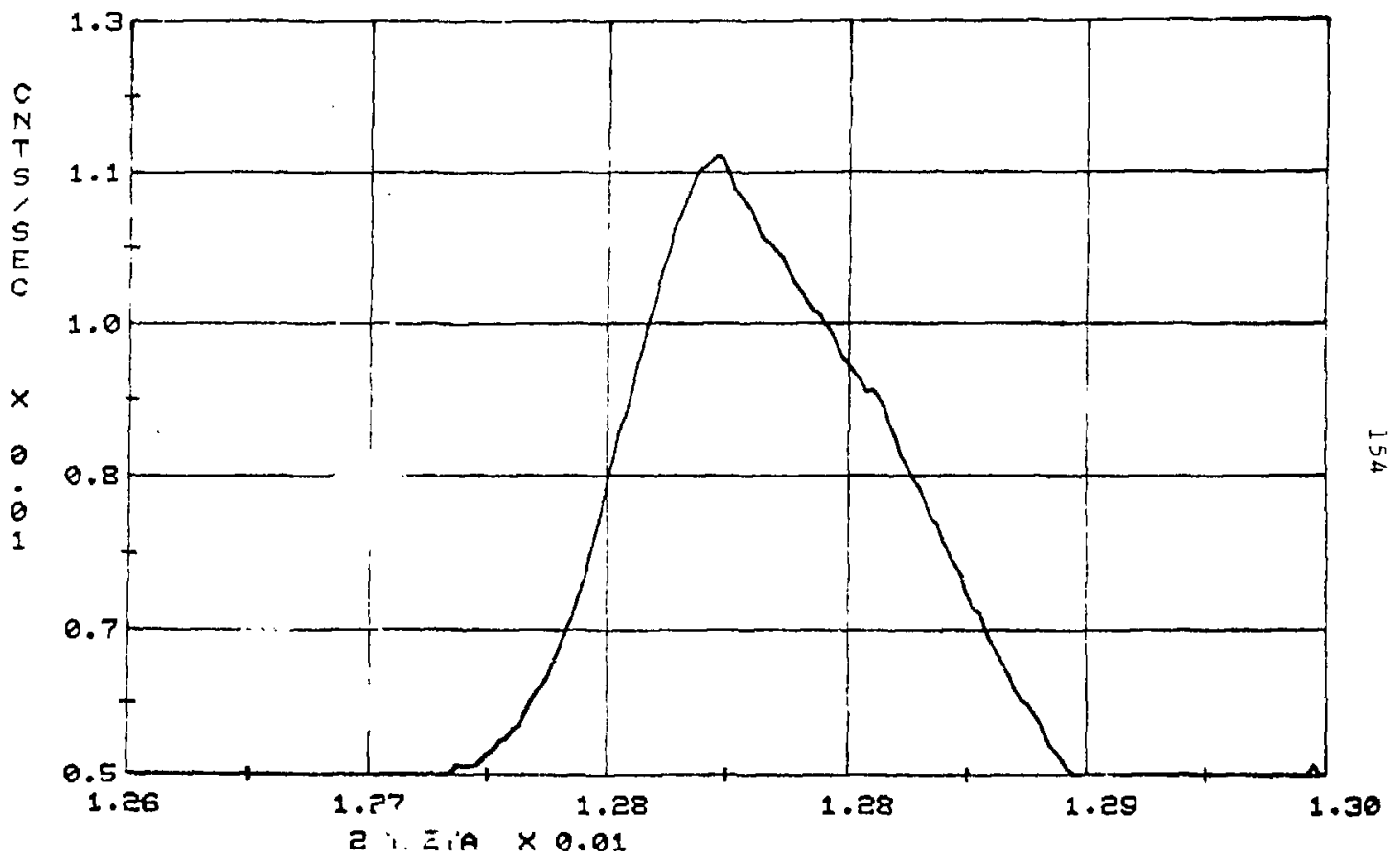

Fig. 49. Dit : action profile of the $(611,532) 1$ ines at $124 \mathrm{~K}$. 


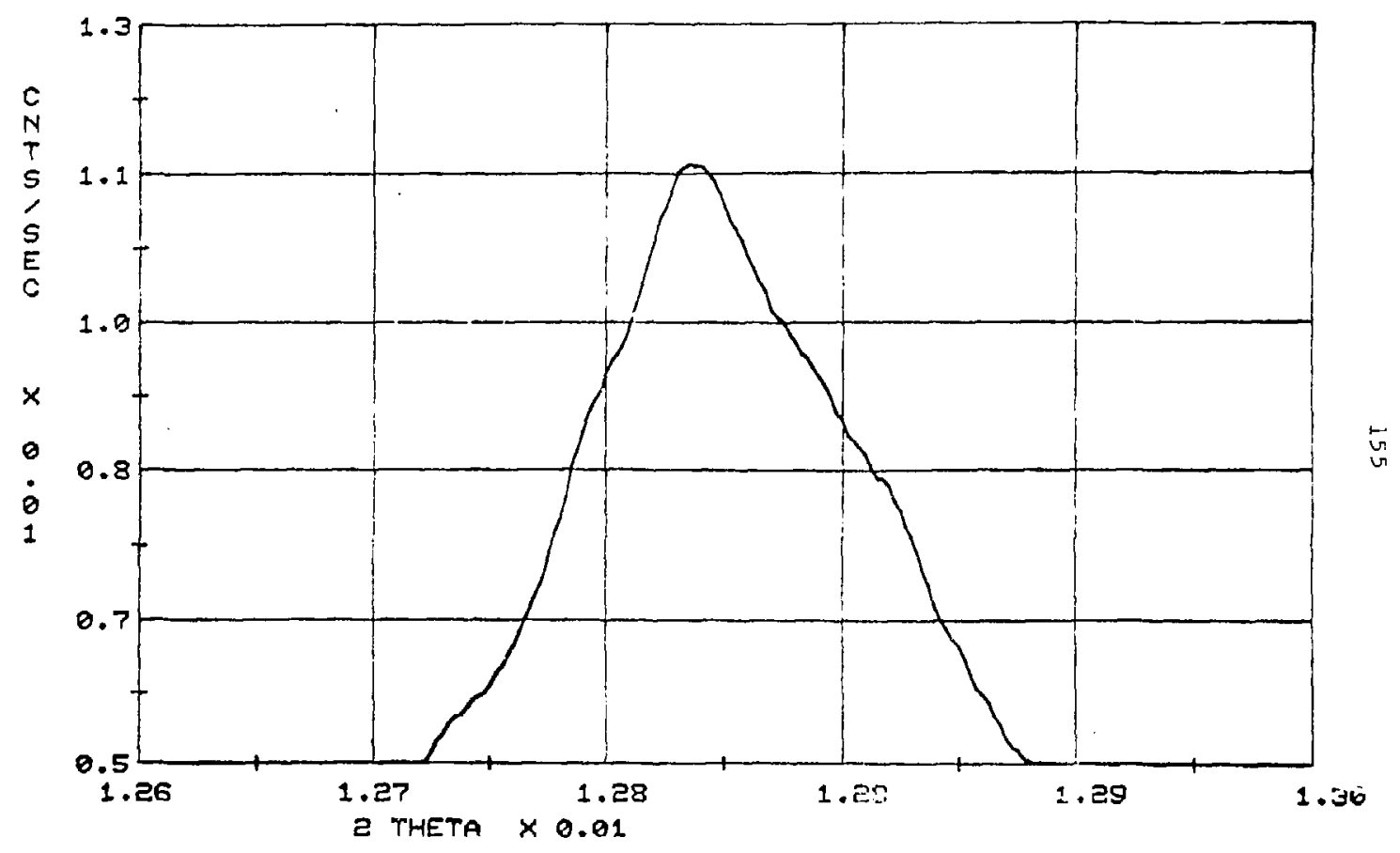

Fig. 50. Diffraction profile of the $(611,532)$ lines at $98 \mathrm{~K}$. 


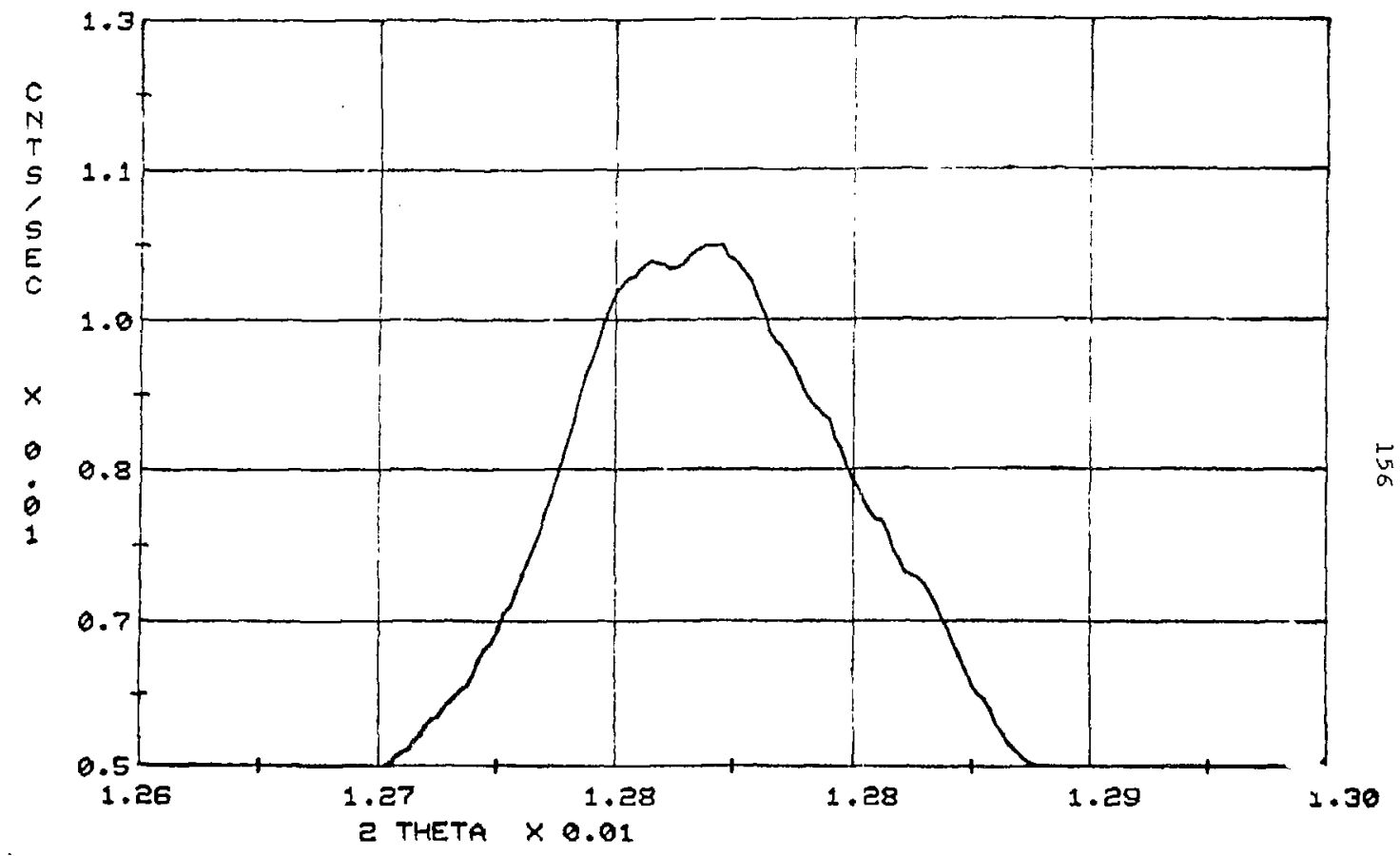

Fig. 51. Diffraction profile of the $(611,532)$ lines at $80 \mathrm{~K}$. 


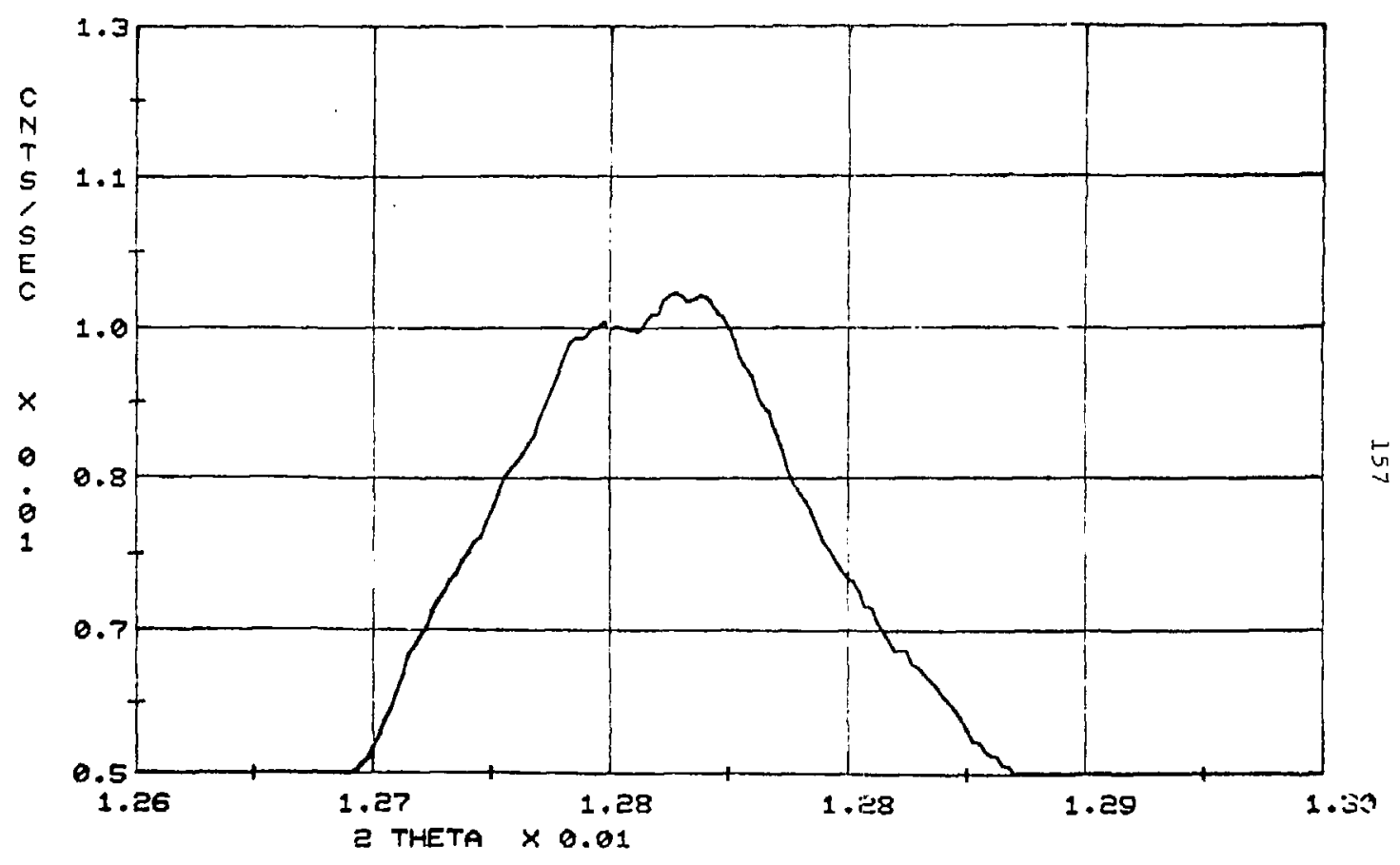

Fig. 52. Diffraction profile of the $(611,532)$ lines at $53 \mathrm{~K}$. 


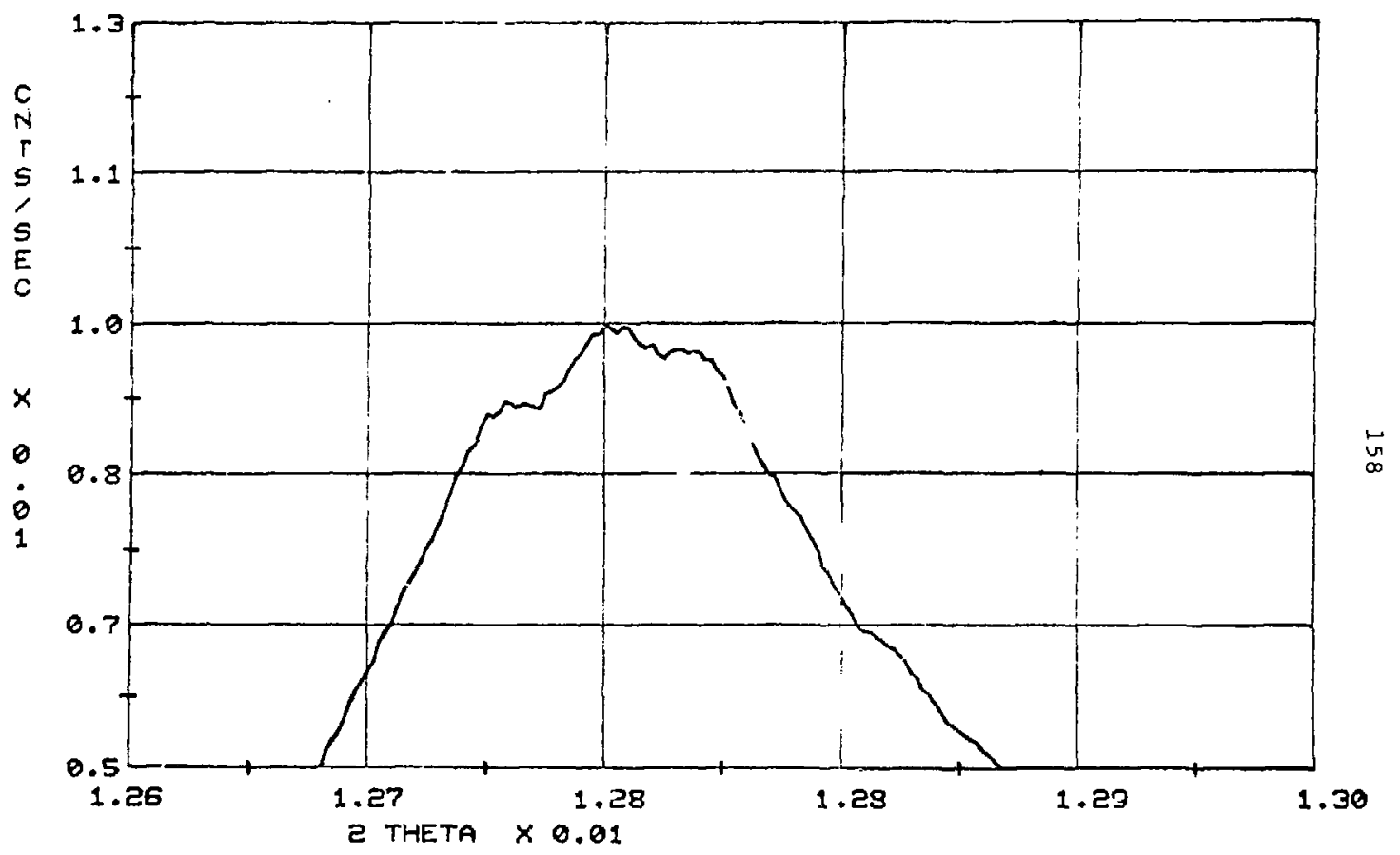

Fig. 53. Diffraction profile of the (611, 532) lines at $43 \mathrm{~K}$. 


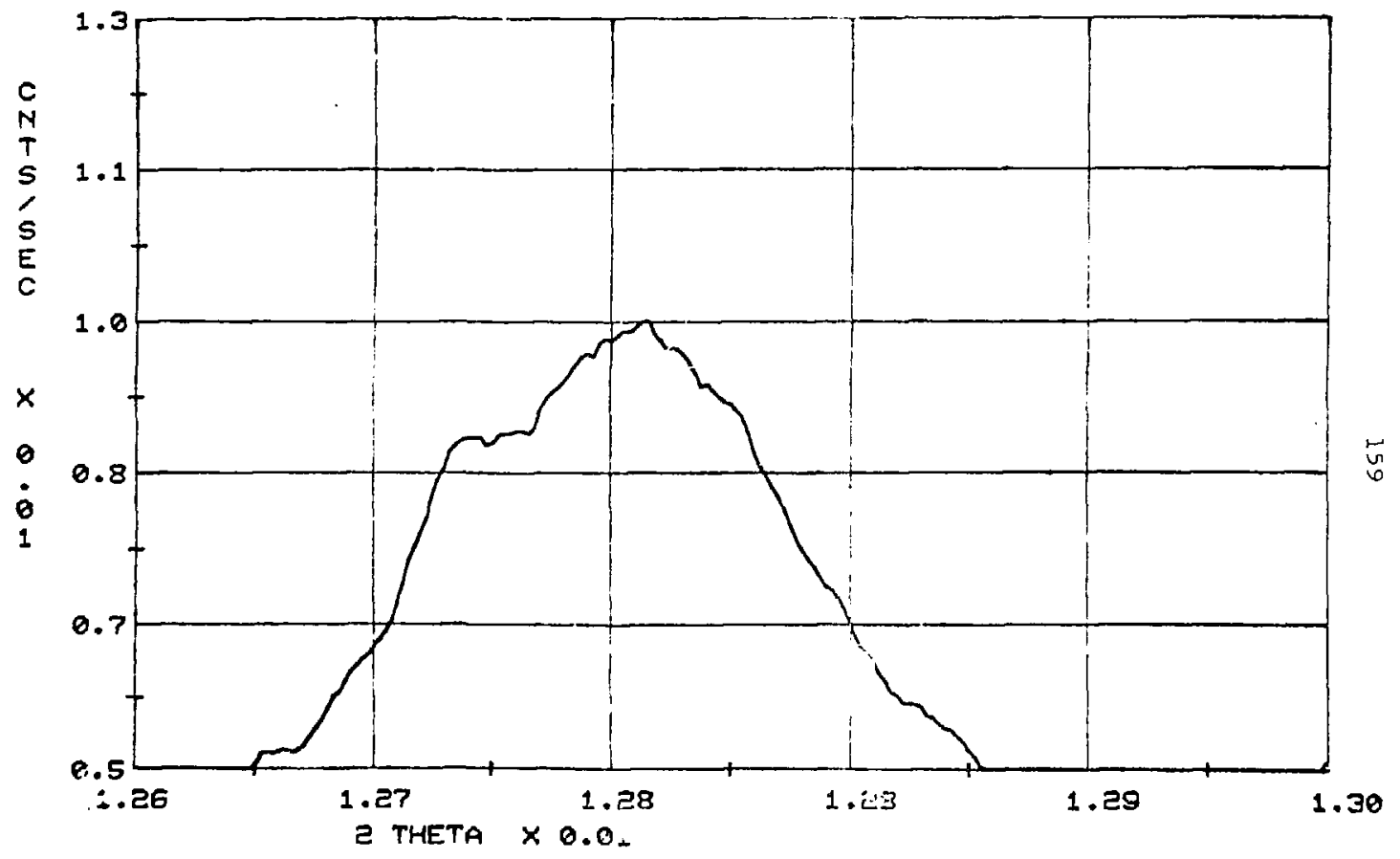

Fig. 54. Diffraction profile of the $(611,532)$ lines at $33 \mathrm{~K}$. 
$\div 60$

Fig. 55. Diffraction profile of the $(611,532) 1$ ines at $19 \mathrm{~K}$. The sample studied in the series of Figs. 46 through 55 had a precompressive strain of -0.65 percent at $19 \mathrm{~K}$. This strain was due to the thermal contraction of the indium sample stage between $19 \mathrm{~K}$ and room temperature. 


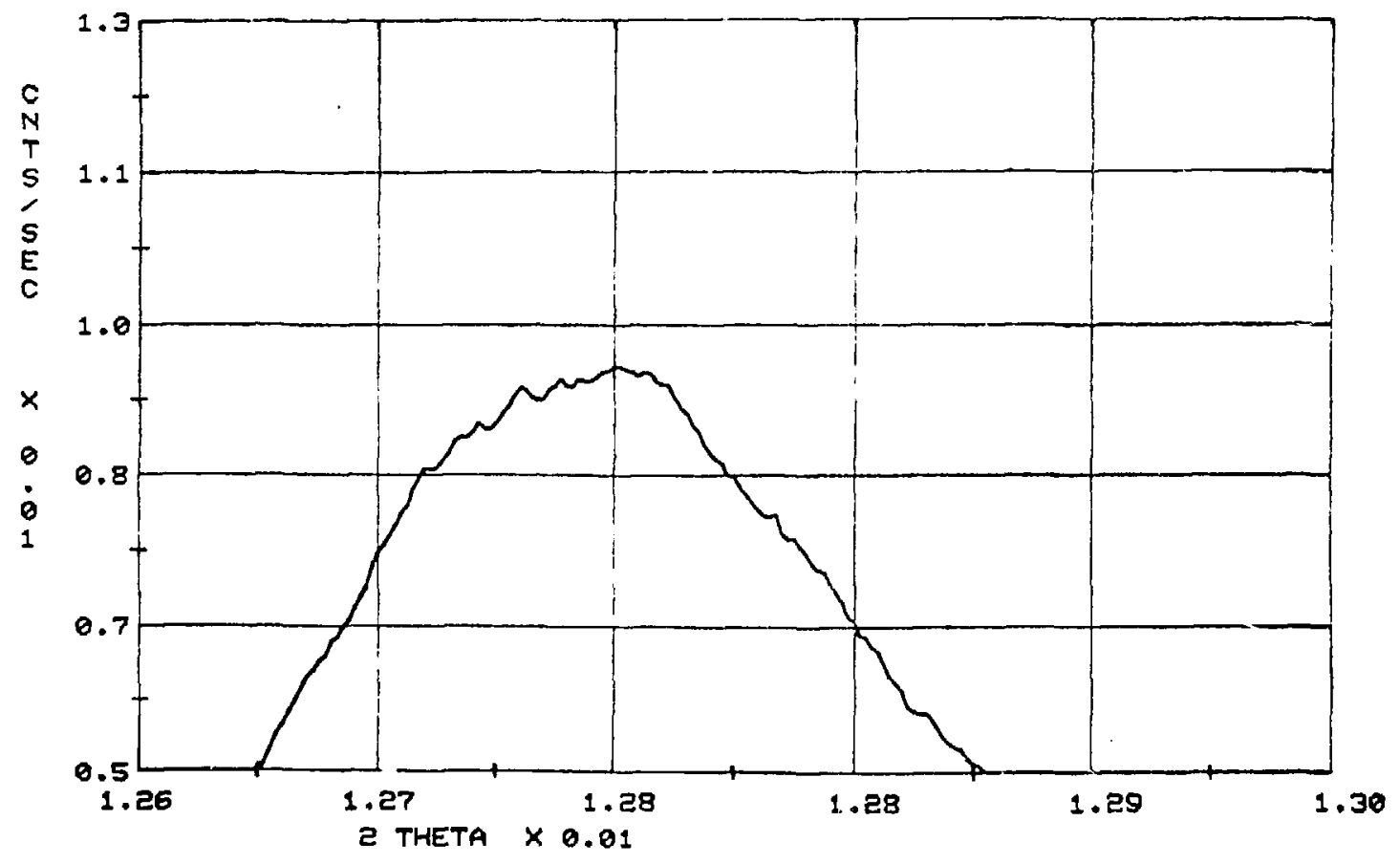




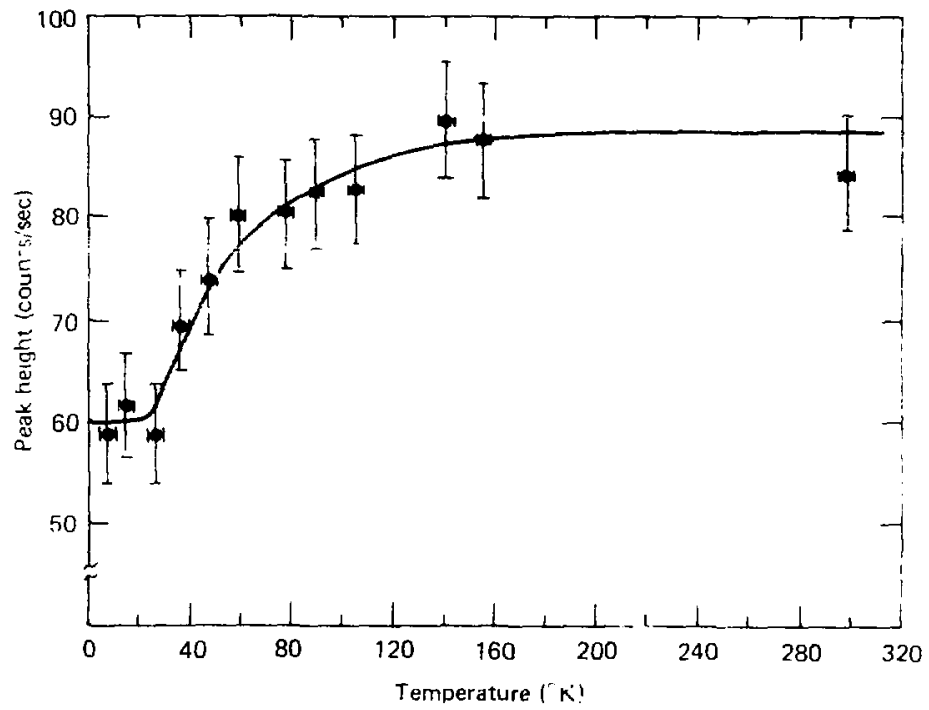

Fig. 56. Plut of the peak neight (above baikground) as a furrtion of temperature. The initiol compressive strain at $8 \mathrm{k}$ is $-\mathrm{il} .05$ percent. 


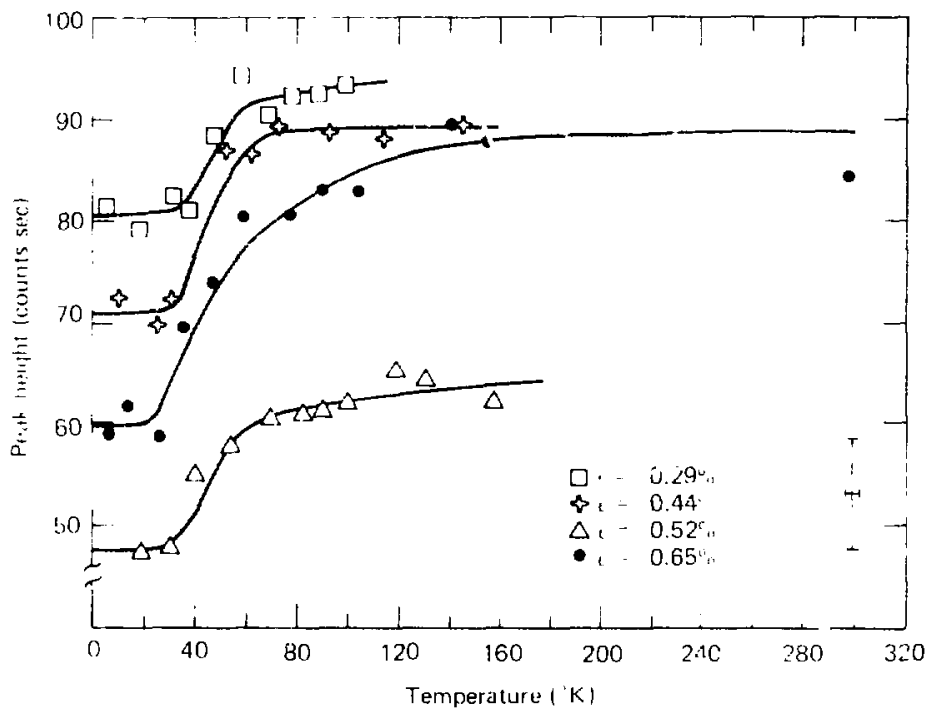

fig. 4'. Plut of the peak hejgnt (athve backgrouncli as a function of temperature and strain. The various strain values rifer to the initlal strains at $8 \mathrm{k}$. The initial peak height, at $8 \mathrm{k}$, is a iunctiun vi lix di ibumenl of each sample used in the experimenl. Fig. 59 shows chat only the change in peak height between low to nigh temperatures is important. 


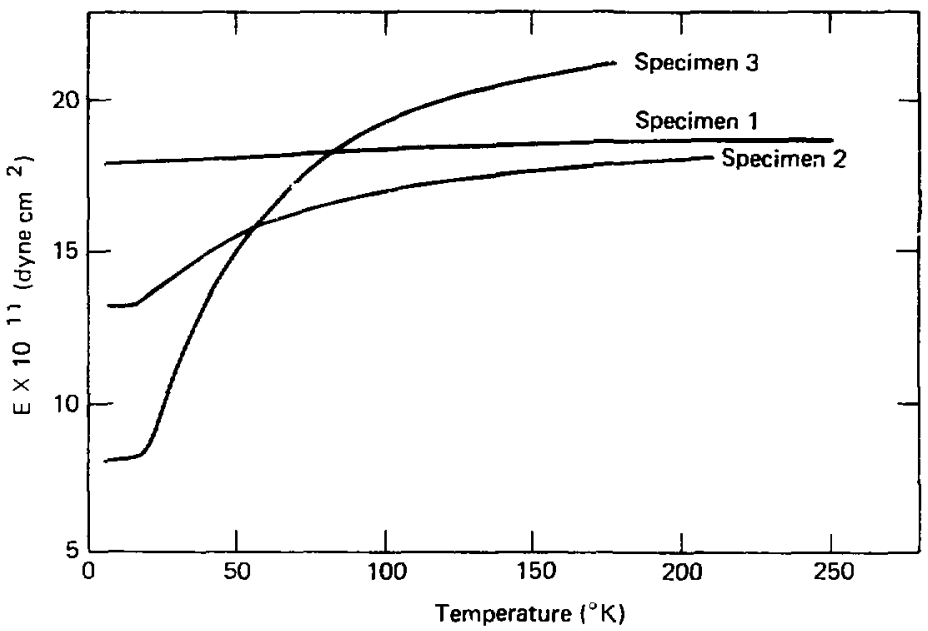

Fig. 58. The temperature dependence of Young's modulus for three different $V_{3} S i$ samples. Compare these curves to those of Fig. 57. 


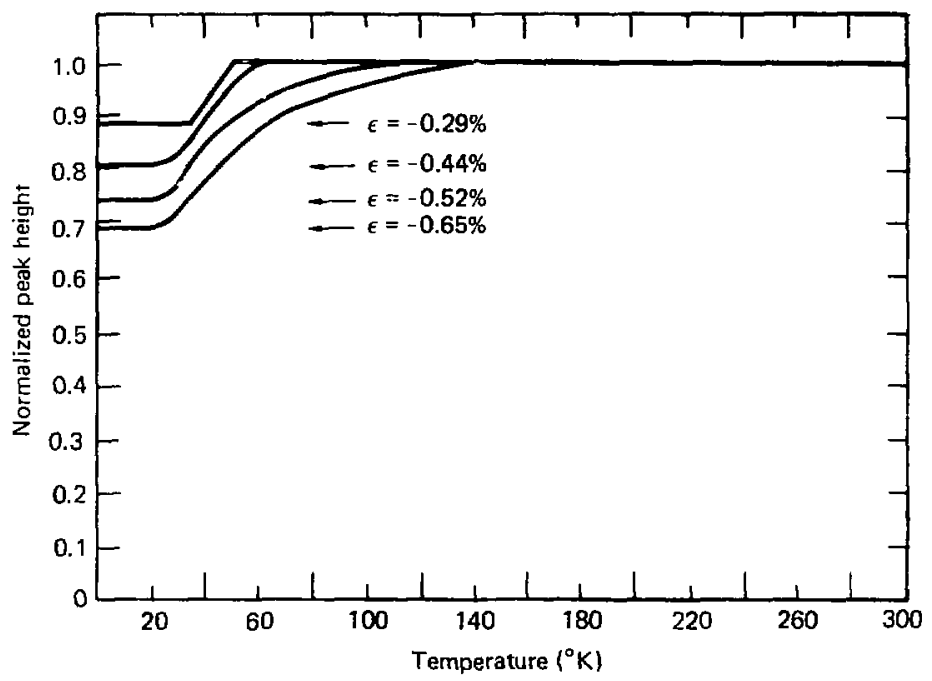

Fig. 59. Plot of the normalized peak height as a function of temperature and strain. These curves were made from Fig. 57 by assuming that at high temperatures the cubic volume fraction is equal to one and normalizing the four curves to their respective maximum heights. Once again the strain values are those measureo at $8 \mathrm{~K}$. 


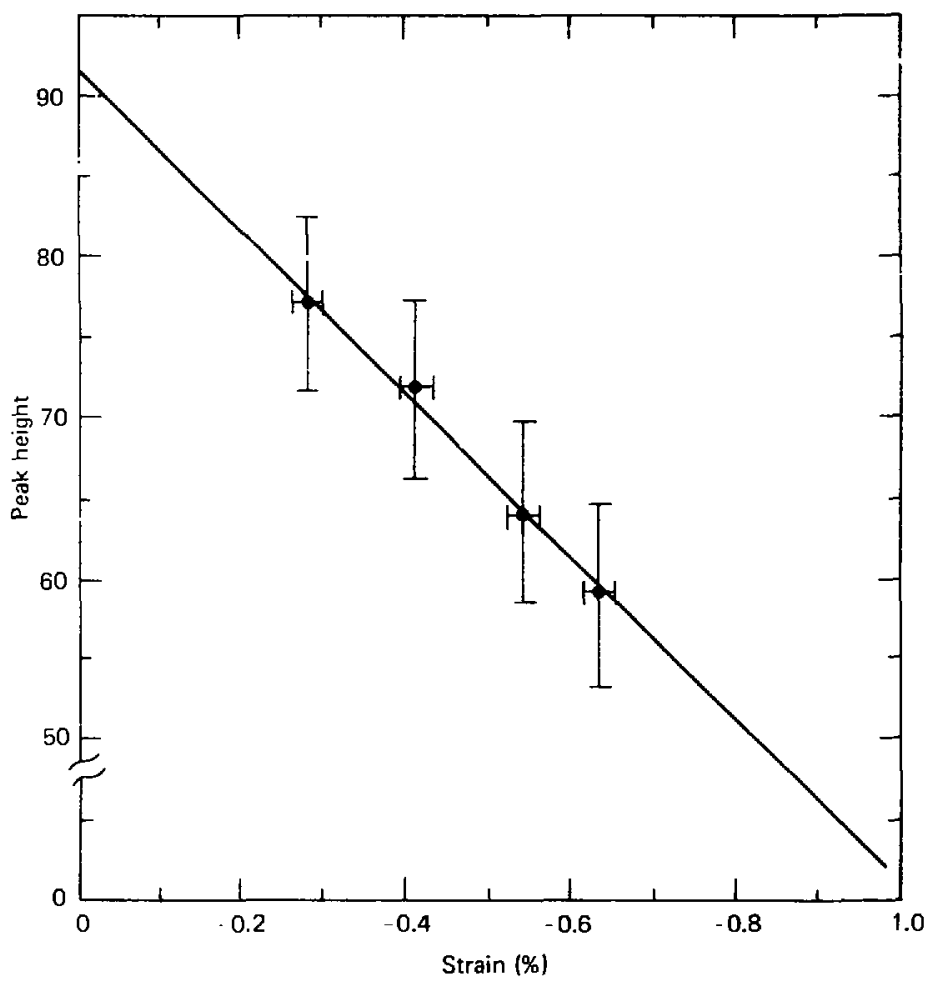

Fig. 60. Peak height as a function of strain at $8 \mathrm{~K}$. One $\mathrm{Nb}_{3} \mathrm{Sn}$ sample was held it $3 \mathrm{~K}$, and the peak height of its $(611,532)$ diffraction profile was measured as a function of stiain. 


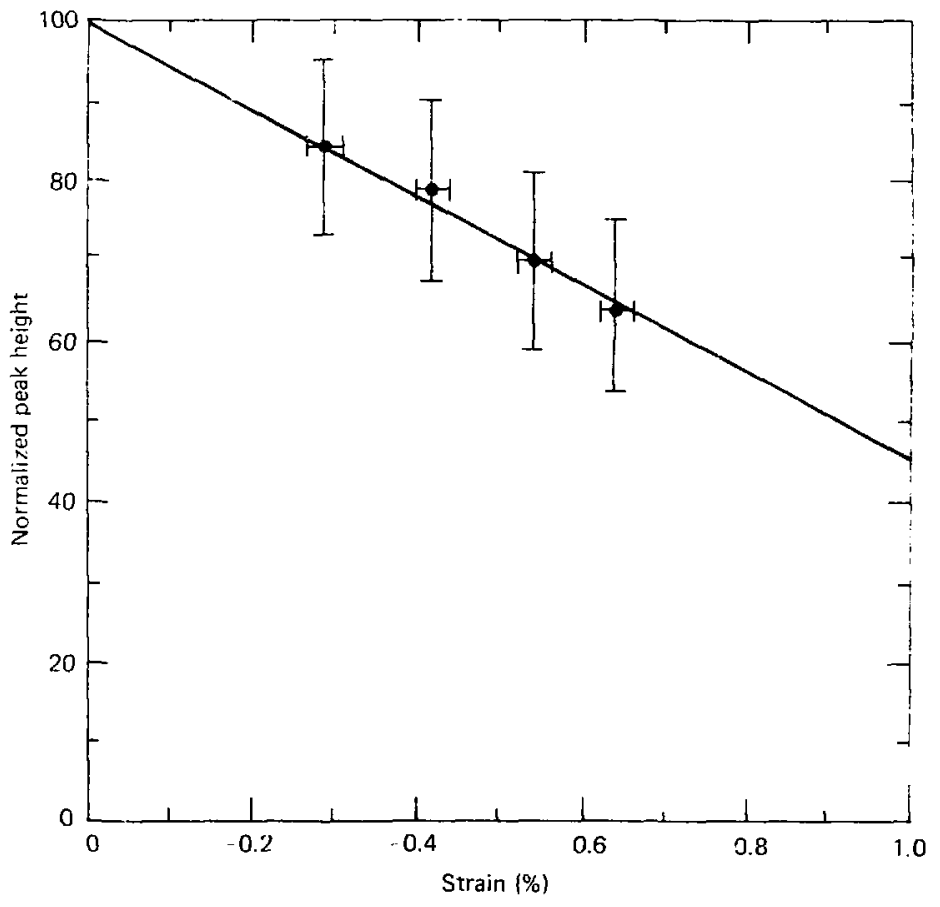

Fig. 61. Normalized peak rieight as a function of strain at $8 \mathrm{~K}$. The plot of Fig. 50 was normalized by the extrapolated peak height at zero strain. This figure indicates that the $\mathrm{N}_{3} \mathrm{Sn}$ should be completely transformed to the tetragonal phase at a strain of approximately -1.8 percent. 


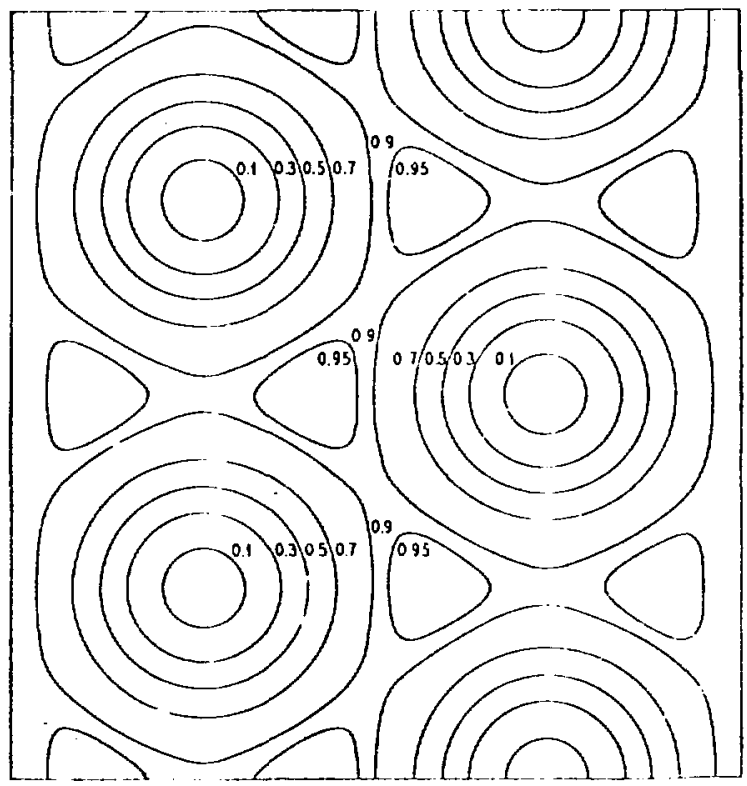

Fig. 62. Triangular lattice structure of supercurrents near $\mathrm{H}_{\mathrm{C} 2}$. The numbered contours indicate the relative value of the superconducting electron dinsity ( $A . M$. Campbell, et. al., March 1972). 


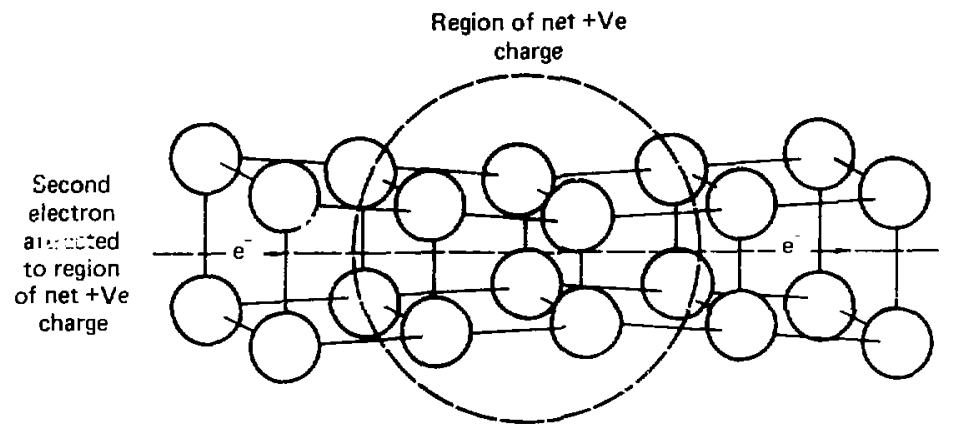

Fig. 63. The electron-phonalectron interaction. The electrostatic attraction betwetn the first electron and lattice ions leave an imward distortion of the ions in the wake of the electron. The distortion simulates a region of higher positive-charge density, which attracts a second electron. 
Tabie i

Interna 1 Bronze-Core Conductor Fabrication Parameters and Critical Current Properties

\begin{tabular}{|c|c|c|c|c|}
\hline Item & $\begin{array}{c}\text { Conduetor } \\
5-1 \\
\end{array}$ & $\begin{array}{c}\text { Conductor } \\
\mathrm{S}-4 \\
\end{array}$ & $\begin{array}{c}\text { Conductor } \\
\text { S-6a }\end{array}$ & $\begin{array}{c}\text { Conductor } \\
5-6 b \\
\end{array}$ \\
\hline Size $(\mathrm{mm})$ & $5.13 \times i .68$ & $5.13 \times i .68$ & $7.61 \times 7.62$ & $7.62 \times 7.5 ?$ \\
\hline Number Fj1aments & 703 & 2,257 & 30,625 & $30,62.5$ \\
\hline Filament Diameter & $55, \mu m$ & $26 \mu \mathrm{m}$ & $35.2 \mathrm{\mu m}$ & $35.2 \mu \mathrm{m}$ \\
\hline $\begin{array}{l}\text { Bronze Composition } \\
\text { Composition After } \\
\text { Peaction \% }\end{array}$ & $13 \% \mathrm{Sn} 87 \% \mathrm{Cu}$ & --- & $\cdots$ &.-- \\
\hline Cu & $63 \%$ & $71 \%$ & $48.7 \%$ & $48.7 \%$ \\
\hline $\mathrm{ND}+\mathrm{Bz}$ & $32.6 \%$ & $22.7 \%$ & $42 \%$ & $38.6 \%$ \\
\hline $\mathrm{Nb}_{3} \mathrm{Sn}$ & $4.4 \%$ & $6.3 \%$ & $9.3 \%$ & $12.7 \%$ \\
\hline $\begin{array}{l}\text { Heat Treatment } \\
I_{c}\left(\rho_{r}=10^{-11} \Omega-\mathrm{cm}\right)\end{array}$ & $750^{\circ}-36$ hrs. & --- & $\ldots$ & $\cdots$ \\
\hline At $H=8 \mathrm{~T}$ & $807 \mathrm{~A}$ & $1,070 \mathrm{~A}$ & $\because, 100 \mathrm{~A}$ & --- \\
\hline$H=10 \mathrm{~T}$ & $406 \mathrm{~A}$ & $640 \mathrm{~A}$ & $\therefore, 150 \mathrm{~A}$ & $7,625 \mathrm{~A}$ \\
\hline$H=12 \mathrm{~T}$ & $139 \mathrm{~A}$ & $273 \mathrm{~A}$ & $\mathrm{i}, 050 \mathrm{~A}$ & $2,600 \mathrm{~A}$ \\
\hline
\end{tabular}


TABLE 2 .

Critical Current Properties for Several Internal Bronze Core Conductors at Various Heat Treatments and Filament Diameters

\begin{tabular}{|c|c|c|c|c|c|c|c|}
\hline $\begin{array}{c}\text { Fillament } \\
\text { Diameter } \\
\mathbf{M m}\end{array}$ & Heat & Treatment & $\begin{array}{l}I_{C} \\
(12 T)\end{array}$ & $\begin{array}{l}\mathrm{Nb}+\mathrm{Bz} \\
\mathrm{Ar} e \mathrm{a} \\
\left(\mathrm{cm}^{2}\right)\end{array}$ & $\begin{array}{c}\mathrm{Nb}_{3} \mathrm{Sn} \text { Area } \\
\left(\mathrm{cm}^{2}\right)\end{array}$ & $\begin{array}{c}\mathscr{x} \\
\mathrm{No}_{3} \mathrm{Sn} / 100\end{array}$ & $\left(\mathrm{Nb}_{3}^{\mathrm{J}_{\mathrm{C}} \mathrm{S}}\right)$ \\
\hline 13 & $750 C$ & - $36 \mathrm{hr}$. & 110 & 0.020 & $4.0 \times 10^{-3}$ & 0.20 & $2.75 \times 10^{4}$ \\
\hline 26 & $750 C$ & $-36 \mathrm{hr}$. & 675 & 0.074 & $2.2 \times 10^{-2}$ & 0.30 & $3.10 \times 10^{4}$ \\
\hline 26 & 7500 & - $36 \mathrm{nI}$. & 215 & 0.023 & $3.4 \times 10^{-3}$ & 0.15 & $6.30 \times 10^{4}$ \\
\hline 42 & 7500 & $-36 \mathrm{hr}$. & 165 & 0.023 & $3.7 \times 10^{-3}$ & 0.16 & $4.50 \times 10^{4}$ \\
\hline 55 & $750 \mathrm{C}$ & $-36 \mathrm{hr}$. & 85 & 0.030 & $3.7 \times 10^{-3}$ & 0.12 & $2.20 \times 10^{4}$ \\
\hline 13 & 6500 & - $120 \mathrm{hr}$. & 200 & 0.020 & $5.2 \times 10^{-3}$ & 0.26 & $3.80 \times 10^{4}$ \\
\hline 26 & $650 C$ & $-120 \mathrm{hr}$. & 400 & 0.076 & $1.4 \times 10^{-2}$ & 0.18 & $2.80 \times 10^{4}$ \\
\hline 26 & $650 \mathrm{C}$ & $-150 \mathrm{hr}$. & 80 & 0.023 & $3.6 \times 10^{-3}$ & 0.16 & $2.20 \times 10^{4}$ \\
\hline 42 & 6500 & - $150 \mathrm{hr}$. & 65 & 0.023 & $2.6 \times 10^{-3}$ & 0.11 & $2.50 \times 10^{4}$ \\
\hline 55 & $650 C$ & $-150 \mathrm{hr}$. & 55 & 0.030 & $2.3 \times 10^{-3}$ & 0.08 & $2.40 \times 10^{4}$ \\
\hline 26 & $700 c$ & $-100 \mathrm{hr}$. & 130 & 0.023 & $3.6 \times 10^{-3}$ & 0.16 & $3.60 \times 10^{4}$ \\
\hline 42 & $700 \mathrm{C}$ & $-100 \mathrm{hr}$. & 100 & 0.023 & $3.6 \times 10^{-3}$ & 0.16 & $2.80 \times 10^{4}$ \\
\hline 55 & 7000 & $-100 \mathrm{hr}$. & 70 & 0.030 & --- & -- & $\ldots$ \\
\hline
\end{tabular}


171 


\section{BIBL IOGRAPHY}

Aihara, K., Suenaga, M., and Luhman, T., "Effects of Differential Thermal Contractian Between the Matrix and the Filaments in Mono- and Multifilamentary $\mathrm{Nb}_{3} \mathrm{Sn}$ on the Superconducting Critical Temperature," Proc. of gth Symposium on Engineering Problems of Fusion Research, San Francisco, CA, pp. 236-240 (Nov. 1979).

Abrikosov, A. A., "On the Magnetic Properties of Superconductors of the Second Group," Sov. Phys. - JETP. 5 , 174 (Dec. 1957).

3arisic, S. and Labbee, J., "The Elastic Constants of V3Si Type Compounds in the Cubic Phase," J. Phys. Criem. Solids 28, pp. 2477-2485 (1967).

Barrett, C. S. and Massalski, T. B., Structure of Metals Crystallographic Methods, Principles, and Data, 3rd Ed., McGraw Hill, NY, PP. 453-464 (1966).

Batterman, B. W. and Barrett, C. S., "Crystal Structure of Superconducting $V_{3} S i, "$ Phys. Rev. Lett. 13,390 (Sept., 1964).

Batterman, B. W. and Barrett, C. S., "Low Temperatur? Structural Transformation ir. V3Si," Phys. Rev, 145, 296 (May 1966).

Bhatt, R. N., "Structural Transition in A-15 Compounds: Possible Landau Theory Descriptions," Phys. Rev. B:17, 2947 (Apr., 1978).

Bilbro, G. and McMillan, W. L., "Theoretical Model of Superconductivity and the Martensitic Transiormation in A-15 Compounds," Phys. Rev. B: 14, 1887 (Sept. 1976).

Bilby, B. A. and Christian, J. H., The Mechanism of Phase Transformation in Metals and Allous, Inst. of Metals, 1956.

Bobrov, E. S., Massachusetts Institute of Technology, CambIiJge, MA, private communilation (June 1980).

Burke, 1., The Kinetics of Phase Transformations in Metals (Pergamon Press, oxford, 1965), pp. 196-213.

Bussiere, J. F., Welch, D. O., and Suenaga, M., "Young's Modulus of Polycrystalline Nb3Sn Between 4.2 and 300 K," submitted to J. Appl. Phys., Aug. 1979. 
Campbell, A. M. and Evetts, J. E., "Flux Vortices and Transport Currents in Type II Superconductors " Adv. Phys. 21 , 199 (Mar. 1972).

Clark, A. F, "Effects of Stress on Practical Superconductors, "Proc. 6th Internitional Conference on Magnet Technology, Alpha, Bratislava, pp. 612-618 (1977).

Clark, A. F., Ekin, J. W. Radebaigh, R., and Reed, D. T., "The Development of Jtandards for Practical Sup irconductors," IEEE Trans. Magn. Mag-15, pp. 224-7 (1969).

Cullity, B. D., Elemorits of X-ray Diffraction, AddisonWesley, Reading, MA, po. 130-131 (1956).

Dayan, M., Goldman, A. M., and Huang, C. C., "Double Superconcucting Transitions in Single Crystals of $\mathrm{V}_{3} \mathrm{Si}, "$ Phys. Rev. Lett. 42, 335 (Jan. 1979).

Deis, D. W., Cornist., D. N., Zbasnik, J. F., Nelsar, R. L., Sackett, S. J., ard Tayler, C. E., Superconducting Magnet Development Program Annual Repart, July 1975 Through September 1976, Lawrence Livermore Laboratory, Livermore, CA, UCRL-5003i-76 (1976).

Deis, D. H., Sarnish, D. N., Rosdahl, A. R. and Hirzel, D. G., "Mechanical Strain o" Large, Multifilament NbzSn Conduztors for Fusion Machines," Proc. 6th International Conference on Magnet Technolagy, Bratislava, Czechoslovakia, Aug. 29-Sept. 2. 1977.

Deis, D. W., Hirzel, D. G., Rosdahl, A. R., Roach, D. R., Freynik, H. S., and Zbasnik, J. P., "Evaluation of Large Multifilament Nb3Sn Canductors With a New 12-Tesla Tensile Tes'c Apparatus," Adv. Crycg. Eng. 24, 317 (1977).

Dois, D. W., Layrence Livermore Laboratory, Livermare, CA, unpubliched dar.a (June 1977).

Durlu, T. N., "High Voltage Transmission Electron Microscopy Studies of Strain Induced Martensitic in Fe-Ni-C Alloys," Acta. Metall. 26, 1855 (Dec. 1978).

Easton, D. S., Kroeger, D. M., Specking, ب., anr, Koch, $\therefore$. C., "A Prediction of the Stress State in Nb3Sn superconducting Ccrijosites," submitted to 3. Appl. Phys., (1979). 
Ebert, L. J., Fenor, R. .T., Hamiiton, C. H. ilecker, : 5., and Wright, $i$. K., Analyticai Approach to Composite Behavior, AFML-TR-69-129, AD-857, B59 (June 1969).

Ebert, L. J., Hecker, S. S., and Hamilton, C. H., "The Stress Strain Behavior of Concentric Composite Cylinders," J. Compos. Mater. 2 , pp. 458-476 (1968).

Ekin, 3. W., "Strain Scaling Law for Flux Pinning in Practical Superconductors," submitted to Cryogenics, Apr. 1980 .

Entel, P., "On Structural Instabilities in It inerant Magnets and Superconductors," Z. Phys. B 2R, pp. 191-?00 $(1977)$.

Foner, S. and McNiff, E. J., "Anisotrophy of tic2 in Single Crystal NozSn and $V_{3} S_{j}$. at High Magnetic

Fields: Limitations of Linear Chain model," Phys. Lett. 58A, up. 3i8-320 (Sept. 1975).

F :eynik, H. S., Roach, D. R., Deis, D. W., and Hirzel, D. G., "Evaluation of Metal Foil Strain Gages for Cryogen: ipplication in High Magnetic Fields," Adv. Cryog. Eng. 24, pp. 463-479 (1977).

GoI'kn:, L. P. and Dorokkov, D. N., "On the ineory of the Structurai Properties of A-15 Type Materia1s." J. Low Temp. Phys. 22, pp. 1-26 (1976).

Ham":ton, C. H., Hecker, S. S., and Ebert,... J., "Mechanical behavior of Unaxially Loaded Multilayered Cylindrical Composites," J. Basic Eng., pp. E61-670 (Dec. 1971).

Hamilton, C. H., Micromechanics of Axially Luaded Filamentary and Cylindrical Cumposites, Ph.D. dissertation, Case Western Reserve University, Cleveland, oH (Sept. 1968).

Handoook on Matorials for Superconducting Machinery, MCIC-HB-04 (Metals and Ceramics Information Center, Batelle Columbus Laboratories, Columbis, ofi 1977:.

Hearn, E. J., Merhanics of Materials Vol l, Pergamon Press, oxfe:d (19;7).

Hearn, E. J., Mechanics of Matrials Vol. 2, Peiganion Press, Oxford, p. $61 \mathrm{lj}(1977)$. 
Hecker, S. S., Elasto-Plastic Analys is of Composite Cylinders in Axial Tension, Ph. D. Thesis, Case western Reserve University, Cleveland, Ohio (Sept. 1968).

Hecker, S. S., "Experimental Studies of Yield Phenomona in Biaxially Loaded Metals," in Constitutive Equations in Viscoplasticity: Computational and Engineering Aspects, Stricklin, J. A. and Saczalski, K. J., Eds. (ASME AMD-Vol. 20, NY, Dec. 1976) pp. 1-34.

Hecker, S.S., Hamilton, C. H., and Ebert, L. J. "ElasticPlastic Analyses: A Simplified Approach," Scr. Metall. 3. pp. 793-i,98 (1969).

Hecker, S. S.. Hamilton, C. H., and Ebert, L. J., "Elastoplastic r.nalysis of Residual Stresses and Axial Loading ill Composils rulinders," J. Mater., JMLSAM 5, pp. 868-900 (Dec. 1970).

Hentenyi, M., Ed. Handbook of Experimental Stress Analyses, John wiley, NY, pp. 440-444 (1950).

Ho, K. M. Pickett, W. E., and Cohen, M. L., "Electronic Properties of $\mathrm{Nb}_{3} \mathrm{Ge}$ and $\mathrm{Nb}_{3} \mathrm{Al}$ From Self-Consistent Pseudcpotentiais. II. Bonding, Electronic Charge Distributions, and Structural Transformation," Phys. Rev. B $: \underline{19}, 1751$ (Feb. 1979).

Hoard, R. W., Scanian, R. M., and Hirzel, D. G., "MAXIMSUPER: A Computer Program to Assist in the Design of Multifilamentary Siperconducting Composites," to be published in Adv. Cryog. Eng. 26.

Hoard, R. H., Scanlan, R. M., Smith, G. S., and Farrell, C. L., "The Effect of Strair on the Martensitic Phase Transition in Superconducting Nb3Sn," Proc. of 1980 Applied Superconductivity Conference, Santa Fe, NM, in Press (Sept. 1980).

Horsch, P., "Electron-Phonon Interaction Due to Interchain Coupling in Nb3Sn," Solid State Commun. 18, pp. 27-30 (1976).

Kato, M., Monzen, R., and Mori, T., "A Stess-Induced Martensitic Transformation of Spherical Iron Particles in a Cu-Fe Alloy," Acta. Metall. 26, pp. 6u5-13 (Apr. 1978).

Kelly, A. and Davies, G. J., "Principles of Fiber Reinforcement of Metals," Metall. Rev. 10, pp 1-77 (1965). 
King, H. W., Cocks, F. H., and Pollock, J. T. A., "Fur'.her Evidence of the Low Temperatire Phase Iransformation in Nb3Sn and $V_{3} S i, "$ Phys. Lett. 26A, 77 (Dec. 1967).

King; H. W., "The Mechanism of Phase Transformation in Crystaliine Solids," Proc. of Int. Symposium, Manchester, July 1968, (Institute of Metals 1969), p. 196.

Kitte1, C. Introduction to Solid State Physics, 5th Ed., John wiley, NY, P. 11- (1976).

K.napp, G. S. and Bader, S. D., "Mode Softening and High Superconducting Transition Temperature in Some A-15 Compounds," Ferroelectrics 16, pp. 263-265 (1977).

Koch, C. C. and Easton, D. S., "A Review of Mechanical Behavior and Stress Effects in Hard Superconductors," Cryogenics 17, pp. 391-413 (1977).

Kramer, E., "Scaling Laws for Flux Pinning in Hard Superconductors," J. Appl. Phys. 44, pp. 1360-1370 (Ma'. 1973).

Labbe. J., "Relationship Betweer Superconductivity and Lattice Instability in the A-15 Compounds," Phys. Rev. 172,451 (Aug. 1968).

Landau, L. D. and Lifshitz, E. M., Statistical Physics, Pergamion Press, London (1958).

Lee, T. K. and Birman, J. L., "New Three-Dimensioral K.P. Model for the Electronic Structure of A-15 Compounds and Application to Anomalous Properties of $v_{3} S_{i}$ and $\mathrm{Nb}_{3} \mathrm{~S}_{n}$ in the Cubic Phase," Phys. Rev. B: 12, 4931 (June 1978).

Luhman, T. and Dew-Hughes, D. Eds., Metallurgy of Superconducting Materials, Academic Press, New York (1979).

Luhman, $T$, and Pande, C., "Flux Pinning in Bronze Processed Nb3Sn," J. Appl. Phys. 47, pp. 1459-1463 (ApI. $1976)$.

Luhman, T. and Suenaga, M., "Effects of Stresses, Induced by Thermal Contraction of a Bronze Matrix, on the Superconducting Properties of NbzSn Wires," Appl. Phys. Lett. 29, 61 (July 1976).

Luhman, T., "Effects of Be Alloy Additions to the Bronze Matrix of NbzSn Monofilame it wires," J. Appl. Phys. 5n, 3766 (May 19:3). 
Luhman, T., Kaiho, K., and Suenaga, M., "Effects of Alloying on the Strain Response of Critical Currents in Nb3Sn Coriductors," to be published in, Adv. Cryog. Eng. 2E.

Lyman, T., Ed., Metals Handbook 8tr. Edition, Vol. 1, Properties and Selection of Metals, ASM, Metals Park, Ohio, p. 1028 (1961).

Magraw, J. E, and Larbalestier, D. C., Current Sharing in Multifilamentary Superconducting Composites - an Experimental Result, Rutherford Laboratory Internal Report SMR/14.

Mailfert, R., Batterman, B. N., and Hanak, J. J., "Observations Related to the Order of the Low Temperature Structural Transformation in $\mathrm{V}_{3} \mathrm{Si}_{\mathrm{i}}$ and $\mathrm{Nb}_{3} \mathrm{Sn}, "$ Phys. Status Solidi 32, K67 (1969).

Matthias, B. T., Corenzwit, E., Cooper, A. S., and Longinotti, L. D., "Instabilities of High Temperature Superconductors," reprinted from Proc. of tne National Academy of Sciences 68, pp. 56-57 (Jan. 1971).

Mendelson, A., Plasticity Theory and Application, MacMillen Book, NY (1968).

Mukherjee, M. N. and Baixeras, J., "On the Relationship Between the Transition Temperature and the Density of States in A-15 Superconductors," Phys. Lett. 16, 375 (Oct. 1978).

Murase, S., Koike, Y., and Shiraki, H., "Studies on Superconducting $\mathrm{Nb}_{3} \mathrm{Sn}$ formed from High-Tin-

Concentration Cu-Sn Alloy," J. Appl. Phys, 49, 6020 (1978).

Muvdi, B. B. arid McNabb, J. W., Engineering Mechanics of Materials, MacMillan, NY (1980).

Nakayama, I., "Structural Transformation and Superconductivity in A-15 Compounds," J. Phys. Soc. Jpn. 43, 1533 (Nov. 1977).

Jlsson, D. M., "A Sequentlal Simplex Program for Solving Minimization Problems," J. Qual. Technol. 6, 53 (Jan. 1974). 
Paul, B., "Macroscopic Criteria for Plastic flow and Brittle Fracture," Fracture: An Advanced Treatise, Ed. H. Liebowitz, Academic Press, NY, pp. 385-483 (1968).

Penfold, D. H., Superconductivity and Structure in Beta-Tungsten Compounds, Ph.D. dissertation, Imperial College of Science and Technology, London, England (1971).

Pickett, W. E., Ho, K. M., and Cohen, M. L., "Electronic Properties of $\mathrm{Nb}_{3} \mathrm{Ge}$ and $\mathrm{Nb}{ }_{3} \mathrm{Al}$ From Self-Consistent Psec opotentials. I. Bond Structure and Density of States," Phys. Rev. B:19, 1734 (Feb. 1979).

Povolotskil, V. D., Lhuravlev, L. G., and Shteinberg, M. M., "Martensitic Transformation During Deformation of Fe-Ni-Alloys," Met. Sci. and Heat Teat. 19, pp. 434-8 (May 1977).

Roberge, R., "Status of the Development of High-Field Als Superconductors," J. Magnetism and Magnetic Materiais ll, pp. 182-185 (Apr. 1979).

Rupp, G., "Enhancement of the Critical Current of Multifilamentary $\mathrm{Nb}_{3} \mathrm{Sn}$ Conductors by Tensile Stress," J. Appl. Phys. 48, 3858 (Sept. 1977).

Rupp, G., "Stress Induced Normal to Superconducting Transition in Multifilamentary Nb3Sn Conductors," IEEE IIans. Magn. MAG-15:189-192 (Jan. 1979)

Scanlan, R. M., Cornish, D. N., Zbasnik, J. P., Hoard, R. W. Wong, J., and Randall, R., "Properties of Multifilamentary NisSn Superconductors Fabricated by the Internal Bronze Approach," to be published in Adv. Cryog. Eng. 26.

Scanlan, R. M., Hoard, R. W., Cornish, D. N., and Zbasnik, J. P., "Mechanical Properties of High-Current Multifilamentary Whosn Conductors," presented at the International Cryagenic Materials Conference, Brookhaven National Laboratory, Upton, NY, May 28-29, 1980.

Shimizu, K., Sakhmoto, H., and Otsuka, K., "Phase Diagram Associated with Stress Induced Martensitic Transformations in a Cu-Al-Ni Alloy," SCr. Metall. 12, pp. 771-6 (Sept. 1978).

Shirane, G. and Axe, J. D., "Phonon Softening of Nb3Sn in T Modes," Phys. Rev. B: 18, 3742 (Oct. 1978). 
Specring, W., Easton, D. S., Kroeger, D. M., and Sanger, P. A "Stress Effects in a Nb3Sn Conductor for Use in the agnetic Fusicn Energy Program," to be published in Adv. Cryog. Eng. 26.

Suenaga, M., Brookhaven Ndtional Laboratory, Upton, NY, Private Communication (Apr. 27, 1979).

Suenaga, M., Luhman, T., Klamut, C., Fabrication and Properties of Conductors for Fusion Magnets, Annual Report Brookhaven National Laboratory, Upton, NY (Oct. 1, 1976 Sept. 30, 1977).

Tadaki, T., Nagaura, T., and Shimizu, K., "Two Different Morphologies and Crystal Structures of Stress-Induced Martensites in a Ag-45 at. \% Cd Alloy," Sci. Metall. 12, pp. 453-6, (May 1978).

Testardi, L. R. and Bateman, T. B., "Lattice Instability of High-Transition-Temperature Superconductors. I I Single-Crystal V3Si Results," Phys. Rev. 154, pp. 402-10 (Feb., 1967).

Testardi, L. R., Kunzler, J. E., levinstein, H. J., and Wernick, J. H., "Unusual Strain Dependence of $\mathrm{T}_{c}$ and Related Effects in A-]5 Superconductors," Solid State Commun. 8, pp.. 907-911 (1970).

Testardi, L. R., Kunzler, J. E., Levinstein, H. J., Maita, J. P. and Wernick J. H., "Unusual Strain Dependence of Tc and Related Effects for High-Temperature (A-15 Structure) Superconductors: Elastic, Thermal, and Alloy Behavior," Phys. Rev. B: 3, 107 (Jan., 1971).

Testardi, L. R., "Structural Instability, Anharmonicity, and High-Temperature Superconductivity in A-15 Structure Compounds," Phys. Rev. B: 5 , 4342 (June 1972).

Testardi, L. R. "Unusual Strain Dependence of $T_{C}$ and Related Effects for High-Temperature (A-15 Structure) Superconductors: Sound Velocity at the Superconducting Phase Transition," Phys. Rev. B:3, 95 (Jan., 1971).

Ting, C. S. and Birman, J. L., "Theory of the Arrest of Elastic Softening in Superconducting A-15 Compounds," Phys. Rev. B: 12, 1093 (A.19. 1975).

Tinkham, M., Introduction to Superconductivity, McGsawH.L11, NY $(1975)$. 
Van der Klein, C. A. M. and Prij, J., "Stress Effects in Nb $3 S_{n}$ - Nb - Bronze Composites, "to be published in Adv. Cryog. Eng. 26 .

Vance, $E . R$, and Finlayson, T. R., "The Lattice Softening in $V_{3} S_{i}, "$ J. Appl. Phys. 39, 1980 (Mar. 1968).

Vieland, L. J. and Cohen, R. W., Studies of Transition Temperatures in Superconductors, Final Report RCA Laboratories, Princeton, NJ (March 1968 - March 1970).

Vieland, L. J. and Cohen, R. W., "Evidence for a FirstOrder Structural Transformation in Nb3Sn," Phys. Rev. Lett. ㄱ. 373-376 (Feb. 1971).

Weger, M. and Goldberg, I. B., "Some Lattice and Electronic Properties of the A-15 Tungstens," Solid State Phys. 28, pp. 1-177 (1973).

Wilson, M., Current Sharing in Resistive Composites, Rutherford Laboratory Internal Report SMR/l.

Zbasnik: J. P., Lawrence Livermore National Laboratory, Livermore CA, Private Commurication (Aug. 1978).

Ziegler, G., "Influence of Strain on NbzSn Multifilamentary Conductors," J. Appl. Phys. 49(7), pp. $4141-43$ (July 1978). 
180 


\section{APPENDIX 1 \\ COMPUTER PROGRAM LISTING}

And what of my life Spent studying fields, The interconnecting fabrics That weave reality's hills, A parable that's true:

Ali with sight cannot see.

So, I looked (again) upon my own, To view them interwoven with you. 
CHAT 16PD 10:50:35 AB8/27/30

PROGRAM J1AXIMSUFER (OUTFUT, TAPEG =OUTFUT)

CODE ANALYSIS

CALL CHANGE (SH+TEST)

OPTIMIZE

$C$
$C$
$C$
$C$
$C$
$C$
$C$
C
$C$
$C$
$C$
$C$

** PPOGKAI1 MAXIMUM SUPERCONDUCTOR CALELLATES THE CRITICAL **

+* EURFENT FOR V'ARIOUS MULTIFILAMEN $T$ COMPOSITE STPAIN DLPENDENTW*

A* SUPEFICONDUCTORS ARRANGED IN CYLIHORICAL GEOMETRY.

** IHIS IS DOHE EY FIKST CALCULATING THE RESIDUAL STRAIH DUE TO**

*:* THCFMAI. CONIRACTION. THEN THE STRAINS ARE FOUND UHIEN THE * *:*

* * CONUSIIE IS PUT UHDER AXIAL LOADING. FIRAILY THE CFIIICAL **

i* CUFRENT DF THE COMFUSITE IS CALCULATED AS A FUNCTIDH, OF THE **

** LFFELTIVE STRAIN ON THE NHSSN CONES.

** CREATIUN DATE : JULY 3. 1979 GY FENALD LARRLEN HUPRD

** MACNETIC FUSIOH EHGINEER ING DEFARTMENT

** LAISECNCE LIVERMORE NAT!ONAL LHGORGTIRY, LIVM. L LALIFORMIA **

COMMON $/ K O N / A(23,23), B(23,1), C(23,1), A P(23,23), E P(23,1)$

COITION JUAR R (11),HI(12),DEFE(11), DEFS(11),EFE(1i)

COHHON $/ H O A / E(12)$, ALPHA (12), EFS $(3,11)$, DSIG $(3,11,100)$,

1 DEPS $(3,11,160)$

RFAL $1 U(12), K(12) \cdot M L(12), P L(12)$

I OIVION FEFG NNU,K,ML,PL, NRING, NZONE,L

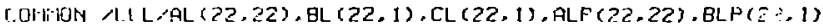

BEAL JCNURM(108)

COHIOH MME MAR(S), IMIN

INTEGER $\checkmark$

DIMENSIOH DEFEN(1BO.11). LPBEL (12), OUTVAL (20)

DIIIENSION IJKAREA (25), TEFE(11), SIG $(3,11)$. TSIGE (11)

DITENSION DUTEPZ(1G9). OUTEPNC 189).

$\begin{array}{lllll}* * N I=1,2,3, \ldots & \text { IF } N I=1 \text { ZONE I IS NIOBIUM } & * * \\ * * * & \text { IF } N I=2 \text { ZONE I IS SRONZE } & * * \\ * * & & \text { IF } N I=3 \text { ZONE I IS NB3SN } & * * \\ * * & & \text { IF NI=4 ZONE I IS VACUUM } & * * \\ * * & & \text { IF } N I=5 \text { ZONE I IS COPPER } & * *\end{array}$

W: THE NUMBER OF MATERIPL ZONES SPECIFIFD MUST BE EDUAL TO

** HEONE + 1 WITH THE LAST OUTER ZONE = VACUUM IN ORDER TO

**: SATISFY THE VAHISHING RADIAL STRESS GOUHDARY COHDITIDN.

X:* A RADIUS MUST BE ASSIGNED TO EACH MATERIAL ZGNE EXCEFT:

** NI $=$ VACUUI1 $=4$.

DATA $N 1 / 2,2,3,3,3,1,1,5,5,4$, LNB35N/4/

DATA R IID. PE -6,21. BE-6.21.2E-6.21.6E-6,22.3E-6.

125.9E-6.27.5E-6,28.5E-6.25.5E-6/

DATA LHBL I/12HNIOBIUM

DATA LABL $3 / 12$ HNB 35 N

/.LABL 2/12HSRONZE

.LABL $4 / 12$ IYVACUUM

n:k

DATA LABL5/12HCOPPER

$$
1
$$

DRTA QUTVRL $-1 . E-2,-9 . E-3,-8 . E-3,-7 . E-3,-6, E-3,-5 . E-3,-4 . E-3$. $1-2 . E-3,-1 . E-3,9.8,1, E-3,2, E-3,3 . E-3,4 . E-3,5, E-3,6, E-3,7 . E-3$.

2日.E-3.9.E-3, 1.0E-2/. NOUTPT/2G/. DEP $/ 9.3002 /$

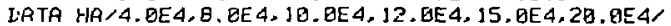

DATA MRING/8/,TO/1024.2/.DT/-0.5/, GAMMA/0.001/.NM 1B/

$M Z=N R I N G+1$ 
C

C

NZONE =NR ING +1
HMATL = HZONE +1
HURPTS $=1$

DD $508 \quad 1=1$, NMATL

IF (NI (I) .EQ.I) I.APEL (I) =LAELI

$I F(N I(I) . E O .2)$ LAEEL $(I)=L A B L 2$

IF $\left(N^{1}(1:=0.3)\right.$ LABFI. $(1)=$ LABL3

IF (NI] (1).FO.A) LALEEL (1) =LABL4

IF $(N]$ (1).FO.S) I REEL ( I) $=$ L.SBLL.S

S.F CONTINUE

LUR ITE $(6,5 B 1)$

DOI lOPIHT (///2X. "THE ZONES ARE MPDE OF THE FOLLOWING MATERIALS: "

$12 X$, "L ISTED IN THE ORDER OF EACH CORRESFONDING $Z$ ONE NUMEER" $/ \ell$ )

WR I TE $(6$, SB2) (L RBEL (I) $, 1=1, N M)$

5 SOZ FORI'HAT (2X, 6A12)

WR 1 TE $(6,5 B 3)$

503 FDRMAT (//2X." THE CORKESPONDING ZOME RADII ARE:"ノ)

lúR I TE (E.,584) $(R(I), 1=1, N Z)$

C

504 FORMAT (11 (E) 3.2$)$

C $++4 i * *$ THERMAL LORDING REGION w*\%****

C

NF- OH: $=2 * F$ IR ING +3

$L=1$

$T=70$

CALL COHST (T)

CALL FLASTI(DT)

[CAL L ELAST2 (DT, MEDN, JER)

IF IIER.ER. 129) is IO PAO

$\mathrm{C}$

[

\#:* FRINT THE INITIAL OUTPUT VALUES OF A,B,C,DEPS. AND DEFE

*⿻丷木

WR I TE $(6,1)$

1 FORMAT ( $/ / / 5 X$. "THE INITJAL A MRTEIX IS: "///

WR J TE $(6,2) \quad((A(1, J), J=1, N E O N), 1=1, N E D N)$

2 FORMAT (11) (E10.2) $)$

UR ITE $(6,3)$

3 FURMAT (///SK, "THE INITIAL B VECTOR IS: "//)

WR I TE $(6,2)$ (B(1,1), I=1, MEQN)

WR ITE $(6,4)$

1 FORMAT (///5X, "THE INITIAL C YECTOR IS: "//)

WR ITE $(6,2) \quad(C(1,1), 1=1$, NEQN $)$

WR 1 TE $(6,5)$

5 FURHRT (//,5X, "THE INITIAL DIFFERENTIAL STRAINS ARE: "//)

WR ITE $(6,6) \mathrm{NZ},((\operatorname{DEPS}(I, J, 1), J=1, N Z), I=1,3)$

6 FORMAT (*IE10.2) $/)$

WR ITE $(E, 7)$

7 FORMAT ( $/ / / 5 X$. "THE EFFECTIVE STRAIHS FOR EACH RFGION ARE:"/ノ) (UR ]TE $(6,6) \mathrm{NZ},(\operatorname{DEFE}(1), \mathrm{I}=1, \mathrm{NZ})$

$\mathrm{C}$
$\mathrm{C}$ ** DECREMENT THE IN]TIAL TEIFERATURE AND COMPUTC NEL STRAINS

$100 \quad T=T r D T$

$L=1$ 
CALL CONST (T)

[ALL EI_AST] (DT)

CALL ELAST2 (DT.NEON, IER)

JF(IER.EO. 129) GO TO $\mathrm{P}$ GE

DO $20 \quad I=1$. HZONE

2. CONT INUE

$259 \mathrm{~L}=\mathrm{L}+1$

CAL $-\operatorname{CONST}(T)$

CAI.L PI.ASTC (ML,PL)

CALLL FLASTI (DT)

C.AI_L ELAST2(DT.PIECIN, IER)

IF (ItER.EO. 129) GO TO $\mathrm{PGO}$

DO $3 B \quad I=1$. WLONE

38 CONTINUE

$D E F E H(L, I)=D E F E(1)$

DO $4 \theta \quad 1=1, N Z O N E$

DISP $1=$ DEFEN $(L, I)$

DH $=$ DEL EN (L- I, I )

DELTAI = AES ( DNP I -DH)

DELTR2 $\because A B S$ (EAMMA *DN)

IF (DELTAI.GT.DELTAZ) GO TO 300

49 CONTINUIE

[D $158 \quad \mathrm{I}=1, \mathrm{NZONE}$

$\operatorname{EPS}(1,1)=\operatorname{EPS}(1,1)+\operatorname{DEPS}(1,1, L-1)$

$E F S(2, I)=E P S(2,1)+D E P S(2,1, L-I)$

(.PS $(3,1)=\operatorname{EPS}(3,1)+\operatorname{DEPS}(3,1, L-i)$

$\operatorname{SIG}(1,1) \cdot \operatorname{SIG}(1,1)+\operatorname{DSIG}(1,1, L-1)$

$\operatorname{SIG}(2, I)=\operatorname{SIG}(2,1)+\operatorname{DSIG}(2,1, L-1)$

$\operatorname{SIG}(3,1)=5 \operatorname{Ig}(3,1)+\operatorname{DSIG}(3,1, L-1)$

TSIGE (1) $=0.7 B F(1) * \operatorname{SORT}($ (SIG $(1,1)-\operatorname{SIG}(2,1)) * * 2+$

$1(5 \operatorname{IG}(2,1)-5 \operatorname{IG}(3,1)) * 22+(5 \operatorname{Ig}(3,1)-5 \operatorname{IG}(1,1)) * * 2)$

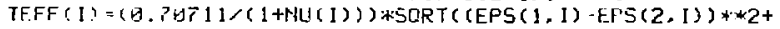

$1(\operatorname{EPS}(2,1)-\operatorname{LPS}(3,1)) * * 2+(\operatorname{EPS}(3,1)-\operatorname{EPS}(1,1)) * * 2)$

150 COITH:KUE

GO 10 'in

306 DO $200 \quad 1=1$, H $Y O N E$

$\operatorname{EFE}(1)=1 \operatorname{tEE}(1)+\operatorname{DEFEN}(L, I)$

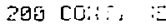

GO TO $=50$

50 IF (T.GT.A.2) GO TO 100

DUTEFC $(1)=E P S(3,1)$

$c$
$c$

DUTEPH (1) = TEFE (LHB3SN)

s:\%: PRIIT IF'E RFSIDUAL STRAIN NEAR 4.2 REG. KE! VIN

잔 WRITE $(6,8) \mathrm{T}$

8 FQRRLT (স/

WR ITE (G.5) NZ, ( (EPS $: 1, J), J=1, N Z), 1=1,3)$

WR ITE $(6,9) \mathrm{T}$

9 FORI.ATT (///SX, "THE EFFECTIVE STRAINS AT T="E1?.3.2X. "ARE: "//)

WR I TE $(6,6) \mathrm{NZ},(\operatorname{TEFE}(1), 1=1, \mathrm{NZ})$ WRITE $(6.10) T$

19 FORMAT ( $/ / / 5 X$, "THE RESIDUAL STRESSES AT T="E12.3,2X. "ARE: "//) WRITE (E.6) NZ, ( (SIG $(1, J), J=1, N Z), I=1,3)$

LRITE $(6.19) \mathrm{T}$

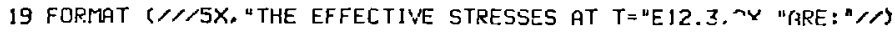


LRITE $(6,6) \mathrm{NZ},(T S I G E(1), 1 \times 1, \mathrm{NZ})$

WR ITE $(6.585) \gamma$

585 FORMAT (///5X, "FXIAL LORDING RESULTS AT T="E12.3.2X, "DEG. K"///)i.

C

C

c

** APPLY AXIAL LOADING AT 4.2 DEG. K AND COMOUTE NEL STRAINS

HEON $=2 * N$ N ING +2

460 DO $11 \quad 1=1$. NZONE

$\operatorname{EPS}(3,1)=\operatorname{EPS}(3,1)+\mathrm{DEPZ}$

$\operatorname{TEFE}(1)=(0.79711 /(1+N U(1))) * \operatorname{SORT}((\operatorname{EPS}(1,1)-\operatorname{EPS}(2.1)) * * 2+$

$1(\operatorname{EPS}(2,1)-\operatorname{EPS}(3,1)) * * 2+(\operatorname{EPS}(3,1)-\operatorname{EPS}(1,1)) * * 2)$

$\operatorname{EFE}(1)=\operatorname{TEFE}(1)$

11 CORTINUE

$L=1$

CALL CONST (T)

C.ALL ELAST3 (DEPZ)

CALL ELAST 4 (DEPZ, NEON, IER)

IF (IER,EO. 129) GO TO 700 :

DO $12 \quad I=1$. NZONEE

$\operatorname{DEFEN}(L, 1)=\operatorname{DEFE}(I)$

12 CONT INUIE

$350 \mathrm{~L}=\mathrm{L}+1$

CF:L CONST(T)

CrILL PLASTC (ML,PL)

C.ALL ELASTS (DEPZ)

CALL ELAST 4 (DEPZ, NEON, IER)

IF (IER.EO. 129) GO TO 700

DO $14 \quad I=1$ - NZONE

$\operatorname{DEFEN}(L, 1)=\operatorname{DEFE}(1)$

14 CONTIHUE

DO $15 \quad 1=1$. NZOHE

$D N P I=D E F E N(L, I)$

$D N=D E F E N(L-1, J)$

DELTA $1=$ =ABS (DNP 1 - DN)

DEL TA2 =ABS (GAMMIA *DN)

IF (DEL TA1.GT.DELTA2) GO TO 580

15 CONTINUE

DO 16 I =1, NZONE

$\operatorname{EPS}(1,1)=\operatorname{EPS}(1,1)+\operatorname{DFPS}(1 ;], L-1:$

$\operatorname{EPS}(2, I)=\operatorname{EPS}(2,1)+\operatorname{DEPS}(2,1, L-1)$

$\operatorname{SIG}(1, \operatorname{I})=\operatorname{SIG}(1,1)+\operatorname{DSIG}(1,1, \operatorname{Li} \cdot 1)$

$\operatorname{SIG}(2,1)=\operatorname{SIG}(2, I)+\operatorname{DSIG}(2, \operatorname{I}, L-1)$

$\operatorname{SIG}(3,1)=\operatorname{SIG}(3,1)+\operatorname{DSIG}(3,1, L-1)$

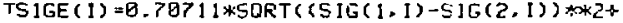

$1(5 \operatorname{Ig}(2,1)-5 \operatorname{IG}(3,1)) * * 2+(5 \operatorname{IG}(3,1)-5 \operatorname{IG}(1,1)) * * 2)$

$\operatorname{TEFE}(1)=(\theta .70711 /(1+N U(I))) * \operatorname{SORT}(\{\operatorname{EPS}(1,1)-\operatorname{EPS}(2,1) * * 2+$

$1(\operatorname{EPS}(2,1)-\operatorname{EPS}(3,1)) * * 2+(\operatorname{EPS}(3,1)-\operatorname{EPS}(1,1)) * * 2)$

16 CONTINUE

GO TO 68

600 DO $17 \quad I=1$, NZONE

$\operatorname{EFE}(1)=1 E F E(I)+\operatorname{DEFEN}(L, 1)$

17 CONTINUE

GO TO 358

C 


\section{5}

C * P* PRINT THE OUTPUT STRESSES AND STRRINS FOR CERTAIN 2 STRAINS **

C

60 DO $18 \quad I=1$, NOUTPT

TEST = APS $(E F S(3,1)-$ OLITVAL (I))

IF (TEJT.LE.2.E-4) GC TO 550

18 CONTINUE

IF (EPS (3, 1) .LT.1.E-2) GO TO 190

S5B NUMP TS = NUMPTS +1

OUTEPZ (NIJMPTS ) =F.PS $(3,1)$

DUTEPN (HLIMOTS) = TEFE (LN33SN,

WR ITE $(6,506)$ EPS $(3,1)$

506 FORMAT (///5X, "THE S IRAINS FOR AN RXIAL STRAIN OF 'E 12.3,2X,":*./)

LWR ITE $(6,6) \quad N Z$. ( (EFS $(I, J), J=1, N Z), I=1,3)$

IJR ITE $(6,598)$ EPS $(3,1)$

598 FGRMAT ( $/ /$ X

WR ITE $(6,6) \mathrm{NZ},(\operatorname{TEFE}(1), \mathrm{I}=1, \mathrm{NZ})$

LIF ITE $(6$, SAT $)$ EPS $(3,1)$

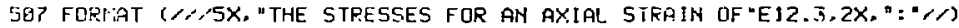
LIR I TE $(6,6) \mathrm{NZ},((5 I G(I, J), J=1, N Z), I=1,3)$

LUR ITE (E.21) EPS $(3,1)$

21 FURMAT ( $/ / 5 X$. "THE EFFECTIVE STRESSES AT EPSZ = "E12.3,2X.":"

WRITE (6.6) NZ, (TSIGE (1), 1=1, HZ)

IF (EPS $(3,1) . L T .1 . E-2)$ GO TO 490

$c$
$c$

*:M***** CRITILAL CURRENT CALCULATIONAL REGION *

F $25 \quad \mathrm{HA}=1, \mathrm{r}$.

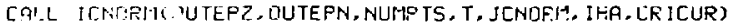

LEIIE (6.5.5a)

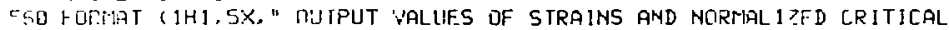

1 CDUKFENIS" (/P)

WP. IIE (5.5日1)

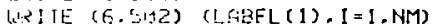

WRIIE $(6,513)$

WRITL (5.5B4) (R(I), 1=1.NZ)

WR I TE $(6.566)$ HAC IHA)

566 FDRITAT ( $/$ SX, "RPPLIED MAGNETIC FIELD IN GALISS = $=$ E 12.3)

WR ITE (6.SSP) CRICUR

S67 FDRMAT (/SX, "NBSSN CRITICAL CUFRENT DENSITY.AT MINIMUM SIFAIN = 1.E12.3." HiPS,[Mik*2")

(.JP. I ITE (6.561)

501 FDFMAT ( $/, 5 X$ " "AXIAL STRAIN" 5X, "NB3SN STRR11, ,5X, "IClVORMAL IZED",

$1 / /)$

DO $5631=1$. NUi 1 PTS

IJR ITE (6.562) OUTEPZ(I), OUTEPN(J), JCNDRM(I)

562 FORMAT (SX.E12.3.5X,E12.3.5X,E12.3\%

c

563 CONT INLIE

C W.KCONWERT Z STRAINS AND CFITICAL CURRENTS TO RUPP NLEMALIZAI:OH**

IF (IHA.GT. 1) GO TO ?5

NUMPMI = MUIMCTS 1

AHCOLHT $=0$

DO $22 \mathrm{I}=1$, IIUMP 1 :1

IF (ABS (DUTEPH (I)) . LT. ABS (DUTEPN $(I+1))$ ) GO TD 23

GO TO 22

23 MCOUNT $=$ NCDUNT+1 
IF (NCOUNT .EQ. I) KINDEX=I

22 COINTINUE

IF (JCNDRH

AD JUST $=1,0, J C N O R M(K, I N D E X)$

GO TO 6 B2

601 AD JUST $=1.0$

502 RUPFNM=DUTCFZ(K ]HIEEX)

DO $24 \mathrm{~J}=1$. NUMDTS

OUTEFZ $(J)=$ DUTEPZ $(J)-R U P P N M$

JCMORM $(J)=J C$ JDRR $(J) * A D J U S T$

2A COANTIMUE

I.R I TE $(6,5 E 4)$

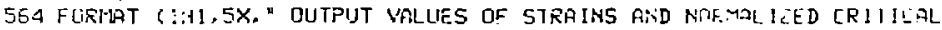

: CURRENTS CONVERTIED TO RUPP NORITAL IZFITIUN" $/(\rho)$

WR I TE $(6,591)$

WR ITE $(6,5 E 2) \quad(L . A B E L(I), I=1 . N M)$

IJR I TE (6. I. 33$)$

WNE I TE ( $(5,5 \in 4)(R(I), I=1, N Z$ )

UR ITE, 6.566$)$ HA (IHA)

L'R.]TE $(6,5 G 7)$ CRICUR

ISR] TE $(6,561)$

LO $5 E 5 \quad I: 1$, NUIPTS

(1.RITE (6.562) OUTEPZ(1),OUTEPH(I), JCNORM( 1)

565 COHTINU.'E

25 CONIINUE

150 T0 806

7

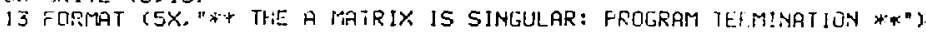

SUD 5 IDP

END 


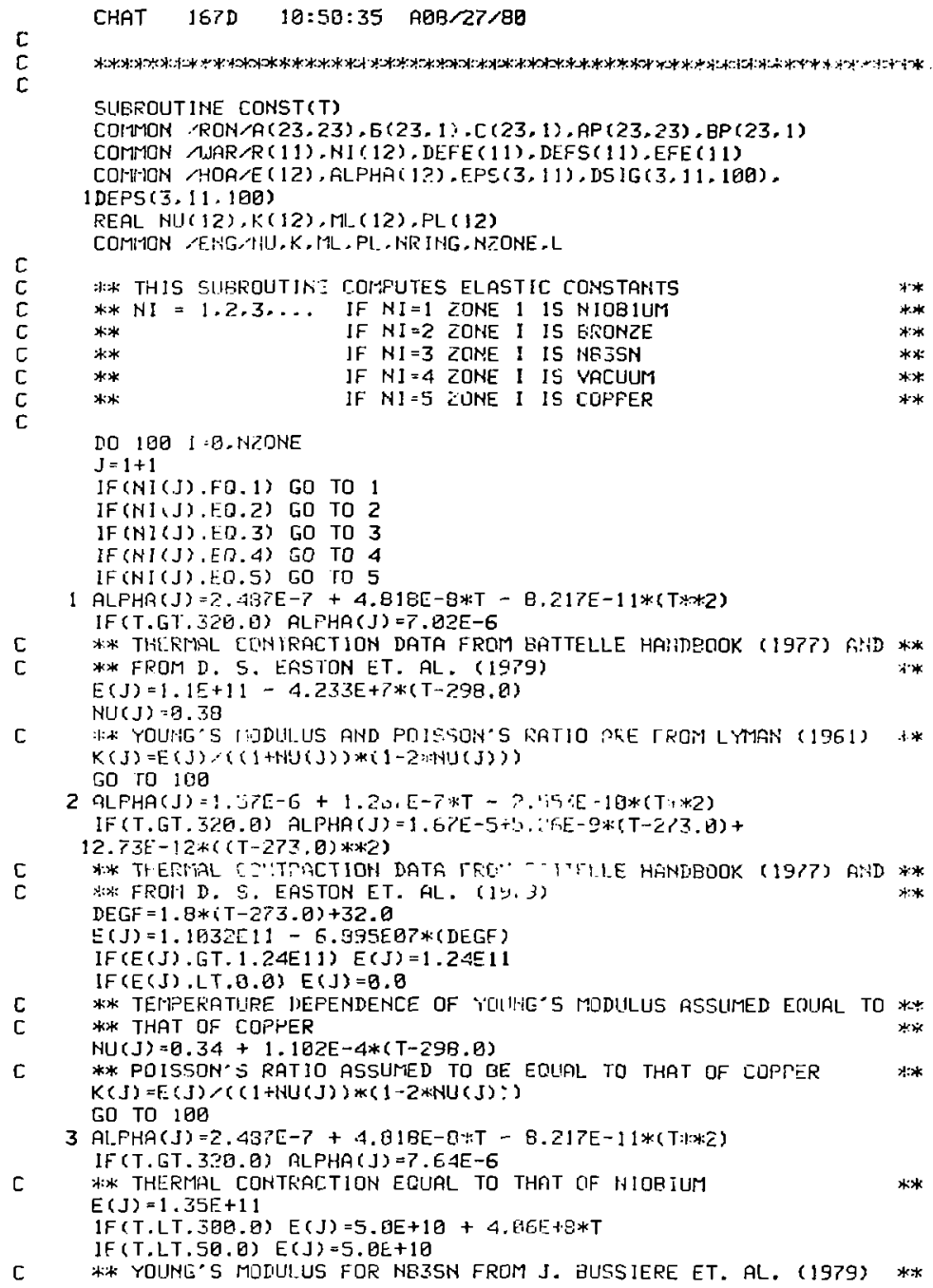


C NU $\quad$ * TH

$K(J)=E(J) /((1+N U(J)) *(1-2 * N U(J)))$

GO TO 100

4 RLPHA $(J)=0.0$

$E(J)=B$. $\theta$

HU $(J)=0 . B$

$K(\mathrm{~J})=0.0$

IO TO 100

5 TAPHA $(\mathrm{J})=1.57 \mathrm{E}-6+1.267 \mathrm{E}-7 * \mathrm{~T}-2.553 \mathrm{E}-1 \mathrm{~B} *(\mathrm{~T} * 4.2)$

IF (T.GT.320.5) ALFHA (J) $=1.67 \mathrm{~F}-5+5.2 \mathrm{EE}-9 *(T-273.0)+$

$12.33 E-12 *((T-2) 3.8) * * 2)$

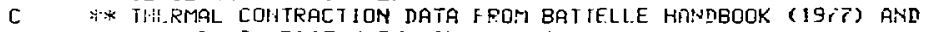

C ** FROM D. 5. EASTON ET. AL. (1379)

DEGF $=1.8 *(T-273.8) \div 32.0$

$E(J)=1.1832 E 11-6.695 E 97 *(D E G F)$

$1 F(E(J) . G T .1 .15 E 11) E(J)=1.15 E 11$

IF (E (J).LT.g.B) $E(J)=0.8$

MU $(J)=0.34+1.182 E-4 *(T-298 . B)$

C * FOISSOH'S RATIO FOR COFPER AS A FUHCTIOH OF TEMFERATURE IS **

C n:* FROI1 HFCKER'S THESIS (19E3) WHICH ALSD HAS YOUHG'S IFDULUS ** $K(J)=E(J) /((1+1)(J)) *(1-2 * *+U(J)))$

180 CONTINUE

RE TURN

END 


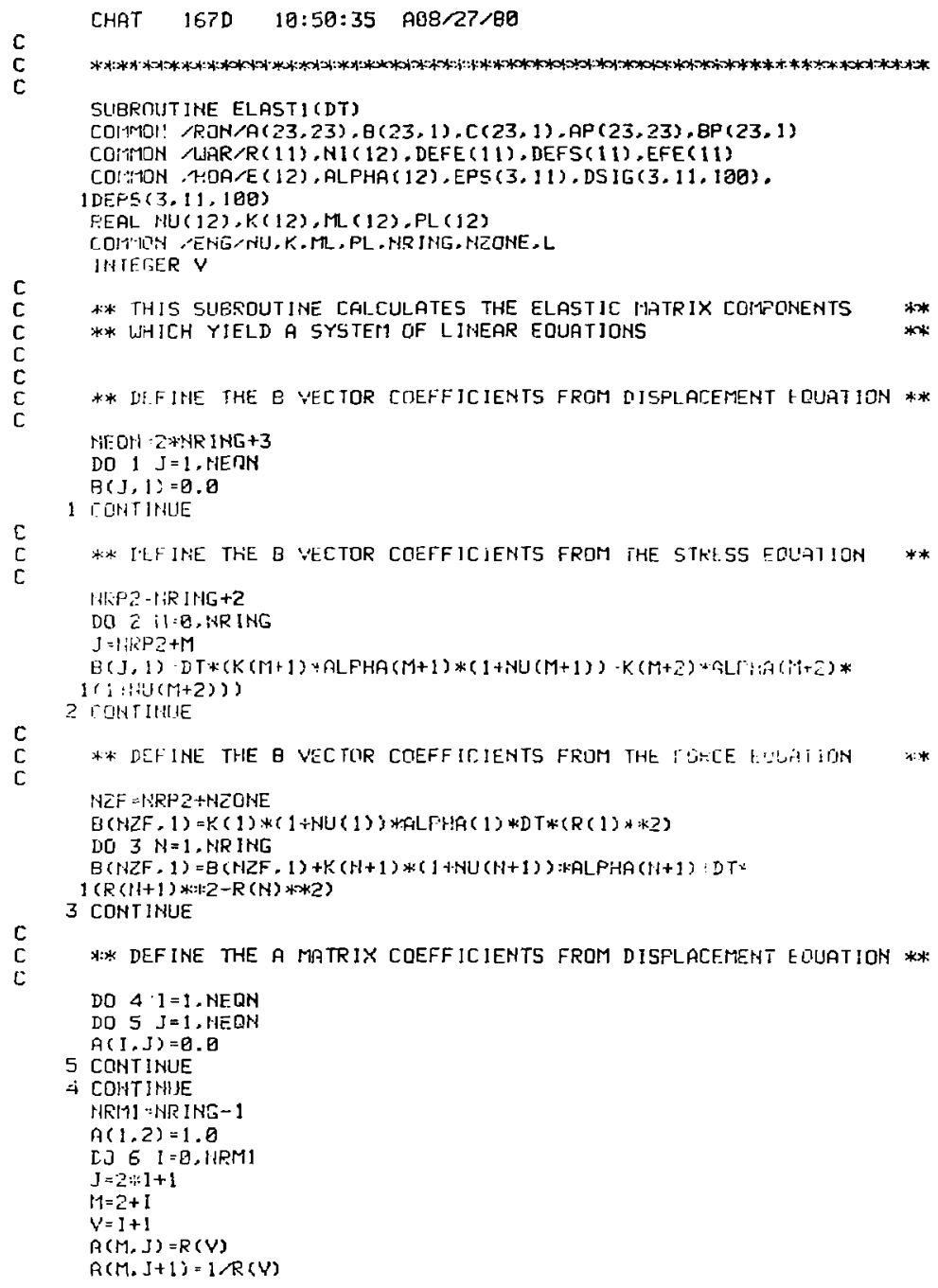


IF (I.EQ.E) $A(M, J+1)=0.0$

$R(M, J+2)=-R(V)$

$A(M, J+3)=-1 /(R(V))$

C

C

** DEF INE THE a MATRIX COEFF JCIENTS FROM THE STALSS ECUHTION

**

$\mathrm{M}=\mathrm{M}+\mathrm{I}$

$\mathrm{J} 1=2$ *VIPI ING +1

DO $71=0 . M R J N G$

$J=2 * I+1$

$M=+1$

$Y=1+1$

$A(M . J)=K(V)$

$R(M, J+1)=-K(V) *(1-2 * * U U(V)) /(R(V) * * 2)$

IF (1.EO.O) $R(H . J+1)=B . \theta$

IF (J.FF. J1) GO TO 8

$A(M, J+2)=-K(V+1)$

$A(M, J+3)=+K(V+1) *(1-2 * N U(V+1)) /(R(V) * * 2)$

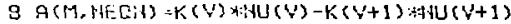

C

7 CONTIHAUE

C

** DEFINE IHE A IMIRIX COEFFICIENTS FROM THE FORCE EOUHTION

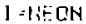

$A(1,1+1) N)=K(1) *(1-N U(1)) *(R(1) * 2)$

$\{(1,1)=K(1) * 2 *+1 U(1) *(R(1) * * 2\})$

IOO $9 \mathrm{~J}-1$. IHRINT

$M=2 * J+1$

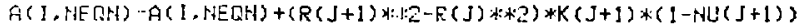

$A(I, M)=(R(J+1) * * 2-R(J) * * 2) * k(J+1) * 2 * * i u(J+1)$

9 L. LIT I IHIJE

I'E ILIRH

EIID 


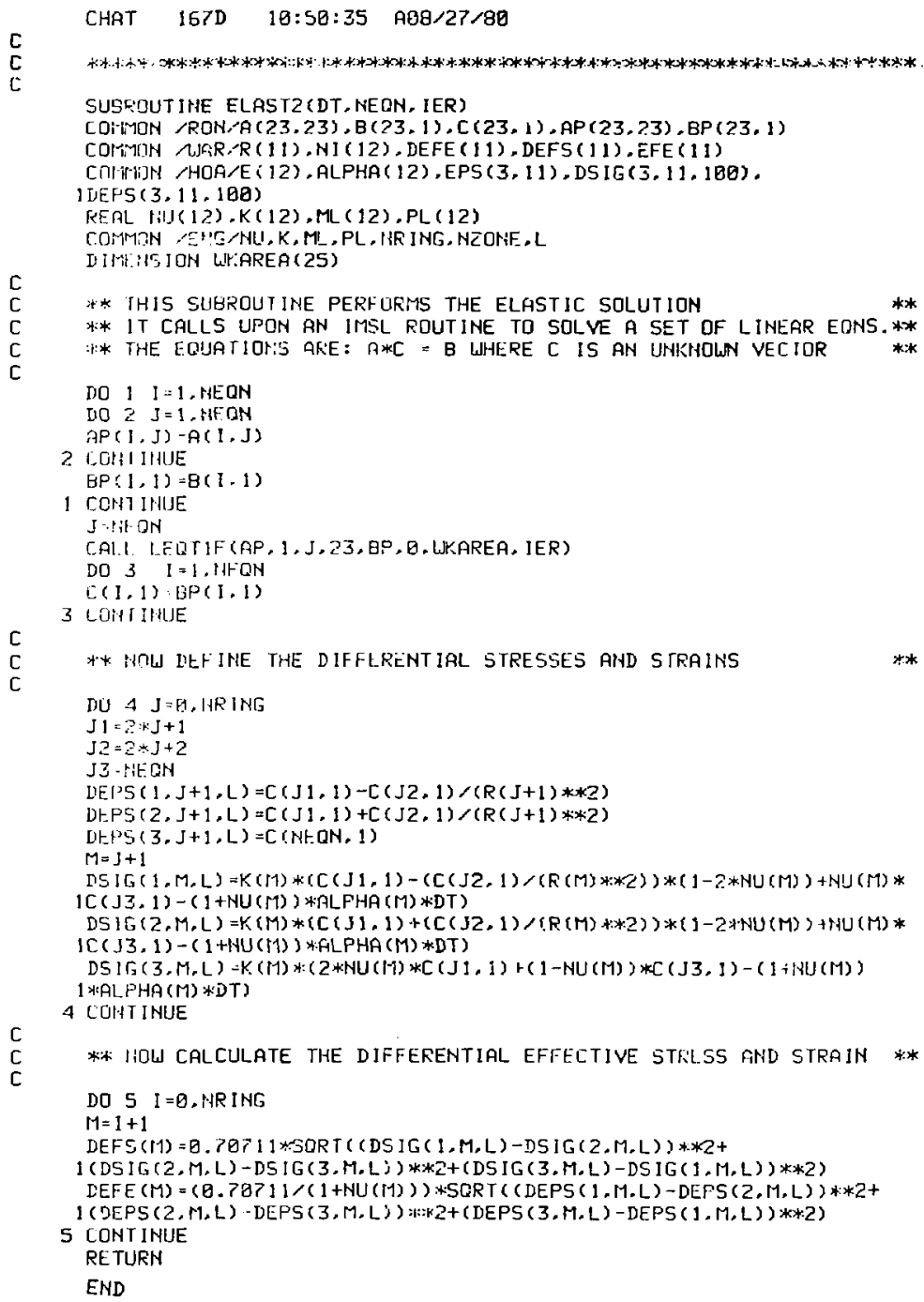




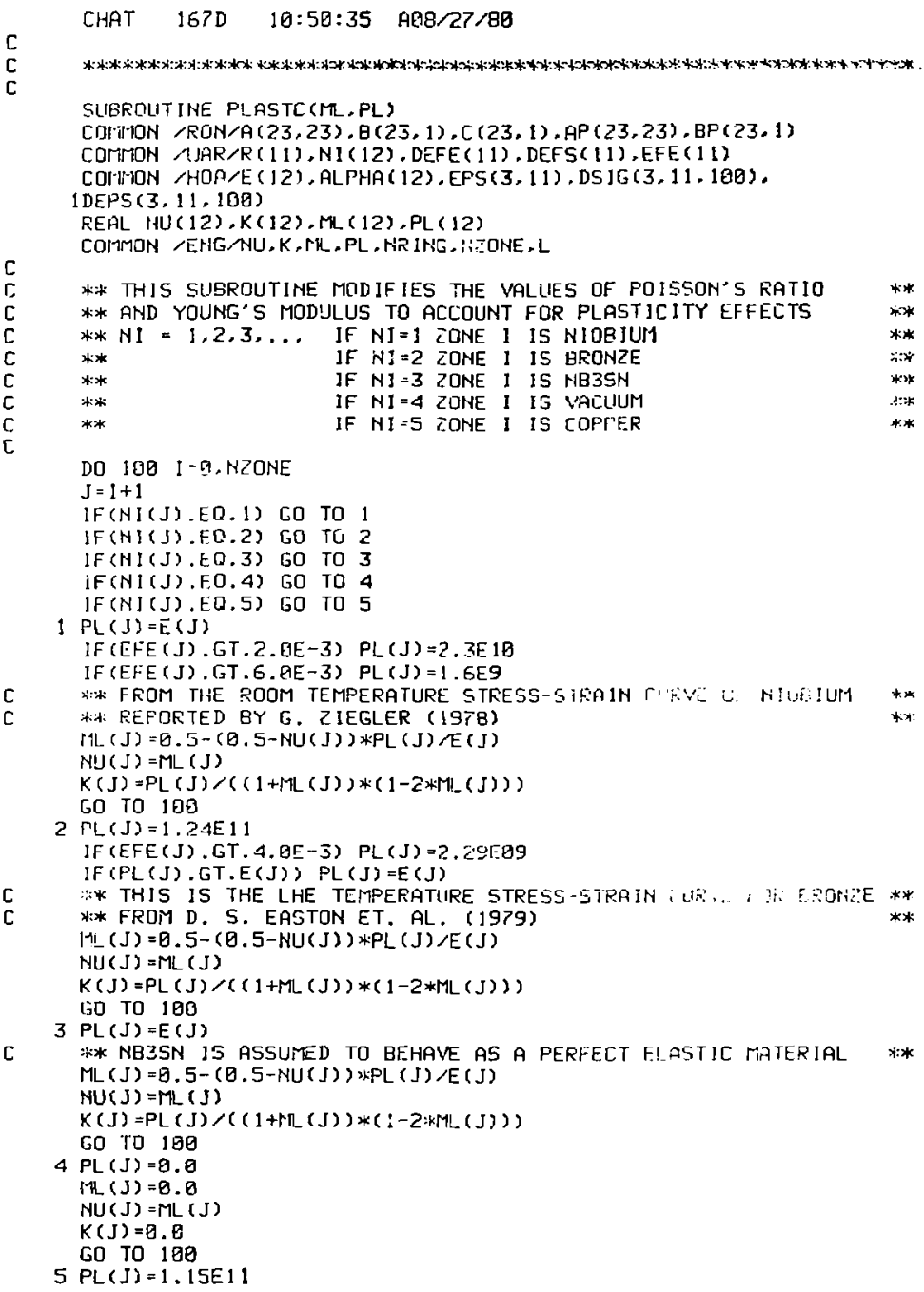


193

IF (EFE (J).GT.2.5E-3) PL (J) =4. 4EJB

IF (EFE (J).GT.4.BE-3) PL (J) $=1.25 E 9$

C ** THIS IS THE LHE TEHIPERATURE STRESS-STRAIN CURVE FOR COFFER **

C *** MEASUPED BY D. DE IS (1977)

ML $(J)=0.5-(0.5-\mathrm{NU}(J)) * P L(J), E(J)$

$\mathrm{NU}(\mathrm{J})=\mathrm{ML}(\mathrm{J})$

$K(J)=\mathrm{Pl}_{-}(J)>\left(\left(1+M L_{-}(J)\right) *(1-5 * 1 \cdot \mathrm{L}(\mathrm{J}) \mathrm{J})\right.$

3 BO CONTIHUE

PETLIRH

EHD 


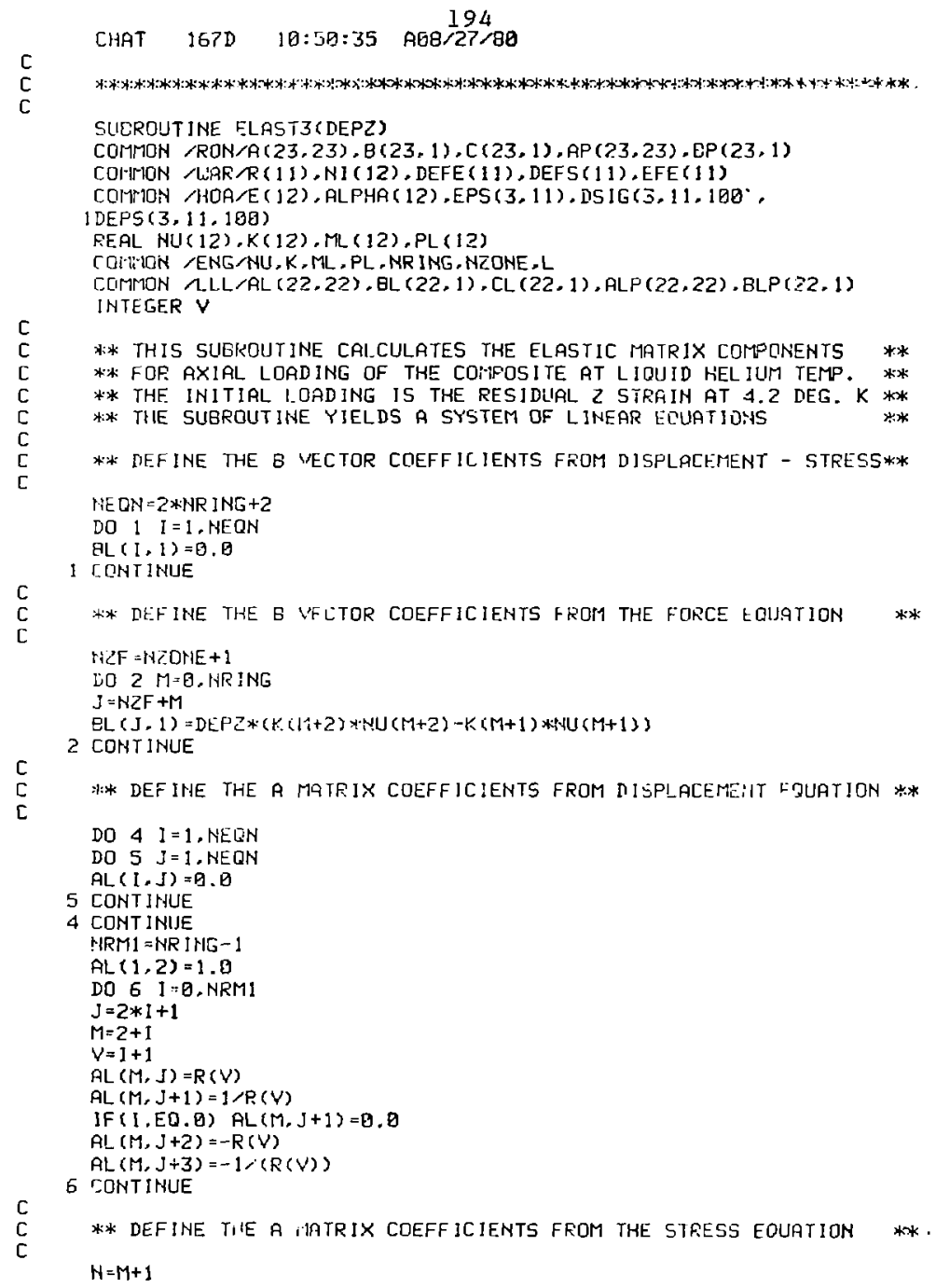


195

$\mathrm{J} 1=2$ *HR $\mathrm{ING}+1$

DO $7 \quad 1=0$. HR ING

$J=2 * 1+1$

$\mathrm{M}=\mathrm{N}+\mathrm{I}$

$Y=\mathrm{I}+1$

$\mathrm{AL}(M, J)=K(\mathrm{~V})$

AL $(M, J+1)=-K(W) *(I-2 * * N U(V)) /(R(V) * * 2)$

$J F(1 . E Q . B)$ AL $(M, J+1)=0.0$

IF (J.GE.JI) GO TO 7

AL $(M, j+2)=-K(\psi+1)$

$A L(M, J+3)=+K(Y+1) *(1-2 * N U(V+1)) /(R(V) * * 2)$

7 CONTINIUE

RE TURN

END 


\section{6}

CHAT 167D 10:50:35 A9B/27/80

$c$
$\mathrm{C}$

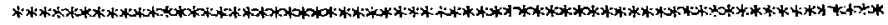




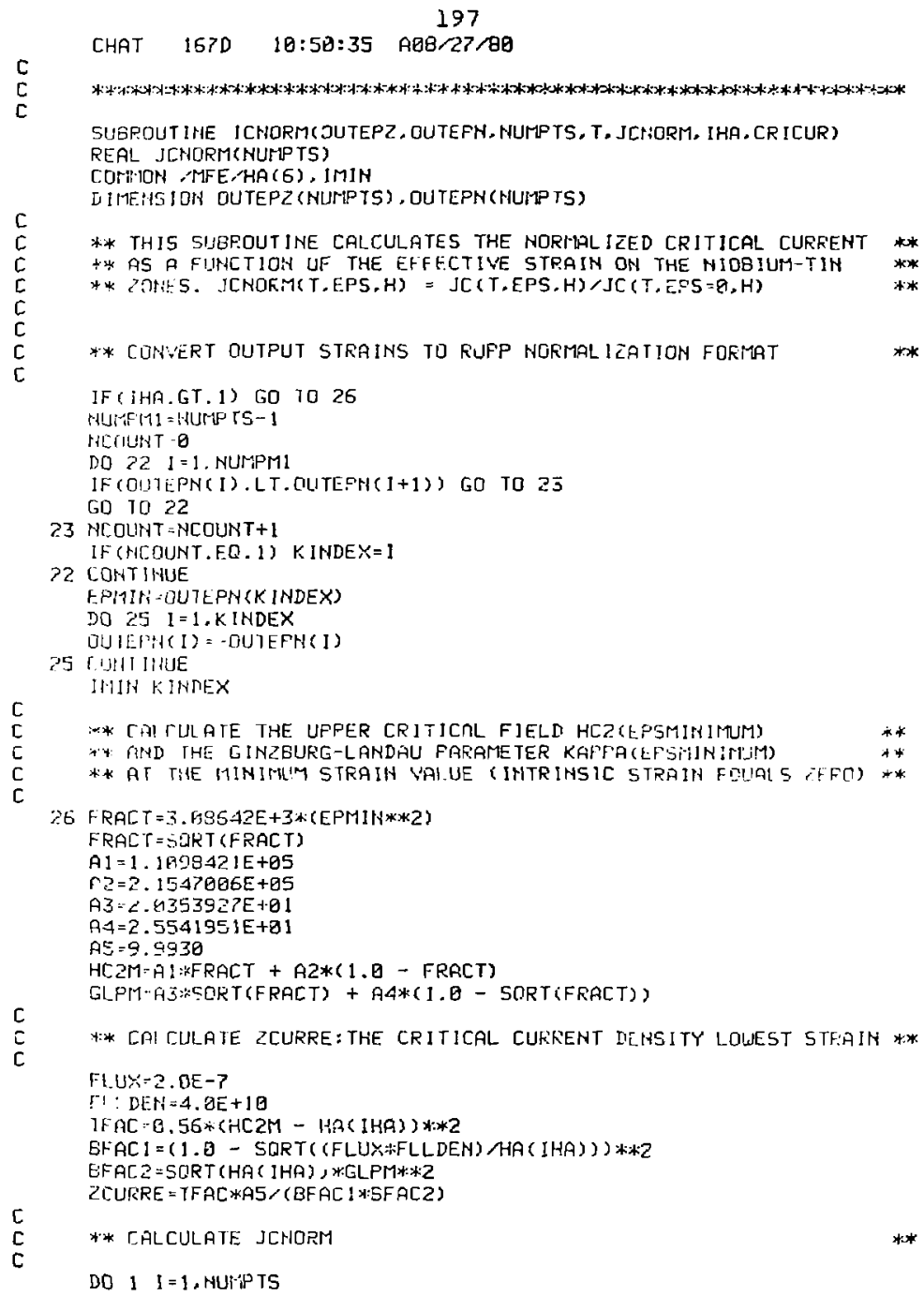


EPSN=ABS (OUTEPH (I))

IF (I.EQ. IMIN) CR I CUR = ZLURRE

IRACT $=3.08642 E+3 *($ EFSN**2)

FRAC T $=$ SERT $($ FRAC T)

$H[2 E P=91+F A C T+A 2 \div(1.6-F F A C T)$

C.LPEP = A3*SORT (FRACT) + AA*(1.日 - SORT (FRACT)

$T F A C=0.55 *(H C 2 E P-H A(I H A))+\$ 2$

BF AC $1=(1 . \theta-5 U R T((F L U X * F L L D E N) / H A(1 H ! A))) * * 2$

SFALC = SURT $(H G($ IHA) $) *$ GLFEF *:2

FI IILUR = TFAC *HJ / (GFRC $1 *$ EFAC2)

IF (HFI IHR) . FF. H(2M) GO TO 2

IF (HIA (IHAO) . T,F.HC. B.P) GD TD 2

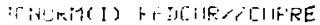

130 10 1

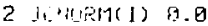

7 CIIPTIJHLE.

$1 \because T L$ TLN

IND 
This section contains a sample o:Itput of an internalbronze-core geometry conductor modeled on the MAXIMSUPER computer program. The following comments and cutput, istings, together with comment cards in the program, a $e$ intended to assist the reader and serve as a brief user's guide.

First, the program echoes the input data: the materials comprising each zone (NI) and the corresponding zone radii in meters ( $R$ ). Then, the code prints the triaxial stresses and strains and resulting effective stresses and strains in each of the specified zanes arising from the thermal contraction between $1024 \mathrm{~K}$ to liquid helium temperature. Axial sauing is applied to the model conductor at $4.2 \mathrm{~K}$, and the resulting stress-strain states are printed at various values of the axial $z$ strain.

After the axial strain has increased to 1.0 percent, the program prints a summary sheet of the stress-strain states and critical current densities for the $\mathrm{Nb}_{3} \mathrm{Sn}$ zone in which the $J_{C}$ values are to be calculated (usually assigned to the center of the $\mathrm{Na}_{3} \mathrm{Sn}$ annular ring layer). The listing includes a tabulation of the axia? strain versus the effective strain on the central $\mathrm{Nb}_{3} \mathrm{Sn} z$ cne and the resulting normalized critical current density degradation. The effective strains on the $\mathrm{Nb}_{3} \mathrm{Sn}$ are 
scanned to determine the lowest value, and $\nu_{c}$ is calculated at this minimum strain. All other $J_{C}$ calculations at various axial strains occurring before the minimum are affixed with minus signs (for visual effects) to indicate that the $\mathrm{Nb}_{3} \mathrm{Sn}$ is initially under compressinn before the applied loading relieves the precompression and places it in tension.

The first entry in the axial strain column represents the toial axial thermal contraction arising from the cooldewn between 1024 to $4.2 \mathrm{~K}$. For most conductors modeled, it varied between -1.0 to -1.5 percent. In the laboratory, this value is never measured, since the gages are affixed at room temperatur and :?roed at liquid helium temperature. In crder to convert the proyram results to predict laboratory experiments, the axial strain, which corresponds to the minimum $\mathrm{Nb}_{3} \mathrm{Sn}$ effective strain, is subtracted from every entry in the axjal strain column. This normalizes the program output into the Rupp format indicated in figures $5,28,29$, and 30 . Therefore, the zero offset axial sirain (intrinsic strain) and normalized critical current density columns predict the Rupp normalization curves as a function of applied magnetic fields for each conductor modeled. 
THE ZONCS ARE WIADE OF THE FOLLOWING MATERIGLS:

LISTED IN THE ORDER OF EACH CORRESPONDING ZONE NUMEER

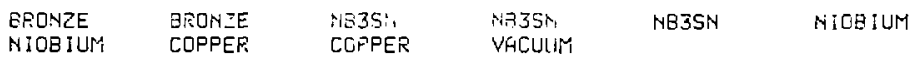

THE CORRESPONDING ZOHE RF:.: I I GRE:

1.06E- $75 \quad 2.10 E-95 \quad 2.12 E-05 \quad 2.16 E-35 \quad 2.23 E-65 \quad 2.50 E-05 \quad 2.75 E-05 \quad 2.85 E-95 \quad 2.95 E-95$ THE RESIDUAL STRAINS AT T* 4.20日E+OD GRE:

$-1.79 E-02-1.79 E-02 \quad 3.50 E-03 \quad 3.12 \bar{E}-03 \quad 2.48 E-03 \quad 7.36 E-03 \quad 5.31 E-93 \quad-2.21 \bar{E}-02 \quad-2.17 E-92$

$-1.79 E-62-1.79 E-02-1.77 E-82-1.73 E-92-1.57 E-92-1.48 E-82-1.21 E-82-1.25 E-02-1.28 E-02$

$-1.47 E-02-1.47 E-02-1.47 E-92-1.47 E-02-1.47 E-02-1.47 E-02-1.47 E-02-1.47 E-02-1.47 E-02$

THE EFFECTIVE STRAINS RT T= 4.2DEE+OB RRE:

$2.45 E-03 \quad 2.45 E-03 \quad 1.47 E-92 \quad 1.45 E-02 \quad 1.35 E-02 \quad 1.45 E-02 \quad 1.26 E-02 \quad 5.84 E-03 \quad 5.39 E-03$

THE RESIDUAL SWRESSES AT T: 4.200E+00 ARE:

$1.55 E+08 \quad 1.55 E+08 \quad 1.35 E+68 \quad 9.73 E+07 \quad 3.57 E+07-1.79 E+95-3.68 E+07-1.59 E+97 \quad 8.11 E-06$

$1.55 E+09 \quad 1.55 E+0 E \quad \cdots 1.93 E+09-1.90 E+09-1.83 E+09-2.93 E+09-3.08 E+08 \quad 4.20 E+08 \quad 4.21 E+08$

$2.77 E+98 \quad 2.77 E+08-1.63 E+09-1.63 E+09-1.63 E+99-2.62 E+68-3.64 E+08 \quad 3.72 E+98 \quad 3.89 E+08$

THE EFFECTIVE STRESSES AT TI 4.2J日E+OB ARE:

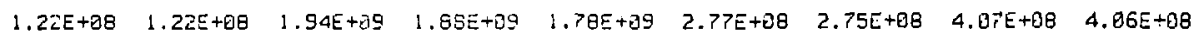


THE STRAINS FOR AN AXIAL STRAIN OF -9.911E-03 :

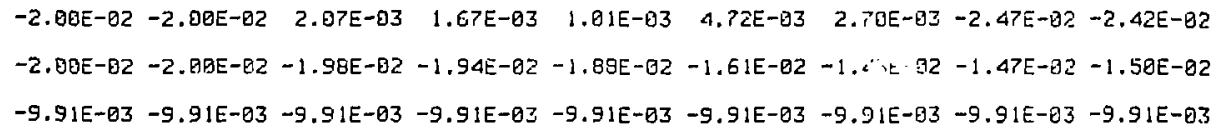


THE STRAINS FOR AN AXIAL STRAIN OF 7.EQ9E-E3:

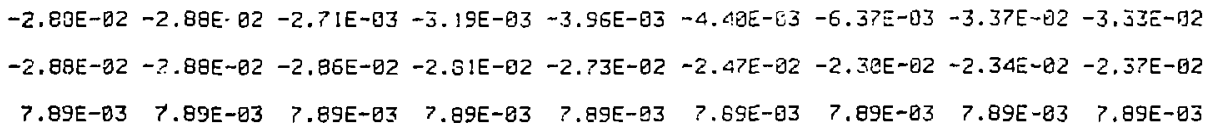

THE EFFECTIVE STRAINS AT EPSZ= $7.809 E-E 3$ :

2.45E-02 2.45E-02 2.41E-02 2.37E-02 $2.39 E-02 \quad 1.90 E-02 \quad 1.79 E-8 \% \quad 2.51 E-02 \quad 2.49 E-02$

THE STRESSES FOR AN AXIFL.STRAIN OF $7.869 E-0.3$ :

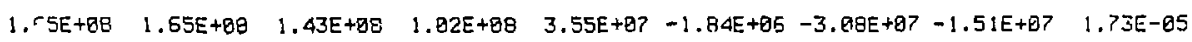

$1.65 E+08 \quad 1.65 E+68-z .10 E+99-2.06 E+09-1.99 E+09-2.92 E+08-3.07 E+08 \quad 4.10 E+0 \theta \quad 4.22 E+08$

$5.88 E+96 \quad 5.05 E+8 \theta-5.59 E+9 g-5.59 E+08-5.59 E+98-2.25 E+0 \theta-2.68 E+9 \theta \quad 4.91 E+96 \quad 4.17 E+0 \theta$

THE EFFECTIVE STRESSES AT EPSZ: 7.389E-03 :

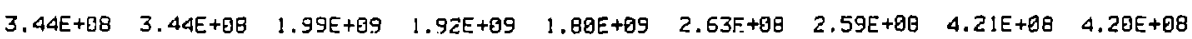


APPLIED MAGNETIC FIELD IN GAUSS =

$4.960 E+64$

HESSN CRITICAL CLPRENT DEHSITY AT MINIMUM STRAIN =

1. $942 E+36$ ARFS CM*2

AYIAL STRAIN WBZSH STRAIN ICIUORALIZED

$-1.471 E-02$

$-1.011 E-02$

$9.311 \mathrm{E}-63$

$-9.111 E-03$

$-8.911 E-03$

8. $111 E-73$

?.911E-B3

$-7.111 E-03$

$-6.911 \mathrm{E}-\mathrm{E3}$

$-6.111 E-83$

$-5.911 E-83$

$-5.111 E-03$

$-4.911 E-03$

- $4.111 E-03$

$-3.911 E-83$

$-2.111 E-03$

$-1.911 E-03$

$-1.111 E-B 3$

$-9.113 E-04$

$-1.113 E-94$

8. $865 E-65$

S. SBPE-DA

I. G89E-03

1. $899 E-03$

2. $989 E-03$

2. $899 E-93$

ง. $889 E-83$

3. $895 \mathrm{E}-03$

4. ES9E- 03

4. $399 E-93$

$$
\begin{aligned}
& -1.427 E-62 \\
& -1.3535-82 \\
& \text { 1. } 355[-02 \\
& \text { 1. } 364 E-02 \\
& \text { 1. } 36 E E-02 \\
& \text { 1. } 381 E-02 \\
& \text { 1. 386E-02 } \\
& \text { 1. } 4 \text { E } 7 \mathrm{E}-82 \\
& \text { 1. } 413 \mathrm{E}-82 \\
& \text { 1. } 439 E-02 \\
& \text { 1. } 446 E-B 2 \\
& \text { 1. } 47 \mathrm{GE}-02 \\
& \text { 1. } 496 \mathrm{E}-02 \\
& \text { 1. } 523 \mathrm{E}-12 \\
& \text { 1. } 532 \mathrm{E}-02 \\
& \text { 1. 62SE-92 } \\
& \text { 1. 6:40E-92 } \\
& \text { 1. } 688 \mathrm{E}-02 \\
& \text { 1. } 791 \mathrm{E}-9 ? \\
& \text { 1. } 752 \mathrm{E}-82 \\
& \text { 1. } 765 E-02 \\
& \text { 1. } 82 \mathrm{DE}-\mathrm{Q2} \\
& \text { 1. } 833 \mathrm{E}-02 \\
& \text { 1. } 890 \mathrm{E}-02 \\
& \text { 1. } 965 \mathrm{E}-02 \\
& \text { 1. } 964 \mathrm{AE}-82 \\
& 1.979 E-012 \\
& 2.040 E-02 \\
& \text { 2. } 055 E-032 \\
& \text { 2. } 118 \mathrm{E}-02
\end{aligned}
$$

9. $240 E-01$

1. $.000 E+B 0$

9.935E-BI

$9.853 E-B 1$

9. $962 \mathrm{E}-01$

9. $797 E-6 !$

$9.66\lfloor E-01$

9. $447 \mathrm{PE}-0]$

9. 3S6E-B)

9. $118 E-01$

9. $945 E-6 I$

․ $325 E-\theta]$

8. $644 \mathrm{~A}-B 1$

B. 2SE. -91

8. 191E-01

7. $275 \mathrm{E}-91$

7. $155 \mathrm{E}-01$

6. $721 \mathrm{E}-01$

6. 6RBE -01

6. 1SUE :?

6. $034 \mathrm{E}-01$

5. 567E-B1

5. $450 E-B 1$

4.991E-01

4. 864E-91

4. $339[-61$

$\therefore .284 \mathrm{E}-01$

3.829E-日1

3. $717 E-81$

$3.27>E-01$ 


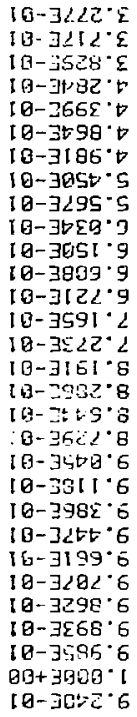

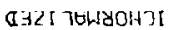

26- $3311^{\circ} 2$

$20-3550^{\circ} 2$

$2 \theta-300 \cdot 2$

$20-36 \angle 6^{\circ} 1$

$20-3596^{\circ} 1$

$20-3506 * 1$

$20-3060^{\circ} 1$

टB-3EEह I

20-3028. 1

20-359:.

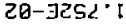

20- $\exists 102.1$

$20-3889 \cdot 1$

20-3059. 1

टด-3Bटy-1

20-3อद्व

2B-75\%- 1

20-39it: 1

20-3s2t.

ट0-395: 1

$20-3625 \cdot 1$

$2 \theta-7 E 15$.

$20-3 \angle 8 \cdot 1$

टg- उ9EE 1

ट0-3185.1

$20-399:-1$

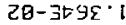

20-3รS5. 1

टह-चรदร.1-

$20-3 \angle 25 \cdot 1-$

NIUAL HSEHA

NIUAls 7blid

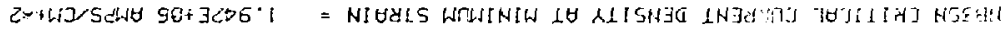

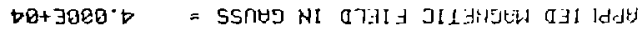


FITI IID WHIIETIC FIFLD IN GAUSS $=8.000 E+84$

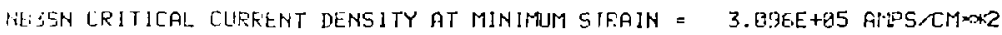

RYIAL SIKAIN FIBZSN STRAIN JCHOKMALIZED
4. FIASE-93
$-1 . \triangle 27 E-\theta 2$
8. $649 E-81$
b.
-1.35 र $2 E-132$
1. $\theta A \theta E+\theta \theta$
2. HOGL- 04
1. 3บSE-E2
1. $36.4 E-B 2$
9. $573 \mathrm{E}-01$
1. CEHE-03
1. $366 E-02$
9. $\$$ UE-OI
1. $20 \mathrm{EE}-03$
1. 3 BIE-02

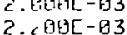
1. $396 E-02$
1. $497 \mathrm{E}-02$
1. $A$ I $3 E-62$
$1.4: 9 E-62$
1. $.45 E-02$
1. $+.8 E-82$

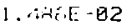
$1 . S A Z-02$
$1.332 \mathrm{C}-02$
1.625E-02
1. $640 \mathrm{E}-02$
$1.686 \mathrm{E}-02$
1.701E-02
. JEE-02
i. $\checkmark 65 E-02$
1. $82[1 \mathrm{E}-02$
1. $\triangle 33 E-02$
$1.690 \mathrm{E}-02$
1. 905E-02
: . .64E-02
$9.751 E-01$
9. 4 P $3 E-6$ ?
9. $390 \mathrm{E}-01$
3. $911 E-B 1$
8. $9 B \mathrm{SE}-01$
8. 43EE-DI
ด. 309E-01
7. $766 \mathrm{E}-01$
7.62?E-81
$7.021 E-01$
6. $965 \mathrm{~F}-01$
5. $395 E-\theta 1$
5. 226E-81
4. 559E-B1
4. 39?E- 11
3. $736 \mathrm{E}-01$
3. 5 P 5E- 01
2.947E-01
2. $796 E-01$
2.214E-31
2. $076 E-01$
1.556E-0.
1. $435 E-01$
1. 9 Y $9 E-02$
2. $04 \mathrm{BE}-52$
1. $490 E-82$
2. $855 E-02$
$9.919 \mathrm{E}-02$
8.913E-92
1. 5 GEE-02
2.119E-02
5. 306E-02 


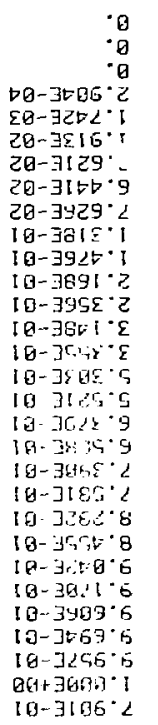

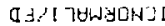

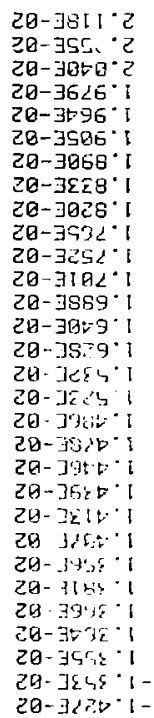


209

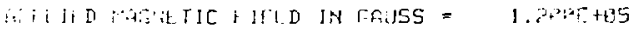

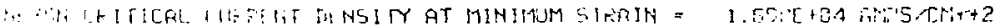

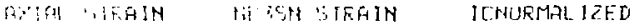

$\therefore 1.1 \div 1: 1+3$

ig.

$\therefore, \therefore \therefore-5-84$

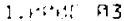

$1, \ldots, 1,1013$

$\therefore 1+i+1+3$

$\therefore \therefore-10^{2}$

?...1 $\$ 13$

3. $\therefore$.

$4,1+1+14-03$

A. $\therefore+4+4+45$

$\therefore \ldots+13$

$\because \ldots \because 83$

$\rightarrow 1015[-013$

b. IFtic - 93

8.1167 15

8. . U $15[-13$

9. $15 \theta \theta E-03$

9. $260 E-63$

1. 5i61月[ - 02

1. $13 \mathrm{AE}-\mathrm{GZ}$

1. 1EJE-02

1. $13 \mathrm{QE}-02$

1. $\because \mathrm{BOC}-02$

1. $27 \mathrm{GE}-92$

1. 3U1E-02

1. . $\checkmark$ VE - 02

1. $46 B[-02$

1. $47 C E-82$

1. सㅡ- 02

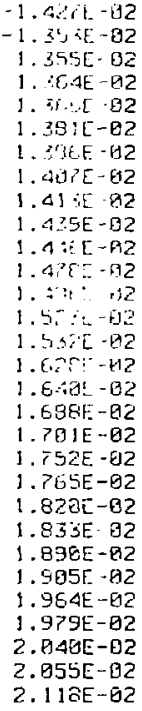

$-1.92 \mathrm{t}-1 \mathrm{H}$

1. $3545-02$

1. $\therefore \delta, A E-B 2$

1. $1.5-82$

1. $1175-62$

1. 41 IE 82

1. $475 E-02$

$4:[-02$

1. $5, \therefore-02$

1. $5.55-02$

1. $6.95 \div-12$

. $6 \div 02-02$

1. $701 E-02$

$1.752 E-62$

1. $765 \mathrm{E}-02$

1. $820 \mathrm{E}-62$

1. $83 \mathrm{JE} \cdot 32$

1. $905 \mathrm{~F}-02$

$1.964 E-62$

979E-日2

2. $955 E-02$

2. $112 \mathrm{E}-62$
5.6 UE 91

1. ODOE + 08

9. $9 \sqrt{3} 3 E-01$

9. $3195-61$

$9.1765-01$

9. 1SCE-O1

7.9175 .01

6. $114 E_{-}-91$

6. $39 t+[-91$

5.03SE-B 1

4.695[-8!

3. $\because \overline{3}[\bar{L}-91$

3. PHAE-01

1.79 7 E- 11

1. $.325 E-91$

$3.244 i-13$

2.645E-84

b.

r.

0.

a.

B.

g.

ט.

a.

5.

0.

b.

0.

B. 


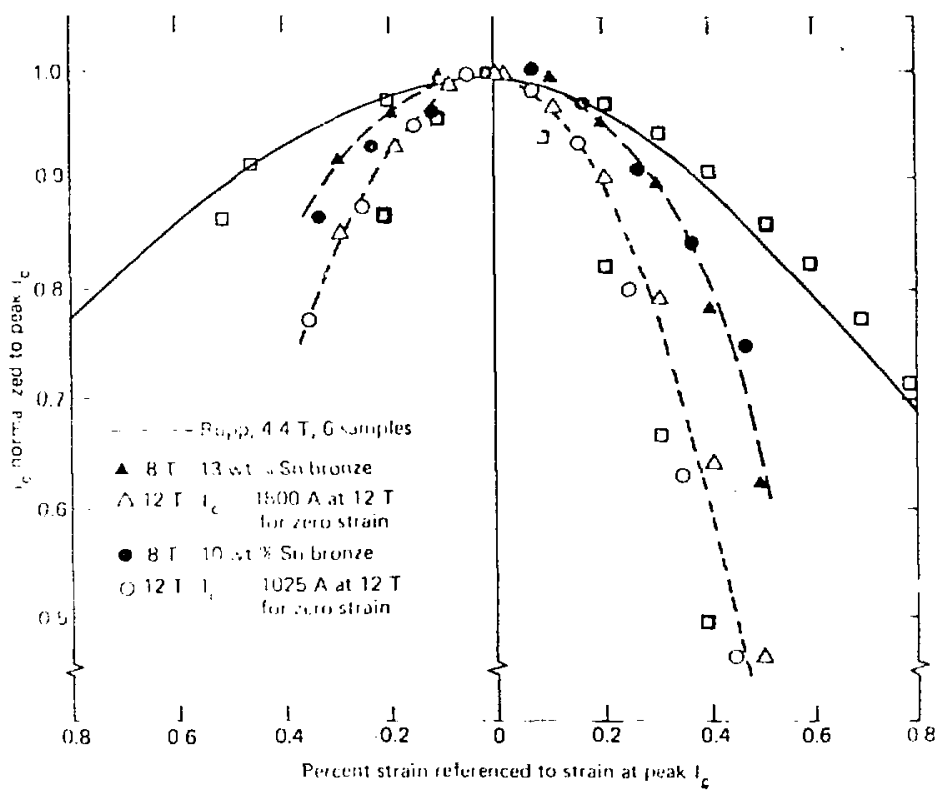

A comparison of the MAXIMSUPER program predictions with experimental data for the strain degradation of $I_{C}$. The above plot is from Fig. 5, with the squares representing the 4 and 12 Tesla predictions of equation 5-36. 


\section{VITA}

Ronald Warren Hoard, the son of Robert Glen Hoard and Golda (Taylor) Hoard, was born in Chicago, Il.inois, on July $13,1953$.

His secondary schools were Hyde Park and James $H$. Bowen High Schools, both in the city of Chicago. After graduation he attended Cornell University in Ithaca, New York, and received two degrees from the Department of Applied and Engineering Physics:

1. Bachelor of Science in Engineering Physics, June 1975

2. Masters of Engineering in Engineering Physics, June 1976

He then enrolled in the Department of Nuclear Engineering at the University of Washington in Seattle, washington, where the present work was completed in conjunction with the Lawrence Livermore National Laboratory in Livermore, California. 